\title{
A Longitudinal Case Study of a Public Sector Change Team
}

By

\author{
Rob Smart, M.B.A
}

\author{
A thesis submitted to \\ the Faculty of Graduate Studies and Research \\ in partial fulfilment \\ of the requirements for the degree of \\ Doctor of Philosophy, Management
}
Sprott School of Business
Carleton University
Ottawa, Ontario

(C) copyright Robert C. Smart, 2010 


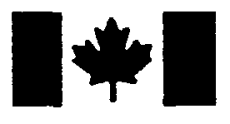

\author{
Library and Archives \\ Canada \\ Published Heritage \\ Branch \\ 395 Wellington Street \\ Ottawa ON K1A ON4 \\ Canada
}

Bibliotheque et

Archives Canada

Direction du

Patrimoine de l'édition

395, rue Wellington

Ottawa ON K1A ON4

Canada
Your file Votre référence
ISBN: 978-0-494-67898-5
Our file Notre réference
ISBN: $978-0-494-67898-5$
NOTICE:

The author has granted a nonexclusive license allowing Library and Archives Canada to reproduce, publish, archive, preserve, conserve, communicate to the public by telecommunication or on the Internet, loan, distribute and sell theses worldwide, for commercial or noncommercial purposes, in microform, paper, electronic and/or any other formats.

The author retains copyright ownership and moral rights in this thesis. Neither the thesis nor substantial extracts from it may be printed or otherwise reproduced without the author's permission.
AVIS:

L'auteur a accordé une licence non exclusive permettant à la Bibliothèque et Archives Canada de reproduire, publier, archiver, sauvegarder, conserver, transmettre au public par télécommunication ou par l'Internet, prêter, distribuer et vendre des thèses partout dans le monde, à des fins commerciales ou autres, sur support microforme, papier, électronique et/ou autres formats.

L'auteur conserve la propriété du droit d'auteur et des droits moraux qui protège cette thèse. $\mathrm{Ni}$ la thèse ni des extraits substantiels de celle-ci ne doivent être imprimés ou autrement reproduits sans son autorisation.
In compliance with the Canadian Privacy Act some supporting forms may have been removed from this thesis.

While these forms may be included in the document page count, their removal does not represent any loss of content from the thesis.
Conformément à la loi canadienne sur la protection de la vie privée, quelques formulaires secondaires ont été enlevés de cette thèse.

Bien que ces formulaires aient inclus dans la pagination, il n'y aura aucun contenu manquant.

\section{Canada}




\section{ABSTRACT}

Organizational change is a complex and daunting task which can overwhelm and frustrate individual employees. To improve the implementation of change, organizations are turning to special teams of change agents assembled to help lead the transformation effort. Despite the importance of both organizational change and effective teamwork in organizational life today the factors that influence the effectiveness of change teams have yet to be empirically established. The potential for change teams to improve how organizations plan and implement change appears to warrant the conceptual development of a framework for organizational change teamwork.

This exploratory case study applies a longitudinal qualitative methodology to describe the effectiveness of a public sector organizational change team and examine how government administration can better support change teams to plan and implement change. The change team under study was the Strategic Transfer Initiative Team which was responsible for leading the first wave of a Government of Canada wide transformational change to shared information technology services. Semi-structured interviews and a team effectiveness survey were conducted with twelve team members at both time 1 and time 2. The semi-structured interviews explored the unique factors affecting teams working on change and asked team members to comment on ways to improve the effectiveness of change teams.

The findings from this research suggest that change teams face challenges related to both teamwork and the task of implementing change. The use of change teams appears to have benefits for both the organization and the individuals on the team. The findings from this case study also revealed that change team effectiveness may be influenced by the change life-cycle. Finally, the results of this study show that senior level support for these change teams is essential for the success of the change team.

The case study concludes with recommendations for supporting the work of change teams and the development of a model of change team effectiveness to be used in future research on change teams. 


\section{ACKNOWLEDGEMENTS}

This thesis is dedicated to my wife Annie and our Kid Canada.

There are a number of people who deserve recognition for their part in this thesis. I would like to thank my family (especially my chief editor) and friends for their patience and support throughout this phase of my life. Taking on the necessary challenges in life is much easier when you've got a support network as strong as I do. Thank you all.

I would also like to thank my Supervisor, Dr. Linda Duxbury. I have learned a lot over the past few years; however if there is one piece of advice that I can pass on to any future Ph.D. candidates reading this thesis, it is this: a good supervisor makes a world of difference. I was lucky, I had a great supervisor. Thanks Linda.

I would also like to acknowledge Dr. Ian Lee and Dr. Steven Murphy for their role on my thesis committee and their guidance during this thesis. As well, a big thank you to my fellow Ph.D. candidate Maggie Stevenson, without whom my studies would not have been nearly as enjoyable or successful.

Finally, this thesis would not be possible without the contributions of the Strategic Transfer Initiative Change Team who were the subjects of this case study. They were a great group of people to work with and I believe that their work serves as an excellent example for future Public Sector Change Teams. 


\section{TABLE OF CONTENTS}

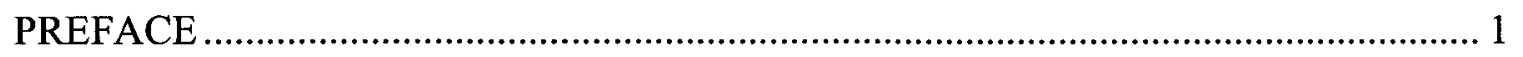

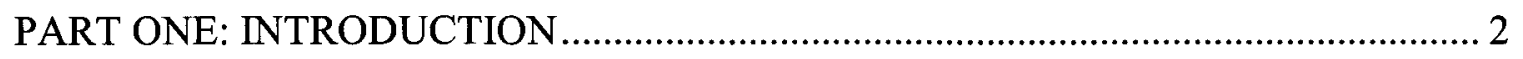

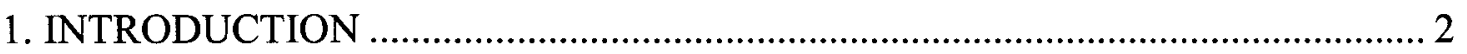

1.1 Research Objectives ..................................................................................... 3

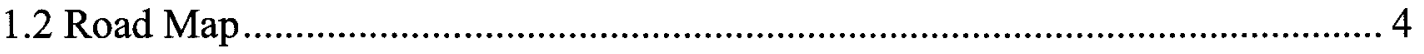

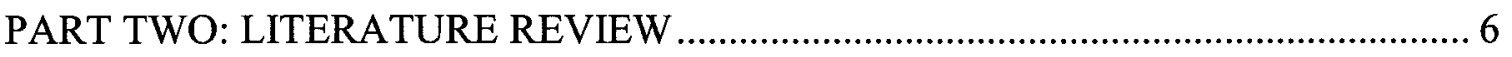

2. PUBLIC SECTOR PLANNED TRANSFORMATIONAL CHANGE …….............. 7

2.1 Planned Transformational Change...................................................................... 8

2.1.1 Planned vs. Emergent Organizational Change .............................................. 9

2.1.2 Transformational vs. Incremental Change ................................................ 18

2.2 Public Sector Organizational Change …………….............................................. 28

2.2.1 Drivers of Public Sector Change................................................................. 29

2.2.2 Challenges Related to Change in the Public Sector....................................... 30

2.2.3 Strategies for Managing Public Sector Change ........................................ 32

2.2.4 Critique and Future Research.................................................................... 34

2.3 Impacts of Organizational Change ....................................................................... 35

2.3.1 Employee Resistance and Support for Change ............................................. 36

2.3.2 The Impact of Organizational Change on Workload ..................................... 44

2.3.3 The Impact of Organizational Change on Stress ........................................... 48

2.4 Critique of the Organizational Change Literature ............................................ 52

2.4.1 Strengths and Limitations ........................................................................... 52

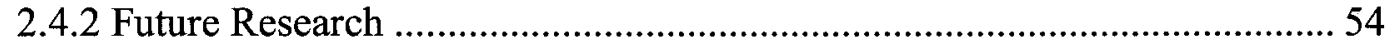

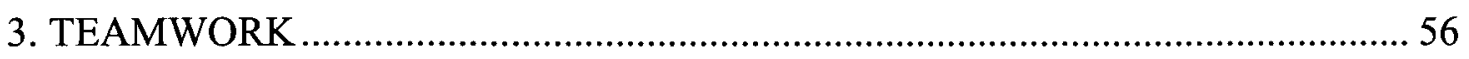

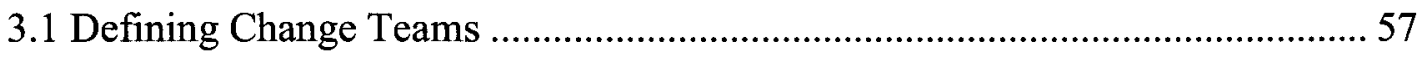

3.2 Classifying Teams .................................................................................... 58

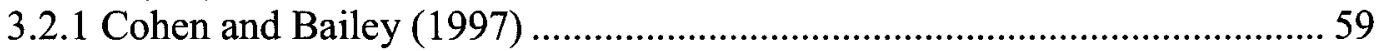

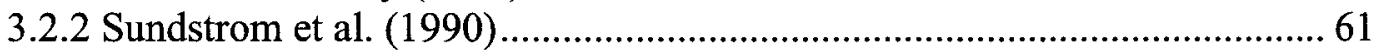

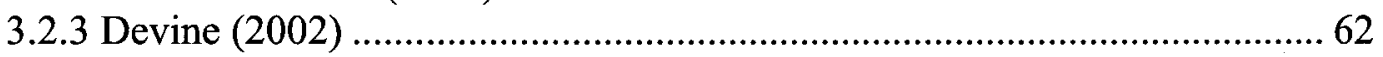

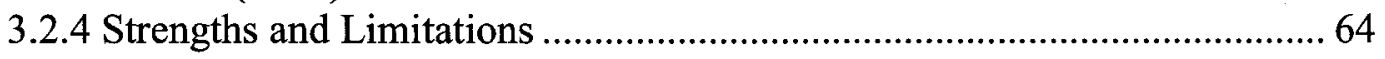

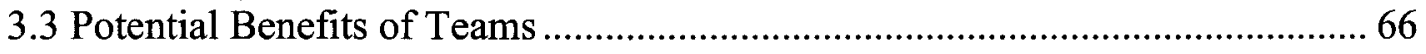

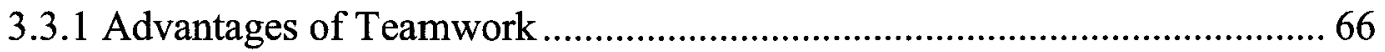

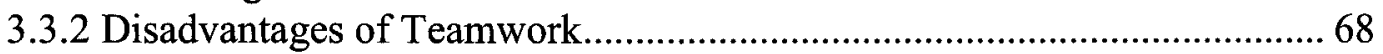

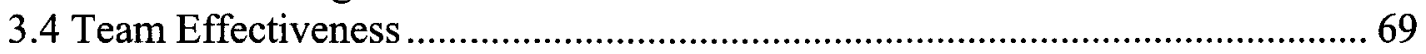

3.4.1 Defining Team Effectiveness................................................................. 70

3.4.2 Measuring Team Effectiveness.............................................................. 72

3.4.3 The Team Effectiveness Model .............................................................. 75

3.4.4 Campion's Model of Team Effectiveness.................................................. 78

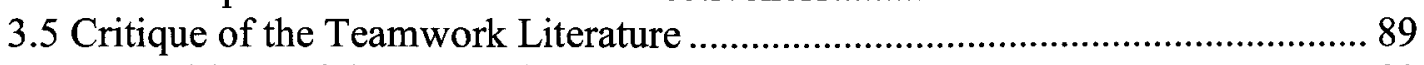

3.5.1 Critique of the General Teamwork Literature ………….............................. 89 
3.5.2 Critique of the Measurement of Team Effectiveness ............................... 91

3.5.3 Critique of the Campion Model of Team Effectiveness ............................ 92

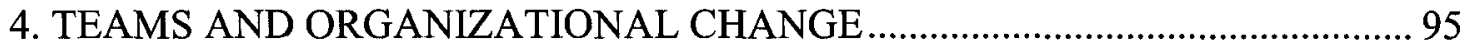

4.1 Exploring Teams and Organizational Change ................................................ 96

4.2 Characteristics of Change Teams............................................................. 99

4.2.1 Change Team Composition..................................................................... 99

4.2.2 Team Cohesion and In-Group Bias...................................................... 100

4.2.3 Communication and Goal Setting ........................................................ 103

4.3 Critique of Change Teams Literature ......................................................... 103

PART THREE: RESEARCH QUESTIONS \& INITIAL FRAMEWORK ................... 107

5. RESEARCH QUESTIONS \& INITIAL FRAMEWORK................................... 108

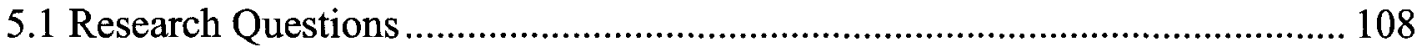

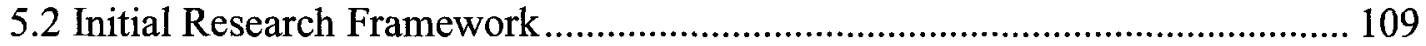

5.2.1 Change Team Effectiveness................................................................ 111

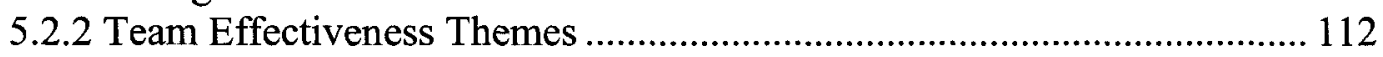

5.3 Dimensions of Organizational Change ..................................................... 118

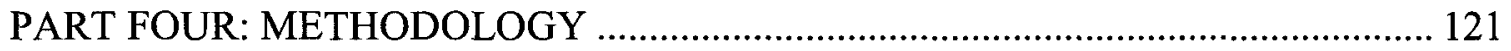

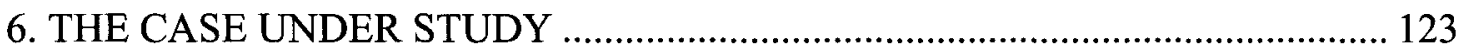

6.1 The Suitability of the Case Study Approach................................................. 123

6.1.1 Benefits of the Case Study Approach .................................................. 124

6.1.2 Limitations of the Case Study Design .................................................... 127

6.2 Description of the Change and the Change Team ....................................... 128

6.2.1 The IT Shared Services Initiative ........................................................ 129

6.2.2 Description of the Change Team ....................................................... 132

6.2.3 The Death Valley of the Change.......................................................... 137

7. THEORY DEVELOPMENT FROM CASE STUDIES ..................................... 143

7.1 Theory Development Using Eisenhardt's Model .......................................... 143

7.1.1 Grounded Theory Development ....................................................... 144

7.1.2 Theory Testing vs. Theory Development ............................................ 145

7.2 Stages of the Eisenhardt's Model ............................................................ 146

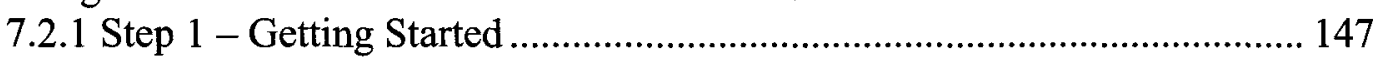

7.2.2 Step 2 - Selecting the Case for Study ................................................ 148

7.2.3 Step 3 - Crafting Instruments and Protocols ........................................... 148

7.2.4 Step 4 - The Overlap of Data Collection and Data Analysis ................... 149

7.2.5 Step 5 - Constant Comparison: Within-Case and Cross-Case Analysis ... 149

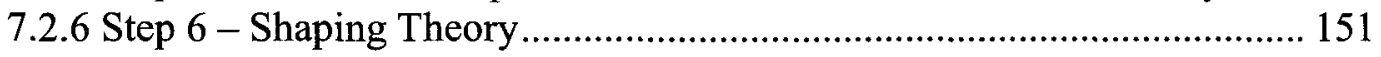

7.2.7 Step 7 - Enfolding the Literature ................................................... 151

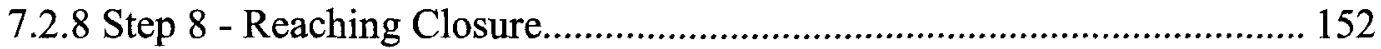

7.3 Strengths and Weaknesses of Eisenhardt's Model ..................................... 153 
8. SAMPLING, DATA COLLECTION, AND DATA ANALYSIS ........................ 155

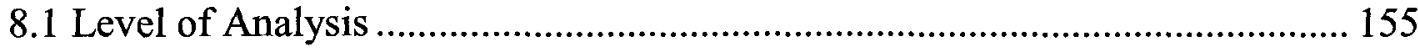

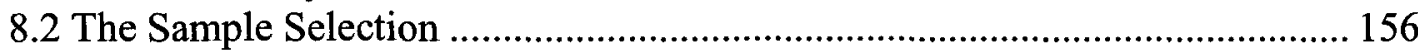

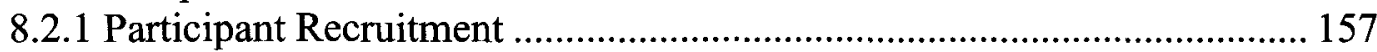

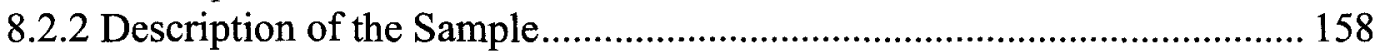

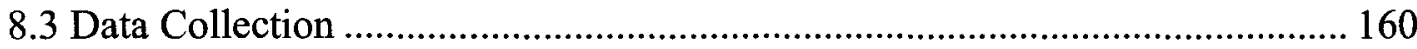

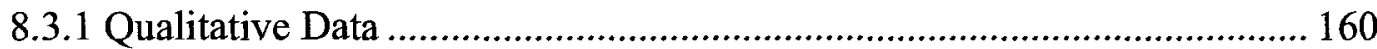

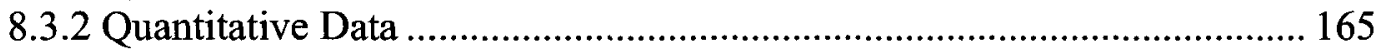

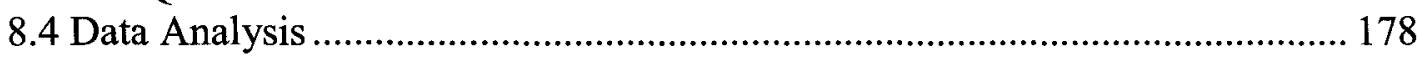

8.4.1 Analyzing the Qualitative Data................................................................... 178

8.4.2 Analyzing the Quantitative Data................................................................. 184

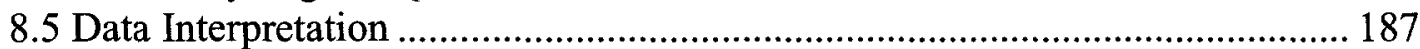

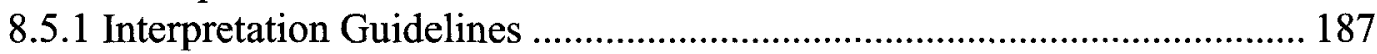

8.5.2 Interpreting Longitudinal Data ................................................................. 189

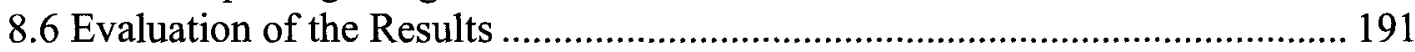

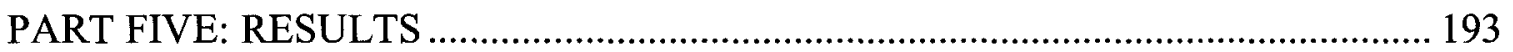

9. BENEFITS AND CHALLENGES OF CHANGE TEAMS................................... 196

9.1 Benefits of Change Teams .......................................................................... 196

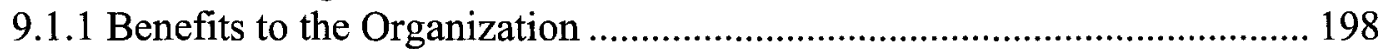

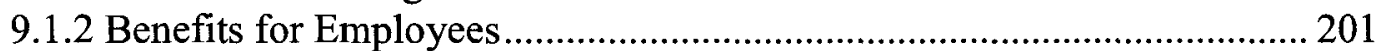

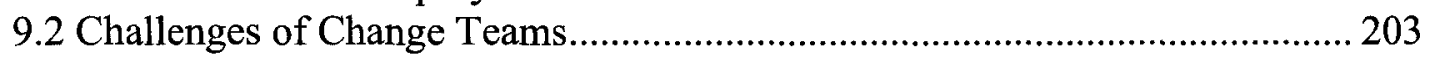

9.2.1 Challenges Related to Change Management ........................................... 205

9.2.2 Challenges Related to Teamwork ……………….................................... 207

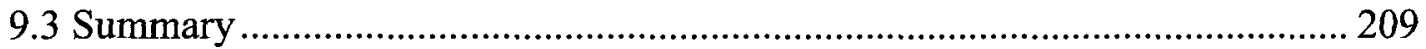

10. THE EFFECTIVENESS OF CHANGE TEAMS................................................ 211

10.1 Factors having a Positive Impact on Change Team Effectiveness ................ 212

10.1.1 Supporting the Change Initiative ...................................................... 212

10.1.2 Critical Success Factors for Change Team Effectiveness........................ 218

10.2 Factors Limiting Change Team Effectiveness .............................................. 224

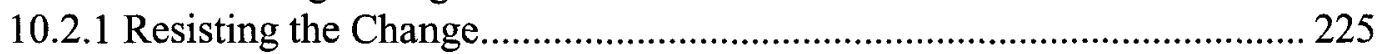

10.2.2 Improving the Effectiveness of Change Teams ..................................... 230

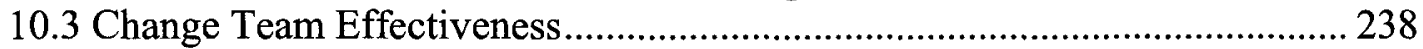

10.3.1 Dimensions of Change Team Effectiveness .......................................... 238

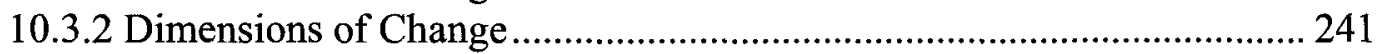

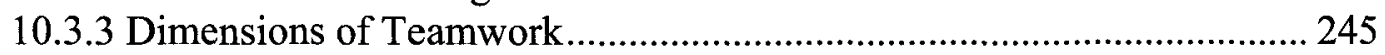

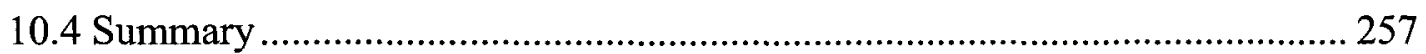

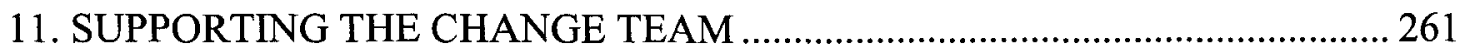

11.1 Improving Support from Senior Management ............................................... 261

11.1.1 Supporting Change Management......................................................... 263

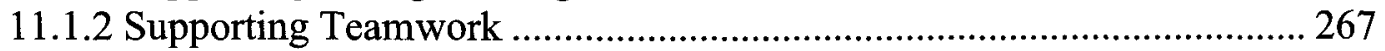

11.1.3 Supporting both the Change and the Team............................................. 268

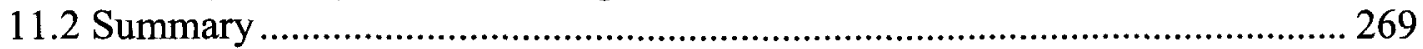


12. USING TEAMS TO IMPLEMENT CHANGE …………………………....... 272

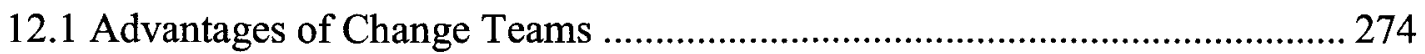

12.2 Drawbacks of Change Teams ...................................................................... 279

13. A MODEL OF CHANGE TEAM EFFECTIVENESS ..................................... 282

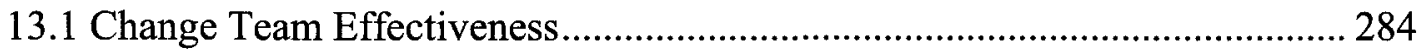

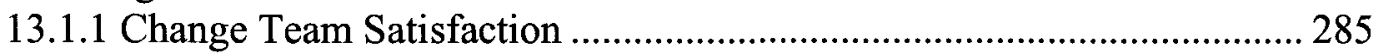

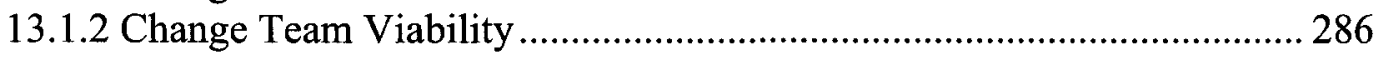

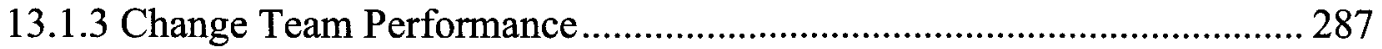

13.2 Characteristics of Effective Change Teams ................................................. 288

13.2.1 Defining the Change Team's Task ......................................................... 289

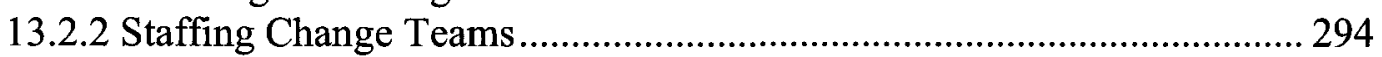

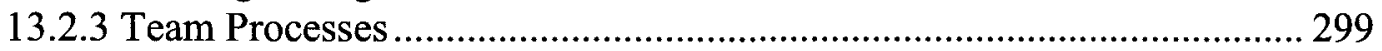

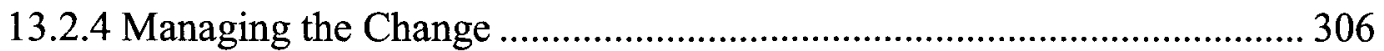

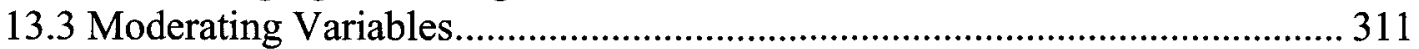

13.3.1 The Change Life-Cycle and Change Team Effectiveness ......................... 311

13.3.2 Other Moderating Variables .................................................................. 319

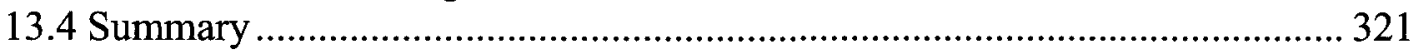

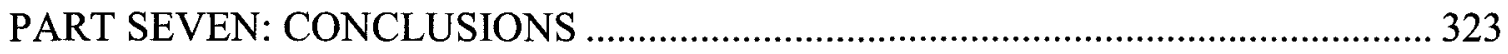

14. CONCLUSIONS AND CONTRIBUTIONS OF THIS RESEARCH.................. 324

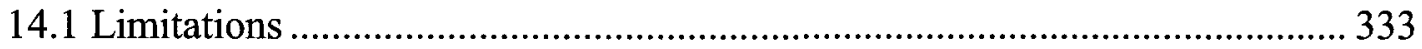

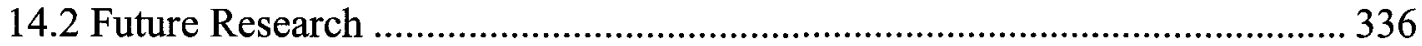

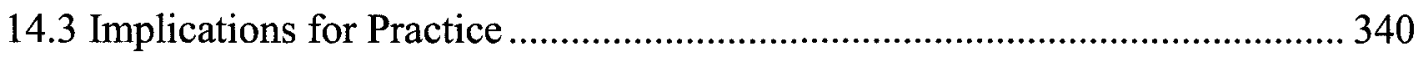

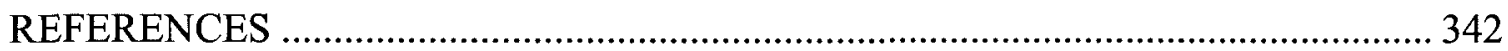

\section{LIST OF TABLES}

Table 2-1 Classifications of Organizational Change ........................................................ 8

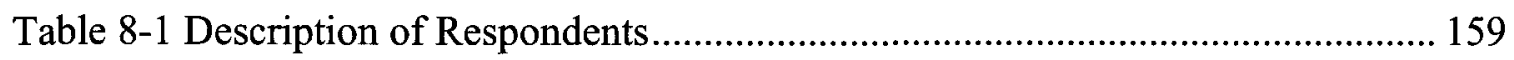

Table 8-2 Part 2: Team Effectiveness Outcomes....................................................... 167

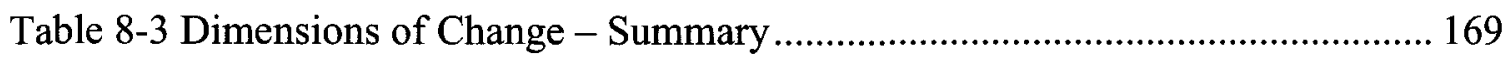

Table 8-4 Part 4: Characteristics of Change Teams (Task Design) ................................ 172

Table 8-5 Part 4: Characteristics of Change Teams (Interdependence) - Summary....... 173 
Table 8-6 Part 4: Characteristics of Change Teams (Composition) - Summary ............ 174

Table 8-7 Part 4: Characteristics of Change Teams (Context) - Summary ................... 176

Table 8-8 Part 4: Characteristics of Change Teams (Process) - Summary.................... 177

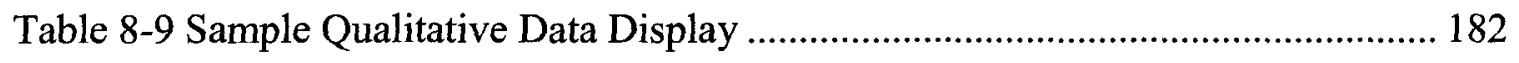

Table 8-10 Sample Quantitative Data Display .................................................. 186

Table 9-1 Benefits of being on a Change Team .................................................... 197

Table 9-2 Challenges faced by Change Teams ........................................................ 203

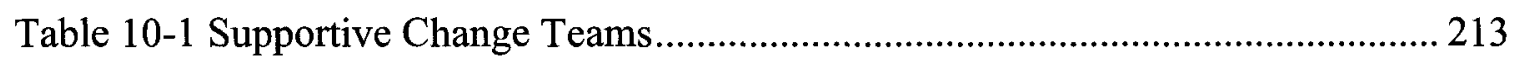

Table 10-2 Critical factors for Change Team effectiveness ..................................... 219

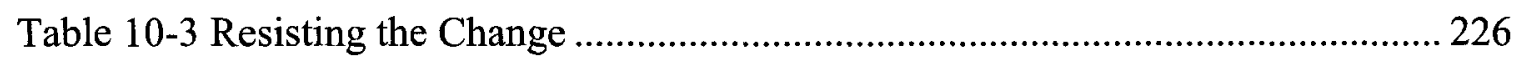

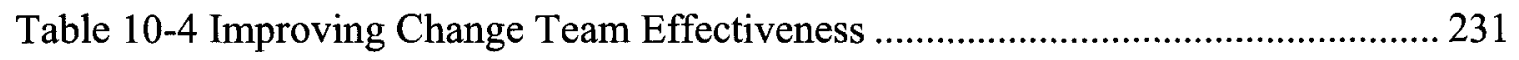

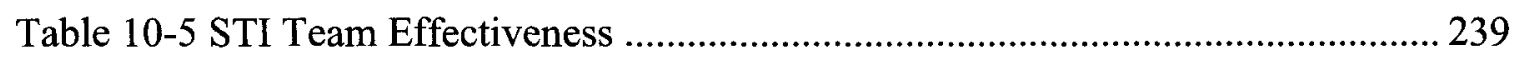

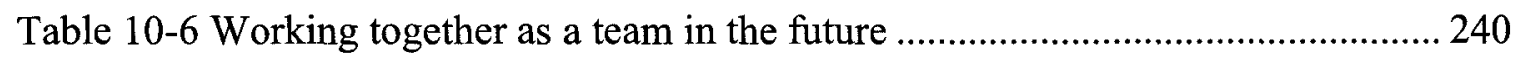

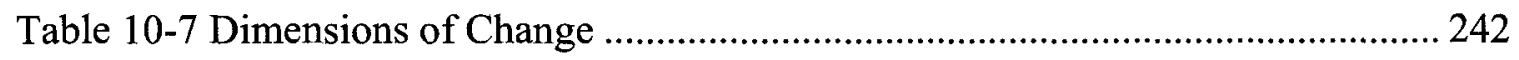

Table 10-8 Changes in job stress during the change................................................. 243

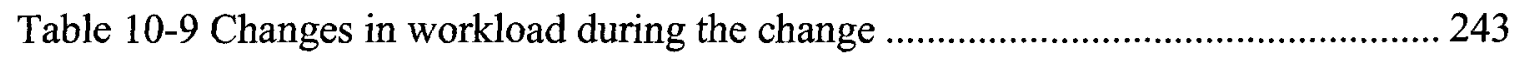

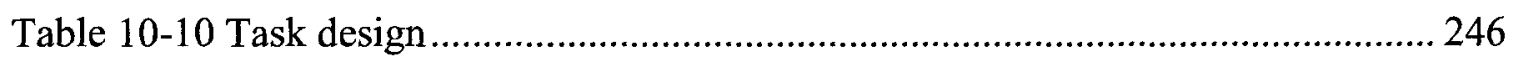

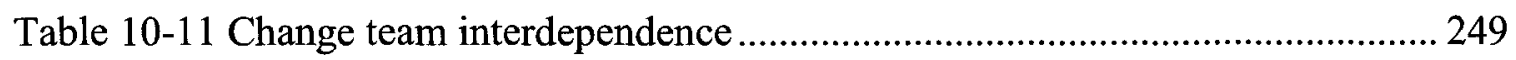

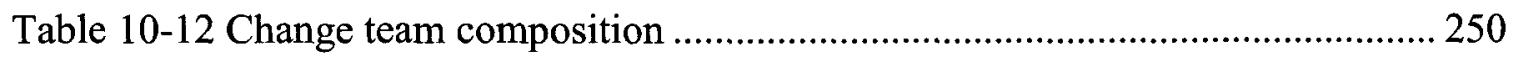

Table 10-13 STI Change Team Processes ............................................................... 252

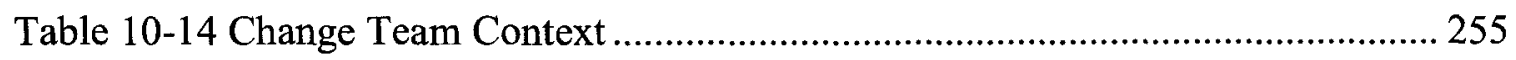

Table 10-15 Summary of the Qualitative STI change team data ................................ 257

Table 10-16 Summary of the Quantitative STI change team data ................................ 260 
Table 11-1 Supporting Change Teams …………………....................................... 262

Table 11-2 Summary of the Qualitative Data on Supporting Change Teams ................ 269

Table 13-1 The Impact of the Change Life-Cycle on Change Team Effectiveness ....... 312

\section{LIST OF FIGURES}

Figure 3.1 - Campion et al. (1996) Team Effectiveness Model.......................................... 77

Figure 5.1 -Framework for Change Team Effectiveness ............................................... 110

Figure 6.1 - Shared IT Services Historical Timeline ...................................................... 130

Figure 6.2 - Government of Canada's Shared Information Technology Strategy ......... 133

Figure 6.3 - STI Change Team Functional Subgroups ……………………………..... 135

Figure 6.4 - STI Team Deliverables Timeline ............................................................. 136

Figure 6.5 - The Death Valley of the STI Change ......................................................... 140

Figure 12.1 - Using Teams to Implement Change ………........................................ 273

Figure 13.1- General Model of Change Team Effectiveness ........................................ 283

\section{LIST OF APPENDICES}

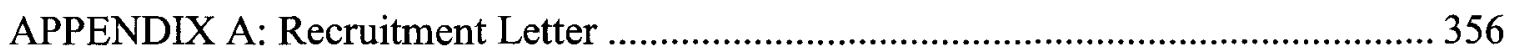

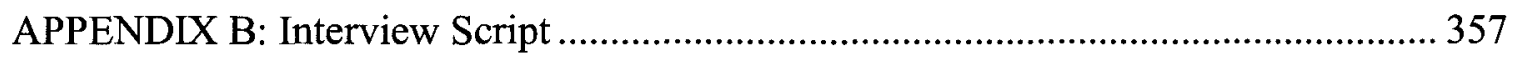

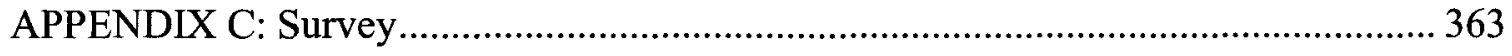




\section{PREFACE}

The current economic crisis both globally and in Canada has meant that organizations have had to adapt and change the way they do business in order to survive. In the past decade there has been a tremendous growth in the amount of academic research in the area of organizational change. More than ever businesses need specific guidance on how to make successful change a reality. This research initiative came about as a result of an opportunity to be involved in one of the most wide-reaching and influential organizational change efforts in Canada: the transfer to a Shared Services Information Technology Environment by the Federal Government of Canada.

Early on in the Shared Services Change Initiative it became clear that successful teamwork would play a major role in the success or failure of this change initiative. The transfer to IT Shared Services was an ideal venue to examine the dynamics of teamwork during organizational change. The change effort that is the subject of this research has far reaching impacts at the local, national, and global level. In the current business environment where both teamwork and organizational change have become a way of life, this research was a natural fit and an opportunity to positively influence both the academic and practitioner view of organizational change teams. 


\section{PART ONE: INTRODUCTION}

\section{INTRODUCTION}

The field of organizational change is currently facing a number of challenges. The available literature on organizational change has increased dramatically since Kurt Lewin proposed his influential theory of planned change in 1951. The current global recession and political climate suggest that the importance of managing change for organizations will only continue to increase in the future (Lloyd \& Maguire, 2002; Weick, 2000). Yet, despite our advancements in the study of organizational change many researchers in the field still suggest that a clear majority of change efforts that are implemented continue to fail. Balogun and Hailey (2004) for example report that seventy percent of change programs fail. Similarly, Beer and Nohria (2000) report that approximately two-thirds of change efforts fail. This suggests that there remains quite a bit of work to understand organizational change, and that it may be necessary to get more detailed information on what factors can make or break the success of a change effort. Specifically, future research should move forward with the existing change literature as a foundation to examine areas of organizational change that may be contributing to the current struggles being experienced by practitioners of change (Burnes, 2004b; Kanter, Stein, \& Jick, 1992; Van de Ven \& Poole, 1995). The current research aims to be a part of this movement forward for the change literature by examining the effectiveness of organizational change teams in the context of a large scale public sector change.

Organizational change has been studied intensely by researchers in many disciplines over an extended period of time (Burnes, 2000b). Early researchers focused 
on the general nature of change and the strategies that organizations could employ to manage change effectively (Beer \& Nohria, 2000). Throughout the development of the change literature there has also been considerable work done on the role individuals play during the change process (W. Burke, 2002). With the extensive work of organizational change researchers and practitioners over the years and the importance of such critical factors as interpersonal relationships (Lawerence, 1964), coalition building (Kanter et al., 1992), employee participation (Kotter \& Schlesinger, 1979), and dispersed leadership (Katzenbach, 1996). Yet, despite the apparent synergies between teamwork and organizational change there remains a gap in the literature with respect to where teamwork fits into organizational change theory.

\subsection{RESEARCH OBJECTIVES}

The goal of this research is to contribute to the organizational change literature by improving how organizations use teams to successfully plan and implement organizational change. The three objectives which will guide this research are as follows:

1. To increase the understanding of why change teams are used to plan and implement organizational change and what benefits and challenges are associated with the use of change teams to implement change.

2. To explore change team effectiveness. Specifically, this study examines the teamwork and change related factors that may impact the effectiveness of change teams and aims to develop a model of change team effectiveness that can be used in future research on change teams. 
3. To explore the ways in which organizations can support change teams in their work.

To date, there has been very little research on organizational change teams in general, and specifically on organizational change teams that are involved in a major public sector transformational change. This research strives to contribute to both the change and teamwork literatures by undertaking a longitudinal case study of a large scale planned public sector transformational change. It is also hoped that this research will inform upper management, lower level managers, and individual team members on the impacts of organizational change, change team effectiveness, and the impact of effective change teams on the outcomes of organizational change. Such knowledge should increase the appropriate use of teams during change.

\subsection{ROAD MAP}

This thesis is composed of seven parts including the first part, the introduction. Part 2 covers the literature review for the paper and consists of three subsections, each of which explores an area of research relevant to the effectiveness of change teams and the research objectives outlined above. The purpose of the literature review is to merge this research into the existing literature related to change and team effectiveness and lay the foundation for this study by developing an initial research framework. Following the literature review, Part 3 of this thesis presents the research questions and the initial research framework that guides the current research effort. Part 4 of this thesis presents the methodology used to conduct this research. Included in this section is a description of the sample, the sample collection plan, the measurement tools used in this research, and finally the data analysis. Part 5 reports the results of the study and is organized according 
to the research questions laid out in part three. Part 6 presents a discussion of the results of this study and the model of change team effectiveness that is the primary results of this thesis. The final part of this thesis (Part 7) is comprised of the concluding chapters. In this part the conclusions, contributions, limitations and implications for future research chapters are presented. 


\section{PART TWO: LITERATURE REVIEW}

The literature review is divided into three chapters, each of which helps the researcher understand organizational change teams. The literature related to organizational change is very extensive and a complete review is beyond the scope of this thesis. For this reason, Chapter 2 focuses on the literature on planned public sector transformational change. By focusing on this specific area of organizational change this review will be reduced to a manageable amount while still presenting and critiquing the organizational change themes that are relevant to this thesis. Similarly, the literature on teamwork in organizations is very large and as such, a complete review of the teamwork literature is beyond the scope of this thesis. Chapter 3 provides a concise review and critique of the teamwork literature that is relevant to this study of team effectiveness. Chapter 4 reviews and critiques the research to date on organizational change teams and discusses the future of research in this area. 


\section{PUBLIC SECTOR PLANNED TRANSFORMATIONAL CHANGE}

At the heart of this research is the goal to better understand the nature of organizational change and how organizations can make successful change a reality. The literature on organizational change has grown exponentially over the past fifteen years and researchers today are supported by a large and diverse collection of theories and studies conducted on change (Burnes, 2004b; Young, 2009). The proposed research examines a planned transformational change in the public sector. Accordingly, the review of the change literature focuses on public sector planned transformational change. The first section in this chapter presents some of the different classifications of organizational change and discusses where the current case under study fits into those classifications. The second section specifically examines the literature on planned change. The third section in this chapter presents the literature on transformational change. The fourth section of this chapter examines the research done on change in public sector organizations. The fifth section of this chapter looks at some of the impacts of organizational change on workers. Finally, this chapter concludes with a critique of the research in the area of planned transformational public sector change. The goal of this chapter is to provide an overview of the literature on public sector planned transformational change and to help put the change under study, the Shared Services Initiative (SSI), into context. 


\subsection{PLANNED TRANSFORMATIONAL CHANGE}

A key challenge for any researcher in the area of organization change is to distill this large body of research into a clear and concise picture of the area of organizational change that they will be researching. This is a particularly important task for research on organizational change teams because the type of change that change teams are working on may have a significant impact on the team's experiences. One area of the change literature which can be particularly confusing is the classification of different types of organizational change. There are a wide variety of classifications of change available for researchers to build upon (Todnem By, 2005; Burke, 2008). This section will provide an overview of these typologies to help clarify the change in which the team under study is operating in. Table 2-1 summarizes several of the most common classifications of organizational change and highlights the classification schemes that are most relevant to this thesis (these classifications are starred in Table 2-1).

Table 2-1 Classifications of Organizational Change

\begin{tabular}{ccc}
\hline$\star$ Planned & vs. & Unplanned \\
Anticipatory & vs. & Reactive \\
\hline$\star$ Transformational & vs. & Incremental \\
Discontinuous & vs. & Continuous \\
Revolutionary & vs. & Evolutionary \\
\hline
\end{tabular}

While each of the classifications listed above offers a slightly different perspective on change, it is beyond the scope of this literature review to provide a full analysis of each classification. Therefore the review of the literature will be focused on 
the classification schemes that are most relevant to the current research case study. The transformational versus incremental classification scheme is relevant to the current thesis research because the public sector organization being studied is attempting to change both its structure and culture on an organization wide scale. In addition, the change teams being studied in this research are taking a planned transformational change. For this reason the next two subsections will focus on the planned versus unplanned, and transformational versus incremental classification schemes. While the research related to the other classifications listed in Table 2-1 will not be explicitly reviewed, where there is overlap with the two primary classification schemas this overlap is discussed. By examining these two change classifications this literature provides a useful platform for understanding the context within which this thesis research is conducted.

\subsubsection{Planned vs. Emergent Organizational Change}

A trend in the literature has been to try to classify change according to dichotomous classification schemes (Pettigrew, 2000). One of the most popular dichotomies used by researchers is the planned versus unplanned (or emergent) organizational change dichotomy. This classification of change strategies as either planned or emergent is one of the most fundamental dichotomies in the organizational change literature (Burke, Lake, \& Paine, 2009; Pettigrew, 2000). This section on planned organizational change presents the definitions of both planned and emergent change, the key theories related to both approaches to change, and finally discusses the current research on how planned and emergent approaches to change may be related. 


\subsubsection{Planned Change}

One of the most popular dichotomies used by researchers is the planned vs. unplanned (or emergent) organizational change dichotomy. Planned change or organizational development (OD) as it is referred to in the literature (Weick \& Quinn, 1999 ) is the oldest approach to organizational change. In 1969 French defined OD as "a long-range effort to improve an organization's problem solving capabilities and its ability to cope with changes in its external environment with the help of external and internal behavioural scientist consultants or change agents" (p. 446). Another definition of OD proposed by Sinangil and Avallone (2002) is quite similar. These authors describe planned change as "a process by which behavioural science principles and practices are used in a planned and systemic way to attain such goals as developing greater organizational competence, improving the quality of work, and organizational effectiveness" (p.332). Both of these definitions highlight the scientific and systemic approach to change under this strategy. These definitions also highlight the importance of behavioural science in planning for change.

The historical foundations of all organizational change research owe a great deal to the planned change or Organizational Development (OD) theorists. Around 1950 Kurt Lewin and his supporters began to develop the theory of organizational development that would come to dominate the organizational change movement over the next twenty years (Greiner \& Cummings, 2004). The model of organizational change provided by Lewin (1958) is one of the simplest yet influential ideas in behavioural sciences to date (Burke et al., 2009; Wieck \& Quinn, 1999). The model of change provided by Lewin (1951) proposed that change occurred through three stage process. In the first stage the 
organization must unfreeze its current state of equilibrium. For Lewin (1951) this stage of the change process was critical for management as it was necessary to reduce the forces of resistance to change in the organization. Lewin's (1947) previous work on force field analysis lent itself well to this theory of change (Weick \& Quinn, 1999). In the second phase of change the organization actually implements the changes to be made. The third stage of Lewin's model explains how an organization must continuously support and adopt the changes in order for true change to occur and the organization to refreeze into a new equilibrium. Lewin (1951) suggested that the organization could plan and execute change in each one of these stages. Lewin's $(1951 ; 1958)$ contributions to our understanding of change are enormous (Burke et al., 2009; Wieck \& Quinn, 1999) and the importance of culture, and politics in the model truly influenced the future of organizational change research. Lewin's (1958) model of change is considered the foundation of planned organizational change and the OD field.

Lewin's unfreeze-change-refreeze theory and the idea of force field analysis are central to understanding change, however Burnes (2004b) also explains that Lewin (1951) believed that it was essential for change agents to analyze and understand how social groupings are formed, motivated, and maintained and how the behaviour of those groups can be changed. In this regard, the current thesis research on teams put together for a change effort would be a very important part of the planned change effort as these teams could heavily influence the social groupings in the organization. The traditional position of OD theorists is that it is the role of management to reduce the barriers to change for these groups that were under the control of the organization. This was argued to be easier than attempting to strengthen the forces for change, which were often 
external and unpredictable, and usually elicited a stronger resistance to change response from the organization (Burnes, 2004a).

Planned change remains an important part of the change literature (Burnes, 2004b). Current planned change researchers continue to focus on the development of more efficient and effective processes, as well as the alignment of the organizational culture to support these processes (Price \& Chahal, 2006). As will be discussed in the next section on emergent change, because of the longitudinal nature of large scale planned change efforts, planned change theorists must be aware of emergent change perspectives (Weick, 2000). However, the original focus of planned change researchers on individual and group behaviours as being critical to organizational remain a valuable part of organizational change theory.

\subsubsection{Emergent Change}

Perhaps the most influential debate in the study of organizational change over the past half century has been the debate between researchers who argue that change is planned versus those who argue that change is emergent (Burke et al., 2009; Weick \& Quinn, 1999). As discussed, planned change refers to a set out sequence of actions or events that are carried out to improve an organization from its previous existing state to an improved and different state. By contrast, emergent or unplanned change refers to the actions or events in an organization as a reaction to an event or crises, usually external to the organization that causes the organization to change to a new state (Nadler \& Tushman, 1995). 
The traditional planned change approach suggests that organizations are able to accurately predict and plan for both internal and external forces of change. However, there are some researchers who believe that this model of change does not do a good job of framing how organizations change takes place in reality. Many emergent change theorists contend that planned change cannot exist in organizations where external and internal forces for change are constantly in flux and often out of the control of the organization. For example, Kanter et al. (1992) argue "that organizations are never frozen, much less refrozen, but are fluid entities" (p.10). Kanter et al. (1992) are not alone in arguing that Lewin's (1951) model of change may be missing a critical characteristic of organizational change specifically, that organizations are constantly changing. Weick (2000) argues adamantly that planned change theorists have presented a distorted view of how organizational change takes place. Weick (2000) explains that planned change theorists view organizational inertia as something that requires a top-down vendor driven solution in order to be altered. Instead Weick explains that emergent change initiatives are being launched from the bottom up and management would do much better to notice and support these organizational changes then to focus on prepackaged top-down solutions. According to Weick (2000, p. 237) emergent change, "consists of ongoing accommodations, adaptations, and alterations that produce fundamental change without a priori intentions to do so. Emergent change occurs when people accomplish routines and when they deal with contingencies, breakdowns, and opportunities in everyday work. Much of this change goes unnoticed, because small alterations are lumped together as noise in otherwise uneventful inertia." 
Similar to Weick's (2000) view of successful change, Bamford and Forrester (2003) explain that successful management of change is "less dependent on organizational plans and projections than on reaching an actual understanding of the complexity of issues involved and identifying the range of possible options" (p. 548). Emergent change theory argues further that because of the complex and varied nature of the environment, having an organization attempt a set of linear change processes like that expressed by OD practitioners is unlikely to achieve the desired result. Instead, emergent change theorists propose that bottom up solutions will be more effective in dealing with the emergent change forces from the environment than top down executive plans (Bamford \& Forrester, 2003).

The strategy of emergent change is largely based on evolving perspectives on the nature of the relationship between the organization and its environments (Burnes, 2004b). Emergent change advocates point out that it is by managers responding to their internal and external environments that organizations change over time. With this approach, the skills, knowledge, and capabilities of an organization become a competitive advantage as more flexible organizations will theoretically be better suited to respond to their environment (Burnes, 2004b). For Hayes (2002) emergent change is all about matching organizational resources with opportunities in the environment. Hayes (2002) explains that the cultural and political forces within the organization must be flexible enough to adjust to changes in the environment if the organization is to succeed with an emergent change strategy.

The idea that organizations should try to become flexible and receptive enough to deal with the complexity of change is one of the main reasons that emergent change is 
often referred to as reactive change (Nadler \& Tushman, 1995). One of the challenges to the emergent change school of thought is that it is more of a critique of planned change theories than a solution to how organizations should manage change (Bamford \& Forrester, 2003). In order for emergent change theory to continue to move forward it should examine the OD perspective of change to find strategies for managing change that are congruent with the emergent view of organizational change.

\subsubsection{Trends in the Planned vs. Emergent Change Dichotomy}

The proceeding discussion of planned and emergent change theory gives some perspective on the debate that has shaped the field of organizational change for the past fifty years. This subsection discusses the current state of the planned versus emergent change debate and discuss the implications for the current research.

During the 1970 s there was a significant backlash against OD as its critics claimed that OD was not capable of dealing with the real changes that organizations were being forced to make (Greiner \& Cummings, 2004; Tichy \& DeRose, 2002). The critique of planned change continued throughout the 1980s and Weick (2000) noted, it seemed that the emergent change school of thought was as much a stand against the OD approach as it was a new way of approaching change. Researchers such as Weick (2000) have suggested that planned change strategies not only were not the answer for organizations, but prevented organizations from realizing other emergent strategies that were available to them. Kanter et al. (1992) and Weick (2000) both suggest that planned change may not even be possible given the unpredictability of the environment and the nature of organizational inertia. This point is very relevant to the current thesis research, as the 
environment surrounding the federal government organization which is the topic of this research is extremely complex and is evolving constantly.

This trend in the literature (Pettigrew, 2000) whereby emergent change has begun to supersede planned change is one that is not without rebuttal. According to Pettigrew (2000) it seems strange that we should try to argue for just one type of change when the complexity of organizational change suggests that a more diverse toolbox of strategies may be required to successfully manage change. Recent research suggests that OD and emergent change are not mutually exclusive strategies for change (Burnes, 2004b; Greiner \& Cummings, 2004). In recent years there have been a growing number of researchers that have attempted to find a useful link between the structured processes of planned change and the flexible guidelines of emergent change. Bamford and Forrester (2003) and Burnes (2004b) both found strong synergies between planned and emergent change strategies in their respective case studies on organizational change. Both authors argue that it would be a critical error for a manager to assume that either perspective could exclusively provide the answers needed to successfully manage change. Instead of settling on competing theories, Bamford and Forrester (2003) concluded that planned and emergent theories of change are complementary tools for a manager when dealing with change. Managers need to understand what they are trying to achieve, the context within which their organization is operating, and then apply the two strategies together in order to achieve the desired ends.

These findings are supported by the work of Greiner and Cummings (2004) who explain that planned change can successfully apply its core values to the problems presented by emergent change. At its core, planned change seeks to develop an 
organization where individuals are open to continuous learning. This basic goal of OD is consistent with goal of a bottom up emergent strategy for change that has been proposed under emergent change theory (Bamford \& Forrester, 2003). Grenier and Cummings (2004) explain that planned change strategies are being used more frequently in the implementation of strategic change plans that have been triggered by emergent change. Unlike the 1960s OD approach, strategists rarely take the lead on change strategy formation but rather offer input in to ongoing change implementations. According to Grenier and Cummings (2004) OD has begun to focus less on the resistance side of change management, and instead taken a more positive approach to aligning peoples motivation, vision, and positive expectations with forces for change that are identified in the context of the organization. The literature on planned change shows that OD is still focused on improving organizational effectiveness and on the development and learning at an individual level but has widened its lens to embrace a more emergent view of organizational change. The result will hopefully be a more flexible and useful set of strategies for managers of change to manage organizational change with.

For the current research these trends in the study of planned change are encouraging as they suggests that the planned change approach can be used successfully, even when change may in fact be emergent in its truest form. The key takeaway from this research is the emergent change theories contribute to successful implementation of change by developing and supporting lower level individual and group change agents (Weick, 2000). This should make the organization more responsive and flexible in the face of a dynamic environment. These fundamentals of emergent change are not necessarily counter to the fundamental planned change approach which seeks to use 
behavioural science methods to support the organizational change with an aligned culture. The current research is a prime example of how the planned change approach must evolve to include the principles that make up the emergent change approach to change.

\subsubsection{Transformational vs. Incremental Change}

The second classification of change strategies that is related to the current research is the transformational versus incremental change dichotomy. The current research examines teams responsible for carrying out a transformational change initiative so a review of the relevant transformational change literature is important to understanding exactly what environment these teams will be operating in. This section presents the definitions of both incremental and transformational change, outlines the key theories related to both approaches to change, and finally discusses the current research on the current trends in transformational change research.

\subsubsection{Incremental Change}

The theory of organizational change proposed by Nadler and Tushman (1995) describes organizations as being in one of two forms of change, continuous or discontinuous. The continuous change described by Nadler and Tushman (1995) is closely linked to incremental change which carries an organization along the same path for an extend period of time (Romaneli \& Tushman, 1994). According to Gross, Pascale and Athos (1998) incremental change are adjustments to existing structure, strategy, 
culture, processes, and control systems of an organization that do not fundamentally change the organization. Kanter et al. (1992) described incremental changes as long marches (as opposed to bold strokes which refer to transformational change). This type of change has become associated with traditional organizational development practices and seeks to increase organizational effectiveness by improving existing structure, culture, processes, and control mechanisms. The desired changes that result from incremental changes will be heavily influenced by the existing characteristics and behaviours of the organization and will not likely veer too far from the existing status quo of the organization. Incremental change has also been described in the literature as evolutionary change (Grenier, 1972) as it tends to follow a stable evolutionary path.

One of the trends in the organizational change research is that organizations are believed to undergo long periods of incremental change (Burke et al., 2009; Wichenesvsky, 2004). Incremental changes are seen as an important way for organizations to fine tune their existing strategies and culture. However, in a sample of U.S. bank holding companies over two decades, Wichenesvsky (2004) found that organizations that underwent longer than average periods of incremental change (without undergoing transformational change) experienced increased risk of failure. These findings suggest that while incremental change is important, organizations may require transformational change to meet the changing demands of the environment.

\subsubsection{Transformational Change}

Transformational change refers to a fundamental shift in the culture, structure, processes, power distribution, and control system of an organization (Romanelli \& 
Tushman, 1994). This definition is similar to the definition of discontinuous change given by Nadler and Tushman (1995) who explain that discontinuous change represents a break from the previously existing path by some substantial event or strategy shift. Nadler and Tushman (1995) explain that organizations go through tuning or adaptive changes when they are in the continuous mode of change, and they go through reorientation or recreation when they experience discontinuous change. Transformational change has also been described in the change literature as revolutionary change (Grenier, 1972).

This type of change differs from incremental change because it seeks to reinvent the organization at a very fundamental level. After a successful transformational change an organization will have shed key elements of its culture, structure, processes, and control mechanisms and will have in their place a new set of fundamental elements (Romanelli \& Tushman, 1995). The process of shedding previously embedded values and behaviours is a very difficult and tenuous time for an organization. Burke (R. Burke, 2002) explains that it requires a high level of commitment throughout the organization to successfully transform the fundamental nature of the organization.

Transformational change can be planned or emergent, and in fact emerging business wisdom indicates that it may be in the best interest of the organization to plan a transformation even when it is enjoying tremendous success at its current form of doing business (Gross et al., 1998). The ability to successfully perform transformational change has been heralded by some researchers as a necessary skill to achieve sustained success over the long-term in the current business environment (Gross et al., 1998). During the 1970s, 1980s and 1990s much of the research on change focused on transformational change and Grenier and Cummings (2004) argued that this shift in change theory was a 
result of changing environmental and organizational conditions which favoured a more dramatic and reactive approach to change management. Wischnevsky (2004) confirms that organizations operating in a shifting environment may increase their likelihood of success if they are able to effectively transform their organization as required by the environment.

According to Hammer (1990) one of the company's best tools for reinventing itself is through operational innovation. Hammer (1990) argues that operational innovations result in deep (fundamental) changes in how the business works and when these changes are tied to strategy they provide a valuable way for organizations to better control their own transformation. Although Hammer's (1990) focus on practical innovations to reinvent the organization is valuable, the fact remains that aligning innovation and strategy is often very difficult, especially when facing dramatic change in the environment which requires quick transformational change. Romanelli and Tushman (1994) tested the punctuated equilibrium model of organizational change proposed by Gersick (1991) and found that the majority of organizational changes in the US minicomputer producer market were short bursts of discontinuous change. In other words, even if an organization wants to transform, it is unlikely that the organization will be able to react as the environment in which they operate shifts.

Another interesting finding of Romanelli and Tushman's (1994) work was that major environmental changes and changes in leadership significantly increased the likelihood of transformational change compared to incremental change via the punctuated equilibrium theory. According to Romaneli and Tushman (1994) a company that changed its leadership was more likely to experience transformational change (as opposed to 
incremental change). While the occurrence of major environmental changes is likely not under the control of the organization, an organization can control its choice of leadership. Romanelli and Tushman's (1994) findings suggest that a company seeking to transform itself, would do well to consider a change in leadership. By keeping the same leadership in place and attempting to change, Romaneli and Tushman (1994) suggest that incremental changes are more likely.

One weakness with the findings of Romaneli and Tushman (1994) is that the study did not measure for changes in culture when determining whether or not the organization had undergone incremental or transformational change. Several researchers (Gersick, 1991; Schein, 1999) have argued that by definition transformative change must affect the culture of an organization in order to have occurred. Despite this shortcoming authors such as Shein (1999) support the idea that a change in leadership can push an organization to transform, suggesting that this strategy may be considered as a valuable tool for helping to bring about transformational change.

Along with innovation and leadership there are several other processes that organizations can use to bring about transformational change. Goss et al. (1998) argue that organizations can take five steps to increase the likelihood of transformation. First, the change team must assemble a critical mass of key stakeholders. By assembling a critical mass of stakeholders the change effort will be more likely to survive the significant resistance that will likely oppose the transformation. Second, they suggest that an organizational audit is a good way to find out what the fundamental structures, processes, and culture of the organization looks like. They note that it will be easier to 
determine whether transformational change is happening if the executive change team has a clear picture of what the organization looked like prior to the change.

The third activity to increase the likelihood of transformation is to create urgency with a burning platform. Transformational change is a very emotional process (Gersick, 1991) in which employees are forced to severe emotional ties with the 'old' way of doing business. A burning platform or crisis can give people the emotional jolt needed to cut those ties and begin to embrace the new business. The fourth suggestion put forth by Goss et al. (1998) is to use conflict to fuel the creative process. Transformational change will likely result in a high degree of conflict which if managed properly can fuel creative solutions (Nutt \& Backoff, 1997).

Finally, Goss et al. (1998) recommend that the organization engineer operational breakdowns. This activity involves searching for areas of the business where operations are not performing and attempting to innovate a solution around real problems. This strategy is supported by the work of Hammer (2004) who argued that operational innovation is one of the best ways for a company to transform itself.

Each of the activities identified by Goss et al. (1998) give insight into how organizations can better manage transformational change. Unfortunately, these steps have not been empirically tested. In fact, it is a characteristic of the literature on transformational change that many of the theories on transformational change are presented as general descriptions rather than tested strategies for practitioners. The future of transformational change research will hopefully address this shortcoming and continue to build support for transformational change strategies. 
According to these transformational change researchers (Gersick, 1991; Grenier, 1972) it is critical that organizations seeking to transform examine the underlying needs to change and the basic elements of their current business. Transformational change can be planned or unplanned but it must alter the underlying assumptions and beliefs that guide decisions within the organization (Goss et al., 1998). This section has also highlighted several actions that organizations can take to increase the likelihood of successful transformational change. Innovation, change in leadership, creating a burning platform, managing conflict, and performing an organizational audit have all been suggested as useful strategies to affect transformational change, however these theories need to be studied further in order to provide a more useful and generalizable solution to the problem of transformational change.

\subsubsection{Trends in Transformational vs. Incremental Change Research}

In recent years the majority of the research related to the transformational versus incremental change dichotomy has been dominated by research on transformational change (Burke, 2008; Grenier \& Cummings, 2004). According to Goss et al. (1998) the reason for this imbalance is that traditional incremental change programs treat symptoms of the problem, which will result in gradual improvements but not in a complete solution. Under environmental conditions of high uncertainty and variability, the capability to successfully transform has been argued to be a critical factor in the success of firms (Wischnesvsky, 2004). Gross et al. (1998) argue that transformational change will remain at the forefront of the change literature because of the increasing environmental uncertainty in the environment due largely to globalization. 
One of the important trends in the transformational change literature has been the importance of culture. Researchers have found that in order for an organization to truly experience transformational change, the culture of the organization must be altered (Price \& Chahil, 2006). The research of Hoag et al. (2002) supports this argument. These authors found that employees who experienced change found that existing culture was one of the biggest obstacles to change and that management often underestimated the difficulty in changing that culture. According to these authors it is internal factors such as culture, rather than external forces, which are most likely to impede organizational change. These findings are important to this research because it may be possible that change teams could help to influence the existing culture of an organization to support the change. Participation on change teams could potentially increase the involvement of key individuals and groups who may then influence their existing subculture groups to support the change.

One approach to dealing with transformational change is to develop organizations that are capable of both incremental and transformational change at the same time. This idea was developed in an article written in 1996 by Tushman and O'Reilly entitled Ambidextrous Organizations: Managing Evolutionary and Revolutionary Change. According to Tushman and O'Reilly (1996) the key to success for businesses is being able to simultaneously implement both evolutionary (and incremental) and revolutionary (or transformational) change. The study conducted by O'Reilly and Tushman (2004) examined four distinct strategies for implementing transformational products or services. The four strategies used to implement transformational change that were examined were: implementation using existing structure, implementation using cross functional teams, 
implementation using unsupported dedicated teams, and implementation using an ambidextrous strategy. The ambidextrous strategy was defined by O'Reilly and Tushman (2004) as "structurally independent units, each having its own processes, structures, and cultures but integrated into the existing senior management hierarchy" (p.76). O’Reilly and Tushman (2004) found that the ambidextrous strategy was superior in both maintaining the existing business success and also in developing the new products or services. While these findings require further examination and a more thorough longitudinal study to better control for factors other than implementation strategy framework, however there are several key lessons from this research.

First, the forces of inertia in the existing businesses are strong (O'Reilly \& Tushman, 2004). If they are allowed to influence the new business, as is the case when organizations use existing structures, and cross functional teams to implement the change, then these political, structural, and cultural forces will likely crush efforts to transform the business. The second learning point about implementing change is that in order to transform business products or services, political support from upper management is required. The companies examined by O'Reilly and Tushman (2004) that choose to isolate teams tasked with the change also failed to achieve the desired results. An ambidextrous organization finds a way to protect the emerging new business form while integrating it into the company at the senior levels. This allows the change the resources and time needed to grow while providing it with support and protection from senior levels. The research by O'Reilly and Tushman (2004) also gives a third lesson to managers attempting to implement change. In order to successfully manage an ambidextrous company senior managers must be able maintain two different focuses for 
emerging and existing businesses. Emergent businesses should be focused on innovation and growth, and have an entrepreneurial feel to them. Management can support emergent businesses with visionary leadership, targets for new products and growth, and buy supporting risk taking and experimentation. In contrast senior management must at the same time lead existing businesses with a more controlling style, focused on costs and profit, efficiency and margins. The contrast between the two types of business is stark and it represents a challenge for any senior leadership team.

The notion of an ambidextrous organization is a critical learning tool for teams seeking to understand the challenge of implementing change. The work by O'Reilly and Tushman (2004) does however have weaknesses that limit the conclusions that can be drawn from their work. First, the findings require further investigation and empirical support due to the small sample of firms in the study. Second, the classification of implementation structures should also include hybrid structures (eg. many resources, individuals and teams may be required to maintain regular operations while helping with the change effort) that companies may have to employ due to resource constraints.

Despite these weaknesses, the O'Reilly and Tushman (2004) research on ambidextrous organizations has been supported by other researchers in recent years. Erikkson and Sundgren (2005) discussed the importance of taking an ambidextrous approach to change as well. According to these authors, organizations should have two change strategies (pragmatic, top down strategy and a bottom up, decentralized strategy) that operate in parallel at different organizational levels and in different parts of the change process. These authors found this approach to be successful during a large merger of two pharmaceutical companies. These findings are supported by the work of Graetz 
and Smith (2005) who also suggest that organizations need to adopt forms of organizing for change that allow for 'controllability' and responsiveness. These findings showed the applicability of the concept of the ambidextrous organization to a change setting. This concept should be on the minds of researchers and practitioners attempting to solve the dilemma of implementing change while continuing to succeed in their current business.

\subsection{PUBLIC SECTOR ORGANIZATIONAL CHANGE}

General theories of organizational change are applicable in both the private and public sectors (Nutt \& Backoff, 1993). However, in the past ten years there have been an increasing number of studies looking specifically at organizational change in the public sector (Karp \& Helgo, 2009; Neal \& Taylor, 2006; Sminia \& Van Nistelrooij, 2006; Wise, 2002). The fact that these studies were conducted specifically in the public sector suggests that it is important to review the literature on public sector change and identify areas in which public sector change may be different from change in other sectors. The purpose of this literature section is to identify the areas of change management that may be critical success factors to public sector change. The first part of this section provides a review of the drivers of organizational change that are most relevant in the public sector. The second part of this section examines some of the specific challenges for the public sector organizational change that have been presented in the literature. The third part of this subsection will discuss some of the critical strategies for successful public sector organizational change. Finally, this section concludes with a critique of the literature on public sector change and discusses the future research required to further this area of study. 


\subsubsection{Drivers of Public Sector Change}

As discussed in Chapter 2.1.1.1, the forces for and against change are constantly acting on an organization. This subsection examines the critical forces for change that influence the direction, frequency, and intensity of public sector change. Robertson and Seneviatne (1995) conducted a meta-analysis of change studies on public and private organizations and found that large private and public sector change is equally likely to occur. These authors also concluded that while it is more difficult to change work setting arrangements in public organizations (formal structure, goals, procedures, and reward systems) individual behaviours and organizational outcomes were difficult to change in both sectors. Robertson and Seneviatne (1995) argue that perceived differences in terms of public organizations being incapable of change due to excessive bureaucracy and unmotivated employees are largely untrue. While these authors agreed that change was difficult in public sector, the performance benefits for change were slightly higher for public organizations, and the difference between the challenges and benefits of change in the public sector was certainly not a great enough difference to prevent planned public sector change from being a viable option.

One of the most obvious forces for change in the public sector is the political influence that will shape change efforts and can vary during the life of the change effort (Nutt \& Backoff, 1993; Fernandez-Alles \& Llama-Sanchez, 2008). Nutt and Backoff (1993) suggest that public sector organizations are often constrained by government mandates which make transformational change difficult. This is particularly important in cases such as the current thesis research where the organizational change takes place over 
the span of several different political leadership changes. Each government will put forth its own mandate for the change which could significantly facilitate or hinder the change.

Wise (2002) also discussed some of the forces which make public sector change unique. According to Wise (2002), public reform is not just driven by economics, ideologies, or a new political agenda. In addition to these more well known drivers, Wise (2002) explains that demand for greater social equity, demand for democratization and empowerment, and the humanization of the public service are all forces that continually push to change the public sector. Wise's conclusions are supported by the work of Fernandez-Alles and Llama-Sanchez (2008) who also suggest that these pressures highlight the need for better change management practices in the public sector. The public sector environment is one of the most challenging and complex change environments that have been studied in the change literature. These macro level forces mentioned by Wise (2002) and Nutt and Backoff (1993) are at the centre of any change in the public sector and their impact on the change effort can be both dramatic and unpredictable.

\subsubsection{Challenges Related to Change in the Public Sector}

In addition to having some unique forces for change, the public sector also has its own unique challenges when it comes to managing change. Vann (2004) argues that 'clashing grammars' can prevent change from happening in the public sector, and inadvertently cause a great deal of resistance to change. According to Vann (2004) the language used for information technology change is often significantly different for consultants, contractors, and even between different departments within the government. 
These grammar differences can often be a result of unique interpretations of the change from each department and can raise uncertainty, stress, and have an overall negative effect on communication about the change (Randall \& Procteur, 2008). The result is that employees will likely be resistant because they are not getting a clear picture of the change. Vann (2004) also claims that this source of resistance often gets in the way of constructive resistance (open resistance) which would help the change. Vann (2004) suggests that there is too little research on resistance to change in the public sector.

Nutt and Backoff (1993) also discuss some of the unique challenges of public sector change. In their view, the most significant challenge for change managers in the public sector are the constraints placed upon them by political mandates which will shape change efforts and can change during the life of the change. Nutt and Backoff's work is supported by other research (Todnem By, Thomas, \& Klarner, 2008) who suggest that performance expectations can become difficult due to the lethargy and inertia inherent in the political time frames. In addition, the scope of impact is often very large in public sector change and with the wide spectrum of affected stakeholders, stakeholder analysis is very important and time consuming. Finally, the level of public scrutiny is high for public change, and media scrutiny is often an important challenge that must be face by managers.

Another challenge for the public sector is that ownership for change is often spread out among various internal and external stakeholders (Nutt \& Backoff, 1993). As a result, public change strategy must be co-developed with its stakeholders, and ideals may be more effective than specific goals because of the difficulty of setting goals for public organizations. Nutt and Backoff (1993) explain that a feature of public change is 
that organizational goals for the change can be unclear, making authority and resource limitations difficult and complex to manage.

It is important for public organizations to take thorough stock of stakeholders and resources as this process will help to identify potential barriers to change. The challenges discussed by Nutt and Backoff (1993) are very useful for managers of public sector change to be aware of. Nutt and Backoff (1993) provided this discussion of public sector change with the hope that these findings would be a springboard for future work that would uncover the subtleties of public sector change. However, since this research, the amount of change research in the public domain has been dwarfed by the research that has continued in the private sector. The current thesis research is in a position to build on the literature that examines the challenges of public sector change.

\subsubsection{Strategies for Managing Public Sector Change}

Researchers have offered some advice for managers dealing with the unique forces of change and the challenges of organizational change in the public sector. According to Sminia and Van Nistelrooij (2006) who conducted a case study of a public sector organization in the Netherlands, public organizations tend to take a top down approach to change. Employees often feel helpless to influence the change and therefore are more likely to resist change in the public sector. Sminia and Van Nistelrooji (2006) suggest that top management in public sector organizations must concentrate on finding ways to involve employees in organizational change. While these findings are consistent with the general change management literature, Sminia and Van Nistelrooji (2006) stress that within the public sector, employee involvement is even more critical to successful 
change than in the private sector. The authors argue that the traditional approach to change in the public sector has been a top down approach. Therefore, getting employees motivated and comfortable with participating in change may be a new experience and challenge for managers. As discussed, Vann (2004) also explains that it is necessary to create a shared meaning around principles, processes, and language early in the change process.

Another recommendation for successful change in the public sector change is related to the role of the political agenda in driving change. Nutt and Backoff (1993) recommend appraising their origins and historical political commitments before embarking on change. By examining why the public sector department was created and what the historical mandates have been, managers should have a better understanding of potential resistance or support for future change.

In addition to examining the historical commitments of the public sector organization, Bramson and Buss (2002) suggest that building support, and gaining alignment commitment plays an important role in public sector change. While this recommendation is not different from private sector wisdom it is important to understand that the political dimension surrounding change in the public sector can more often be complicated by non business interests such as human rights groups, powerful unions, and public opinions. In order to influence these forces for change, building a coalition capable of supporting change requires political support from a wide spectrum of stakeholders. Maintaining this coalition can be a difficult task for public sector change leaders.

Finally, Ferlie et al. (2003) discuss the traditional thinking that public organizations should learn from private sector organizations when it comes to effective 
management of change. These authors explain that while it would be a mistake not to learn from the existing private sector research, there are some unique characteristics of public sector change which may require researchers to venture beyond the private sector strategies. These authors discuss the need for research to examine inter-agency and interorganizational working, which is an important component of the government paradigm. Change efforts in the public sector often require the cooperation of several agencies or departments. The political influence of each department on the change effort is a unique challenge for public sector managers and certainly one which requires future investigation.

\subsubsection{Critique and Future Research}

This subsection critiques the literature on public sector change and examines some of the challenges faced by researchers working in this area. One of the most glaring weaknesses of the research presented in this subsection is that none of the studies have attempted to empirically examine the differences between public sector and private sector change. To continue to justify research on public sector change as something that is unique and different from what occurs in the private sector it is important the researchers empirically examine the difference between private and public sector change.

The public sector change literature also suffers from a lack of longitudinal research done on the impact of public sector challenges of change on individuals or groups. Research on both employee well-being and performance should be examined. The long term impacts of organizational change on employees in the public sector is an area that could help to improve the efficiency of government employees by shedding 
light on issues such as change weariness and resistance to change. It will also help us to better understand the impact of changes in government on the change process itself.

Another weakness of the public sector change literature is that there are often very different contextual factors involved in studying different public sector organizations. For example, findings from a study on organizational change in the Ministry of Defence in Japan may not be applicable to the Department of Agriculture in Canada. The political, cultural, and geographic contextual factors may mean that grouping all public sector organizations together under one area of change research may not be the most accurate classification. Researchers on the topic of public sector change should be aware of the potentially influential contexts under which public sector change is studied.

The research on public sector change discussed in this section provides a foundation for developing theories related to public sector change. However, future research must provide a more fine tuned approach to studying the unique process which is public sector organizational change.

\subsection{IMPACTS OF ORGANIZATIONAL CHANGE}

One of the major reasons that organizational change has received as much attention as it has from researchers and practitioners is due to the dramatic impacts that organizational change has on the individuals and groups within that organization. Often the success of an organization can hang in the balance during a change period. Additionally, the likelihood of success is closely related to the impact of the change on individuals and groups within the organization and their reaction to those impacts (Mabin 
et al., 2001). For that reason the focus of this section will be on how change impacts both individuals and groups. While research has identified many impacts that organizational change has on individuals and teams within an organization, three seem to be key: resistance, workload, and stress. These three outcomes are a focus of this thesis. The literature reviewed in this section is meant to support the decision to include these change variables in the initial framework for this research. This section also helps to put the current study into context.

The first part of this section presents the literature on resistance to change. The second part of this section reviews the literature on workload as it is related to organizational change. Finally, the third part of this section examines the impact of organizational change on the stress that employees experience. Each of these three subsections also discuss why these impacts of change variables may be important to the success of organizational change teams and merit inclusion in the initial research framework for this case study.

\subsubsection{Employee Resistance and Support for Change}

Perhaps the most widely researched aspect of organizational change is the resistance to change that accompanies almost all organizational transformations (Mabin et al., 2001; Ford, Ford, \& D'Amelio, 2008). Resistance to change can be defined as "any conduct that serves to maintain the status quo in the face of pressure to alter the status quo" (Zaltman \& Duncan, p. 76). Resistance has become linked to change in both the academic literature and in the minds of managers, with some researchers arguing that humans are naturally limited in their ability to change and thus are predisposed to change 
resistance (Ford, Ford, \& D'Amelio, 2008; Kotter \& Schlesinger, 1979). While initial researchers and practitioners in this area treated resistance to change as an opposing force to change (Lawerence, 1964), the consensus has shifted and resistance is now more often viewed as a healthy part of the change process that, if managed properly, can actually help bring about successful change (Malbin et al., 2001).

This subsection examines the literature related to resistance to change and the implications of this research for the current study. The first part of this subsection examines the nature of resistance to change and some of the common manifestations and impacts of resistance identified by researchers. The second part of this subsection discusses the literature related to why individuals resist change in organizations and how managers can effectively channel that resistance into support for the change. The third part of this subsection examines the role of employee input and involvement in the change, and how these measures relate to resistance and support for the change. Finally, this subsection closes with a critique of the resistance to change literature and discusses why resistance to change is included in the current study on change teams.

\subsubsection{Classifying Resistance to Change}

In the classic article How to Deal with Resistance to Change, Lawrence (1964) explains that resistance may take the form of "persistent reduction in output, increase in turnover, chronic conflict, sullen hostility, wildcat or slowdown strikes, and the expression of 'a lot of pseudo-logical reasons why the change will not work' (p. 4)". This type of active resistance can potentially harm both the change effort and the current business activities of the organization. Researchers in this area have continued the steady 
development (Cutcher, 2009; Ford, Ford, \& D'Amelio, 2008; Kotter \& Schlesinger, 1979) of our understanding of resistance to change and advise managers to be wary of the different forms and sources of resistance but caution against using preformed notions of how employees will resist. These authors argue that the reaction to change experienced by groups and individuals within the organization is very unique and as a result groups and individuals will resist change in many different ways. Resistance as described by Lawerence (1964) is known as active or manifested resistance and is often the form of resistance feared most by mangers in an organization. This form of resistance is a highly visible form of resistance and although it may appear to be the most detrimental form of resistance, if managed properly it can help correct critical elements of the change transformation and actually strengthen the change effort (Atkinson, 2005; Cutcher, 2009; Mabin et al., 2001). Active resistance may bring important issues to the attention of senior management and will likely force a resolution.

The second type of change resistance is passive or latent resistance to change. Passive resistance to change can be defined as "demonstrating moderate opposition to a change by engaging in more covert or subtle behaviours aimed at preventing the success of the change" (Stanley et al., 2005, p. 450). It is important that managers and employees are aware of both latent and active types of resistance that are a part of organizational change. Passive resistance represents a two phase challenge for managers. Unlike active resistance, passive resistance is not easily visible to managers during a change effort and therefore managers must actively seek out reasons for the resistance. Until latent resistance is identified and brought to the surface it will not be possible for managers to confidently engage the resistance (Kotter \& Schlesinger, 1979). Latent or passive 
resistance is an easily missed form of resistance; however, it can also be very a detrimental form of resistance to change efforts because the latent resistance in an organization will be more likely to fester and become a part of the organizations normal way of life (Lawerence, 1964). One of the weaknesses of the literature on both active and passive resistance to change is the lack of research empirically examining the impact of each type of resistance to change on group level performance. Elrod and Tippett (2002) explain that resistance to change may play a role in individual capabilities during change; however, this research does not examine the impact that resistance has on team performance. This thesis is concerned with the impact of resistance to change on the effectiveness of teams working on the change. The literature on resistance has not yet addressed this issue and as such this thesis should contribute to the body of knowledge in this area.

\subsubsection{Why Do Individuals Resist Change?}

One of the most important tasks of any change leader is to understand why resistance to change is occurring in their organization (Ford et al., 2008; Mabin et al., 2001). The importance of managing resistance to change can be seen in the Elrod and Tippit (2002) study that examined the performance decline during change at both the individual and organizational level. According to these authors, the human response to change naturally takes the organization through a 'death valley' of change where performance will suffer until resistance to change is overcome.

Kotter and Schlesinger (1979) acknowledge that there are "probably an endless number of reasons that people resist change" (p. 109) but highlight four main reasons: 
parochial self-interest, misunderstanding and lack of trust, differences in assessments, and a general low tolerance for change. These arguments are echoed by Kanter (1985) who also explains that people can also resist change for fear of the unknown, loss of control, loss of face, degradation of skills, and lack of confidence in either management or the change.

The change literature has several examples (eg. Piderit, 2000; Strebel, 1996) linking resistance to the individual's own fears, lack of faith in management, and lack of faith in the plan for change (Strebel, 1996). Mabin et al. (2001) divide the factors that affect resistance into individual, group level, and organizational level factors. Individual factors influencing why employees might resist change include personality factors and attitudes based on previous experiences with change. Group level factors for resistance include group cohesiveness, social norms, and participation in decision making. Finally, organizational factors influencing resistance include threats presented by unknown environments, challenging existing status quo, and workload consequences.

The literature on why individuals resist change is related to this study because it may give some suggestions for how managers can reduce the levels of resistance present on their change teams. Unfortunately, there is very little longitudinal research done on the impact of resistance on group performance and therefore it is unclear whether resistance to change is something that managers should strive to reduce. However, the literature on why individuals resist change does help to put the current research on change teams into context. 


\subsubsection{Building Support for Change}

Having reviewed what resistance to change is and the literature on why employees resist change, the final part of the subsection examines the literature on how managers can help to turn resistance to change into support for change. In a classic study on resistance to change, Coch and French (1948) examined group resistance to change and how it affects the performance curve for organizations. According to these authors groups that participated in planning and implementation of the change were more likely to quickly recover from the performance loss. More recently, Morgan and Zeffane (2003) found in their research from the Australian Workplace Industrial Relations Survey that participation and input from employees served to protect the trust between management and employees which may become corroded during the change process. The findings of these studies illustrate the importance of involving employees in the implementation of change.

Kotter and Schlesinger (1979) also argue that participation and involvement from employees in change can help managers deal with resistance. According to these authors managers have several options when deciding how to handle resistance, each with its own advantages and drawbacks. Along with participation and involvement, Kotter and Schlesinger (1979) recommend that managers use education and communication, facilitation and support, negation and agreement, manipulation and co-optation, and finally as a last resort, coercion. Kotter and Schlesinger (1979) explain that the choice of strategy for dealing with resistance to change largely depends on situational factors such as the amount of resistance anticipated, the manager's position of power within the 
organization, the availability of data on the change implementation plan, and the stakes involved if resistance is not addressed.

The change situation will influence how managers will attempt to deal with resistance to change; however it should be noted that Kotter and Schlesinger (1979) also argue that participation and involvement from employees is a desirable strategy when managers have enough time, influence, and information on the change. These recommendations are consistent with the work of Lawerence (1964) who also advocates participation for managing resistance to change but cautions against token participation exercises. Lawerence (1964) explains that managers often make the mistake of using participation to get employees to buy into technical changes that will take place. According to Lawerence (1964), workers are much more concerned with how their relationships at work will be impacted than the technical solutions that will be changed. Employees are more likely to resist changes if they feel that their input into how social relationships will be impacted is not taken into account for the change. This classic article on resistance highlights the idea that managers must carefully analyze resistance and the change situation, and design employee participation around the issues that matter most to the change implementers.

The idea that employees are weary of change because it will alter the social relationships that exist is also linked to the work of Strebel (1996) who argues that employers must revisit the personal contracts with employees facing a change. Strebel (1996) explains that personal contracts with employees involve formal, psychological, and social dimensions. Managers often communicate around the formal dimension of the personal contract by explaining changes in the basic tasks and performance levels that 
will be required. Unfortunately, as Lawerence (1964) argued, managers often neglect the psychological contracts (the unwritten expectations and commitments) and social compacts (the unwritten rules for what the company will value and how it will allocate resources). According to Strebel (1996) managers can reduce resistance to change by communicating the need and reasons for change, allowing employees to revise and buy into new compact terms, and finally by formalizing the new compact with formal and informal rules to support the new compact. The message behind both Strebel (1996) and Lawerence's (1964) work is that a sound technical argument for change will do little to reduce resistance to change if employees are not satisfied that their psychological and social compacts will be improved or maintained after the change.

\subsubsection{Critique and Implications for the Current Research}

The primary weakness of the research on resistance to change stems from the fact that the most common and potentially dangerous forms of resistance are very difficult to quantify and therefore empirically link to successful change (Ford et al., 2008; Mabin et al., 2001). Despite the lack of empirical support for the resistance literature, the basic idea that employee's resistance to change depends on the extent to which the change impacts the social norms of the organizations is consistent throughout the literature and should be considered in any future research on change.

Another area of the resistance to change literature that can be improved is the impact belonging to a team has on resistance. Belonging to a change team may allow individuals a greater level of input into how the new organization will operate both technically and socially in the future. As well, the social setting of a change team may act 
as a stepping stone toward the new organizational form, which facilitates transition from their existing social structure to a new one. It is hoped that this thesis adds to our understanding of the impact of team membership on resistance to change.

In summary, the literature on resistance to change suggests that both active and passive types of resistance may be an important factor in the effectiveness of change teams. It is important to note that resistance to change can be a natural and healthy part of the change process (Burke, 2008; Kotter \& Schlesinger, 1979) so the impact of resistance to change on change teams may in fact be helpful to a certain point. It is also relevant to the current study that the use of employee participation to reduce resistance is a viable strategy if managers allow for employee involvement to extend beyond token participation in technical decisions into meaningful input regarding the formation of new psychological and social contracts that will shape the new organization (Strebel, 1996). Organizational change teams provide a good opportunity to involve employees in the change and perhaps reduce the level of resistance experienced by employees. The resistance literature shows that resistance to change doesn't have to be a dreaded subject for managers; if they manage it properly, resistance can help to bring about lasting, successful change (Burke, 2008; Mabin et al., 2001).

\subsubsection{The Impact of Organizational Change on Workload}

One of the most noticeable impacts of organizational change on individuals is the increase in workload experienced by workers attempting to participate in the change while continuing to perform their day to day jobs (Decker et al., 2001; Robinson \& Griffiths, 2005). As discussed in this literature review, transformational change requires 
significant effort from almost all of the employees, and this effort combined with the work necessary to keep the everyday operations of the organization up and running can cause a significant increase in workload. This subsection on the impacts of workload begins by examining how the existing research on change suggests that workload may be affected by organizational change. The second part of this subsection presents some of the challenges associated with increased workload during change. Finally, the third part of this subsection critiques the literature on workload and organizational change, and discusses the inclusion of workload in this research on change teams.

\subsubsection{Workload and Change}

The relationship between organizational change and individual workload levels is important to the current research because it may be related to the ability of the team to perform effectively. Workload may be represented as the total demands on time and energy that is associated with a team member's role on the team (Bohen \& ViverosLong's, 1981). An individual's position in the organization, their experience, skill, personality, and the social groups that they associate with may all factor into the impact of change on their workload levels (Ferguson \& Cheyne, 1995; Newell \& Dopson, 1996). There is a general view in the literature that organizational change tends to bring about an increase in workload for many workers (Smith \& Burke, 1992) and that an increase in workload can lead to a drop in satisfaction (Smith \& Burke, 1992) and even performance (Cox-Fuenzalida et al., 2006). Cox-Fuenzalida et al. (2006) found that sudden increases in workload levels, (often associated with change) can result in impaired performance. One of the weaknesses of change related workload research is that the impacts of change 
on workload are difficult to predict due to the different contextual factors involved. One such contextual factor that has not been examined is whether or not members of a team working directly on the team perceive an increase in workload.

\subsubsection{Impacts of Increased Workload}

As discussed above, organizational change is perceived to increase the workload of employees (Smith \& Burke, 1992). This perspective is echoed by Newell \& Dopson (1996) who argued that during organizational change many employees, especially those in middle and frontline management roles experience longer hours and increased workloads. Research by Goffee and Scase (1992) suggests that this increased workload may have a lasting impact on an employee's careers. Employees who struggle to manage their workload during change (especially changes related to downsizing) may develop negative attitudes towards the change and become discouraged about their overall career prospects within the organization. While this idea requires further longitudinal study, it does highlight some of the potential negative impacts of increased workloads during change.

Even when the workload levels are not high, many employees can feel the pressure to put in extra hours and take on extra work to avoid being perceived as slacking or not pitching in for the change. Simpson (1998) found that during times of change there was pressure to be 'present' and to be perceived as a contributor. This pressure was in part driven by fear of redundancy and by competition for advancement in the new organization. The study by Simpson (1998) argued that the culture of 'competitive presenteeism' (not wanting to be seen as a slacker) surrounding change effort could also 
have a negative impact on employees and serve to increase workload around the change. To deal with increasing workload and avoid being seen as absent, workers may purposely create uncertainty around work time location. The study by Simpson (1998) highlights the potential for employees to feel pressure to increase their workload during change and shows how organizational change can become perceived by employees as 'more work'.

\subsubsection{Implications for the Current Research}

The research on workload and organizational change suggests that individuals may experience increasing workload during times of organizational change (Smith \& Burke, 1992). The literature on increased workload and organizational change is unclear as to the impact of increased workload during change on either individual or team level performance. Research done by Cox-Fuenzalida et al. (2006) in a controlled experiment setting, found that sudden increases in workload levels, (often associated with change) can result in impaired performance. These findings suggest that sudden increases in workload may impact the change teams overall effectiveness. It may also be possible; however, that by working on a change team, team members may be in a better position to moderate the effects of change on their personal workload levels. While the research reviewed in this subsection on workload provides some context for this study, additional empirical work in general and longitudinal in particular is needed to examine the specific impacts of change on individual and team effectiveness. 


\subsubsection{The Impact of Organizational Change on Stress}

Research on organizational change has found that during change, employees may be more susceptible to anxiety, uncertainty, fear of loss, and job stress (Burke, 2008; Callan, 1993; Jimmieson, Terry, \& Callan, 2004). The impact of stress on performance for both individuals and teams is an important factor in this research and will be examined in this subsection. The first part of this subsection defines employee stress and examines how researchers feel that stress may be impacted by organizational change. The second part of this subsection presents some of the potential challenges associated with stress during change and the impact it may have on individuals. Finally, the third part of this subsection critiques the literature on organizational change and stress, and discusses the importance of stress in the current research on change teams.

\subsubsection{Organizational Stress and Change}

Job stress as defined by Lazarus (1999) refers to the dynamic transaction between a person and her job environment that is appraised as potentially challenging, threatening, or harmful. Job stress can cause employees to feel "a sense of time pressure, anxiety, and worry that is associated with job tasks" (Hunter \& Thatcher, 2007, p. 954). Job stress can potentially have a negative impact on team member satisfaction and thus on overall change team effectiveness. Organizational change has been found to be linked to increased stress levels for employees (Ashford, 1988; Brockner et al., 1993; McHugh, 1997). According to Jimmieson, Terry, and Callan (2004) employees are more likely to experience increased anxiety and uncertainty over their future during a time of change. 
These factors make employees more susceptible to high levels of stress during organizational change.

\subsubsection{Impacts of Stress on Teams and Individuals}

There is inconclusive evidence on the impact of job stress on the performance of individuals. Research by Huguet et al. (1999) suggests that there is considerable experimental research to support the idea that stress may focus individuals and improve task performance to a certain level. LePine et al. (2005) showed through their metaanalysis of the stress literature that two different types of stressors may have different impacts on performance. Hindrance-oriented stressors (e.g., organizational politics, bureaucracy, role ambiguity) are negatively related to job performance, but challengeoriented stressors (e.g., high workload, time pressure, job scope) motivate workers and can be positively related to job performance even as they evoke other strains such as fatigue and exhaustion. In a research study on bank branch employees Hunter and Thatcher (2007) found that job performance under stressful conditions suffered if commitment was low. Hunter and Thatcher's (2007) research on the moderating effects of commitment may have some implications for the role of support for change in moderating the impact of stress on performance in the current study. Employees working on change teams who experience low levels of support for the change and high levels of stress may see a similar effect on performance as described in Hunter and Thatcher (2007). The current thesis research may be able to extend the findings of this research to study of change teams by examining the impact of support from the group on performance levels. 
While the research on individual performance and stress suggests that there may be some performance benefits associated with stress, the team performance literature is not as positive. With regards to teams, Driskel et al. (1999) found stress to negatively affect team performance by narrowing their attention to individual issues. It appears that stress may have an effect of increasing self-focus and decreasing team focus (Driskell et al., 1999; Gladstein \& Reilly, 1985). In Driskell et al.'s (1999) research, team members who lost their team focus underperformed even more when team interdependence was increased. When these authors controlled for stress in the relationship the performance decline was reduced. This empirical study has important implications for the current research. Individuals on change teams may be under an increased risk of stress (Ashford, 1988; McHugh, 1997) which work by Driskell et al. (1999) suggests may affect change team performance. The current research will help to advance this research by examining the relationship between stress and team performance in an organizational change setting.

Along with examining the link between organizational change and employee stress researchers have also looked at ways in which organizations can identify signs of stress and support those employees before stress has a negative impact on both the employee and the organization. There has been recent research into the impact on employees of negative rumors during organizational change (Bordia et al., 2006). According to Bordia et al. (2006) negative rumours are more prevalent than positive rumours during change. Employees who report negative rumours are more likely to report change related stress than those who report positive rumours or no rumours at all. Bordia et al. (2006) argue that it is possible that rumours are expressions of employee concern and stress levels during change. This research suggests that to stay on top of 
rumours that management needs to be aware of the informal information channels. In doing so it is expected that they will have a better idea of the stress levels of their employees during change.

Decker et al. (2001) have also found that employees who have been employed longer experience lower levels of stress during change. These findings could be due to the idea that more tenured employees would feel more secure in their job and may have experienced change in the company previously. Decker et al. (2001) also found that skill based training, counselling, and leadership training efforts were ways that organizations could help to reduce stress both during the change and even after the disruptive change is complete.

\subsubsection{Critique and Implications for the Current Research}

The research findings discussed in this subsection support the idea that organizations can and should continue to find ways to support employees and help them to manage stress during transformational organizational change. The literature on stress and organizational change is a well researched area (Decker et al., 2001). The research shows (Driskell et al., 1999; Gladstein \& Reilly, 1985; Lepine et al., 2005) that stress plays a critical role in the performance of both individuals and teams. These findings justify the inclusion of the job stress variable in the current study. The current research attempts to contribute to the literature on stress and change by examining the impact of job stress on team effectiveness in a large scale public sector change. 


\subsection{CRITIQUE OF THE ORGANIZATIONAL CHANGE}

\section{LITERATURE}

This section begins with a discussion of the strengths and weaknesses of the organizational change literature reviewed in this section. The final part of this subsection examines the future of research on public sector planned transformational change and where the current research may contribute to the literature.

\subsubsection{Strengths and Limitations}

A Business Source Complete (online database) search under the general descriptor organizational change yields over 9,928 academic peer reviewed articles published between 1975 and 2009. A Google Scholar search of organizational change during the same time period yields 16,900 hits. The large volume of work that has been done on organizational change over the past half century represents both a strength and a weakness of this body of literature. It is a strength because it has brought to the surface a wide variety of variables that affect the success or failure of organizational change. For example, leadership, culture, conflict, resistance, and impacts of change have all been shown to influence the change process.

At the same time the amount of research done on organizational change in a relatively short period of time has left researchers gasping for air as they attempt to build a logical approach to the successful management of change. Many theories of change which are put forth are done so without strong empirical support or a high consideration for contingencies which may influence the theory's effectiveness. Researchers are faced with a difficult task of selecting among a large number of seemingly important change 
related variables. To include all of the variables that have been suggested to be important to the change process would make research in this area extremely difficult. Researchers would be faced with a large response burden for subjects, and the challenge of finding large enough samples to study all the relevant variables in the change equation. Yet by excluding variables researchers risk missing key variables in the change process. The large amount of research that has been done on organizational change forces researchers to make tradeoffs when attempting to confidently investigate new areas of organizational change.

Another strength of the change literature that may be able to help with this weakness is the multitude of case study based research into organizational change. These case studies provide insight into the situational factors that may influence existing theories of change and provide a fertile ground for future meta-analysis of organizational change theories. Using case studies to examine change theories has helped researchers focus on leadership and culture during change and has also driven the evolution of theory about change from planned to unplanned change.

As mentioned above the lack of empirical research in the change literature has made it difficult for researchers to model the change process (W. Burke, 2002; Todnem By, 2005). Empirical research on change is often difficult to collect due to the fact that variables such as culture, leadership, conflict, and resistance which have shown to affect change are all themselves, a challenge to measure. One of the primary challenges with all of these variables is the appropriate unit of analysis (ie. organization, group, individual) when examining change processes. When all of these levels that are interacting to impact change variables are brought together it becomes difficult for researchers to confidently 
assess change strategies and provide recommendations that are applicable in other change settings.

The large number of ways to examine change presented in the preceding literature review also highlights another weakness of the organizational change literature (Todnem By, 2005). The terminology and classification schemes used to describe organizational change is not always intuitive and consistent (for example, planned versus unplanned, reactive versus anticipatory). This fact can make it difficult for researchers to apply new findings to existing change theories. Future research would benefit from a consistent classification scheme and nomenclature surrounding organizational change.

Another limitation of the existing research on organizational change is the lack of longitudinal research that has been conducted. Perhaps due to the dynamic nature of organizational change (where employees' roles and responsibilities often are in flux) the majority of studies have been a post change analysis of the strategies and impacts of change. The current thesis research hopes to address this weakness by examining impact of change on change teams over a period or two.

\subsubsection{Future Research}

Future research on change in general should continue to look at specific organizational change situations such as public sector change. By examining the variables that appear to have a large impact on change strategies researchers can examine the usefulness of general change strategies in a public sector change environment. It is also important that future research address the glaring absence of teams from the change 
literature. The use of teams to execute change is a viable strategy that has not been examined by researchers and represents another primary area in which this research can contribute to the literature. Finally, the literature on public sector change is also lacking longitudinal empirical research. The current study helps to address all of these issues as it will empirically examine the impact of a planned transformational change on change teams over time in the study. Overall, the current thesis research is well positioned to contribute to the development of the literature on public sector planned transformational change. 


\section{TEAMWORK}

Teams have come to represent one of the basic building blocks of organizational life (Ilgen, 1999). The widespread use of teams in the business world has led to the general acceptance of teams as a valuable strategy for achieving higher returns for the organization in a variety of business situations (Hackman, 1990). One of the more recent applications of teamwork in an organization is the use of teams to help bring about transformational organizational change (Schein, 1999). Despite the logical application of teamwork for planning and implementing change there has been a lack of research into the specific benefits and drawbacks for using teams in change or how they can be used most effectively. For this reason, the impacts and outcomes of change teams remain uncertain. To better understand this specific type of team this study will attempt to build a model of teamwork that will include key variables for change team effectiveness.

This section of the literature review examines the extensive literature pertaining to teams within organizations and as such will provide a foundation for the development of a model of change team effectiveness, one of the goals of this thesis. Due to the amount of literature in the area in this literature review will focus on team effectiveness. Particular attention is given to how team effectiveness has been modelled in the literature.

The first part of this chapter provides a definition of a change team. The second section reviews the literature on team classification schemes and the traditional roles of teams within the organization. The third section presents the benefits and challenges of teams in organizations. The fourth and final section examines a prominent team effectiveness model put forth by Campion et al. (1993) which serve as the foundation for 
the discussion of team effectiveness models and the development of an effectiveness model for transformational change teams.

\subsection{DEFINING CHANGE TEAMS}

Teams have become a critical strategic tool for organizations today and continue to be applied to new business situations in an attempt to improve effectiveness and efficiency (Devine, 2002). Over the past fifty years, the terms team and group have often been used interchangeably in literature reviews. The term "group" has closer ties to the social group research done prior to 1980 . This research was not limited to organizational settings. The past twenty-five years has seen the evolution of teamwork terminology to the point where teams are being distinguished more clearly from group research. Devine (2002) provides a very thorough definition of a team developed from the work of prominent researchers such as Hackman (1987), Cohen and Bailey (1997), and Sundstrom et al. (1990). Devine (2002) defines a team as "a collection of individuals who share a common goal, whose actions and outcomes are interdependent, who are perceived by themselves and others as a social entity, and who are embedded in an organizational context"(p.291). This definition typifies the general trend towards the use of the term 'team' to refer to organizational groups brought together for a specific task. Consistent with this trend in the literature (Devine, 2002) the current research will define a change team as,

"a collection of individuals who share a common goal related to the planning or implementation of organizational change, whose actions and outcomes are interdependent, who are perceived by themselves and others as a social entity, and who are embedded in an organizational context." 
This definition is consistent with Langton and Robbins (2007), who explain that a team can be fundamentally differentiated from a group based on the extent of common interest and accountability to team members for performance.

While the uncertainty around the nomenclature of teams has done little to slow down the amount of research done on teams, it has made classification of teams in organizations more challenging. In this review of literature, the terms 'team' and 'group' will be used according to which ever term was used in the original research.

\subsection{CLASSIFYING TEAMS}

Over the years the classification of teams has proven to be a difficult challenge for researchers (Cohen \& Bailey, 1997). There have been many attempts to classify teams according to their composition, task design, leadership, work design, team processes, and a host of other characteristics that make up the many unique features of teams (Devine, 2002). The goal of developing a classification system for teams has been to facilitate

future research on teams and team effectiveness in different organizational situations by providing a common set of terms, thereby permitting greater generalization across studies (Devine, 2002). One such organizational context for which teamwork is well suited is transformational change. However, to date change teams are not included in the existing classifications of teams.

According to Cohan and Bailey's (1997) review of the teams' literature, "the type of team matters for the determinants of effectiveness. By distinguishing among types of teams, this review clearly indicates that the variables that are studied and the findings that 
are captured vary for different types of teams" (p. 281). The current thesis research is interested in how transformational change teams fit into existing team classifications. This section examines the literature on team classification with a focus on three influential team classification schemes. The first part of this section examines the typology of teams presented in Cohen and Bailey's (1997) review of the team effectiveness literature. The second subsection examines the classification system of Sundstrom et al. (1990) and how organizational teams may be classified. The third part of this section presents the taxonomy of work teams used by Devine (2002) and discusses the place of transformational change teams in the taxonomy. The final part of this section discusses the limitations of these and other classification systems for teams when it comes to research on transformational change teams. The goal of this section on team classification is to review the literature related to the classification of teams in organizations and provide a foundation for understanding where transformational change teams fit into existing team taxonomies.

\subsubsection{Cohen and Bailey (1997)}

The first taxonomy of teams in organizations comes from the work by Cohen and Bailey (1997) on teams and team effectiveness. According to Cohen and Bailey (1997) teams in organizations can be divided into four categories: (1) work teams, (2) parallel teams, (3) project teams, and (4) management teams.

Work teams refer to continuous work units responsible for producing either goods or services. Cohen and Bailey (1997) explain that these types of teams often have a high 
degree of autonomy and have given rise to self-directed work teams who use dispersed leadership in the place of traditional supervisors.

The second type of team in the classification scheme is the parallel team. Parallel teams are individuals from different work units or jobs that are brought together to perform tasks that the organization is not normally equipped to perform. These teams exist in parallel to regular operations in the organization. Cohen and Bailey (1997) give the example of quality improvement teams, special task forces, and quality circles. Although it is not mentioned by the authors, this category of team seems well suited for a transformational change team.

The third category of teamwork listed in the review is the project team. Cohen and Bailey (1997) describe project teams as one-time teams that require knowledge intensive expertise. When the project is done members return to their different functional roles or move on to a new project. The finite time characteristic of project teams and the expertise requirement suggest that perhaps change teams could be classified in this category.

The final category of teams used by Cohen and Bailey (1997) are management teams. These teams are responsible for the overall performance of a business unit. The members of these teams are most often managers responsible for each sub-unit of the organization. The collective expertise and power of these teams makes it possible to set about organization wide initiatives. Cohen and Bailey (1997) explain that management teams are becoming more prevalent due to the turbulence and complexity of the global environment. These are the same environmental characteristics that are cited as reasons for the increased rate and intensity of organizational change. 


\subsubsection{Sundstrom et al. (1990)}

The second classification scheme reviewed in this subsection is the work of Sundstrom et al. (1990). The purpose of this classification system was to provide a framework through which the authors could comment on the usefulness of their team effectiveness models at predicting team effectiveness for each type of team. These authors examined the teamwork effectiveness research to develop an ecological approach to modelling the factors related to team effectiveness. Sundstrom et al. (1990) argued that their team effectiveness model could be applied to the following four categories of production teams: (1) advice and involvement, (2) production and service, (3) projects and development, and (4) action and negotiation. This classification of teams is heavily based on the distinct tasks that teams can be applied to in an organization.

Advice and involvement teams, such as quality circles are teams brought together to provide insight into strategies for improving effectiveness and efficiency in the organization. Sundstrom et al. (1990) explain that these teams, which were traditionally made up of senior level people were often used to gain input from frontline employees and to help with employee buy in for decisions.

The second category of teams used by Sundstrom et al. (1990) is production and service teams (i.e. teams which produce either a service or product). According to Sundstrom et al. (1990) production and service teams are most commonly self-managed teams consisting of frontline employees. 
The third category of teams includes project and development teams. These teams are often made up of white-collar professionals and are often responsible for innovative solutions to non-routine problems. These teams can have complex creative processes and are often given more autonomy in an organization.

The final type of team used in the classification scheme is the action and negotiation team. These types of teams exist for short durations and are comprised of specialized members who cooperate to perform at a high level for a certain event. These teams often require specific roles to be filled by members to compete successfully in the event.

\subsubsection{Devine (2002)}

The third classification system for teams reviewed in this section is the work of Devine (2002). In this research the author conducted a thorough literature review of the existing classification systems for teams and groups in the field of psychology and management. The result of this literature review is a taxonomy of teams that divides fourteen types of teams into two clusters. The first cluster of teams, intellectual teams, refers to knowledge work done in the organization. According to Devine (2002) knowledge work "involves thinking as a core task, mental skills, a nonlinear work process, the derivation of new knowledge and information as the primary work outcome" (Devine, 2002, p.296). Intellectual teams were compared to physical work teams which "involved a core task, physical skills, a linear workflow, applying existing knowledge, and a tangible product" (Devine, 2002: p.296). Teams related to transformational change likely fall under the intellectual teams category. 
Devine (2002) identified six types of teams that were categorized as intellectual work teams. The first type of intellectual team is the executive team, which is typically engaged in an unstructured task that is highly affected by a turbulent environment. Members of the executive team are usually from different backgrounds or functional areas, and often represent a large portion of the power and resources in the organization. The outputs from these teams are varied and often are organization wide and strategic in nature.

The second type of intellectual team identified by Devine (2002) is the command team, who are responsible for critical real time decisions for the organization. These teams are often widely geographically and physically distributed and rely on advanced information technology to collect and integrate the information needed to perform their role.

The third type of team in the classification scheme is the negotiation team. This type of team is usually made up of group members from different departments or divisions who represent their respective departments' interests. The negotiation team has a specific goal and members work to maximize the outcomes for their constituents. This type of team is often formed under time pressures and has to deal with higher than normal levels of resistance and conflicts in the group.

The fourth type of team identified by Devine (2002) is commission teams. According to Devine (2002), commissions are teams brought together for special projects. Their role is to devise a solution or plan for the project and to see that the plan is carried out effectively. Once the project is over, members either return to their previous work teams or move onto the next project. 
The fifth type of team identified by Devine (2002) is the design team. These teams perform hands on, creative work which is often for an external client. The members are often cross functional and like commissions, members are brought together for a specific project.

The final type of intellectual team identified by Devine (2002) is the advisory team, which is brought together to examine a problem and provide advice on how to improve organizational efficiency or effectiveness. Advisory teams often have members from various functional backgrounds and exist outside the normal structure of the organization.

\subsubsection{Strengths and Limitations}

Each of the three classification schemes examined in this section provide some insight into the various capabilities and applications of teams in organizations. The final part of this section presents the strengths and limitations of each of the three classification schemes. Specifically, this part examines how each of the classification schemes applies to the change teams to be studied in the current thesis research.

The work of Cohen and Bailey (1997) provides a simple yet effective classification scheme for teams; however, this taxonomy likely needs one modification to accommodate change teams. Intuitively, it seems to make sense that change teams are some combination of project teams and management teams. Management teams would be largely responsible for setting the strategic direction of the change and mapping out the general strategy for implementing the change. Project teams would be necessary to 
accomplish specific tasks related to the implementation of the change plan. Interestingly, both project change teams and management of change teams would likely need to exist in a parallel form in order to allow for the company to continue operations while undertaking the transformational change. Eventually the transformational change would also alter or create new work teams responsible for delivering the product or service arising from the change.

The classification system used by Sundstrom et al. (1990) examines four basic categories of teams. Unfortunately these categories of teams are not exhaustive and the authors acknowledge that certain types of teams, such as top management teams and corporate transition and merger teams, may not fit into their four applications of work teams. The types of teams that do not fit into the framework are the types of teams which seem to be most relevant during organizational change.

The classification of intellectual teams put forth by Devine (2002) is an attempt to build upon the many distinct classification systems produced in the literature. This framework is useful for researchers attempting to structure their research and measure critical variables for team effectiveness. The team classification system developed by Devine (2002) provides insight into the potential nature of transformational change teamwork as it suggests that such teams can be categorized as an intellectual team. Unfortunately, it may be difficult to classify teams using this criterion as it is likely that many transformational change teams may overlap team types presented in this scheme. This research will attempt to build on the work of Devine (2002) by deciding how best to classify transformational change teams in the existing classification scheme. 


\subsection{POTENTIAL BENEFITS OF TEAMS}

A cornerstone of organisational life, the ability to work in teams, has become an important skill for employees (Campion, 1993; Cohen \& Bailey, 1997). Survey research has shown that approximately $80 \%$ of Fortune 500 companies use various forms of selfmanaged teams as a part of their regular operations (Thomas et al., 2002). Despite their widespread use, some researchers (Allen \& Hecht, 2004) question the use of teams for many situations suggesting that the performance benefits of teams are often over exaggerated. Devine (2002) explains that although teams have a high rate of prevalence in organizations, especially those with multiple departments and more employees, organizations typically do not support these teams in terms of team-level feedback or compensation practices. Overall, the literature on team effectiveness presents a variety of benefits and challenges associated with teamwork in organizations. This section presents the research on teams and their benefits and challenges.

\subsubsection{Advantages of Teamwork}

One of the most important benefits of using teams in an organizational setting is the positive effect that teams can have on employee satisfaction and attitudes toward their work (Cohen \& Bailey, 1997; Griffin et al., 2001). Research has shown many of the perceived benefits of teams come from the fact that teams are associated with improved social and emotional states which translate in to more satisfied workers (Allen \& Hecht, 2004). Cohen and Bailey (1997) explain that teams can result in higher levels of employee participation which can benefit both the individual and the organization. In addition to the improved employee satisfaction, Guzzo and Dickson (1996) argue that 
teams offer employees the chance to enhance their skills, build networks, and gain valuable experience that they may not have been able to gain through individual tasks. These benefits suggest that teams may have a positive impact on individual employees. In the context of this study, this research suggests that change teams may offer individual employees the opportunity to gain experience, build networks, and improve their social experience in their organization.

One area of the teamwork literature that is contested by researchers is the notion that teams offer performance benefits for organizations (Allen \& Hecht, 2004). In their meta-analysis of the team effectiveness literature Guzzo and Dickson (1996) found mixed results for the relationship between the use of a variety of teams and organizational performance. Those researchers who do support the idea that teams offer performance gains argue that teams can improve decision making (Strubler et al., 2007), increase innovation (Catmull, 2003; Nurmi, 1996), and handle multiple complex tasks better than individual workers (McGrath, 1991). Heywood et al. (2008) also suggest that teams may reduce absence rates, an added benefit for organizations.

The performance of teams is an important topic for the current study. The literature on this topic suggests that change teams may be able to improve the performance of the organization provided that members are able to participate fully in the team experience (Katzell \& Guzzo, 1983; Strubler et al., 2007). When people take a significant and influential part in the decisions that they value the quality of decisions is likely to be improved and team members will likely be more motivated during the execution of the task. According to Strubler et al. (2007) the positive outcomes of teams are available to those teams who can successful find the right mix of people, processes, 
and contextual variables, suggesting that understanding the team effectiveness model is important for organizations who wish to realize the benefits of teamwork.

\subsubsection{Disadvantages of Teamwork}

As discussed in the previous section, the literature related to the benefits of teamwork is balanced by several research studies that question the usefulness of teams. Allen and Hyck (2004) raise several questions of the team's ability to generate new innovation and suggest that the perceived benefits of teams may benefit from a 'halo effect' as a result of the social emotional benefits that team members gain from membership on the team. Kerr et al. (1996) examined research studies on teams in laboratory and field settings and found that the productivity and efficiency of teams working on a project were not always greater than the same number of individuals working independently. Nurmi (1996) suggests that poorly functioning teams can slow down decision making and tie up valuable resources in an organization. For the purpose of this study, these findings suggest that change teams may not be the answer for the task of implementing organizational change.

Additionally, Hackman and Morris (1975) point out that when poorly designed tasks are present team members may become frustrated and engage in social loafing. This idea is supported by Campion et al. (1996) who designed their relative team size variable specifically to address the problem of social loafing on teams. Social loafing behaviour can have other detrimental impacts on the organization such as decreased employee satisfaction and commitment (Karau \& Williams, 1993) 
Hackman (1990) points out that team performance offers a wide spectrum of results in terms of the quality and efficiency of the work performed by teams. Hackman (1990) cautions against blindly using teams to solve 'any problem' stating that they are simply inefficient at solving some problems. Allen and Hect (2004) argue that there is limited empirical support for improved productivity as a result of using teams. Allen and Hecht (2004) do acknowledge that manipulating some team variables can improve team performance and thus offer some of the performance gains advertised by many teamwork researchers. This recommendation highlights the importance of the team effectiveness model, suggesting that careful analysis of the factors in the team effectiveness model may improve the odds for organizations looking to gain performance benefits from teamwork.

\subsection{TEAM EFFECTIVENESS}

For several years, researchers have been attempting to improve the level of understanding around teamwork by modelling the key factors involved in effective teamwork. The roots of the team effectiveness research are deeply embedded in social psychology research. Beginning with the Hawthorne studies in the 1920s and 1930s, research on work groups has been conducted in a wide variety of social settings and environments (Salas, 2004).

Between the 1930s and 1970s our understanding of teams was drawn from research on small groups and the wide variety of factors that influenced their performance. Team effectiveness as it is currently studied began to emerge in the 1980's as organizations started to use teams more often and for a greater number of tasks. From the early 1980 's to the present, organizations have increased their reliance on teams as an 
integral part of their daily operations (Ilgen, 1999). The increase in the use of teams has brought team effectiveness research to the forefront of academic research in organizational behaviour.

The increased focus on specific organizational issues has resulted in an extensive amount of research on team effectiveness models and the formation of several very useful comprehensive models of team effectiveness. Researchers such as Gladstein (1984), Hackman (1987), and Campion et al. (1993) all produced comprehensive models of team effectiveness that have strongly influenced how teams are managed and applied in organizations. The fundamental starting block for these models is the definition of team effectiveness. The first part of this section examines the team effectiveness variable, how it is defined, measured, and the limitations of measuring team effectiveness using the approach outlined in the literature. The second part of this section discusses some of the common factors that have been associated with high team effectiveness by examining the team effectiveness models mentioned above. This section focuses on the model of team effectiveness put forth by Campion et al. (1993) to provide a framework for understanding the variables which may impact the effectiveness of transformational change teams. The literature reviewed in this section represents a small but influential portion of the team effectiveness literature. The goal is to provide a framework for examining the factors related to effective teamwork during transformational change.

\subsubsection{Defining Team Effectiveness}

Teamwork can have many outcomes for the individual, the team, and the organization. Team effectiveness has been put forth by researchers (Hackman, 1987; 
Salas et al., 2004; Sundstrom et al., 1990) as the measure of team outcomes. Guzzo and Dickson (1996) explain that there is no singular, uniform definition of outcome effectiveness for teams. Many researchers have chosen to define team effectiveness according to one or more of the following team outcome variables: team performance, team member satisfaction, and team viability. Team performance represents the most traditional team outcome and is generally defined as the measurable outputs (usually in the form of a product or service) of a team (Salas et al., 2004). Team member satisfaction is defined by Hackman (1987) as the impact of the team experience on individual team members. Finally, in their research on teams, Sundstrom et al. (1990) define team viability as the willingness of team members to participate in future projects with the team. The concept of team effectiveness has developed to represent a combination of these three variables. Unfortunately, there exists in the literature a considerable amount of variance in how these three variables are combined and measured (Campion et al., 1993) to generate a team effectiveness measure.

Researchers have struggled to agree upon one standard framework for measuring team outcomes (Guzzo \& Dickson, 1996). Team effectiveness refers to the multidimensional construct that has become most commonly used to describe team outcomes in teamwork models (Ilgen, 1999). Salas et al. (2004) explain that there are dozens of intriguing conceptualizations of team effectiveness and the conceptualization of team effectiveness is often dependent on the availability of reliable team output data in research studies.

According to Gladstein (1984), team effectiveness should be made up of two distinct measures, team level performance and team level satisfaction. Campion et al. 
(1993), Hackman (1987), Sundstrom et al. (1990), and Gladstein (1984), all include performance and group member satisfaction in their definition of team effectiveness. Campion et al. (1993) add a third effectiveness factor to their model, manager judgments. According to Campion et al. (1993) manager judgments of performance help to supplement subjective team based performance measures done by team members.

Hackman (1987) also includes a third measure of team effectiveness in their model, sustainability which they define as the extent to which teamwork maintains or enhances a team's ability to work together in the future or the team's viability. Neither, Campion et al. (1993) or Gladstein's (1984) incorporate sustainability into the group effectiveness construct. The ability of a team to work together in the future could be very important in a large change effort where teams are brought together for different phases of the change and may be asked to work together again on future tasks or change efforts.

\subsubsection{Measuring Team Effectiveness}

While conceptualizing team effectiveness has proven to be a challenge for team effectiveness researchers, measuring team effectiveness has proven to be an equally challenging task. Gladstein (1984) argued that team level performance should be measured by an objective measurable output where possible. Objective measures of team performance refer to measures that can be measured independently of human raters, such as units produced or overall sales. Objective team performance measures have the benefit of reducing human bias in team effectiveness ratings, especially where team satisfaction and viability are also subjectively measured by team members. Gladstein (1984) argued that researchers who subjectively measured team performance were at risk of adding 
another measure of satisfaction rather than true performance. Gladstein (1984) suggested that wherever possible researchers should include an objective measure of performance. The objective performance measure also helps to link team performance to important business metrics where possible. In her research Gladstein (1984) represented team performance by measuring the second-quarter sales revenue that each team brought in above the standard set at the beginning of the year for their particular market. She then combined this evaluation with an aggregated member-rated team performance measure.

Hackman (1987) measured performance by comparing the productive output of the team with the performance standards set by the individuals who were the recipients of the product or service performed by the team. This measure of performance is a subjective rating given by the recipient and differs from work by Gladstein (1984) and Shea and Guzzo (1987) who included a more objective measure of performance in their team effectiveness models. Hackman's (1987) measure of performance does have the benefit of being rated by an external group or individual to the team being studied, as well as the linkage of team outcomes to an important business area which is customer satisfaction with the task. Researchers must still be aware that the ratings of team performance under Hackman's (1987) research may better represent the recipient's satisfaction with the output rather than actual performance of the task.

Productivity was measured by Campion et al. (1993) according to appropriate objective measures for the team. These measures included six measures of work not completed by the group each week and ranged from new work that was unfinished to the number of calls that were unanswered for the week. Productivity levels were adjusted for group size and group territory. The objective measure of performance used by Campion 
et al. (1993) helps the researchers to generalize the findings of the team effectiveness research to the organizational setting.

In their 1996 study of knowledge workers Campion et al. (1996) used manager judgments of team performance as surrogate objective measures of performance where objective measures were not available. Performance in this research was measured using questions on the questionnaires completed by both team members and managers respectively. By having a manager evaluate the performance of the team on work quality, the researchers could cross reference the other available objective or subjective performance measures to determine whether they were an accurate measure of performance.

Team satisfaction, defined as the satisfaction of team members with their group experience, may be the most consistent variable in the team effectiveness literature. Gladstein (1984) and Hackman (1987) measured team satisfaction with an aggregated member-rated questionnaire covering three aspects of team satisfaction: satisfaction with the team, satisfaction with meeting customer needs, and general satisfaction with extrinsic rewards and work. Campion et al. (1993) also measures team satisfaction with a survey of team members based on their interpersonal experiences as a part of the team.

The third measure of effectiveness that is included in some team effectiveness studies is team viability. In Hackman's (1987) model, team viability is the extent to which teamwork maintains or enhances a team's ability to work together in the future. The ability of a team to work together in the future could be very important in a large change effort where teams are brought together for different phases of the change and may be asked to work together again on future tasks or change efforts. Sundstrom et al. 
(1990) also include team viability as a measure of team effectiveness in their model. Both Hackman (1987) and Sundstrom et al. (1990) treated team viability as a subjective measure that team members would assess after a team experience.

On the surface, Hackman's (1987) conceptualization seems to be the most comprehensive measure of team effectiveness as it incorporates all three aspects of team effectiveness: performance, satisfaction, and sustainability. Unfortunately, the fact that Hackman's effectiveness measure does not contain an objective measure of performance is the major limitation of this measure as it reflects one of the major concerns of organizations regarding teamwork (Shea \& Guzzo, 1987).

\subsubsection{The Team Effectiveness Model}

Team research in recent years has seen "a heightened interest in teams embedded in public and private production and service organizations" (Ilgen, 1999, p.129). Academic research produced numerous models of team effectiveness which were aimed at helping to better understand team effectiveness (Gladstein, 1984; Hackman, 1987). These models have shifted away from the descriptive nature of small group performance models and were for the most part normative in their approach, as they attempted to provide a prescriptive solution to the problem to team effectiveness in organizations (Ilgen, 1999).

Early team effectiveness models were built on the input/process/output (IPO) framework that was a stalwart holdover from the small group research that occurred prior to 1980 (Ilgen, Hollenbeck, Johnson, \& Jundt, 2005). Using this approach researchers 
have focused on the task of determining what inputs to the team could be manipulated so that the organization maximizes the performance of these teams. Researchers such as Hackman (1987), Gladstein (1984), and Shea and Guzzo (1987) and many other researchers all have models of team effectiveness that have influenced our current understanding of team effectiveness. A complete review of the team effectiveness model would represent a major undertaking that is beyond the scope of the current thesis research. Instead, this review of the team effectiveness model will instead focus on the model of team effectiveness developed by Campion et al. (1993; 1996).

There are a number of reasons behind this decision to focus on one influential team effectiveness model. First, by focusing on the Campion et al. $(1993 ; 1996)$ model of team effectiveness this review will be able to present the basic components of the team effectiveness model in a manageable and organized format. Second, the team effectiveness model of Campion et al. $(1993 ; 1996)$ was developed at the end of an explosive period of research in the team effectiveness area which remains highly influential for researchers in the area today. The model put forth by Campion et al. (1993; 1996) incorporates the work of Cummings (1981), Gladstein (1994), Hackman (1987), and Shea and Guzzo (1997). As such, it builds on much of the influential work on team effectiveness done during the 1980s and provides a useful model for examining team effectiveness outcomes (Salas et al., 2004).

Third, the model of team effectiveness development by Campion et al. (1993) has continued to influence researchers in the field of team effectiveness (Cohen \& Bailey, 1997; De Dreu, 2002; Guzzo \& Dickson, 1996; Wagemen et al., 2005). 
The following subsection provides an examination of the team effectiveness model put forth by Campion et al. (1993; 1996). Figure 3.1 shows Campion et al.'s (1993; 1996) model of team effectiveness. The Campion et al. (1993; 1996) model is organized into five major themes that the authors identified as being critical to team effectiveness: job design, interdependence, composition, context, and process. Within the five themes of team effectiveness, there are nineteen group characteristics that were tested for their relationship to team effectiveness. Each of these themes represents a significant amount of previous research into team effectiveness. The team effectiveness criteria in the model includes three variables: productivity, satisfaction, and manager judgments.

Figure 3.1 - Campion et al. (1996) Team Effectiveness Model

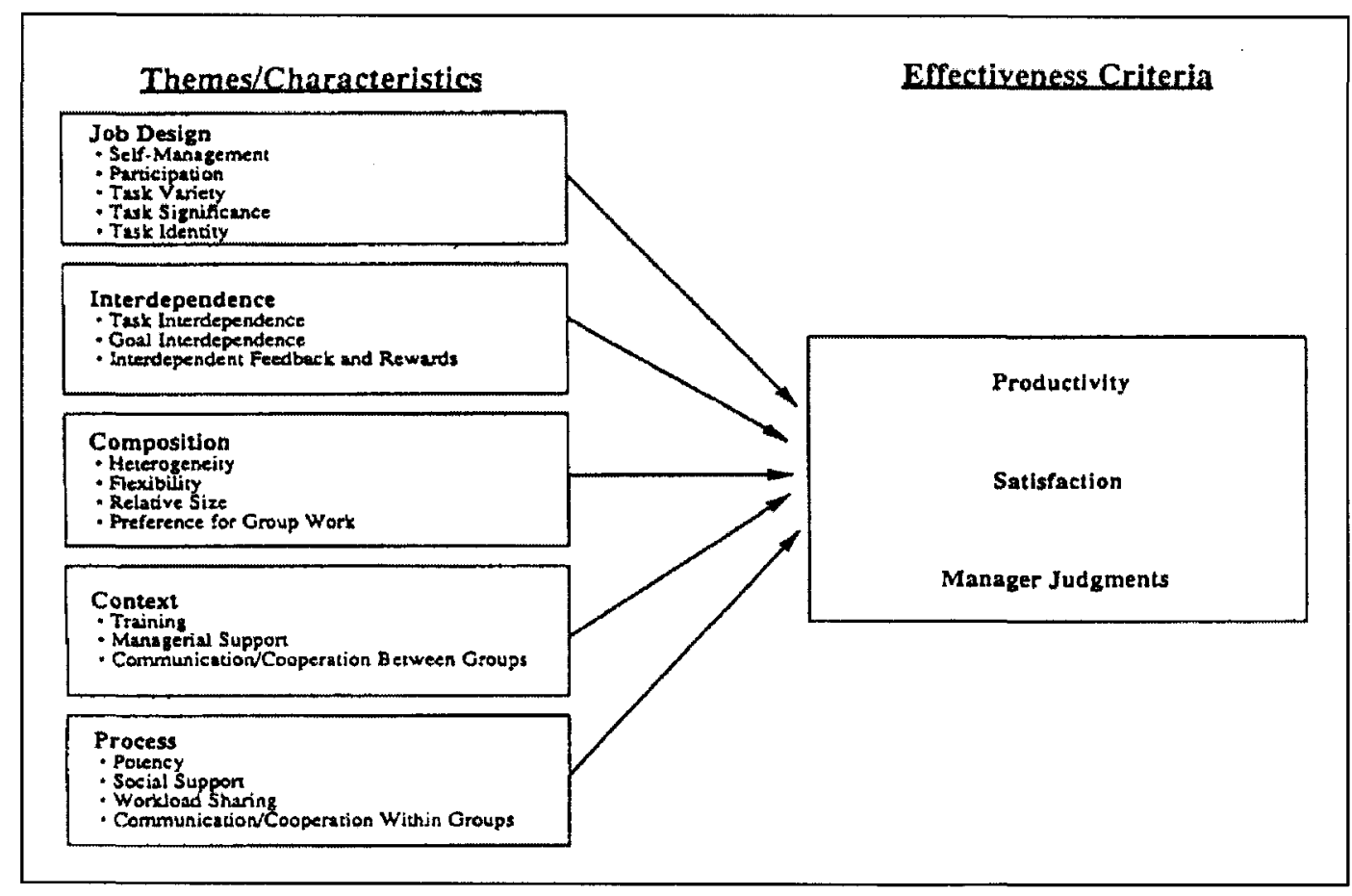

To test their model (Figure 3.1), Campion et al. (1993; 1996) examined five geographical units of a large financial services company. Approximately four hundred 
employees responded to a questionnaire aimed at determining the impact of the group characteristics on team effectiveness. While, the results of this study are discussed later in this subsection, it should be noted that support for the model of team effectiveness developed by Campion et al. (1993) goes beyond the empirical study used to test the model. As mentioned, Campion et al. (1993) developed their model based on the work of team effectiveness researchers before them. Allen and Hecht (2004) commend the work by Campion et al. (1993) in their article "The Romance of Teams" for providing a model of team work grounded in theoretical research. Allen and Hecht (2004) argue that the empirical research that accompanies the model is necessary to advance the understanding of the impact of inputs on team effectiveness and avoid an overabundance of wishful theorizing about the value of teams.

\subsubsection{Campion's Model of Team Effectiveness}

The next subsection of this thesis begins with an examination of how Campion et al. (1993) conceptualized team effectiveness and each of the five themes in the model. This is followed by a discussion of the strengths of the Campion et al. (1993) model and a summary of the empirical study used to validate the model.

\subsubsection{Team Effectiveness}

Figure 1 shows that the effectiveness criteria used in the model is made up of three parts: productivity, satisfaction, and manager judgments. Campion et al.'s (1993) definition of team effectiveness resembles the work done by Hackman (1987), Sundstrom 
et al. (1990), and Gladstein (1984) which define effectiveness according to both performance and group member satisfaction. Campion et al. (1993) also adds a third effectiveness factor to their model, manager judgments. The conceptualization and measurement of team effectiveness in Campion et al.'s (1993) model was discussed in subsection 3.4.2. As previously mentioned, Campion et al.'s (1993) use of manager judgments to supplement team member ratings of performance is a valuable contribution of the model. This measure of performance represents an option for researchers who do not have readily available objective performance measures in their study. It should also be noted that Campion et al. (1993) do not include team viability in their model, which is contrary to the recommendations of several researchers (Hackman, 1987; Sundstrom et al., 1990). As this may be an important variable for teamwork in an organizational change setting, Campion et al.'s model was modified in this thesis to include the team viability construct.

\subsubsection{Job Design}

The first theme included in Campion et al.'s (1993) model of team effectiveness is the job design characteristics that impact effectiveness. The job design theme refers to specific characteristics (self-management, participation, task variety, task significance, task identity) of the teams' task or job that affect the team outcomes. Job design in the model is based heavily on the work of Hackman (1987), Gladstein (1984) and Guzzo and Shea (1992). The job design characteristics used in the model begin with selfmanagement levels in the team. Self-management refers to the level of autonomy that the team operates with while working on their task. The self management variable is similar 
to the autonomy variable that is included in Sundstrom et al's (1990) ecological model of team effectiveness. Hackman (1987) also argues that greater autonomy may increase the team's effort levels. Campion et al. (1993) discuss self-management in conjunction with participation as a way to increase commitment and transfer ownership of the task to the team. According to Campion et al. (1993) participation in decisions can be particularly important to increase the team level of responsibility. This idea can be expanded by increasing participation levels through goal setting and performance standards (Sundstrom et al., 1990).

Another characteristic of job design that is hypothesized in the model to impact team effectiveness is task variety. Task variety involves rotating members on different team tasks so that each member is not stuck doing the same repetitive work. In Hackman's (1987) normative model of team effectiveness task variety is seen to increase the skills and knowledge of the group.

Campion et al. (1993) also stress the importance of task significance in the model. Task significance refers to the belief that the team's task has significant consequences for the organization and/or customers. Campion et al. (1993) argue that members should believe in the importance of their work both to their customers (internal and external) and to the organization as a whole.

The final aspect of the job design theme is task identity, which refers to the degree to which the team completes a whole, identifiable, and separate piece of work in the organization. This characteristic is derived from work conducted by Cummings (1981) and Hackman (1987). Campion et al.'s (1993) list of team design characteristics is based on many of the influential research models of team effectiveness in the 1980s. 


\subsubsection{Team Interdependence}

The second construct hypothesized to affect team effectiveness in Campion et al.'s (1993) model is interdependence. Team interdependence refers to the degree to which teams are interdependent in their task work, goals, and feedback. This theme is based largely on the work by Shea and Guzzo (1987) which includes task interdependence and outcome interdependence as primary factors in determining team effectiveness. Campion et al. (1993) explain that interdependence is a defining characteristic of groups and is often the reason that team work is chosen over piecework.

According to Campion et al. (1993) team interdependence is made up of three types of interdependence. The first type is task interdependence which refers to the extent to which members are dependent on one another to accomplish the group task. Task interdependence is the most common in effectiveness models and is supported by researchers such as Hackman (1987), Shea and Guzzo (1987) and Saavedra et al. (1993).

The second type of interdependence in Campion et al.'s (1993) model is goal interdependence. This refers to the level to which group and individual goals are highly connected and shared by all members of the team. Goal interdependence has been studied as a part of complex interdependence by Saavedra et al. (1993) and found to influence subjective group ratings of effectiveness.

The final type of interdependence according to Campion et al. (1993) is feedback and reward interdependence. Similar to task interdependence, feedback interdependence is also a common feature to models by Hackman (1987) and Shea and Guzzo (1987). The use of interdependence by Campion et al. (1993) is based on a solid review of the 
literature. However, similar to the critique of job design, Campion et al. (1993) do not explain whether the impact of interdependence is direct on team effectiveness or indirect through other variables in the effectiveness model.

\subsubsection{Team Composition}

Team composition has been a common theme in team effectiveness literature for a long time. Composition refers to the various characteristics of the individuals that make up of the team. Campion et al. (1993) include traditional composition variables such as heterogeneity, flexibility, preference for group work, and relative size in their model.

Team heterogeneity refers to the mix of talents/skills/experience on the team. Research on heterogeneity has produced mixed results in terms of team effectiveness (Pearce \& Ravlin, 1987). Researchers have reached a mild consensus that the value of heterogeneity is largely dependent on the type of task to be performed and note that heterogeneity has been most found to be valuable in groups designed for creative tasks (Hackman, 1987).

Flexibility and relative size, two of the other variables included under the composition rubric, are two of the more agreed upon aspects of team effectiveness. Flexibility refers to the extent to which team members are flexible enough to perform each other's tasks as needed. Sundstrom et al. (1990) explain that task flexibility can improve training and satisfaction of team work. Relative team size refers to the idea that teams should only be as big as the minimum number of members required to do a task (Hackman, 1987). 
The final composition variable in the model (Campion et al., 1993) is preference for team work which is defined as a team member's predisposition for teamwork. As argued by Campion et al. (1993) preference for team work is a valuable variable to include in the team effectiveness model because of its impact on team member ratings of performance and satisfaction. Campion et al. (1996) removed the preference for teamwork variable from the model in their 1996 research because it failed to predict any of the effectiveness outcomes. Consistent with Campion et al.'s (1996) model, the current research does not include this variable.

Also of interest is that Campion et al. (1993) choose not to include the level of skills and knowledge in the team as a predictor of effectiveness. Although the heterogeneity characteristic in the Campion model refers to the mix of skills in the group, researchers such as Hackman (1987), Cummings (1981), and Gladstein (1984) have all included a specific variable tapping this construct to level of adequate skill in their models as a determinant of team effectiveness. The current change team model is consistent with the work of Campion et al. (1996) and includes the heterogeneity variable as the measure of skills and knowledge on the team.

\subsubsection{Context}

The fourth theme of team effectiveness identified in Campion et al. (1993) is the theme of context. Many team effectiveness models avoid this category of variables because of its complexity and the difficulty involved in testing models that include context variables. Campion et al. (1993) include three measures of context in their model. 
The first context characteristic is the training that the team receives. Campion et al. (1993) describe the literature support for this variable as mixed. The authors cited the importance of training in helping improve decision making and interpersonal skills as a major reason to include context variables in their model. Although training is likely an important variable to include in the current research on change teams, it may be that training has an impact on team effectiveness through other variables such as skills, potency, and participation than having a direct impact on effectiveness.

Another context variable in the model is management support. Managerial support refers to the level of management controlled resources (materials, information) made available for the team. Campion et al. (1993) view managers as particularly important to acquiring resources. The Campion et al. (1993) model examines the level of support received by the team from both senior management and direct from the team manger. In an organizational change setting both of these levels of managerial support are seen as important in the literature (W. Burke, 2002; Cummings, 1999).

The final context characteristic in the model is the communication and cooperation between groups. This variable refers to the degree to which teams communicate and cooperate with other groups within the organization to help achieve their goals. Campion et al. (1993) explain that managing team boundaries and externally integrating the team with the rest of the organization are important team functions that have been found to influence team effectiveness. Communication between individuals and teams is also an important feature of successful change (Mabin et al., 2001) so the inclusion of this variable in the current research may be significant. 


\subsubsection{Process}

The final theme in the model refers to the team processes that influence effectiveness. Team processes are the activities that go on in a team that influence effectiveness (Campion et al., 1993). The first characteristic of team process that is hypothesized to influence effectiveness is team potency. Potency or efficacy as it is often labelled in later team research (Pescosolido, 2003) refers to the team's individual and collective beliefs that it can accomplish the task at hand (Shea \& Guzzo, 1987).

The next two characteristics of team processes are social support and workload sharing. Social support in the model is defined as the extent to which team members help each other and have positive social interactions. Workload sharing is related to the extent to which team members are willing to accept and share each other's work in order to achieve the team's goals. Although not discussed by Campion et al. (1993) these two characteristics may strongly influence member satisfaction and may be related to performance through increased commitment and effort from team members. Gladstein (1984) discusses social loafing which may also be avoided through increased social support and workload sharing.

The final characteristic of effective team processes in the model is communication and cooperation within the team. This variable measures the degree to which team members communicate and cooperate with other team members to help achieve their goals. Campion et al. (1993) explain that this characteristic has been supported in laboratory settings but remains to be fully tested in field settings. Gladstein (1984) was critical of team effectiveness models that highly valued communication and cooperation as she found that these models correlated well with member satisfaction but not with actual performance. 


\subsubsection{Testing the Model}

To test their model of team effectiveness Campion et al. (1993) conducted a study of teams in a large financial services company. The study examined teams in different work territories and sub territories. There were a total of eight sub territories, each with its own work group and manager. Work groups ranged in size from 5-30 people. This wide spread of group size represents a potential weakness of the study. Each of the work groups was permanent and tasks were mostly clerical and uniform across the groups. Groups were similar in terms of tenure, education, and gender (approximately 95\% female). Five employees per team completed a work questionnaire for each of the eighty groups, giving a sample of approximately 400 individuals and 80 teams. This large sample was necessary due to the fact that the group was the level of analysis. Managers also completed the questionnaire for all but three of the groups. The wide spread of group size represented a concern when using the results to validate the Campion et al. (1993) and was addressed in the 1996 study.

The questionnaire that was used in the study assessed each of the 19 hypothesized inputs into team effectiveness outlined in the model (Campion et al., 1993). As well, to measure team effectiveness satisfaction a separate opinion survey was filled out by the entire organization. This gave researchers a view of effectiveness that was more representative than five members per team. To measure performance Campion et al. (1993) chose to focus on work not completed by the group during the week. The six measures of incomplete work were: new work unfinished, percentage new work unfinished, revisions unfinished, percentage revisions unfinished, calls not answered, and 
percentage calls not answered. While this method of measuring team performance may have been acceptable for this study Campion et al. (1996) recognize the limitations of this measure of performance for non-clerical work. In Campion et al. (1996), the study was replicated for a sample of knowledge workers and measures of performance based on peer and manager evaluations were used in the place of the incomplete work measures. The final measure of group effectiveness, manager evaluations, was assessed through the manager questionnaires that were administered. The manager questionnaire asked managers to rate their team's effectiveness according to organizational values of team effectiveness.

The results from the study provide support for the model of team effectiveness proposed by Campion et al. (1993). To control the error rate, each of the themes was combined into a composite variable and examined for predictive ability for the effectiveness criteria. Each of the five sets of work group characteristics were found to correlate to at least one of the three measures of team effectiveness.

Job design was found to correlate with all three effectiveness criteria. In fact, Campion et al. (1993) found job design to be the most useful predictor of team effectiveness as every characteristic of job design (except for task identity) related positively with all three measures of team effectiveness. Interdependence was also found to relate to all three criteria. Interdependent feedback and rewards were related to employee satisfaction. This finding supports work by Shea and Guzzo (1987) who argued the importance of outcome interdependence in their model of team effectiveness. Composition was found to relate strongly to manager judgments of effectiveness and has a weaker relationship with productivity and satisfaction. Interestingly, heterogeneity 
showed no relationship to any effectiveness criteria, while preference for team work only correlated with satisfaction. These findings could reflect the nature of the work (clerical work) as creativity may not have been required for this work. Context characteristics were found to be positively related to satisfaction and manager judgments. The final theme, process related mostly to productivity and manager judgments. Within the process theme, potency was found to be related to all three factors of effectiveness, which supports work done by Shea and Guzzo (1987) on potency.

Campion et al. (1996) tested the 1993 model again in 1996 and found general support for each of the themes in the model. Other researchers have found support for the themes included in the Campion et al. (1993) model as well. The impact of task interdependence has been confirmed by Saavedra et al. (1993) who advanced the variable by including goal and feedback interdependence as a combined variable called complex interdependence. Similarly, the importance of selecting individuals with a preference for teamwork has been supported by Kiffen-Petersen and Cordery (2003) who found that trust in co-workers and management would influence a person's preference for teamwork. Another area of support has been for the importance of group potency for team effectiveness. Lester et al. (2002) found in their empirical study that group potency positively influenced process effort, satisfaction and performance in work groups. Group potency has also been argued to be an important variable in effective teamwork models by Shea and Guzzo (1987) and Druskat and Wolff (2001). Overall, the model of team effectiveness proposed by Campion et al. (1993) is based on a strong foundation of classical theoretical models of team work and has received support as an influential model of organizational team effectiveness. 


\subsection{CRITIQUE OF THE TEAMWORK LITERATURE}

The teamwork literature shares many strengths and weaknesses with the research on change that has been reviewed in the first section of the literature review. Similar to the change literature, there has been a great deal of research on teams and team effectiveness. This popularity has produced numerous theories of teamwork and models of team effectiveness. The plethora of theories on teamwork has provided researchers and practitioners with several options for using teams even when teamwork may not be the best solution (Cordery, 2004). The teamwork literature also suffers from several weaknesses that are similar to the organizational change literature. This critique section begins with a critique of the overall literature and concludes with a critique of the Campion et al. (1996) model of team effectiveness.

\subsubsection{Critique of the General Teamwork Literature}

First, the teamwork literature remains divided by a lack of a clear definition and classification scheme for teams in organizations. There is a definite need to unify the work on classifying teams to allow researchers to efficiently build upon past research. An extension of the current research may be to contribute to the literature by taking the findings from this research and exploring how organizational change teams fit into the influential classification schemes by Cohen and Bailey's (1997), Devine (2002), and Sundstrom et al. (1990). 
The second critique of the teamwork literature is the lack of both empirical and longitudinal research done to support the models of team effectiveness put forth by researchers. While the model of team effectiveness developed by Campion et al. (1993) was tested for both clerical (1993) and knowledge (1996) team samples, the model requires further testing in order to identify its utility and validity with other types of teams. The goal of future research should be to develop existing team effectiveness models to fit various organizational settings. The longitudinal research proposed by the current thesis research should advance our knowledge of the applicability of Campion's model by examining the effectiveness of organizational change teams in a public sector setting.

The final weakness of the teamwork literature that may be addressed by the current research is the lack of research on public sector teams and teams who are working on change. Teamwork is a complex construct which is impacted heavily by both contextual and task variables. As noted earlier, the public sector represents a different set of contextual and task variables than most team effectiveness theories are tested against. Similarly, organizational change has been shown to be a unique organizational experience that has not been applied to existing team effectiveness research. The current research has the potential to significantly contribute to the teamwork literature by modifying the existing classifications and models of team effectiveness to incorporate public sector organizational change teams. 


\subsubsection{Critique of the Measurement of Team Effectiveness}

There are three main critiques to the current approach of measuring team effectiveness that researchers must be aware of. The first criticism is of the aggregation of individual performance and satisfaction scores to represent team level outcomes. It has been argued that this process of measuring team level outcomes is an inappropriate measure of team level variables and often out of line with objective manager ratings (Kirkman et al., 2001).

The second criticism revolves around the over reliance on self-assessment to measure team effectiveness in general and in particular team performance. A study conducted by Kirkman et al. (2001) suggests that team members' implicit models of team effectiveness may impact the team's self-rated performance. Therefore, team effectiveness scales which rely heavily on self-rated scales may not be an accurate measure of effectiveness. Gladstein (1987) concluded that the mental models of team members were found to accurately measure satisfaction but failed to have any relationship to actual performance. Therefore, subjective group ratings of performance may not address the performance problems that the organization is working to improve. Hackman (1987) also acknowledged that a potential weakness of the conceptualization of effectiveness used in his model is that it is heavily reliant on subjective ratings of performance which may be influenced by the mental models of team effectiveness that the team members possess (Gladstein, 1984). The model could be improved and made more appealing to organizations if there was a measure of objective performance included into the model outcomes. 
The third criticism of team effectiveness measures is related to the appropriateness of performance measures for the team. The findings of Gladstein's (1984) research showed that researchers and managers should be careful to choose performance measures which accurately represent the team's performance and not external factors. Gladstein (1984) found for example, that the performance measure used in her study, sales performance, was related to the specific sales market and the organizational tenure of the groups. There was however, no support from the data for the relationship between inputs, process, task design and the objective performance measure of effectiveness. Each of these criticisms provides researchers with guidance for how team effectiveness can be measured in order to better understand teamwork.

\subsubsection{Critique of the Campion Model of Team Effectiveness}

The first challenge of the model of team effectiveness developed by Campion et al. $(1993 ; 1996)$ is related to the empirical research which provides support for the model. More specifically, there is concern that the wide spread of group size and the measure of productivity limit Campion et al.'s (1993) ability to test their model. In the (1993; 1996) research study Campion et al. measured group characteristics by aggregating to the group level from individual questionnaires with 53 items covering the 5 themes and 19 characteristics identified as influencing the effective teams. The teams used in the study were teams of five to thirty clerical employees. The productivity of these teams was measured by work incomplete at the end of the research time.

These shortcomings were addressed by Campion et al.'s (1996) study of knowledge workers team effectiveness. In this second study the group sizes were smaller 
and the use of knowledge workers extended the application of the model beyond clerical work. However, in Campion et al. (1996) there was no objective measure of performance due to the nature of work. Instead peer and additional supervisor ratings were used in the place of work not completed in the clerical work group study (Campion et al., 1993). Although, the results of the Campion et al. (1996) research generally supported the model further research is required to test the model on a variety of organizational teams. As well, the static nature of both studies (Campion et al., 1993; 1996) suggests that further research is needed in order to account for the temporal and dynamic nature of team effectiveness. This study seeks to overcome both of these shortcomings.

The role of team processes in the model of team effectiveness developed by Campion et al. (1993) is another criticism of the model. Although, Campion et al. (1993) relied heavily on the work of Gladstein (1984) and Hackman (1987) the treatment of process in the model is more like that of an input to team effectiveness. Both Gladstein (1984) and Hackman's (1987) models of team effectiveness present team processes as moderating the relationship between inputs and team effectiveness. By treating traditional input variables such as context, composition, interdependence, and job design as directly influencing the outcomes of teams, Campion et al. (1993) has ignored several of the most important influences that these variables have on the team processes. The interdependence between the five themes in the variables, in particular team processes, represents a weakness of this model.

Overall, the model of team effectiveness put forth by Campion et al. (1993) provides an excellent framework from which this research can explore the factors related to team effectiveness in an organizational change setting. The model of team 
effectiveness developed by Campion et al. (1993) unifies much of the research on group effectiveness in the 1980s. A major benefit of the Campion et al. (1993) model is that the model has distilled the literature on teamwork into five major themes and nineteen characteristics of effective teams. The inclusion of job design, interdependence, composition, context, and process themes in the team effectiveness model is theoretically and empirically supported by the work done by Campion et al. (1993). For the purpose of this research the Campion et al. (1993) model of team effectiveness with the modifications discussed in the literature review will be the foundation for the exploration of team effectiveness in transformational change teams. 


\section{TEAMS AND ORGANIZATIONAL CHANGE}

The final chapter of the literature review examines the research that has explored the role of teams during organizational change. As discussed in Section 3.1 the current research defines a change team as,

"A collection of individuals who share a common goal related to the planning or implementation of organizational change, whose actions and outcomes are interdependent, who are perceived by themselves and others as a social entity, and who are embedded in an organizational context."

The first two chapters of this literature review provided an examination of the extensive work done on both organizational change and teamwork respectively. During this review it was determined that researchers from both fields of work have suggested that teamwork may be critical to successfully implementing change. Pascale and Sternin (2005) argued that teams are critical to organizational change because more than individual change champions, teams will be more likely to create larger levels of buy in, come up with innovative solutions for the change, and potentially create an entire community of change champions. Similarly, in their review of team effectiveness literature Guzzo and Dickson (1996) write that, "complicated though it is, it is imperative to examine research evidence on teams and change in organizational systems." (p. 327)

Despite the massive amount of research done on both teams and organizational change, and the identification of change teams as a potential area for future research in both fields, there has been surprisingly little research into the link between teams and successful organizational change. There has however, been limited research on specific aspects of teamwork during organizational change. This chapter of the literature is dedicated to the research that has been conducted on change teams to date. To begin, this 
chapter examines the nature of research on teams during organizational change and some of the challenges to individuals and organizations identified by researchers (Guzzo \& Dickson, 1996; James \& Ward, 2001). The second section discusses some of the characteristics of change teams that have been studied by researchers such as Wang et al. (2006) and Verville and Halington (2003). The final section of this chapter discusses the potential of using teams to implement change and the future research that can help to make teamwork a more effective and efficient change implementation tool. The purpose of this chapter is to present the research related to organizational change teams, put the current study into context, and identify the key gaps in the literature that this thesis research may fill.

\subsection{EXPLORING TEAMS AND ORGANIZATIONAL CHANGE}

As previously mentioned, research in both teamwork and change field have identified organizational change teams as an area of research that had the potential to enhance both fields. In their review of the team effectiveness literature Guzzo and Dickson (1996) discussed the role of teams during organizational change. These authors argue that previous work on team effectiveness has ignored the state of the organizational system in which the team is operating. This thesis explores one such influential and unique system state: transformational change. Guzzo and Dickson (1996) also explain that the team effectiveness literature often does not fully account for the fact that team members often exist in several different system states at once. In the situation of organizational change, team members are often required to balance their time and effort between one or more change initiatives with their ongoing work responsibilities. The 
impact of this feature of team membership is that many variables related to team effectiveness in an organizational change setting may be influenced by factors outside the team and its task.

The arguments put forth by Guzzo and Dickson (1996) are supported by O'Reilly and Tushman (2004) in their article, The Ambidextrous Organization. Their research supports the idea that team effectiveness in a change setting is a complex issue and it may be hard for the researcher to identify effect relationships. Along the same line Guzzo and Dickson (1996) explain that research on teams in a change setting is therefore often better suited to case study analysis rather than controlled experiment methods. The case study method, while being less rigorous, allows for a much greater understanding of the situational factors that will influence team effectiveness in an organizational change setting. As such, this is the approach that is used in this thesis.

While Guzzo and Dickson (1996) provide a useful discussion of organizational change, many of their examples refer to organizations who wish to change to a team based organizational structure. While this form of organizational change may be implemented using a team based strategy it is not necessarily the case, and it is not the purpose of this research to examine the benefits of changing day to day operational structure to a team based form. Unfortunately, the work by Guzzo and Dickson (1996) does not explain how teams can be used to implement various organizational change strategies. The current thesis research will attempt to fill this gap in the review of team effectiveness provided by Guzzo and Dickson (1996).

One research case study that examines teamwork in an organizational change context is the study of Glaxco Wellcome by James and Ward (2001). For this research, 
James and Ward (2001) examined how a dispersed multinational team was formed and managed to complete a change project for their organization. Findings from this case study reveal several important insights into the nature of change teamwork and the process of studying change teams. First, the case study methodology and results from the James and Ward (2001) case study show the importance of context to understanding team effectiveness. In this case study, team members working in several different global locations were asked to come together on the project. The team members took a cross cultural survey prior to beginning work with the team. This survey served the purpose of examining existing assumptions on teamwork issues such as leadership, conflict, and communication. James and Ward's (2001) research serves as an example of how researchers can approach the challenge of team members who work and take their cultural cues from different environments. This feature common to change teams makes studying the team context very complicated and difficult.

The second aspect of researching teamwork highlighted by James and Ward (2001) is the need to consider the influence of concurrent work being done during the teams' tenure. The Glaxco Wellcome team consisted of members who were involved in outside work projects during the lifetime of the change effort. One of the ways in which the research examined the impacts of concurrent work was to continually evaluate the goals and standards for communication set out by the group. The findings indicated that team goals and processes may be adjusted during the course of the project and that the outside work environments of the team members may influence the team's direction. These findings on the context of teams and the influence of concurrent tasks highlight important features of change teams. 


\subsection{CHARACTERISTICS OF CHANGE TEAMS}

Compared to the large amount of research done on both teams and change, the research and understanding of change teams is still in a very exploratory stage of development. The limited research that has been conducted on change teams does; however, give some indications as to the characteristics of change teams which may influence team effectiveness. Researchers such as Wang et al. (2005), Terry and Callum (1998), and Verville and Halington (2003) have all studied how teams operate in organizational change settings. This section examines the work done specifically on the characteristics of change teams. The first part of this section examines the importance of team composition to team effectiveness in a change environment. The second part of this section discusses the relevance of in-group bias and group cohesion for change teams. The third and final part of this section discusses the communication and goal setting processes that may help to make change teams operate more effectively and efficiently. The research on change teams is still in a very early stage and it is the goal of this section to examine this literature on effective change teams so that the current research may extend these findings and further the understanding of the characteristics of effective change teams.

\subsubsection{Change Team Composition}

One of the critical areas for managing change teams that has been examined by researchers is team composition. Verville and Halington (2003) conducted a case study of 
four teams responsible for acquiring and implementing an organization wide ERP system. This type of IT project represents a significant change in operations for the organization and is relevant to the current thesis research. Verville and Halington (2003) found that because the change projects were strategic in nature and impacted the entire organization the composition of the teams necessarily required members representative of a wide range of sectors in the organization. In addition, the case studies revealed that team members were comprised of both internal employees and external experts to help with the decision of which ERP system to select and the implementation plan. Verville and Halington (2003) also found that change teams tended to be comprised of a spectrum of managers, IT professionals, and end users to ensure that the selection decisions and implementation were both strategic and practical to the end user. While the research by Verville and Halington (2003) illustrate the wide impact of change projects and the need for a multidisciplinary team, more specifically it requires further investigation and empirical support. Following change teams over a longer period and examining other possible factors that may impact effectiveness will also help to place the importance of team composition in context.

\subsubsection{Team Cohesion and In-Group Bias}

The role of in-group bias and the importance of team cohesion for change team success have also been examined by researchers (Terry \& Callan, 1998; Wang et al., 2006). Team cohesion refers to the 'togetherness' of a team or the ability of a team to remain connected and pursue a common goal. According to Wang et al. (2006) team cohesion is linked to a willingness to participate and a commitment to learning by team 
members. Wang et al. (2003) argue that the nature of organizational change and the need to participate in learning new ways of doing business makes team cohesiveness a critical team effectiveness variable. The research by Wang et al. (2003) also supports the argument that a willingness to participate and a commitment to learning were both positively related to team cohesiveness. The research also showed that team cohesion levels were positively related to meeting goals set out for the team by management. These findings also highlight the importance of interpersonal relationships within change teams and the appeal of teamwork to individuals. The work by Wang et al. (2003) is limited in that the measure of performance, managers' goals, could be extended to include other stakeholders' perspectives on the team's effectiveness.

As argued by Wang et al. (2003) a cohesive team may help to improve team success; however, Terry and Callan (1998) caution that during organizational change groups may serve to foster in-group bias and cause rivalry that may impede the progress of the change effort. The research by Terry and Callan (1998) examined the merger of two hospitals in order to answer questions about group dynamics during organizational change. The results of the study showed clear evidence of in-group bias, specifically on issues relevant to status in the new organization. As well, these authors found that perceived threats from the merger were strongly related to in-group biases.

These results highlight several important considerations for the use of teams during organizational change. First, managers must be aware that existing groups within the organization prior to the change effort will likely tend to promote the beliefs and opinions common to their group. Second, these group-biases may not be representative of reality and may prevent organizational change. Third, managers can potentially use 
change teams to bring together key individuals from various stakeholder groups within the organization, which may have the impact of reducing group biases. The study by Wang et al. (2003) is important in that it highlights some of the drawbacks of creating teams during change efforts.

The findings of Wang et al. (2003) are supported by the work of Vann (2004) who argued that a source of conflict and resistance in public sector change was that teams may be using different grammars related to the change. Vann (2004) gave the example of external consultants who may introduce unfamiliar vocabulary into the organization. These conflicting grammars may serve to increase uncertainty and thus support the existing bias of the group toward the change. The presence of in-group bias may also become a factor for change efforts that extend over a long period of time as team members become increasingly comfortable with the opinions and perspectives of their team members.

According to Schein (1999) a change team must become a temporary parallel system that manages the entire change process. Schein (199) also raises the question of how employees can simultaneously be in two systems (past and the future) at the same time without having their loyalties lay with the old system with which they are more familiar. Schein (1999) also argued that change teams need to be trained, because their informal norms that are held over from previous work patterns can be difficult to break if the whole team does not engage in training. 


\subsubsection{Communication and Goal Setting}

James and Ward (2001) suggested that effective teams will set ground rules for communication, and develop a check list of cultural assumptions prior to beginning work on the change project. James and Ward (2001) argued that this process allowed team members to acknowledge their different cultural assumptions and to work with the differences and similarities to develop new team norms around communication and decision making in particular. It is important that change teams understand that the cultural assumptions of team members will differ and that these cultural norms will influence behaviour during the course of teamwork. James and Ward (2001) also found that the change team in their case study successfully developed a communication plan to gain credibility and support for the change project with key stakeholders. The benefits of the communication strategy geared at identifying and retaining key individuals for the team was that recruitment of new team members as the change project lengthened became much easier as the change project had increased visibility and status within the organization. Another characteristic of the change teams studied by James and Ward (2001) was that team members were required to reaffirm the team ground rules for communication via email and telephone at various intervals during the life of the change project.

\subsection{CRITIQUE OF CHANGE TEAMS LITERATURE}

The research discussed in this section represents a very small portion of the work that needs to be done in order to fully understand change teams. The research relies heavily on the case study method and thus provides researchers with some general 
conclusions about change teams but with few concrete answers to the questions of how change teams operate. There are still many questions to be both asked and answered. This section discusses some of the gaps in the research on organizational change and concludes with a discussion of the possible future directions for research on organizational change teams.

The first gap in the change team literature is the lack of empirical support for the use of teams as a viable strategy for implementing change. According to Pascale and Sternin (2005) teams can be useful during change because teams may be better suited to generate innovative solutions for the change. Teams who work together to champion the change may create an entire community of change champions. While many researchers and practitioners from both the teamwork and organizational change disciplines would argue that the synergies between teamwork and change are undeniable, it is important that researchers not presume that teamwork is superior to individual work when it comes to organizational change tasks. Madsen et al. (2005) showed relationship between social relationships and readiness for change. Yet Madsen et al. (2005) did not include teams as a potential solution for both increasing commitment and positive social relationships to increase readiness for change. The state of research into teamwork and organizational change has suggested many positive benefits from teamwork during organizational change however it is necessary to test these initial findings empirically, and in a variety of organizational change environments.

Another gap in the current research on organizational change is the lack of research into the characteristics of effective change teams. Research by Wang et al. (2005), Terry and Callum (1998), and Verville and Halington (2003) has provided insight 
into the importance of composition and team cohesion to effectiveness. These results are however limited in their application. It is important that research on the effectiveness of change teams build on existing models of team effectiveness. To ignore the work on team effectiveness in traditional teamwork theories would be like 'reinventing the wheel' and likely stall the development of a model of team effectiveness for organizational change teams. Thus far, research on the characteristics of effective change teams has not attempted to build upon existing team effectiveness literature. The current thesis research is designed to help address this gap in the literature on change teams by using a well established model of team effectiveness, developed by Campion et al.'s $(1993 ; 1996)$ to examine the characteristics of effective change teams.

The final gap in the current state of research on organizational change teams is the lack of research into the impact of teamwork on individual team members who belong to change teams. Both Strebel (1996) and Lawerence (1964) have argued that the social support that an individual receives during organizational change will significantly impact resistance and support for the change. Teamwork has the potential to have an impact team members, end users, and managers by increasing their workload, their level of involvement in the change, and their social support group that is linked to the change.

The future of research on organizational change teams is both exciting and daunting at the same time. The foundation for research on change teams from both the organizational change and teamwork literature is solid. While there have been initial attempts to examine change teams, many of these are atheoretical and limited in scope. This thesis helps to fill this gap by building on both the teamwork and change literatures 
in order to help improve the understanding of teamwork in an organizational change setting. 


\section{PART THREE: RESEARCH QUESTIONS \& INITIAL FRAMEWORK}

The literature review presented in Chapters 2-4 highlights organizational change teams as an area that has not been addressed in either the teamwork or organizational change literatures. The current thesis research addresses this gap by building a model of change teamwork that can be used to guide future research. This part of the thesis outlines the initial framework for the case study research and the research questions that drive the methodology used for this study. 


\section{RESEARCH QUESTIONS \& INITIAL FRAMEWORK}

Chapter 5 presents the research questions that are answered in this thesis. The second section in this chapter puts forth an initial theoretical framework that is used to guide the case study research.

\subsection{RESEARCH QUESTIONS}

The primary goal of this research is to enhance the capacity of organizations to successfully implement planned transformational organizational change. Specifically, this research examines the use of organizational change teams as a strategy to implement planned transformational change. The three research objectives and specific questions guide this research as described below.

The first objective of this research is to increase the understanding of why change teams are used to plan and implement organizational change and what benefits and challenges are associated with the use of change teams to implement change. Specifically, research question \#1 asks,

1. a) What are the benefits of using change teams to implement change?

b) What are the challenges faced by change teams?

The second objective of this research is to increase our understanding of change team effectiveness. Specifically, this study identifies and examines team and change related factors that may affect the effectiveness of change teams and aims to develop a model of change team effectiveness that can be used in future research on change teams. Research question \#2 also supports the development of a model of change team 
effectiveness that can be used in future research on change teams. Specifically, research question \#2 asks,

2. a) What are the characteristics of a change team that is effective in supporting change?

b) How can change team effectiveness best be modelled?

The third objective of this research was prescriptive in nature and aims to explore the ways in which organizations can support change teams in their work. In order to address this objective, research question $\# 3$ asks,

3. How can organizations better support change teams?

\subsection{INITIAL RESEARCH FRAMEWORK}

The review of the related literature in Part 2 of this thesis offered a solid foundation from which a conceptual framework of change team effectiveness could be developed. Section 3.3 discussed the team effectiveness models and focused on the work of Campion et al. (1993; 1996). The Campion model of team effectiveness has been revised as shown below in Figure 5.1 to incorporate the variables identified in the literature review as potentially impacting the effectiveness of change teams.

The model shown in Figure 5.1 served as the orienting framework for the grounded theory approach employed in this thesis research. The basic form of the model closely follows Campion's model with the five themes of team effectiveness laying the foundations for the framework. Team task design, interdependence, composition, context, and processes were all determined to be relevant to change team effectiveness and were 
thus included in the framework. In addition, the model includes a sixth theme representing the factors specific to the organizational change setting which may prove to influence change team effectiveness.

Figure 5.1 -Framework for Change Team Effectiveness

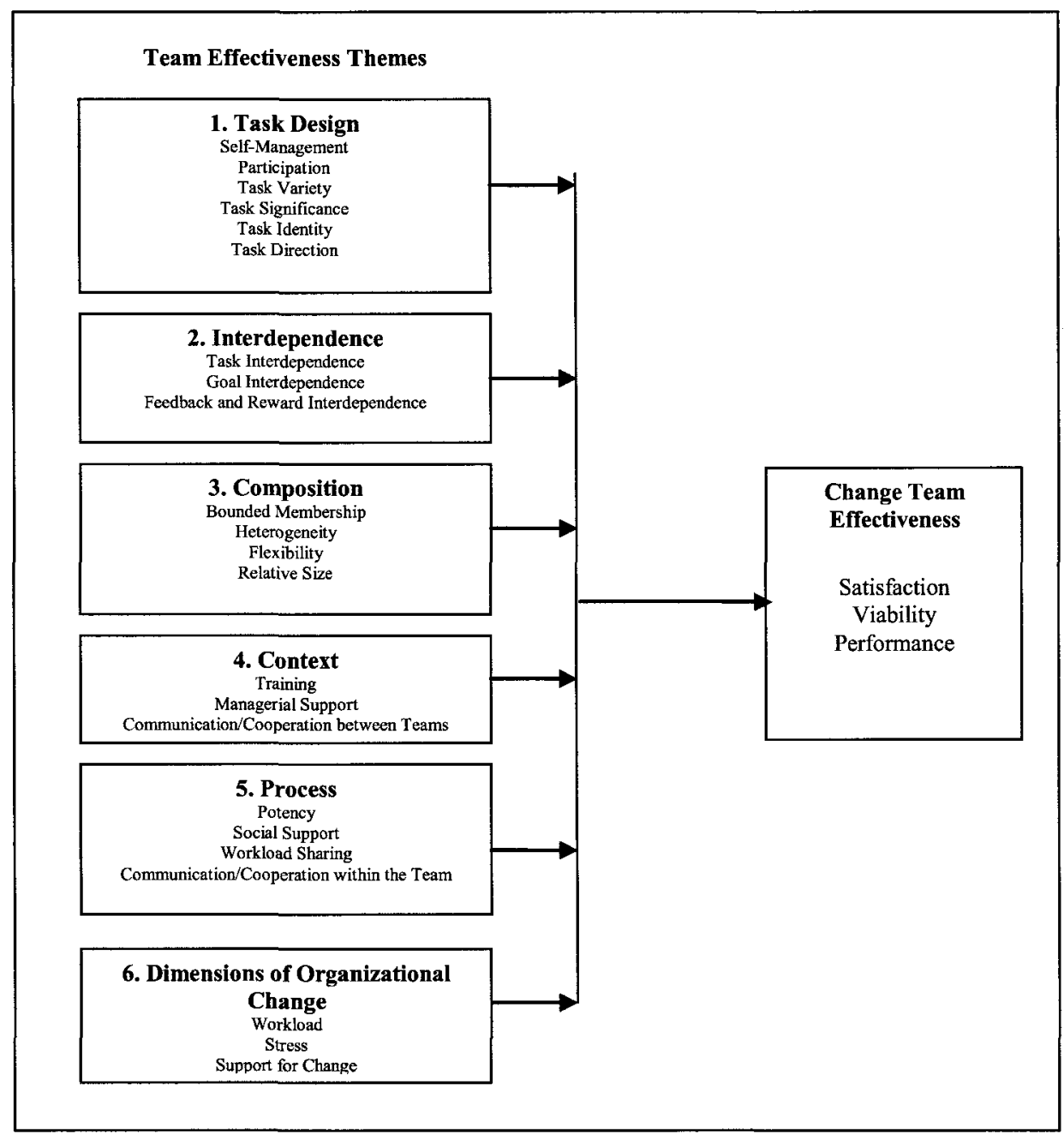

This chapter presents the orienting research framework and describes the rationale for including the six themes of team effectiveness in the framework. The chapter begins with a description of the conceptualization of team effectiveness for change teams as it is put forth in the orienting research framework. The second part of this chapter summarizes the 
relevant material from Section 3.4.4 on the five themes of team effectiveness included in the Campion model of team effectiveness. The third part of this chapter discusses the variables in the orienting framework that emerged from the review of the organizational change literature as potential predictors of change team effectiveness.

\subsubsection{Change Team Effectiveness}

The literature review in Section 3.4 provided a useful explanation of the development of the team effectiveness construct. The way team effectiveness is conceptualized in this research framework is consistent with existing team effectiveness literature (Campion, 1993; Gladstein, 1984; Hackman, 1987). This subsection discusses the three separate team effectiveness components that were included in the framework to measure team outcomes in this study: performance, viability, and satisfaction.

Team performance has proven to be one of the most challenging parts of team effectiveness for researchers to measure (Guzzo \& Dickson, 1996). As discussed in Subsection 3.4.1 the team performance variable included in the current research framework is a standard feature of team effectiveness models (Salas et al., 2004). In Figure 5.1, team performance refers to the team member's judgment of the team's performance levels during the research period.

The second component of team effectiveness, team viability, refers to the estimated ability of the team to successfully work together on future projects (Sundstrom et al., 1990). This measure of effectiveness may have increased relevance to our study of change teams as large transformational change efforts can continue on for several years 
(as is the case in the current research) and teams must consider the importance of working together on future tasks. A team that 'burns' itself out may not be in the best interest of the organization or the long term transformational change effort.

Consistent with other research (Campion et al., 1993; Hackman, 1987; Salas et al., 2004) in this area, the final component of team effectiveness that is included in the research framework is the satisfaction of team members with the team experience. Team satisfaction, refers to the extent to which team members are satisfied with the task and the interpersonal relationships that make up their teamwork experience.

\subsubsection{Team Effectiveness Themes}

The first five themes identified in the research framework shown in (Figure 5.1) are in large part derived from the work of Campion et al. $(1993 ; 1996)$ who distilled a wide range of literature into five common themes related to team effectiveness. The five team effectiveness themes contain twenty-one characteristics of work teams. When designing the research framework for this study, it was considered appropriate to include all five of Campion's team effectiveness themes. The Campion model was reviewed in detail in Subsection 3.4.4 and therefore this section focuses primarily on the adjustments that this model makes to the model of teamwork by Campion. This section provides a brief definition of each team and establishes the relevance of each variable to change team effectiveness. 


\subsubsection{Task Design}

The first theme in the change team effectiveness framework is made up of the task design characteristics that impact effectiveness. According to Campion, task design is defined as the characteristics of the team's task that influence team effectiveness. The framework for this research includes the individual task design characteristics of selfmanagement, participation, task variety, task significance from the original Campion model. Of these four original variables related to task design, participation was the variable that appeared to be of potentially increased significance in a change context. Participation refers to the degree to which all members are allowed to participate in team decisions. The use of participation to improve employee effort and reduce resistance to change is well supported in the change literature (Morgan \& Zeffane, 2003) suggesting that this characteristic may carry an increased weight in determining the effectiveness of an organizational change team.

In addition to the four task design variables that originated from the Campion model of team effectiveness the framework for change team effectiveness (Figure 5.1) also includes two additional variables within the task design theme: task identity, and task direction. Task identity, which refers to the degree to which the team completes a whole, identifiable, and separate piece of work in the organization (Campion et al., 1993) was removed from Campion et al.'s 1993 model in their 1996 study. It was put back in the framework as research has shown that uncertainty and ambiguity about work and roles that often accompany organizational change, can lead to employee frustration and stress (Marks \& Shaw, 1995; Robinson \& Griffiths, 2005). The presence of a clear task identity for the team may serve to offset some of the impacts of the change environment and focus the teams' efforts to improve team effectiveness. 
The final characteristic in the task design theme, task direction, is also related to the increased climate of uncertainty during an organizational change. Task direction refers to the purpose and goals of the team during their time together. This characteristic is taken from the work of Wageman et al. (2005) and presents a picture of how clear team members feel the teams' goals are. Although not in the Campion et al. (1996) model of team effectiveness, the importance of including task direction in this study is supported by existing organizational change literature (Borida et al., 2006; Robinson \& Griffiths, 2005) which suggests that employees may experience increased uncertainty during change which could impact on team performance. Unlike task identity, which refers to the team's distinctiveness in the organization, task direction measures the clarity of the team's work from the perspective of its team members.

\subsubsection{Team Interdependence}

The second predictor of change team effectiveness in the thesis framework is the level of team interdependence. This theme from Campion et al.'s $(1993 ; 1996)$ model is based largely on work by Shea and Guzzo (1987) which includes task interdependence and outcome interdependence as primary factors in determining team effectiveness. Campion et al. (1993) explain that interdependence is a defining characteristic of groups and is often the reason that team work is chosen over piecework. Task interdependence refers to the extent to which members are dependent on one another to accomplish the group task. Task interdependence is a common variable in effectiveness models. Its' use in this model is supported by researchers such as Hackman (1987), Shea and Guzzo (1987) and Saavedra et al. (1993). 
The second type of interdependence in the research framework is goal interdependence, which refers to the level to which group and individual goals are highly connected and shared by all members of the team (Campion et al., 1993).

The final type of interdependence in the framework is feedback and reward interdependence. Similar to task interdependence, feedback interdependence is also a common feature to models by Hackman (1987) and Shea and Guzzo (1987). Feedback and reward interdependence refer to the extent to which feedback and rewards are linked to the team's performance. Each of these characteristics of effective teams are listed in the Campion et al. (1993) model and the support for the inclusion of these variables was discussed in the literature Section 3.4.4.3.

\subsubsection{Team Composition}

The team composition theme is one of the most fundamental themes in team effectiveness research. The research framework draws heavily from the work of Campion et al. (1993) and includes the following composition variables: heterogeneity, flexibility, preference for teamwork, and relative size. The heterogeneity of a team is the mix of talents/skills/experience that comprises the team. Flexibility refers to the extent to which each of the team members are flexible enough to perform each other's tasks as needed. The relative size of the team refers to the size of the team relative to the work that has to be done. Relative team size refers to the idea that teams should only be as big as the minimum number of members required to do a task (Hackman, 1987). Each of these variables put forth in the Campion et al. (1993) model of team effectiveness was discussed in Section 3.3.4.4. Along with the four composition inputs taken from the 
Campion model, the research framework in this study also includes the characteristic of bounded membership which refers to the degree to which team membership is identifiable within the organization. This variable is similar to the task identity variable in the task design theme. The concept of bounded membership is taken from Wagemen et al. (2005) and addresses the importance of managing uncertainty and ambiguity in an organizational change setting by providing a measure of how clearly the team is able to identify its members and task from other employees and tasks in the organization.

\subsubsection{Team Context}

The fourth theme of team effectiveness in the research framework is that of context. Many team effectiveness models avoid this category of variables because of its complexity and the difficulty involved in testing models that include context variables. The framework derives all three of its characteristics from the Campion model (see Section 3.4.4.5). The first context characteristic is the training that the team receives. The second context variable in the model is management support. Campion et al. (1993) view managers as particularly important to acquiring resources and the variable plays a similar role in the research framework for this study. The final context characteristic in the model is the communication and cooperation between groups which measures the extent to which teams communicate and cooperate with other teams within the organization to help implement change. 


\subsubsection{Team Processes}

The fifth theme in the research framework includes the team process characteristics that have been found to affect effectiveness. As discussed in Section 3.4.4.6, process is a topic that has challenged researchers at great deal, especially in the Input/Process/Output models of group work that are the foundation for current team effectiveness models (Hackman, 1987). Although, Campion et al. (1993) relied heavily on the work of Gladstein (1984) and Hackman (1987), their treatment of process in the model is different from many other team effectiveness models. Both Gladstein (1984) and Hackman's (1987) models of team effectiveness present team processes as moderating the relationship between inputs and team effectiveness. By treating traditional input variables such as context, composition, interdependence, and job design as directly influencing the outcomes of teams, Campion et al. (1993) has ignored the potential relationships between these sets of variables and the team processes. Due to the exploratory nature of this research, this weakness of the model is acceptable as it may allow for the moderating role of team processes to emerge from this case study (Ilgen et al., 2005).

In their model, Campion et al. (1993) describe four critical characteristics of effective team processes. The first characteristic of team process that influences effectiveness is team potency. Potency or efficacy as it is often labelled in later team research (Pescosolido, 2003) refers to the teams' individual and collective beliefs that it can accomplish the task at hand. The second team processes is the extent to team members provide positive social support for one another. Workload sharing, the third characteristic in the process theme, is related to social support but focuses more on task 
related helping behaviours. The final characteristic of effective team processes in the model is communication and cooperation within the team.

\subsection{DIMENSIONS OF ORGANIZATIONAL CHANGE}

In addition to the five team effectiveness themes described in Section 5.2 the research framework shown above includes a sixth set of variables that is specifically related to the dimensions of organization change that have been linked to employee effectiveness. The rationale for including these potential predictors unique to the change environment is presented and discussed in this section. The issues specific to change teams include workload, stress, and support for change variables (see Figure 5.1).

The impacts of organizational change on individuals in an organization have justifiably been one of the most researched topics in the change management literature (Decker et al., 2001). The first dimension of change variable that may impact employees is workload, which refers to the amount of work that an employee must complete as a part of their job. As discussed in detail in Section 2.3.2.1, research (Simpson, 1998) has shown that workload levels can increase during times of change. Inclusion of this variable in the model allows this research to examine the effect that change has on the workload of team members and to shed light on how changes in workload effect change team effectiveness. This variable differs from workload sharing which describes the extent to which team members share work with each other and rely on workload sharing to manage their daily workload. The workload variable examined in this model refers to the amount of work that each team member has at different stages of the change process compared to workload levels in other comparator periods. It is hypothesized that an 
increase in employee workload may lead to a decrease in change team effectiveness by decreasing team satisfaction levels (Cox, 2003; Driskell et al., 1999) or by increasing the sense of work role overload. The inclusion of workload in the model allows this research to examine the impact of workload on team effectiveness in a change context.

The second impact of change variable is job stress. Modifying the definition of stress provided by Lazarus (1999) job stress can be defined as the dynamic transaction between a person and his/her job environment that is appraised as potentially challenging, threatening, or harmful. Work on a change team may increase the levels of stress felt by team members because work related to planning and implementing change is often uncertain, high profile in the organization, and can come on top of existing job responsibilities. The potential impact of job stress on team member satisfaction (Cox, 2003; Driskell et al., 1999) and thus on overall change team effectiveness warranted the inclusion of job stress in the research framework.

The final dimension of change variable included in the model is the level of resistance and support for change reported by change team members. Resistance to change (explained in detail in Section 2.3.1) refers to the latent or visible behaviours of team members which are designed to slow or halt the implementation of change. The support for change variable refers to the latent or visible behaviours of team members which are designed to bring about the implementation of change. Resistance to change has been suggested to negatively impact both employee attitudes and performance during change (Mabin et al., 2001). Therefore, it was reasoned that the levels of support and resistance to change that are expressed by change team members may negatively in turn 
have an impact on change team satisfaction, viability, and performance and as such has relevance in this research. 


\section{PART FOUR: METHODOLOGY}

The method of research for this thesis is the case study. According to Yin (2003)

the case study is appropriate when the contextual conditions (large scale organizational change) are highly pertinent to the topic of interest (change team effectiveness) and the objective is to explore the context in depth. The context of change teamwork is of high importance to this research and the case study approach allows for a deep exploration into the work of change teams, specifically how the change itself will influence the team. The Government of Canada (GoC) Shared Services Initiative (SSI) provides a unique opportunity to examine the use of teams in an organizational change setting in the public sector. The case study methodology is well suited to examine the work of this change team within the context of transformational change. Part four of this thesis describes the case study methodology used to conduct this research. It is divided into three chapters: the case under study (Chapter 6), theory development from case studies (Chapter 7), and the sampling, data collection and analysis (Chapter 8). Details on each of these chapters are reviewed below.

The first chapter of this part of the thesis (Chapter 6) discusses the case under study in this thesis, the Strategic Transfer Initiative Team (STI team). This chapter begins with a discussion of the suitability of the case study method for his research. This chapter also provides a description of the change under study and the change team that is the focus of this research. Chapter 7 goes on to describe the grounded theory methodology that is used in this research and presents Eisenhardts' (1989) steps for conducting grounded theory as a suitable process for this thesis research. Chapter 8 
presents the practical application of the grounded theory case study method and describes sampling, data collection, and data analysis procedures that were used to explore the research questions for this thesis. 


\section{THE CASE UNDER STUDY}

According to Yin (2009) every exploratory case study should have a statement of purpose that drives the research design. In this thesis, the purpose of the case study research is to explore the use of change teams to implement planned transformational change. This thesis research was initiated in the summer of 2007. The researcher approached the team leader for the STI team about collecting data on the team responsible for oversight of the change. Given the importance of the change and the quality of the team assembled to manage the change, the opportunity to observe the final months of the STI team's work together allowed for a valuable window into the work of change teams. Within this chapter, two sections further explain the case under study and the suitability of the case study approach taken for this thesis research. Section 6.1 discusses the merits of the case study design and the case selected for the goals of this research. Following the discussion of suitability of this research method, Section 6.2 describes the planned transformational change that was under way at the research site where this study takes place and describes the change team that is the target of this longitudinal case study.

\subsection{THE SUITABILITY OF THE CASE STUDY APPROACH}

The type of case study used for this thesis research is a longitudinal embedded single case study approach (Yin, 2009). A case study is defined by Yin (2009) as "a comprehensive empirical inquiry that investigates contemporary phenomena in depth and within its real-life context, especially when the boundaries between the phenomenon and 
the context are not clearly evident" (p. 18). This definition suggests that the case study method fits well with the current opportunity to study a change team working in the rich context of the Government of Canada's (GoC) transformational change to a Shared Information Technology Services Environment (IT-SSE). This section provides a summary of the benefits and limitations of the case study approach as they apply to the current research.

\subsubsection{Benefits of the Case Study Approach}

The primary benefit of the case study approach is that it is an effective methodology for the development of theory, particularly in a complex area which has not been specifically examined (Bartunek et al., 2006; Eisenhardt \& Graebner, 2007; Siggelkow, 2007). The current case meets both of these conditions as it combines two very large and complex research topics, teamwork and change. Furthermore, while both change and teamwork have separately been examined by researchers, change teamwork represents a gap in both literatures that required further exploration. Our choice of the case approach is supported by Patton (2002) who explains that where the primary objective of the research is a complex unexamined area the research method should be exploratory in nature and further that a qualitative research method is recommended. It is also supported by Guzzo and Dickson (1996) who note that research on teams in a change setting may be better suited to case study analysis rather than controlled experimental methods.

A second benefit of the case study approach is that it allows the researcher to observe the phenomena of interest within the context in which it exists (Yin, 2003). This 
may be the most important benefit of the case study design for this research. The challenges around modelling change team effectiveness are directly related to the relationship between the change team and the organizational change in which they operate. Understanding the context in which a change team operates and how those conditions may impact the effectiveness of the team represents a significant advantage for the case study research design.

Eisenhardt (1989) explains that the case study approach is also well suited to research designs which examine multiple levels of analysis. The current research examines change team effectiveness, an outcome which can theoretically be impacted by organization, team, and individual level factors. Although the team level of analysis is the primary level of analysis used for developing a model of change team effectiveness, the case study design allows the researcher to become more involved with the organization and provide a more in-depth explanation of the multi-level interactions (ie. individuals with team; team with organization) of the variables in the study (Hartely, 1994).

A fourth benefit of the case study design is that it allows the researcher to examine a specific type of change in-depth, using a multi-method approach (Eisenhardt, 1989). The case study format allows the researcher to develop a closer relationship to the organization and this makes both quantitative (for example, team surveys) and qualitative (for example, team member interviews) research a practical part of the research design.

According to Yin (2009), the use of a single organization case study design for this thesis research is appropriate for the following reasons. First, the case under study represents an extreme instance of the phenomenon of interest. The change to Shared IT Services underway at the $\mathrm{GoC}$ represents one of the largest and most important 
transformational changes that the GoC has undertaken in decades (Whitfield, 2007). Additionally, the commitment of the $\mathrm{GoC}$ to dedicate an entire team of change professionals for two years to this change is a clear use of change teams to implement transformational change.

The second rationale for the single case design is that the phenomenon of interest is rarely accessible for study (Yin, 2009). The small number of research studies on change teams to date illustrates this point (Verville \& Halington, 2003). The use of change teams has proven to be a difficult phenomenon for researchers to gain access to. Finding a fully dedicated change team in the public sector that is working together for nearly two years on the same project is a unique research opportunity.

The third rationale for the single case study design is that the opportunity to study the same case at two periods in time allows for the research to examine how the conditions associated with change team effectiveness may change over time as the change itself evolves (Yin, 2009). This feature of the case study design is particularly valuable when observing the impact that change has on the team over time.

Finally, this case study research design has the benefit of being longitudinal in nature. Siggelkow $(2007$, p. 22$)$ explains that longitudinal case study research provides the researcher with "the ability to get close to theoretical constructs is of particular importance in the context of longitudinal research that tries to unravel the underlying dynamics of phenomena that play out over time". Team members were surveyed and interviewed twice: once at the beginning of the study and then again four months later (see Figure 6.1). The rationale behind the four month period is as follows. First, the four month period represents the prime performance period for the team (see Section 6.2 for a 
full description of the change). Second, this period of time captured an important transition period in the change itself (see Section 6.5). This longitudinal case study design allows us to examine how change team effectiveness varies over time and identify possible links between change team effectiveness and the stage of change which should allow the research to potentially develop a more meaningful model of change team effectiveness.

\subsubsection{Limitations of the Case Study Design}

Although, the benefits of the case study format make it an effective technique for researchers developing new theory on phenomena such as change team effectiveness, there are some critical weaknesses that researchers using this technique must be aware of (Gummensen, 2000; Yin, 2009). Two of the most important limitations of the case study method are: the lack of statistical validity and the lack of generalizability of the results. Gummensen (2000) explains that it is particularly important that the researcher is aware of the statistical validity limitation when interpreting the data from the current single case study research. Observed differences between scores may be used to infer theoretical relationships in the change team model; however, further research is required to move beyond theorizing about the effectiveness of change teams and begin to test relationships in the model.

The second limitation of the case study method stems from the fact that the outcomes of this case study may not be highly generalizable. In fact, a common critique of the case study method is that it lacks the ability to significantly affect the area of research because of its limited capability to generalize to larger populations 
(Gummensen, 2000; Yin, 2009). This weakness of the case study methodology is a common challenge faced by researchers; however, Yin (2009) explains that case studies are "generalizable to theoretical propositions and not to populations" (p. 15). This characteristic of case study research fits well with the primary objective of the current research which is to generalize the observations from this case to a model of change team effectiveness. For the current research opportunity at the $\mathrm{GoC}$, the strengths of the case study and the opportunity to study the STI change team over time as they implement a planned transformational change outweighs the potential weaknesses of the case study method.

\subsection{DESCRIPTION OF THE CHANGE AND THE CHANGE TEAM}

This thesis looks at the role of a change team in implementing the Government of Canada's (GoC) change to IT Shared IT Services. This section consists of three subsections that together provide a description of the change and the role of the STI change team within that change. The first subsection (Subsection 6.2.1) describes the objectives of the Shared IT Services change. The second subsection presents the STI change team and describes the government department in which the team operates. Finally, Subsection 6.2 .3 presents the life-cycle of the change that was studied for this research. 


\subsubsection{The IT Shared Services Initiative}

While the concept of Shared IT Services has been on the GoC agenda for several years, a strategy to actually bring about Shared IT Services did not really begin to take hold until after the explosion of the internet as a tool by which the $\mathrm{GoC}$ would interact internally and with its citizens. The transformational change to shared IT services has been slowly evolving for over a decade and will likely continue to evolve for several years to come. Also known as the Shared Services Initiative (SSI), this large scale transformational change has been underway since 1993 when the Treasury Board Secretariat announced a plan to create internal service delivery units on a shared IT services model (Whitfield, 2007).

The goal of the GoC's ongoing plan to change to a Shared IT Services environment is to fundamentally improve the way that the GoC provides service to Canadian citizens. More specifically, the $\mathrm{GoC}$ is seeking to leverage the billions of dollars being spent each year on IT, implement best practices across departments, and reverse the trend of standalone IT infrastructure services in individual departments and agencies. The change to shared IT services is a wide reaching and ambitious transformational change effort which involves complex technical, social, financial, human, and political factors. The $\mathrm{GoC}$ hopes that by consolidating their IT services into a single entity, led by the IT branch of Public Works and Government Services Canada (PWGSC/ITSB), it could offer better services to Canadian citizens and their own employees.

In the new shared services environment IT standards, procurement, and services would be consolidated across departments and provided by a central organization, the 
Information Technology Shared Services Organization (IT-SSO). Previously, GoC departments and agencies had largely been responsible for both the procurement and service of their own IT systems. According to Romanelli and Tushman (1994), transformational change refers to a fundamental shift in the culture, structure, processes, power distribution, and control system of an organization. This definition fits well with the description of the SSI which aims bring about significant changes to the GoC in each of these areas. In fact, the SSI has already resulted considerable HR, procurement, services, and budgeting changes to the GoC (Whitfield, 2007). While the changes to IT structures and processes are the most visible components of the SSI, the planned changes to the power distribution and controls systems throughout the $\mathrm{GoC}$ are some of the most challenging aspects of this transformational change.

Figure 6.1 - Shared IT Services Historical Timeline

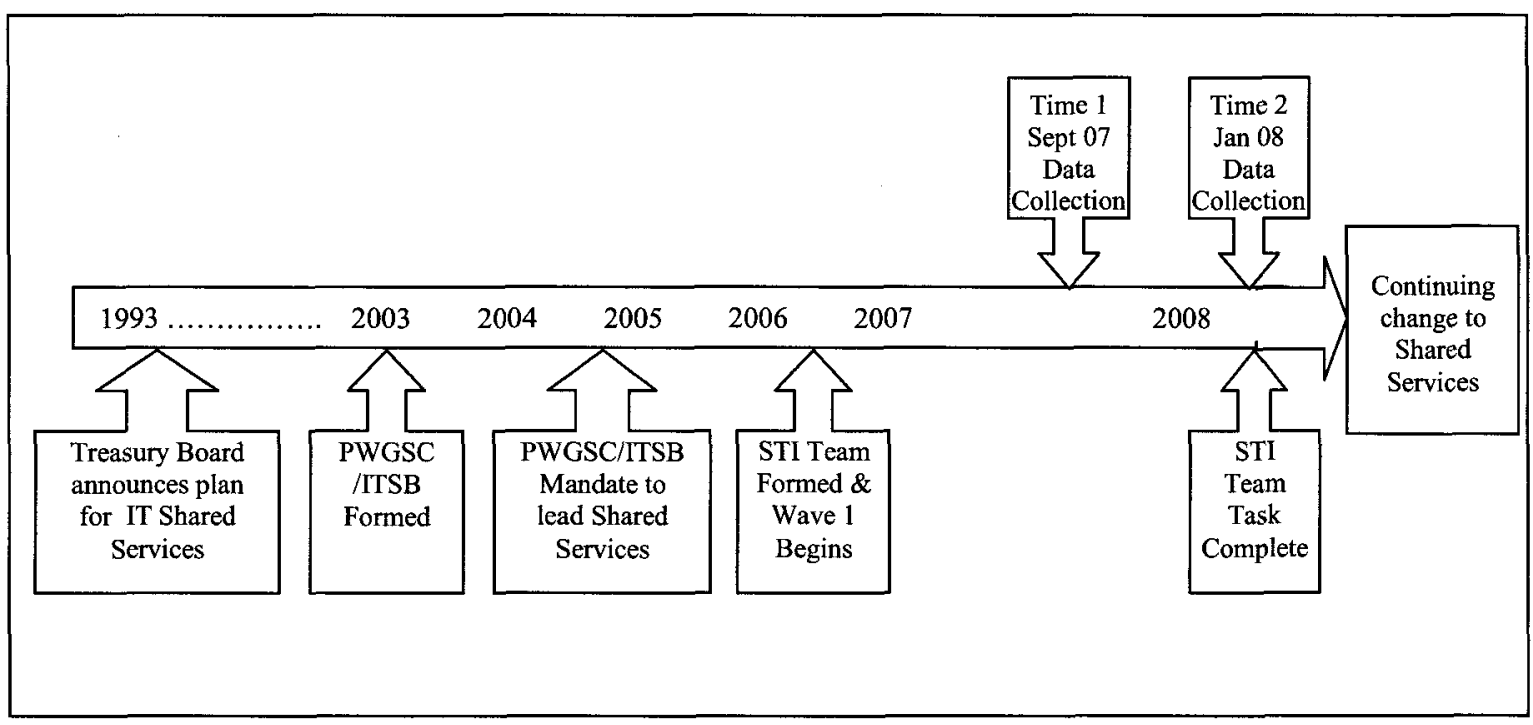


All of these changes described above are designed to create a new IT-SSO, led by PWGSC/ITSB, which will be responsible for creating a shared IT services environment in the GoC (PWGSC/ITS Fact Sheets, 2008). Figure 6.1 shows the historical timeline of the shared IT services in the GoC up to the point of our study. A primary objective of the SSI, which is still underway at the time of this report, is to reduce the number of departmental financial, personnel and material management systems in use across the government and to achieve significant cost savings for these common processes (Treasury Board of Canada, 1996). Throughout the mid to late 1990s the SSI began to take shape in pockets throughout the $\mathrm{GoC}$ with departments attempting to seek out efficiencies from common IT services. By the end of the 1990s it was clear that a central department to lead the SSI was needed to move the transition forward.

From 1993 to 2004 the shared IT services concept had remained primarily a long term strategy that the GoC slowly explored as a way to improve their IT services. As the GoC became more reliant on online systems to do business and serve Canadians, the agenda for shared IT services began to gain political momentum. In 2003 the Information Technology Services Branch (ITSB) of Public Works and Government Service (PWGSC) Department was formed to begin to standardize and manage the IT needs of PWGSC (ITS Fact Sheet, 2008). In 2004, the Treasury Board of Canada requested that government departments begin to review their IT operations in order to identify ways to more efficiently deliver their IT services in a government wide approach (PWGSC, 2008). In 2005 LeGoff's report stressed that the Shared Services Initiative would result in "better work organization and a pooling of resources that would lead to the creation of synergies and economies of scale and could achieve significant savings for the 
Government of Canada" (LeGoff, 2005, p.1). By 2005 the PWGSC department's IT branch had been restructured and began delivering on the plan by creating an IT Shared Services Organization (IT-SSO) and building a team with both public and private experience to lead the ambitious shared IT services agenda (LeGoff, 2005). This team, which would later be known as the Strategic Transfer Initiative Team (STI Team), was designed to lead the first wave of $\mathrm{GoC}$ departments through the change to Shared Services. The STI team is the team under study for this research.

\subsubsection{Description of the Change Team}

On October $27^{\text {th }}, 2008$ at the Canadian Government Technology Exhibition and Conference Distinction Awards Gala the STI team received a Silver medal in recognition for their hard work and dedication towards moving IT Shared Services in the GoC forward. This award recognized almost two years of hard work on one of the largest and wide reaching organizational change efforts in Canada. This thesis is a case study of the work of the STI team on IT Shared Services in the GoC. This section helps to put this case in context by describing the composition, structure, and task of the STI team. 
Figure 6.2 - Government of Canada's Shared Information Technology Strategy

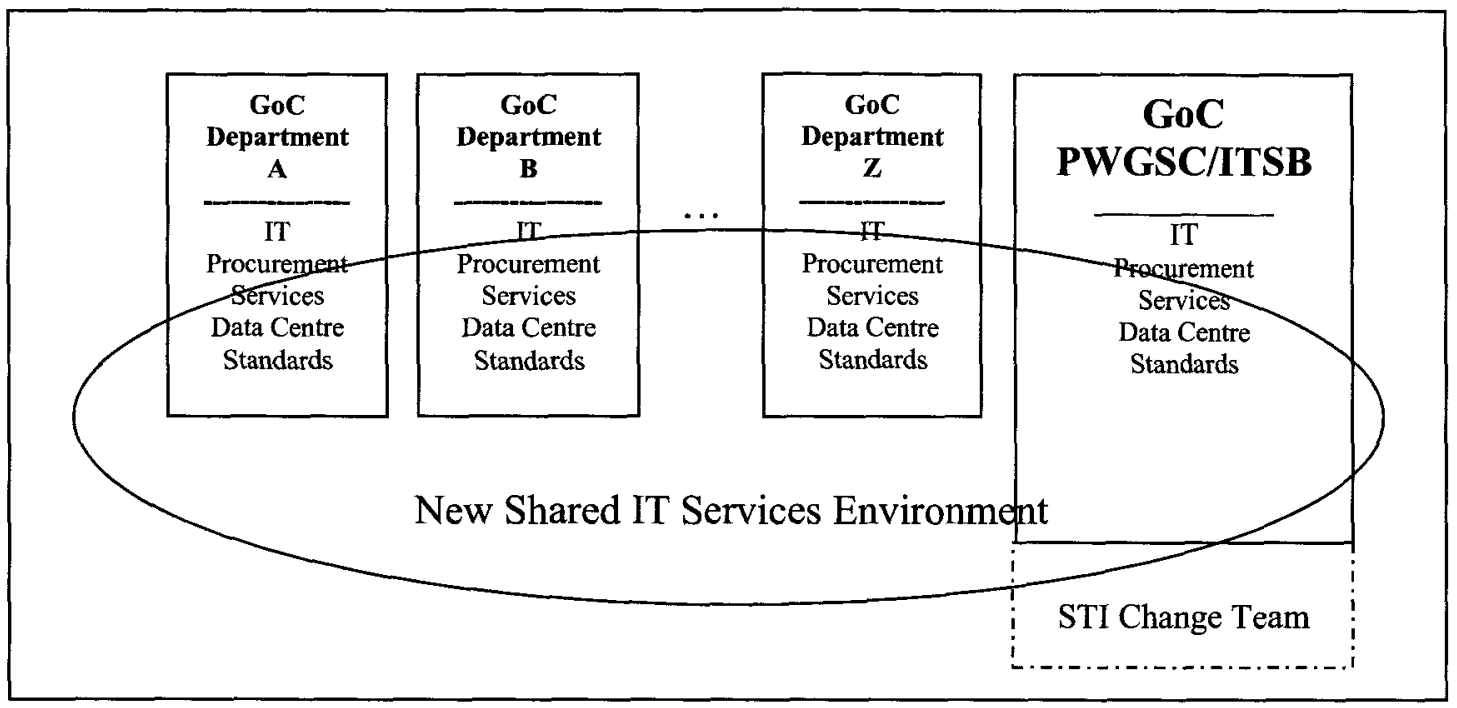

The STI team was formed in 2006 as a project team that would be responsible for the oversight of the first wave of $\mathrm{GoC}$ departments and agencies that were transferring into the new IT-SSO. Figure 6.2 illustrates the goal of the STI change team, which was to lead each of the GoC departments that were part of the first group of departments transitioning to a new shared IT services environment.

Chapter 3 of this thesis defined a change team as, "a collection of individuals who share a common goal related to the planning or implementation of organizational change, whose actions and outcomes are interdependent, who is perceived by themselves and others as a social entity, and who are embedded in an organizational context". The term 'team' is used in this thesis to describe the subject of this case study for several reasons. Although often used interchangeably in the academic literature with the term 'group', there are some researchers who argue that the two terms not interchangeable and the distinction should be made to help clarify the topic of research (Fisher, Hunter, \& Macrosson, 1997). Those researchers who distinguish teams from groups tend to do so by arguing that teams have higher levels of interdependence, mutual accountability, 
common goals, and shared outcomes (Cohen \& Bailey, 1997; Katzenbach \& Smith, 1993). The STI change team was characterized by high levels of each of these variables. Team members were interchangeable across tasks and members reported that communication and workload sharing were essential to work on the team. Team members also reported that their interconnectedness as a team was a critical component of their work and contributed to their effectiveness in their task. In terms of the common goals and shared outcomes of team members, the successful transformation of each of the Wave 1 departments into the Shared IT Services model was a major unifying goal for each of the team's members and an opportunity for all of the team members to be on the leading edge of the SSI. All of these characteristics of the STI team suggest that the label 'team' was appropriate for this thesis.

The STI Project Team was a mix of twenty-two GoC employees and external consultants who were seen as change experts, capable of the leadership, collaboration, communication, and project management skills that were required to successfully lead the Wave 1 transition. The STI team had two tasks which they were responsible for during the Wave 1 transition. First, the team was responsible for providing oversight for the successful transfer the six GoC departments that made up Wave 1 into shared services led by PWGSC/ITSB. Second, the team was also responsible for developing documentation for the Proof of Concept, which was a record of the teams' experiences and lessons learned from the Wave 1 transition and the IQTT methodology. This document would serve as a template for future waves of departments that would transfer to the IT-SSO. Fulfilling these two objectives would take up most of the STI Team's time in 2007. 
Figure 6.3 shows the four main oversight functions that the STI team provided for the Wave 1 transitioning departments: People Management, Project Management, Finance and Outcomes Management, and Stakeholder Management.

\section{Figure 6.3 - STI Change Team Functional Subgroups}

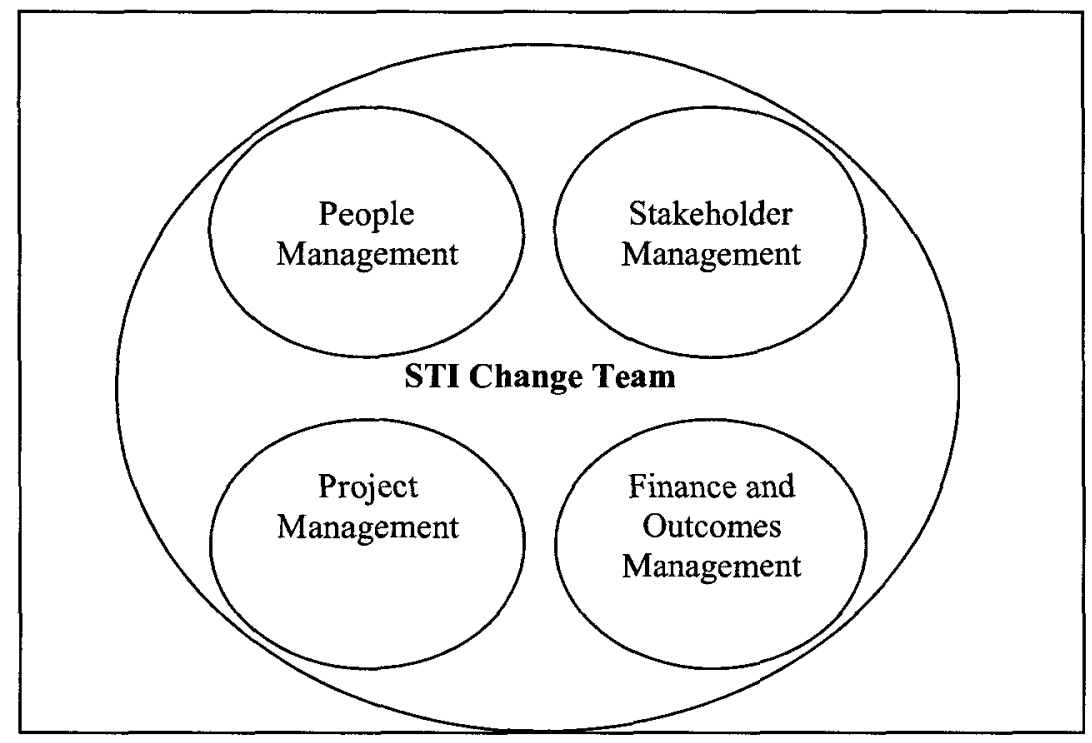

STI team members were assigned to one of these four functions in order to better support each of the Wave 1 department in their transition. The People Management subgroup was responsible for supporting the human resource related issues throughout the IQTT process. The Stakeholder Management subgroup was responsible for reporting to key stakeholders, such as the Treasury Board of Canada on the progress and issues related to each change project. The Finance and Outcomes subgroup was responsible for ensuring that all financial transactions related to the transition project were consistent with the service agreements set out in qualification phase of the IQTT process. Finally, the project management subgroup provided project management support for each individual 
department transitioning to the IT-SSO. Team members were generally assigned to one of these functional groups but would be moved around based on the requirements of the transferring departments and were all considered part of the STI Team.

The STI team worked together from fall of 2006 until early 2008. Both of their primary tasks were accomplished between the $\mathrm{T} 1$ data collection (October 2007) and the T2 data collection (January 2008) periods of this study. Figure 6.4 shows the timeline for the team's deliverables relative to the data collection periods for this longitudinal research.

Figure 6.4 - STI Team Deliverables Timeline

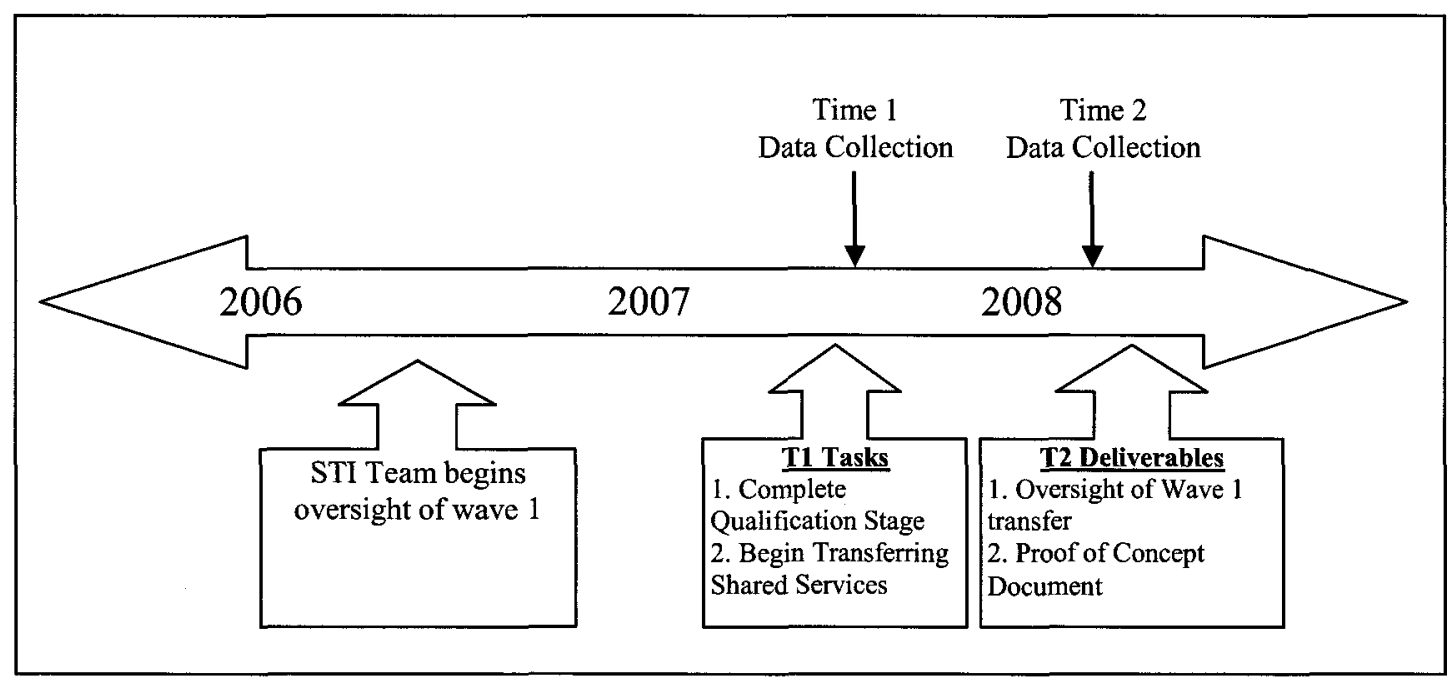

Following January 2008 and the submission of the Proof of Concept document the STI team was disbanded in January of 2008 , and members went their separate ways, although many of the team members continued to work on projects in the GoC related to Shared IT Services. 


\subsubsection{The Death Valley of the Change}

In 2006 the business case for Shared IT Services in the GoC was almost a decade old and the political forces had aligned to push the SSI to the forefront of the GoC agenda. In Figure 6.1 we showed the historical timeline of the transformational change to Shared IT Services and positioned this research initiative in terms of time. This subsection narrows our focus and examines the nature of the Shared IT Services change during the period of this research.

By fall of 2006, the STI team had evolved so that the team was in position to lead the first wave of departments into a new Shared IT Services Organization. The full transformation to Shared Services was set to follow a staged approach where GoC departments and agencies would be assisted in their move into the IT-SSO in different groups or 'waves' of transitioning departments. Wave 1 represented the first wave of GoC departments to undertake the transformation to Shared IT Services. The first wave of departments was selected for their ability to change and the benefits that they would accrue from Shared Services. The concept behind the phased approach was the Wave 1 would be a learning experience for the transition of future departments to Shared Services in a process. The STI team would be responsible for transitioning these waves into the new Shared Services Organization and providing their expertise in project management, organizational change, and people transition. The STI Team was also responsible for reporting back to Treasury Board on the progress of each of the Wave 1 departments.

Each of the departments in Wave 1 had very different levels of services, people, and infrastructure that they were interested in transforming to Shared Services so the deliverables that the STI had to meet for each department were unique and challenging in 
their own way. The strategy for transitioning the Wave 1 departments was that each department would go through the Service Integration Methodology IQTT process (Identification, Qualification, Service Transition, and Transformation). The purpose of this methodology was help to ensure the Wave 1 departments and PWGSC/ITSB went through a rigorous analysis and preparation before any change to Shared Services occurred. The identification stage of the process involved identifying the best candidate departments to transfer to the new Shared Services Organization. The qualification stage was an extremely interactive stage where the transitioning department, PWGSC/ITSB, and the STI Team collaborated to come up with formal agreements that detail exactly what, when and how the department was to transition to Shared Services. The Wave 1 departments would negotiate the services, people, and infrastructure to be transferred to the Shared Services Organization during the identification and qualification stages of the IQTT. Because the departments were transferring to Shared Services voluntarily the qualification stage of the process was critical in ensuring a smooth transition that would satisfy both the transferring department and PWGSC/ITSB. The third stage, service transition involved the actual transfer of IT services from the transitioning department to the IT-SSO. The final stage of the IQTT process was the transformation stage, where the IT service was fully transformed to the new Shared Services model.

At the beginning of 2007 the IQTT process for the Wave 1 departments was completing the service qualification phase. This phase was concerned with the careful planning and analysis needed to move forward into the service transition phase. It was felt that by going through the IQTT process each department would have a clear plan for 
the services, people, and infrastructure that would be a part of their unique transition to Shared Services (ITS Fact Sheet, 2008).

According to Elrod and Tippett (2002) organizational change follows a consistent pattern from the start of the change to the end of the change that can be divided into three phases. In his critical review of the change literature Todnem By (2005) summarized Elrod and Tippett's (2002) work by explaining that change is characterized by the way that it comes about. The organization will go through different states which range from a state of anticipation to an unsatisfactory state (labelled the resistance phase in Figure 6.3) to finally a state of acceptance.

Elrod and Tippett's (2002) model was formed by comparing models of change from several seemingly unrelated disciplines. The key characteristic of all of these models was that the middle phase in the model was characterized by struggle and resistance. This model maps well onto the organization change that was the site of this case study research, the Wave 1 transition of Shared IT Services at the GoC. The impact of this change cycle on the team represents a potentially valuable lens through which the effectiveness of the STI change team can be viewed. Figure 6.5 shows the model of change put forth by Elrod and Tippett mapped to Wave 1 of the Shared Services organizational change and the data collection points of this thesis. 


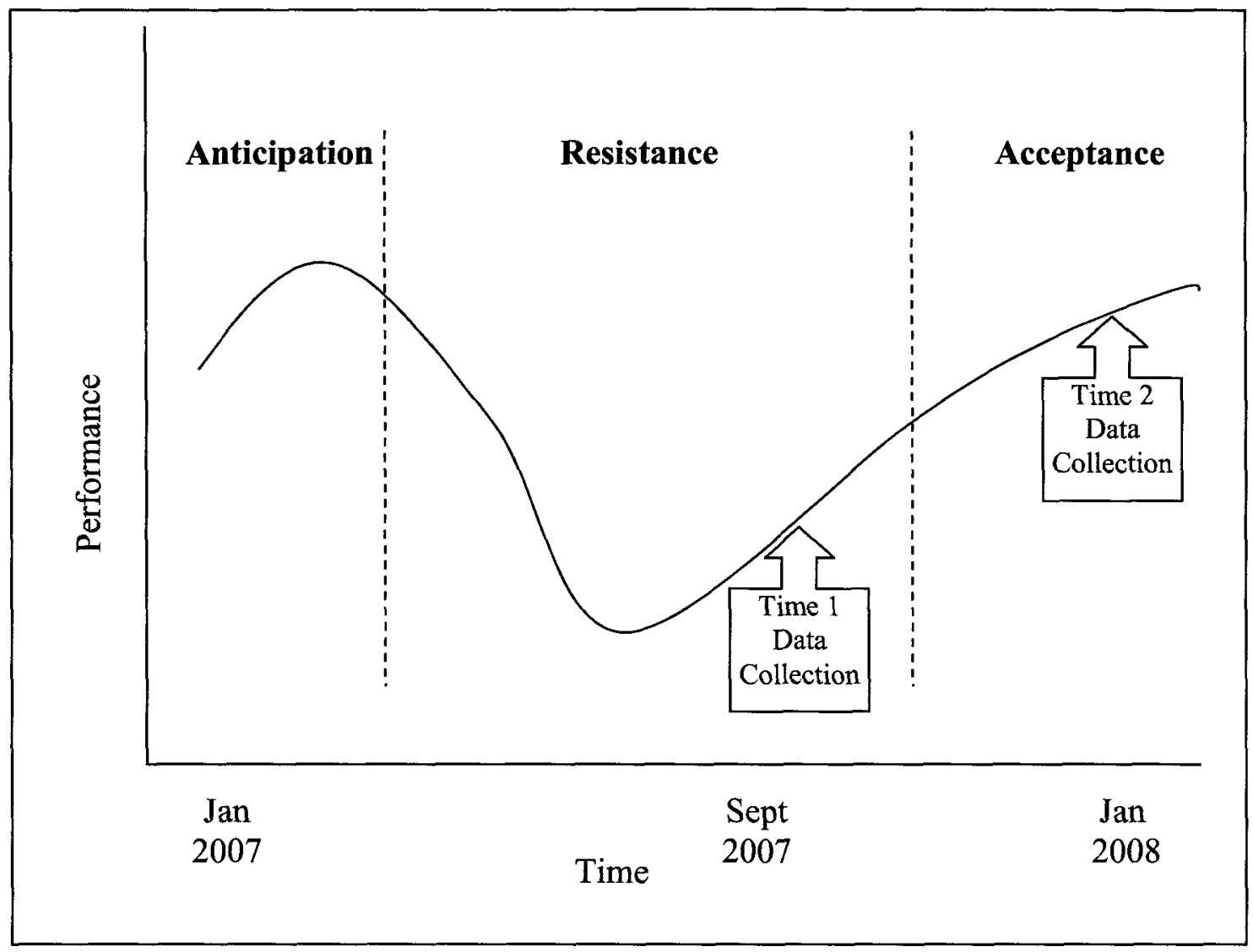

Examining the Wave 1 transition, these three phases can be applied to the change context in which the STI team operated for the duration of this research. In the first phase (ie. prior to our involvement with the team) PWGSC/ITSB and the transferring departments could be described as being in an anticipation phase. In Figure 6.5 the anticipation phase represents the service qualification phase of the IQTT process. Our review of historical documents (LeGoff, 2005; Whitfield, 2007) suggests that in this phase, the emphasis was placed on planning and due diligence so most members of the organization were not yet impacted by the change effort and were in an anticipatory state for the first wave of departments to transition to shared IT services. This phase was characterized by a general excitement for Shared Services, some uncertainty, but a high 
level of energy when it came to the change. According to Elrod and Tippett's (2002) model the organization experiences a slight spike in performance levels and a temporary increase in support for the change during this phase of the change. The team under study in this thesis was in the anticipation phase of the change cycle before this thesis began (i.e. The Wave 1 transition and the formation of the STI team).

In the second phase of Elrod and Tippett's model the organization goes through a depression stage where the reality of change hits. In this stage the organization can expect a drop in performance and an increase in resistance. Individual employees can experience denial, anger, and resentment towards the change. Vakola and Nikolaou (2005) explain that employee attitudes towards change fall significantly in this phase and that leadership is critical to get through this 'death valley' of change. A retrospective view of our research would suggest that for the team under study this phase occurred roughly through the first two-thirds of 2007 (a period ending around the time 1 data collection). Team members expressed frustration with the change, and specifically the amount of resistance from the organization was a common theme in the time 1 (T1) results. In fact, the data collected at $\mathrm{T} 1$ for this research suggest that the team was at the tail end of the resistance phase just as the organization was moving into the acceptance phase.

The third phase of the model describes a period of acceptance as the final phase of the change cycle. Elrod and Tippett (2002) explain that after going through the anticipation and resistance phases the organization is ready to enter into a phase of acceptance. This phase is characterized by a gradual increase in performance and support for the change. Employees have accepted that the change will take time and hard work. Groups and individuals begin to seek out new opportunities related to the change and 
employees get down to doing tangible work that brings about the implementation of the change. Our study of the Wave 1 transition suggests that this acceptance phase occurred in the late fall of 2007 until the time 2 (T2) data collection period. The interview data showed that STI team members were feeling more positive about change and were focused on performing well as a team to complete their work. These findings suggest that the model of change put forth by Elrod and Tippet (2002) is an accurate representation of the Shared Services change initiative that was the context for this research. As such it will be used as another lens through which to view our data. 


\section{THEORY DEVELOPMENT FROM CASE STUDIES}

Eisenhardt's (1989) framework for theory building is used in this thesis to develop and test the research model. Eisenhardt's framework for theory development synthesizes previous research on qualitative methods by authors such as Glaser and Strauss (1967), Yin (1984), and Miles and Huberman (1984) to form a method well suited for novel theory development in the field of management. This chapter begins with a discussion of theory development and the suitability of the grounded theory case study approach to address the research questions laid out in Chapter 5. The second section in this chapter examines the grounded theory technique which is the research method that drives this case study. The third section of this chapter refines our strategy for theory development by explaining the steps involved in Eisenhardt's grounded theory approach. The final section of this chapter discusses the strengths and limitations of this approach to theory development.

\subsection{THEORY DEVELOPMENT USING EISENHARDT'S MODEL}

When Glaser and Strauss (1967) published their original work on grounded theory in 1967 the goal was to provide researchers with a method for theory development which would be closely tied to real world data. Glaser and Struass (1967) saw the process of theory development as being in stagnant state with most of the work done by researchers either being the verification of existing theory or the development of theory through logic and deduction techniques. The basic principle of the grounded theory approach is that new theory should evolve from the data, in other words the theory should be grounded in 
the data. Strauss and Corbin $(1998$, p. 12) argue that theories that are grounded in the research data are more "likely to offer insight, enhance understanding, and provide a meaningful guide to action." This section briefly describes Eisenhardts' (1989) model of grounded theory as a tool for theory development.

\subsubsection{Grounded Theory Development}

As a tool for theory development, the grounded theory method has undergone a significant evolution since the original work by Glaser and Strauss (1967). The original grounded theory method began with an ideal of 'no theory under consideration'. This ideal allowed for the emerging concepts and relationships that would form the novel theory to be free from the researchers' bias and instead to be completed grounded in the data. The original method of grounded theory also relied heavily on the strategy of constant comparison. Using constant comparison techniques the researcher would go through several iterations of comparing within and between observed cases in order to form categories and code the data. The constant comparison method also involved a return to the literature by the researcher to look for contradictions or verification from previously existing related theory. While the constant comparison strategy remains a crucial part of the grounded theory method, the field of management studies seen a shift from the no theory under consideration ideal to a method in which the researcher begins with research questions and a prior identification of key concepts (Miles \& Huberman, 1994; Yin, 2003). This shift allowed researchers to focus their research on specific areas that required theory development and to provide a more standardized approach to data collection and analysis (Miles \& Huberman, 1994). 
Eisenhardt's (1989) model of grounded theory was selected for this thesis research because it incorporates key elements of the evolution of grounded theory while retaining many of the fundamentals of the Glaser and Strauss (1967) approach. Regardless of the approach to grounded theory selected, the grounded theory case study approach begins with the discovery of an unnoticed area to investigate. For this thesis research, that area is organizational change teams.

\subsubsection{Theory Testing vs. Theory Development}

According to DiMaggio (1995), theory is "an account of a social process, with emphasis on empirical tests of the plausibility of the narrative, as well as careful attention to the scope conditions of the account" (p. 391). Theory allows researchers to describe, understand, and eventually predict (even if only probabilistically) outcomes of interest (Colquitt \& Zapata-Phelan, 2007). Broadly speaking, the theoretical contributions of scientists can be classified along two dimensions: those which generate new theory and those which test existing theory (Colquitt \& Zapata-Phelan, 2007). Research which tests theory generally uses existing theory to help formulate hypotheses that can be tested with observations and either accepted or rejected. Research which builds theory generally follows an inductive method whereby the researcher uses observations to generate theory through inductive reasoning.

A unique feature of Eisenhardt's model for theory development is that it uses techniques normally reserved for theory testing to help improve the process of theory development. According to Eisenhardt (1989), theory should be evaluated by the richness

of its account, the degree to which it has a fit to the data, and the extent to which it 
reveals novel insights. To help the researcher achieve this goal, Eisenhardt's (1989) method uses two primary techniques normally associated with theory testing studies: problem definition and construct validation. The rationale behind using both of these techniques is similar to theory-testing research; however, the execution of these techniques varies considerably. In Eisenhart's model of grounded theory both the research questions and the a priori specification of constructs are techniques that are meant to guide the interpretation of the data and not to test the existing theory. Where the data does not fit, the researcher is encouraged to re-examine these two foundations to find a better fit with the existing theory. The initial framework is not being tested for validity and reliability. Rather it is being examined for its fit with the data from the case under study. To assist in this examining process, Eisenhardt (1989) combines these techniques with theory building techniques such as within-case analysis and replication logic to help improve the researcher's ability to generate novel theory. The execution and interaction of each of these techniques is described in detail in the next section.

\subsection{STAGES OF THE EISENHARDT'S MODEL}

As described in the section above, the method used to explore the area of change team effectiveness in this thesis is based on the approach to building theory from case research put forth by Eisenhardt (1989). This section of the methodology describes eight steps taken from Eisenhardt's (1989) method that comprise the grounded theory method used to conduct the current thesis research and develop a model of change team effectiveness. 


\subsubsection{Step 1 - Getting Started}

The first step for the researcher in Eisendart's model is to develop an initial orienting framework for the study. Eisenhardt (1989) also suggests that the researcher form an initial set of research questions which would focus the study and prevent the researcher from "becoming overwhelmed by the volume of data" (p.536). Once the focus of the research has been clearly laid out the research should then begin to identify the potentially important constructs that may be relevant. The research can identify these constructs from the relevant literature as required. An important note on this step is that the researcher should remain as close to the ideal of no theory under consideration and no hypothesis to test as possible (Eisenhardt, 1989; Glaser \& Strauss, 1967). Although this is impossible to achieve, it is necessary that the researcher should do everything possible to achieve this ideal state that preordained perspectives and biases do not limit the potential findings of the research. The researcher is encouraged to identify possible constructs of interest based on the initial research questions however no construct should be guaranteed a spot in the resultant theory. Additionally, the researcher must be open to the possibility that the research questions may change as the researcher observes the phenomena under study. To do this it is important that the research avoids pre-examining the relationships between the identified construct and instead allow those relationships to emerge through interview or observation. The conceptual model for this research and the research questions were presented in Chapter 5. Both of these will be revisited in Chapter 9 as they provide a baseline for data collection and analysis. 


\subsubsection{Step 2 - Selecting the Case for Study}

The grounded theory technique relies on purposive or theoretical sampling, not on traditional statistical sampling. In traditional hypothesis-testing studies the cases are selected randomly from a population based on their potential to accurately represent the population being examined. This is not the case in grounded theory research where cases are chosen for their potential to contribute to the emergent theory being developed. Thus it may be the case the emerging theory suggests that further sampling is required and thus the cases to be sampled are determined by the ongoing process of explorative research. The practical application of the purposive sampling procedure employed for this research is described in Chapter 8.2.

\subsubsection{Step 3 - Crafting Instruments and Protocols}

Theory building researchers typically combine multiple data collection methods. Although grounded theory research is often associated with qualitative research, it easily can accept quantitative data, or a hybrid of evidence to better support the development of theory. In fact, the use of both qualitative and quantitative evidence to help develop theory in a case study can be a significant advantage for the researcher (Yin, 2009). Quantitative evidence is useful in that it often prevents the researcher from being carried away by their own impressions of the qualitative data. It also is good for corroborating the findings from qualitative analysis. Qualitative data are useful for understanding the relationship that underlay a theory. The questions that are used in the research instruments should flow from the initial research questions and framework. The instruments and protocols used for this research are described in Section 8.3. 


\subsubsection{Step 4 - The Overlap of Data Collection and Data Analysis}

A critical feature of grounded theory research is the frequent overlap of data analysis with data collection (Glaser \& Strauss, 1967). In this step the research begins with an initial description of the case begin observed. The researcher begins with field notes and works to organize the observed data into categories. At this point in grounded theory research the researcher is encouraged to revisit the previously identified constructs from the research framework. This allows researchers to take advantage of the flexible data collection features of case study research. Adjustments to interview scripts can be made after initial interviews to allow the researcher to probe emergent themes or take advantages of opportunities that may arise while in the field. The researcher may also choose to add data sources if the data suggest that further sources of evidence may contribute to the evolving concepts and patterns. This is a unique feature of grounded theory case studies and one that is in line with the exploratory goals of this type of research.

\subsubsection{Step 5 - Constant Comparison: Within-Case and Cross-Case Analysis}

The constant comparison technique is the most central feature of the grounded theory approach (Glaser \& Strauss, 1967). In the Eisenhardt (1989) model a clear process of analysis is a critical feature of a case study. The analysis of the data in a grounded theory study is both the most important and most difficult steps for the researcher. Eisenhardt (1989) explains that there is no standard format for this first stage of data 
analysis and that there are "probably as many approaches as (there are) researchers" (Ibid, p.540). Within step 5 there are two levels of analysis that comprise the constant comparison technique: within-case analysis and cross case analysis. The process of within-case analysis begins with the transcription of the first interviews or write-ups of the first case as the researcher attempts to describe what is happening in the case. Within-case analysis is an attempt to find meaning in the large quantity of data available to the researcher in a case study. The first descriptions of each case should allow the researcher to go beyond initial impressions and become intimately familiar with what is going on in the case (Ibid). The process of within-case analysis should allow the patterns to emerge that will drive the process of cross case analysis and eventually theory shaping.

With a detailed description of each case and an intimate knowledge of the individual cases the researcher may then begin to examine across the cases for confirmation or contention between cases. The primary tactic in this stage is to select a category of interest and look for similarities or differences across cases. Patterns should emerge based on the data and the result is that the researcher can begin to formulate a coding scheme which develops iteratively as the constant comparison technique goes on. The coding scheme will also begin to illustrate patterns which will suggest constructs and relationships between constructs. These concepts should illustrate an event, object, action or interaction that the researcher identifies as being substantial in the data. At this point the researcher is ready to proceed to the next level of analysis, shaping theory. The practical application of the constant comparison approach for this thesis research is discussed in Section 8.4. 


\subsubsection{Step 6 - Shaping Theory}

The shaping of theory is the next stage in Eisenhardt's (1989) iterative case study method. There are two main parts of this stage. The first step is to sharpen the constructs put forth in the within-case and cross-case steps. This occurs through the constant comparison of the constructs under consideration and the data. The second step is to do the same constant comparison for the emergent relationships under consideration. Eisenhardt argues that qualitative data are particularly useful for understanding why emergent relationships are or are not confirmed across cases. With both of these steps the researcher is looking for a close fit between the constructs and the data. The researcher then takes the concepts and relationships and begins to build a framework for understanding the phenomena under study. This working theoretical framework is then reexamined by comparing the theory to the data. The central idea is that "researchers constantly compare the theory to the data; iterating towards a theory which closely fits the data" (Eisenhardt, 1989, p. 541). By achieving a close fit between the resultant theory and the data the researcher will increase the likelihood of developing a valid and testable theory.

\subsubsection{Step 7 - Enfolding the Literature}

In grounded theory, the literature review must be re-examined after the emergence of a substantive theory (Glaser \& Strauss, 1967). The researcher is encouraged to return to the literature to check findings against relevant research to identify consistencies and departures. Confirmation of the theory from the literature strengthens the theory and contributes to the validity of the theory. Contradictions between the theory and the 
literature present a further opportunity to return to the data and challenge the theory under consideration. This iterative examination was used in the current thesis research with the literature on organizational change teams being reviewed prior to the data collection for this thesis and returned to after the development of the model of change teamwork. How the literature was enfolded into theory is included in the discussion chapter of the thesis.

\subsubsection{Step 8 - Reaching Closure}

Eisenhardt (1989) explains that reaching closure in a case study can be a difficult task for a researcher. While the research objectives of the study should guide the researcher when determining closure the task is still difficult and requires the researcher to make challenging decisions. The first challenge for the researcher is to know when to stop adding cases. The researcher should stop adding new cases to the study when they reach theoretical saturation, or when the incremental improvement of the researchers understanding of the constructs and relationships involved becomes minimal (Ibid). A similar strategy is suggested for the researcher's decision to stop the iterations between theory and data. Researchers should again stop when the improvement to the theory from an additional iteration of comparison between theory and data becomes minimal. In the case of the current research, the objectives were to describe the benefits and challenges of a change team and to put forth a model of change teamwork that could be tested. Thus the number of iterations for this research was determined by the ability of the case analysis to contribute to these objectives. 


\subsection{STRENGTHS AND WEAKNESSES OF EISENHARDT'S MODEL}

As with any research method there are some inherent strengths and weaknesses to Eisenhardt's approach to case study. The first potential weakness centers on the fact that because the theory is bottom up and based on a specific case, the researcher may not be able to raise the level of generality of the resultant theory. There is a chance that Eisenhardt's method may produce a narrow and modest theory that would be useful only in specific conditions. In the case of this research, the risk is that the model formed may only be useful in the context of the GoC Shared Services change and may not be useful for the study of future change teams.

The second major weakness which may be present in Eisenhardt's model is the impact of researcher bias on the entire process of theory development. In contrast to traditional grounded theory, in Eisenhardt's model the researcher begins with an initial framework and research questions and is encouraged to become familiar with the literature to identify potentially important constructs. Therefore, from the very start of the process the research may have formed opinions and prejudices on how the final theory should look. There exists a very real possibility then that the researcher's bias may drive the crafting of interviews and surveys, as well as the data analysis. Since the constant comparison method is so important to the success of grounded theory it is critical that the research allow the data and not their own biases guide this process. Otherwise the constructs and relationships that get included in the resulting theory may reflect the researcher's desired outcome rather than the patterns being presented by the data. Researcher bias is not unique to Eisenhardt's approach and it is the researcher's 
awareness of this potential bias and their disciplined approach to the research method chosen that can help to limit the impact of this weakness.

Eisenhardt (1989) argues that her model of case study research using a grounded theory approach tends to unfreeze the thinking of the research and has the potential to generate theory with less researcher bias than theory simply deduced from existing theory. This benefit of unfreezing of the researcher's mindset occurs because Eisenhardt's model offers the researcher dual frames from which to view the research. The first frame is the deductive frame where the researcher views the data from the initial framework and research objectives to the emerging theory. The second frame is the inductive frame, which occurs as the researchers goes through the iterative empirical observation and analysis that step in the field. These viewpoints allow the research a better view of the data from which to form theory.

Another strength of Eisenhardt's model is the fact that it is customized for study in the management field. The model is very pragmatic and well suited for addressing practitioner problems but retains the fundamental important features of grounded theory. Eisenhardt (1989) also explains that the resultant theory is likely to be testable and empirically valid, an important feature of management research. These strengths of Esienhardt's method are well suited to the current research and should allow for a testable and valid theory of change teamwork that is firmly grounded in real world data. 


\section{SAMPLING, DATA COLLECTION, AND DATA}

\section{ANALYSIS}

The purpose of this chapter is to describe the application of the grounded theory methodology that was followed for the sampling, data collection, and data analysis in this case study. The chapter begins with a discussion of the multiple levels of analysis that are examined to provide a more comprehensive view of the factors that may influence change teams. The second subsection describes the characteristics of the sample selected for this research. The third section in this chapter describes the qualitative and quantitative data collected for this longitudinal study. The fourth section of this chapter discusses the methods used to code and display the data collected on the STI change team. Finally, the chapter concludes with a description of the methods that guided the interpretation of the data.

\subsection{LEVEL OF ANALYSIS}

According to Yin (2009) the level of analysis chosen in a case study should be driven by the research objectives of the study. In order to support all three objectives of this thesis, this case study employs a multi-level approach to the case study. The level of analysis for research objective \#1 is at the organization and the individual levels of analysis. The examination of benefits and challenges arising from the work of change teams were focused on outcomes for the individuals on the team and the organization that came about due to the use of change teams. Individual team members commented on benefits and challenges that they saw for themselves and for the organization as a whole. 
Research objective \#2 requires that this research focus on the team level to develop a theoretical model of effective change teamwork. To better understand team level effectiveness this thesis also examined how individual levels of resistance, stress, and workload dimensions may influence team outcomes. Since it is likely that those individual level dimensions of organizational change may influence the team's overall we need to take a multi level approach to our study of change team effectiveness. Finally, research objective \#3 required this research to examine the challenge of supporting change teams from the organizational level. To achieve this level of analysis we were again required to extrapolate the individual's beliefs in this area to the level of the organization.

As discussed in Section 6.1 one of the advantages of the case study method is that it is very flexible method which allows the researcher the opportunity to shift levels of analysis or examine multiple levels of analysis as the opportunity presents itself (Miles and Huberman, 19994). This embedded design (Yin, 2009) feature is especially useful in Eisenhardt's model (1989) of grounded theory where the researcher is instructed to follow the emergent patterns as the data suggests and not to remain fixed on the pre determined framework. The grounded theory case study method supports the multi-level approach that this research takes.

\subsection{THE SAMPLE SELECTION}

The sample for this thesis research was chosen based on a theoretical sampling strategy. In other words the STI change team was selected because of its potential to contribute to a novel theory of change teamwork. Eisenhardt and Grabner (2007) explain 
that there often is a "faulty assumption that the cases should be representative of some population, as are the data in large-scale hypothesis testing research" (p. 27) rather than being chosen for their usefulness in developing theory. Yin (2009) explains that case study research is not governed by a sample size needed to be able to generalize results to a broader population. Instead the sample selected for studying the STI change team was chosen based on the ability of the chosen cases to generalize to a broader theory.

\subsubsection{Participant Recruitment}

The participants for this thesis research come from the members of the STI team who were with the team from September 2007 to January 2008. The initial contact with the team came from a senior member of the PWGSC/ITSB organization who introduced the researcher to the team leader. The added credibility that came from having the support of both a senior manager in the organization and the team leader made access to the team members and gaining background information on the team much easier. The pre-study phase consisted of several informal meetings with the team leader to familiarize the researcher with the team and the Shared Services change in general. It was these interviews that allowed the researcher to map the experiences of this team to Elrod and Tippet's (2002) change cycle (as shown in Section 6.2.3).

The first phase of the research consisted of the $\mathrm{T} 1$ interviews and $\mathrm{T} 1$ online team effectiveness survey for team members. Invitations to participate in the study at $\mathrm{T} 1$ were administered through an email invitation to participate which was emailed (see Appendix A) to each of the four functional group leaders on the STI team (see Figure 6.3) to inform them of the additional interviews that would be taking place and to request their 
participation. Interested participants then contacted the researcher and a time was arranged for a face to face interview (Appendix B) with each of the five group leaders. All four of the group leaders agreed to be interviewed and fill out the online survey at $\mathrm{T} 1$.

In each of the first round of interviews each of the functional group leads were asked at the conclusion of their interview to recommend two additional STI members from their functional area that would have significant knowledge and experience with the STI and the Shared Services change. From this list of key team members additional invites to participate in the $\mathrm{T} 1$ interview were sent out and an additional seven interviews were conducted. Each of these team members also filled out an online survey (Appendix C) at this time. These interviews and surveys were spread out evenly across all four of the functional groups in the STI team. The interviews and surveys were then conducted again four months later at $\mathrm{T} 2$.

\subsubsection{Description of the Sample}

The sample for this case study is presented in Table 8-1. The sample consists of the team leader, four functional group leaders, and seven additional team members for a total of twelve STI team members who participated in this case study. The sample was chosen from the team members who had been with the team from the start of Wave 1 and were likely to be on the team throughout the change effort. This strategy for data collection meant that our potential pool of participants was restricted. The sample of twelve team members represents $55 \%$ of the twenty-two STI change team members who were on the team at $\mathrm{T} 1$ and contains representation from each functional group shown in Figure 6.3. 
Table 8-1 Description of Respondents

\begin{tabular}{|c|c|c|}
\hline \multicolumn{3}{|c|}{ Demographic Information } \\
\hline \multicolumn{2}{|c|}{ Description } & $\mathrm{N}$ \\
\hline \multicolumn{2}{|c|}{ STI Team members interviewed } & 12 \\
\hline \multirow[t]{2}{*}{ Gender } & Male & 7 \\
\hline & Female & 5 \\
\hline \multicolumn{2}{|c|}{ Average \# of years with the STI Team } & 1.5 years \\
\hline \multicolumn{2}{|c|}{ Average \# of years with PWGSC/ITSB } & 10 years \\
\hline
\end{tabular}

The average number of years on the STI team for the sample is 1.5 years which reflects the fact that we tried to select those individuals would have been with the STI team since the beginning of the team's work and would be able to comment on the entire work of the STI team. The average number of years with PWGSC was 10 years, with the majority of the team members with the most tenure in the organization being the functional group leaders. On the STI team 10 out of 12 team members described themselves as having a very high level of experience with organizational change and all team members reported having a high level of experience working in teams. Several of the team members had both private and public sector experience with change. The sample make up reflects how people were selected to be on the change team. That being said, only 6 of 12 team members describe themselves as having more than a moderate level of experience with teams who were working on change. 


\subsection{DATA COLLECTION}

In Eisenhardt's (1989) model of theory development data collection is closely tied to the analysis of data. Data collection also gives the researcher the opportunity to revisit the instruments used for data collection if the data begins to suggest that such alterations would improve the contributions of the research. This section is divided into two subsections that describe the data collected for this thesis: qualitative data collection and quantitative data collection. Yin (2009) explains that the use of both quantitative and qualitative methods in a case study can result in a more convincing and useful theory. This section begins with a description of the qualitative data for this research, followed by a description of the collection of the quantitative data used in this study.

\subsubsection{Qualitative Data}

Qualitative research methods can be a powerful tool with which to explore new areas of management and business life (Gummeson, 2000). The use of qualitative data allowed this research to explore several constructs and obtain a more complete picture of change team effectiveness. The following section describes the qualitative tool used in this thesis research, the semi-structured interview.

\subsubsection{Development of the Interview}

The interview script was originally formed based on the literature review and was driven by the objectives of this research (Chapter 5). The interview was altered three times during the course of the study. The first set of changes to the interview took place 
after consultation with the team leader. The team leader interview was essentially the same as the other interviews; however, the team leader answered questions regarding the composition of the team. This team leader interview combined with pre-testing interviews conducted, determined that the interview was too long and repetitive in a number of places. As a result, the demographic information section was shortened to avoid duplication with the survey and questions on the composition of the team were taken out of the interview as this information was available from the team leader.

The second set of revisions came during the T1 interviews. During the analysis of these interviews it became clear that there were some leading and biased questions in Part 2 of the interview. These questions were related to team communication and the amount of time that employees were spending on the change. It was determined that if the question remained in the script the interview data would likely suffer from biases and reflexivity where the respondents were simply given the answers that the researcher wanted to hear (Yin, 2009). The questions were excluded from the script because they were leading the respondents by focusing their attention on workload and were not yielding quality insights into either topic.

Finally, the third set of alterations to the script came between the $\mathrm{T} 1$ and $\mathrm{T} 2$ interviews. Most of the adjustments to the interview script at T2 involved shortening the number of questions by filling in the demographic information sections in Part 1 and 2 of the interviews and then asking team members to confirm the information. Another alteration to the interview at this stage was that Question 11 in Part 5 was combined with question 10 from Part 4 since they both addressed the support for change teams objective 
and were found to illicit essentially identical information in the $\mathrm{T} 1$ interview (see Appendix B).

\subsubsection{Description of the Interview}

The interview script prepared for this research was designed to specifically address the research questions outlined in Chapter 5. The complete interview script is provided in Appendix B. The interview followed a semi-structured format which according to Yin (2009) are well suited to case study research. The semi-structured format allows the researcher a greater level of flexibility in terms of exploring concepts and relationships during the interview than structured interviews. Whenever possible, the interviews were conducted face-to-face at the research site (PWGSC/ITSB). When faceto-face interviews were not possible, the interview was conducted over the phone. The researcher had a set script to follow (Appendix B) but was allowed to ask questions to get further information or clarification where necessary. The interview lasted an average thirty minutes.

The interview was divided into five parts. The first part of the interview was designed to obtain general information and develop a rapport with the team member. The interview began with the introduction script and an opportunity for the respondent to ask any questions they wished about the study. Also included in this section were a number of brief demographic questions designed to gather information on the respondents and the team. Part 2 of the interview examined the change team in greater detail, asking the respondents to describe the team's primary task and the composition of the team. 
Respondents were encouraged to provide details to help the researcher understand the work of the change team.

Part 3 of the interview addressed the first objective of this research and provided team members with the opportunity to discuss the benefits and challenges of being on a part of a change team. The interviewer prompted the respondents by first explaining that change agents can be in the form of both individuals and teams in an organization and that this question was designed to examine what change team members say as the benefits and challenges of change teams based on their own experience. The open-ended format allowed the researcher to probe further into answers to not only find out what the benefits and challenges related to change teams were, but how strong those benefits and challenges were.

Part 3 of the interview also included question which examined the role of the change team in supporting change. Team members were asked to describe what types of behaviours and values are characteristic of a change team that: a) supports the change and b) resists the change. Interviewees were then asked to comment on the percentage of time that they felt that their team is supportive versus resistant to change and moreover, whether those levels were increasing/decreasing/the same as three months ago. The purpose of these questions is to identify the behaviours, values, and attitudes that are exhibited by teams that are effective in supporting the change that they are working on. Because this area is one of the most understudied areas on change teamwork the questions were designed to give the respondent freedom to discuss any dimensions of change that may impact the team's effectiveness. 
The primary objective of Part 4 of the interview script was to determine the effectiveness level of the team. Part 4 contained a four item measure of team performance. The purpose of this quantitative measure was to focus the discussion of the performance of the team. The scoring and analysis of this measure is explained in Chapter 8.4 on data analysis. Following the four item measure of team performance respondents were asked to elaborate on their ratings and explain in greater detail what it was that they felt made the change team successful and what could be done to improve performance. Again, these questions were open ended and intended to give the researcher an opportunity to ask follow-up questions to get to the heart of the issue of change team effectiveness.

The third research objective evolved out of the iterative data collection and data analysis step in the methodology which revealed that team members wanted to talk about how the organization could better support change teams in the future. In Part 4 we asked respondents to describe how their organization could better support their team as agents of change. This objective was further examined in Part 5 of the script where team members were asked to make recommendations on how to make change teams more effective in their organization. Interviewees were asked to specify the most important thing that management could do to support the change team. Team members were also asked to give one piece of advice to someone placed on a change team and to someone who would be managing a change team. These questions were designed to provide some closure to the interview and to provide further insight into the most important factors related to supporting effective change teams. 


\subsubsection{Administration of the Interview}

The T1 interviews were conducted between September 2007 and November 2007. All the T1 interviews were conducted face to face at the STI team's worksite by the primary researcher. The $\mathrm{T} 1$ interviews averaged 30 minutes in duration and were recorded with permission using a handheld digital recorder. The researcher took notes during the interview process and wrote summary notes immediately following the interviews. The recorded interviews were reviewed after each interview to confirm each of the responses and abstract quotations related to the objectives of the research.

The T2 interviews were conducted four months later (between January 2008 and February 2008). Because several of the team members had moved on from the team, some of the T2 interviews had to be done over the telephone. Again the interviews were tape recorded with permission. The researcher again took notes during the interview and summarized the interview notes after the completion of the interview. The recorded interviews were then reviewed to confirm the data and extract useful quotes.

\subsubsection{Quantitative Data}

Yin (2009) explains that mixed methods research allows researchers to "collect a richer and stronger array of evidence than can be accomplished by any one source alone" (p.63). To complement the qualitative data sources in this thesis a change team effectiveness survey was used to obtain data on the effectiveness of the STI change team. This survey is shown in Appendix C. 
The transformational change team survey used for this research is based on the one used by Campion et al. $(1993 ; 1996)$. It should be noted that all measures in the survey made use of a 7 point Likert scale: (1) Strongly Disagree (2) Disagree (3) Somewhat Disagree (4) Nether Agree or Disagree (5) Somewhat Agree (6) Agree (7) Strongly agree. This scale asked the respondent the extent to which they agreed with each statement related to the change team variable being measured. Respondents were allowed to leave the question blank if they didn't know or the statement was not applicable. This format for responses is consistent with the teamwork surveys developed by both Campion et al. (1996) who used a 7 point Likert scale to improve variance compared to the 5 point scale used in 1993. Wageman et al. (2005) also used a 7 point Likert scale to measure their teamwork variables. The survey itself consists of four parts. Details on each are given below.

\subsubsection{Part One: General Information}

The first part of the change team effectiveness survey is the general information section. The purpose of this section is to gather basic information on the team members' department, team, age, gender, and experience with teamwork and transformational change. Information in this section was used to help interpret the survey data. The actual questions used are as outlined in Appendix C. 


\subsubsection{Part Two: Outcomes of Team Effectiveness}

The second section of the survey instrument deals with the outcomes of teamwork. Table $8-2$ provides a complete summary of the team effectiveness measures included in the survey part two.

Table 8-2 Part 2: Team Effectiveness Outcomes

\begin{tabular}{|llcccc} 
Construct & \multicolumn{1}{c}{ Definition } & $\begin{array}{c}\text { Source of } \\
\text { measure }\end{array}$ & $\begin{array}{c}\text { Question } \# \\
\text { in } \Lambda \text { ppendix } \\
\text { C Part 2 }\end{array}$ & $\begin{array}{c}\alpha \\
\text { Interpretation } \\
\text { of High Seore }\end{array}$ \\
\hline $\begin{array}{l}\text { 1. Overall } \\
\text { Satisfaction }\end{array}$ & $\begin{array}{l}\text { Overall satisfaction of team } \\
\text { members with the task, } \\
\text { interpersonal relationships } \\
\text { on the team, and their work } \\
\text { with the customers }\end{array}$ & $\begin{array}{c}\text { Campion et } \\
\text { al. (1996) }\end{array}$ & $1 \mathrm{a}$ & N/A & $\begin{array}{c}\text { Team members } \\
\text { are satisfied } \\
\text { with their team } \\
\text { experience a } \\
\text { whole. }\end{array}$
\end{tabular}

\begin{tabular}{|c|c|c|c|c|c|}
\hline $\begin{array}{l}\text { 2. Satisfaction } \\
\text { with the task }\end{array}$ & $\begin{array}{l}\text { The extent to which team } \\
\text { members find the task } \\
\text { interesting and meaningful }\end{array}$ & $\begin{array}{l}\text { Campion et } \\
\text { al. (1996) }\end{array}$ & $2 \mathrm{a}, 2 \mathrm{~b}, 2 \mathrm{c}$ & N/A & $\begin{array}{l}\text { The team finds } \\
\text { the their task } \\
\text { interesting and } \\
\text { meaningful }\end{array}$ \\
\hline
\end{tabular}

\begin{tabular}{llcccc}
\hline $\begin{array}{l}\text { 3. Satisfaction } \\
\text { with the team }\end{array}$ & $\begin{array}{l}\text { The extent to which team } \\
\text { members are satisfied with } \\
\text { the interpersonal } \\
\text { relationships on the team }\end{array}$ & $\begin{array}{c}\text { Campion et } \\
\text { al. (1996) }\end{array}$ & 3a, 3b, 3c & N/A & $\begin{array}{l}\text { The team is } \\
\text { satisfied with } \\
\text { the way they } \\
\text { work together }\end{array}$
\end{tabular}

\begin{tabular}{|c|c|c|c|c|c|}
\hline $\begin{array}{l}\text { 4. Customer } \\
\text { Satisfaction }\end{array}$ & $\begin{array}{l}\text { The extent to which team } \\
\text { members } \\
\text { are satisfied with their } \\
\text { interaction } \\
\text { with customers }\end{array}$ & $\begin{array}{c}\text { Campion et } \\
\text { al. (1996) }\end{array}$ & $4 a, 4 b, 4 c$ & $\mathrm{~N} / \mathrm{A}$ & $\begin{array}{l}\text { The team is } \\
\text { satisfied with } \\
\text { their interaction } \\
\text { with customers }\end{array}$ \\
\hline
\end{tabular}

\begin{tabular}{|c|c|c|c|c|c|}
\hline $\begin{array}{l}\text { 5. Team } \\
\text { Viability }\end{array}$ & $\begin{array}{l}\text { The ability of the change } \\
\text { team to work together in } \\
\text { the future. }\end{array}$ & $\begin{array}{l}\text { Wagemen et } \\
\text { al. (2005) } \\
\qquad \& \\
\text { Campion et } \\
\text { al. (1996) }\end{array}$ & $5 a, 5 b, 5 c$ & N/A & $\begin{array}{c}\text { The team feels } \\
\text { that they could } \\
\text { work together } \\
\text { well on future } \\
\text { projects }\end{array}$ \\
\hline
\end{tabular}


The table presents the construct definition, the source (supporting research) of the measure, the number of items in the measure, the questions in the survey (Appendix C) that make up the measure, the reliability of the measure (where available), and finally a brief description of the interpretation of a high score on each construct.

Each of the measures of team effectiveness included in this section was developed by either Campion et al. $(1993 ; 1996)$ or Wageman et al. (2005). The team viability measure is not explicitly represented in the Campion et al. $(1993 ; 1996)$ model of team effectiveness. However, it represents a trend in team effectiveness research from the 1980s and is represented in the recent work of Wageman et al. (2005) on developing a team effectiveness survey. In a major transformational change environment where change teams are required to sustain their effectiveness over several tasks and an extended period of time, team viability strengthens our conceptualization of change team effectiveness.

\subsubsection{Part Three: Impacts of Organizational Change}

The third part of the team member survey (Appendix C) examines the impact of the change on the individual team members. Unlike the other sections of the survey, this part of the questionnaire includes items that were not used in the team effectiveness model of Campion et al. (1996). The four measures included in part three of the survey are: workload, job stress, support for the change, and resistance to the change. Table 8-3 provides a complete summary of the constructs that are measured in the survey part three. The table presents the construct definition, the source (supporting research) of the measure, the number of items in the measure, the questions in the survey (Appendix C) make up the measure, the reliability of the measure as reported by the authors (where 
available), and finally a brief description of the interpretation of a high score on each construct. Details on each construct are given below.

Table 8-3 Dimensions of Change - Summary

\begin{tabular}{|llcccc} 
Construct & Definition & $\begin{array}{c}\text { Source of } \\
\text { measure }\end{array}$ & $\begin{array}{c}\text { Question \# in } \\
\text { Appendix } \\
\text { Part } 3\end{array}$ & $\begin{array}{c}\alpha \\
\text { Interpretation } \\
\text { of High Seore }\end{array}$ \\
1. Workload & $\begin{array}{l}\text { The perceived level of } \\
\text { workload of members of } \\
\text { the team }\end{array}$ & $\begin{array}{c}\text { Bohen \& } \\
\text { Viveros- } \\
\text { Long (1981) }\end{array}$ & $\begin{array}{c}\text { la, 1b, 1c, } \\
1 \mathrm{~d}, 1 \mathrm{e}, 1 \mathrm{f}\end{array}$ & 0.88 & $\begin{array}{c}\text { Individual team } \\
\text { members are } \\
\text { experiencing } \\
\text { high levels of } \\
\text { workload. }\end{array}$ \\
\end{tabular}

\begin{tabular}{llcccc}
\hline 2. Job Stress & $\begin{array}{l}\text { The level of job stress } \\
\text { experienced by the }\end{array}$ & Rizzo et al. & 2a, 2b, 2c, & 0.85 & $\begin{array}{c}\text { Individual team } \\
\text { members are } \\
\text { individual change team }\end{array}$ \\
$\begin{array}{l}\text { members } \\
\text { experiencing }\end{array}$ & 2d, 2e & & $\begin{array}{c}\text { high levels of } \\
\text { job stress }\end{array}$
\end{tabular}

\begin{tabular}{llcccc}
\hline $\begin{array}{l}\text { 3. Support for } \\
\text { change }\end{array}$ & $\begin{array}{l}\text { Refers to both active and } \\
\text { passive supporting } \\
\text { behaviours exhibited by } \\
\text { team members that help to } \\
\text { implement change. of } \\
\text { change. }\end{array}$ & $\begin{array}{c}\text { Herscovitch } \\
\text { \& Meyer } \\
(2001)\end{array}$ & $\begin{array}{c}3 \mathrm{~g}, 3 \mathrm{~h}, 3 \mathrm{i}, 3 \mathrm{j}, \\
3 \mathrm{k}, 3 \mathrm{l}\end{array}$ & $\begin{array}{c}\text { Active } \\
(0.90)\end{array}$ & $\begin{array}{c}\text { Team members } \\
\text { are supportive of } \\
\text { the change }\end{array}$ \\
& & & $\begin{array}{c}\text { Passive } \\
(0.71)\end{array}$ & \\
\hline $\begin{array}{l}\text { 4. Resistance to } \\
\text { Change }\end{array}$ & $\begin{array}{l}\text { Refers to both the active } \\
\text { and passive behaviours } \\
\text { exhibited by team members } \\
\text { that stall or prevents the } \\
\text { implementation of change }\end{array}$ & $\begin{array}{c}\text { Herscovitch } \\
\& \text { Meyer } \\
(2001)\end{array}$ & $3 \mathrm{ab}, 3 \mathrm{~b}, 3 \mathrm{c}, 3, \mathrm{e}, 3 \mathrm{f}$ & $\begin{array}{c}\text { Active } \\
(0.88)\end{array}$ & Team members \\
resist the change
\end{tabular}

Workload: The first impact of change measure is team workload which quantifies the perceived level of workload of members of the team. The survey questions for this 
variable are based on the role overload scale developed by Bohen and Viveros-Long (1981). This scale was modified to include an additional question on workload related to change. Bohen and Viveros-Long (1981) reported a Cronbach alpha of 0.88 indicating that the five item scale is consistent and converges on a measure of role overload for the individual team members.

Job Stress: The second impact of change construct is the level of job stress experienced by the individual change team members. Membership on a change team provides a unique experience for individuals and job stress measures an important feature of that experience. The measure used in this study is based on a five item scale that was adopted from Rizzo et al. (1970). Murphy (2000) has reported a Cronbach alpha of 0.85 using Rizzo et al.'s (1970) scale indicating that the measure is reliable.

Support for Change and Resistance to Change: Section three also includes measures of both support for change and resistance to change. The support and resistance measures in the survey are based on the work by Herscovitch and Meyer's (2001) on commitment to organizational change. The resistance to change measure consists of six items relating to both active and passive support for change. Orth (2002) reported chronblach alpha's of .85 for both the active resistance and .88 for passive resistance questions in the measure (as is shown in Table 9-3). Similar to resistance, there are six items in part three that measure both passive and active support for change. The support for change scales had an internal consistency reliability of .90 for active support and .71 for passive support (Orth, 2002). 


\subsubsection{Part Four: Characteristics of Effective Teams}

The fourth and final section of the team member survey (Appendix C) includes measures of the five themes that Campion et al. $(1993$; 1996) related to team effectiveness in an organizational setting: task design, interdependence, composition, context, and process. In each of the tables in this sub section, unless it is stated otherwise the reliability is reported as it was calculated by Campion et al. (1993; 1996). Tables 8-4 to 8-8 provide a complete overview of how each of the themes were measured part 4 of the survey (see Appendix C). The focus of this discussion is on how these measures were adapted to make them more relevant to a team working on transformational change.

\section{Task Design Theme}

The first team effectiveness theme in the survey is the task design theme. This theme was operationalized using measures of task direction, task identity, self management, participation, task variety, and task significance variables. Table 9-4 provides a complete summary of the constructs that are measured in the survey part 4 task design theme. 
Table 8-4 Part 4: Characteristics of Change Teams (Task Design)

\begin{tabular}{|clcccc} 
Construct & \multicolumn{1}{c}{ Definition } & $\begin{array}{c}\text { Source of } \\
\text { measure }\end{array}$ & $\begin{array}{c}\text { Question } \# \\
\text { in } \\
\text { Appendix } \\
\text { C Part } 4\end{array}$ & $\alpha$ & $\begin{array}{c}\text { Interpretation of } \\
\text { High Score }\end{array}$ \\
\hline 1. Task Direction & $\begin{array}{l}\text { The purpose and goals of } \\
\text { the team }\end{array}$ & $\begin{array}{c}\text { Wageman et } \\
\text { al. (2005) }\end{array}$ & 1a, 1b & N/A & $\begin{array}{l}\text { The team has clear } \\
\text { purpose and goals }\end{array}$ \\
\hline
\end{tabular}

\begin{tabular}{llcccc}
\hline 2. Task Identity & $\begin{array}{l}\text { The degree to which the } \\
\text { team completes a whole, } \\
\text { identifiable, and separate } \\
\text { piece of work in the } \\
\text { organization }\end{array}$ & $\begin{array}{c}\text { Campion et al. } \\
\text { (1996) }\end{array}$ & $2 \mathrm{a}, 2 \mathrm{~b}, 2 \mathrm{c}$ & 0.71 & $\begin{array}{c}\text { The team works on an } \\
\text { identifiable task }\end{array}$ \\
\hline $\begin{array}{l}\text { 3. Self- } \\
\text { Management }\end{array}$ & $\begin{array}{l}\text { The level of autonomy or } \\
\text { self management that the } \\
\text { team operates with }\end{array}$ & $\begin{array}{c}\text { Campion et al. } \\
(1996)\end{array}$ & $3 \mathrm{a}, 3 \mathrm{~b}, 3 \mathrm{c}$ & 0.84 & $\begin{array}{l}\text { The team has a high } \\
\text { level of autonomy in } \\
\text { their work }\end{array}$
\end{tabular}

\begin{tabular}{llccc}
\hline 4. Task Variety & $\begin{array}{l}\text { The degree to which the team Campion et al. } \\
\text { allows each member to perfol } \\
\text { each of the team's tasks. }\end{array}$ & $\begin{array}{ll}\text { (1996) } 5 \mathrm{~b}, 5 \mathrm{c} \\
\text { each }\end{array}$ & 0.80 & $\begin{array}{c}\text { The team provides a } \\
\text { variety of tasks for } \\
\text { team members to } \\
\text { perform }\end{array}$
\end{tabular}

\begin{tabular}{llcccc}
\hline $\begin{array}{l}\text { 5. Task } \\
\text { Significance }\end{array}$ & $\begin{array}{l}\text { The belief that the team's tasl } \\
\text { has significant consequences } \\
\text { the organization }\end{array}$ & $\begin{array}{c}\text { (1996) } \\
\text { the al. }\end{array}$ & $\begin{array}{c}6 \mathrm{a}, 6 \mathrm{~b}, 6 \mathrm{c}, \\
6 \mathrm{~d}^{*}\end{array}$ & 0.81 & $\begin{array}{c}\text { The team views their } \\
\text { task as meaningful and } \\
\text { significant }\end{array}$
\end{tabular}

\begin{tabular}{llcccc}
\hline 4. Participation & $\begin{array}{l}\text { The degree to which all } \\
\text { members are allowed to } \\
\text { participate in team } \\
\text { decisions }\end{array}$ & $\begin{array}{c}\text { Campion et al. } \\
(1996)\end{array}$ & $4 \mathrm{a}, 4 \mathrm{~b}, 4 \mathrm{c}$ & 0.89 & $\begin{array}{c}\text { The team has a } \\
\text { balanced participation } \\
\text { from team members on } \\
\text { decisions that impact } \\
\text { the team. }\end{array}$
\end{tabular}

In the task design section there are three areas in which the survey differs from that used by Campion et al. $(1994 ; 1996)$. Fist, the task direction construct is based on the work of Wageman et al. (2005) and refers to the purpose and goals of the team. The measure was simplified to reflect the importance of having a clearly defined task for an 
organizational change team. Second, while Campion et al. (1996) removed the task identity construct from the 1996 study, it is retained in this study due to the potential importance that a clearly identifiable task may have in the ambiguous and uncertain change environment. Finally, Campion's measure of task significance was augmented by the addition of one additional item to make the measure more specific to the change team setting. This addition helped to take into account the importance of a team feeling that their task is significant to the overall success of the change effort. This additional item is starred $(*)$ in Appendix C.

\section{Team Interdependence}

The next section of the survey (Appendix C) measured the level of team interdependence.

Table 8-5 Part 4: Characteristics of Change Teams (Interdependence) - Summary

\begin{tabular}{|c|c|c|c|c|c|}
\hline Construct & Definition & $\begin{array}{l}\text { Source of } \\
\text { measure }\end{array}$ & $\begin{array}{l}\text { Question \# in } \\
\text { Appendix C } \\
\text { Part } 4\end{array}$ & $\alpha$ & $\begin{array}{c}\text { Interpretation of } \\
\text { High Score }\end{array}$ \\
\hline $\begin{array}{l}\text { 7. Task } \\
\text { Interdependence }\end{array}$ & $\begin{array}{l}\text { The degree to which } \\
\text { team members must } \\
\text { interact with one } \\
\text { another to accomplish } \\
\text { their task }\end{array}$ & $\begin{array}{c}\text { Campion et } \\
\text { al. (1996) }\end{array}$ & $7 \mathrm{a}, 7 \mathrm{~b}, 7 \mathrm{c}, 7 \mathrm{~d}$ & 0.70 & $\begin{array}{l}\text { The team has a high } \\
\text { level of interaction } \\
\text { required to } \\
\text { complete their task }\end{array}$ \\
\hline $\begin{array}{l}\text { 8. Goal } \\
\text { Interdependence }\end{array}$ & $\begin{array}{l}\text { The degree to which } \\
\text { individual and team } \\
\text { goals are linked }\end{array}$ & $\begin{array}{l}\text { Campion et } \\
\text { al. (1996) }\end{array}$ & $8 a, 8 b, 8 c$ & 0.70 & $\begin{array}{c}\text { The team and } \\
\text { individual goals are } \\
\text { interdependent }\end{array}$ \\
\hline
\end{tabular}

\begin{tabular}{|c|c|c|c|c|c|}
\hline $\begin{array}{l}\text { 9. Feedback } \\
\text { Interdependence }\end{array}$ & $\begin{array}{l}\text { The degree to which } \\
\text { feedback and rewards } \\
\text { are linked to the team's } \\
\text { performance }\end{array}$ & $\begin{array}{c}\text { Campion et } \\
\text { al. (1996) }\end{array}$ & $9 a, 9 b, 9 c$ & 0.71 & $\begin{array}{c}\text { The team receives } \\
\text { feedback based on } \\
\text { the team's } \\
\text { performance }\end{array}$ \\
\hline
\end{tabular}


This section of the survey is based on the work of Campion et al. $(1993 ; 1996)$ and was measured by Campion's task, goal, and reward interdependence scales. Table 8-5 provides a complete overview of the three team interdependence constructs found in the survey. The Cronbach alpha data for all these measures were calculated by Campion et al. (1996) and indicate that these scales are a reliable measure of team independence.

\section{Team Composition}

Team composition is quantified in this study using three measures developed by

Table 8-6 Part 4: Characteristics of Change Teams (Composition) - Summary

\begin{tabular}{|c|c|c|c|c|c|}
\hline Construct & Definition & $\begin{array}{l}\text { Source of } \\
\text { measure }\end{array}$ & $\begin{array}{l}\text { Question \# in } \\
\text { Appendix C } \\
\text { Part } 4\end{array}$ & $\alpha$ & $\begin{array}{l}\text { Interpretation of } \\
\text { High Score }\end{array}$ \\
\hline $\begin{array}{l}\text { 10. Bounded } \\
\text { Membership }\end{array}$ & $\begin{array}{l}\text { The degree to which } \\
\text { team membership is } \\
\text { identifiable in the } \\
\text { organization }\end{array}$ & $\begin{array}{l}\text { Wagemen et } \\
\text { al. (2005) }\end{array}$ & $10 \mathrm{a}, 10 \mathrm{~b}$ & N/A & $\begin{array}{l}\text { The team is } \\
\text { recognizable as a } \\
\text { distinct unit in the } \\
\text { organization }\end{array}$ \\
\hline 11. Heterogeneity & $\begin{array}{l}\text { The mix of } \\
\text { talents/skills/ } \\
\text { experience on the } \\
\text { team }\end{array}$ & $\begin{array}{l}\text { Campion et } \\
\text { al. (1996) }\end{array}$ & $11 \mathrm{a}, 11 \mathrm{~b}, 11 \mathrm{c}$ & 0.71 & $\begin{array}{l}\text { The team has an } \\
\text { adequate mix of } \\
\text { skills/talents and } \\
\text { experience to } \\
\text { complete the task }\end{array}$ \\
\hline 12. Flexibility & $\begin{array}{l}\text { The extent to which } \\
\text { team members are } \\
\text { flexible enough to } \\
\text { perform each others } \\
\text { tasks as needed }\end{array}$ & $\begin{array}{l}\text { Campion et } \\
\text { al. (1996) }\end{array}$ & $12 \mathrm{a}, 12 \mathrm{~b}, 12 \mathrm{c}$ & 0.85 & $\begin{array}{l}\text { The team is able to } \\
\text { adjust roles to fit } \\
\text { the demands of the } \\
\text { task }\end{array}$ \\
\hline 13. Relative Size & $\begin{array}{l}\text { The number of team } \\
\text { members relative to } \\
\text { the amount of work } \\
\text { required }\end{array}$ & $\begin{array}{l}\text { Campion et } \\
\text { al. (1996) }\end{array}$ & $13 a, 13 b$ & N/A & $\begin{array}{l}\text { The team has an } \\
\text { adequate number of } \\
\text { members to } \\
\text { perform their task }\end{array}$ \\
\hline
\end{tabular}


Campion et al. (1993) (heterogeneity of the team, team flexibility, and relative size), and one measure developed by Wageman et al. (2005) (bounded membership). As shown in Table 8-6, all these measures have good reliability.

The bounded membership variable is taken from the work of Wageman et al. (2005) and added to the framework because of its applicability to the challenges faced by change teams with relation to maintaining an identifiable membership. The internal consistency rating is low for this measure; however, Streiner and Norman (1989) explain that many scales have a high reliability rating simply because they have several items. In the case of the bounded membership measure, there are only two items in the measure and this may explain the low score. The two items both appear to be measuring how identifiable team membership is (high face validity) and therefore the measure was selected for use in the survey.

\section{$\underline{\text { Team Context }}$}

As shown in Table 8-7, three measures were used to quantify the team context theme: training, support, and communication/cooperation between teams. All the scales have acceptable reliability. 
Table 8-7 Part 4: Characteristics of Change Teams (Context) - Summary

\begin{tabular}{|c|c|c|c|c|c|}
\hline Construct & Definition & $\begin{array}{l}\text { Source of } \\
\text { measure }\end{array}$ & $\begin{array}{l}\text { Question \# in } \\
\text { Appendix C } \\
\text { Part } 4\end{array}$ & $\alpha$ & $\begin{array}{l}\text { Interpretation of } \\
\text { High Score }\end{array}$ \\
\hline 15. Training & $\begin{array}{l}\text { The level of training } \\
\text { received by the team } \\
\text { members related to } \\
\text { the task }\end{array}$ & $\begin{array}{l}\text { Campion } \\
\text { et al. } \\
(1996)\end{array}$ & $15 a, 15 b, 15 c$ & 0.81 & $\begin{array}{l}\text { The team receives } \\
\text { adequate training to } \\
\text { complete their task }\end{array}$ \\
\hline $\begin{array}{l}\text { 16. Managerial } \\
\text { Support }\end{array}$ & $\begin{array}{l}\text { The level of } \\
\text { management } \\
\text { controlled resources } \\
\text { (materials, } \\
\text { information) made } \\
\text { available to the team }\end{array}$ & $\begin{array}{l}\text { Campion } \\
\text { et al. } \\
\text { (1996) }\end{array}$ & $16 \mathrm{a}, 16 \mathrm{~b}, 16 \mathrm{c}$ & 0.90 & $\begin{array}{l}\text { The team receives } \\
\text { adequate } \\
\text { managerial support } \\
\text { for their work }\end{array}$ \\
\hline $\begin{array}{l}\text { 17. Communication/ } \\
\text { Cooperation between } \\
\text { teams }\end{array}$ & $\begin{array}{l}\text { The degree to which } \\
\text { teams communicate } \\
\text { and cooperate with } \\
\text { other groups within } \\
\text { the organization to } \\
\text { help achieve their } \\
\text { goals }\end{array}$ & $\begin{array}{l}\text { Campion } \\
\text { et al. } \\
(1996)\end{array}$ & $17 \mathrm{a}, 17 \mathrm{~b}, 17 \mathrm{c}$ & 0.75 & $\begin{array}{l}\text { The team uses other } \\
\text { teams to help } \\
\text { complete their work }\end{array}$ \\
\hline
\end{tabular}

\section{$\underline{\text { Team Process }}$}

As shown in Table $8-8$ four measures were used to quantify the team process theme in this research: potency, social support, workload sharing, and communication/cooperation within the team. All but one of the measures (team potency) are identical to those used by Campion et al. (1993; 1996). All the scales have acceptable reliability. 
Table 8-8 Part 4: Characteristics of Change Teams (Process) - Summary

\begin{tabular}{|c|c|c|c|c|c|}
\hline Construct & Defïnition & $\begin{array}{l}\text { Source of } \\
\text { measure }\end{array}$ & $\begin{array}{l}\text { Question \# in } \\
\text { Appendix C } \\
\text { Part 4 }\end{array}$ & $\alpha$ & $\begin{array}{l}\text { Interpretation of } \\
\text { High Score }\end{array}$ \\
\hline 18. Potency & $\begin{array}{l}\text { The team's belief that it } \\
\text { is capable of being } \\
\text { effective in their task }\end{array}$ & $\begin{array}{l}\text { Wagemen } \\
\text { et al. } \\
(2005)\end{array}$ & $18 \mathrm{a}, 18 \mathrm{~b}, 18 \mathrm{c}$ & 0.83 & $\begin{array}{l}\text { The team believes } \\
\text { that it can be } \\
\text { effective }\end{array}$ \\
\hline 19. Social Support & $\begin{array}{l}\text { The extent to which team } \\
\text { members help each other } \\
\text { and have positive social } \\
\text { interactions }\end{array}$ & $\begin{array}{l}\text { Campion } \\
\text { et al. } \\
\text { (1996) }\end{array}$ & $19 a, 19 b, 19 c$ & 0.87 & $\begin{array}{l}\text { Team members } \\
\text { support one another }\end{array}$ \\
\hline $\begin{array}{l}\text { 20. Workload } \\
\text { Sharing }\end{array}$ & $\begin{array}{l}\text { The extent to which team } \\
\text { members are willing to } \\
\text { accept and share each } \\
\text { others work in order to } \\
\text { achieve the team's goals }\end{array}$ & $\begin{array}{l}\text { Campion } \\
\text { et al. } \\
(1996)\end{array}$ & $20 \mathrm{a}, 20 \mathrm{~b}, 20 \mathrm{c}$ & 0.92 & $\begin{array}{l}\text { The team does a } \\
\text { good job of sharing } \\
\text { work as required }\end{array}$ \\
\hline $\begin{array}{l}\text { 21. Communication } \\
\text { /Cooperation within } \\
\text { groups }\end{array}$ & $\begin{array}{l}\text { The degree to which } \\
\text { team members } \\
\text { communicate and } \\
\text { cooperate with each } \\
\text { other to achieve their } \\
\text { goals }\end{array}$ & $\begin{array}{l}\text { Campion } \\
\text { et al. } \\
\text { (1996) }\end{array}$ & $21 \mathrm{a}, 21 \mathrm{~b}, 21 \mathrm{c}$ & 0.87 & $\begin{array}{c}\text { The team } \\
\text { communicates and } \\
\text { coordinates work } \\
\text { well }\end{array}$ \\
\hline
\end{tabular}

Wagemen's measure of team potency was included in the measure of team process because it has been found to be an important factor in team performance (Wagemen et al., 2005).

\subsubsection{Administration of the Questionnaire}

The twelve STI team members who were interviewed at T1 were also asked to fill out the online change team effectiveness survey. Respondents were given a web address, login, and password and instructed to complete the survey within 1-2 weeks if possible. Upon completion each survey was tagged with a survey ID and each team member's 
survey response set was downloaded and stored by the researcher. The survey records were kept in confidence for the duration of the study. Those who did not complete the survey were sent email reminders each week after the deadline. This same process was followed for both $\mathrm{T} 1$ and $\mathrm{T} 2$. All team members provided $\mathrm{T} 1$ and $\mathrm{T} 2$ survey data.

\subsection{DATA ANALYSIS}

The grounded theory approach begins with an initiating framework which evolves throughout the case study as a result of the constant comparison technique outlined in Section 7.2. This section presents the data analysis techniques which make up an important part of theory development for case studies. The data analysis process outlined in this section is based on the work of Miles and Huberman (1984) and is presented in this section. Although our discussion of how the data for this thesis has been analyzed is presented sequentially, it should be noted that data analysis began with the first case and continued until the theoretical contributions of the data had been exhausted.

\subsubsection{Analyzing the Qualitative Data}

According to Yin (1994), interviews are essential sources of rich information for case study researchers. The current research followed the three stage qualitative analysis method proposed by Miles and Huberman (1984). The first stage of the qualitative analysis method according to Miles and Huberman (1984) is the data reduction stage. According to these authors, data reduction refers to the process of concurrently selecting, simplifying, abstracting, and transforming the interview data. For the current research the 
process of reduction involved listening to the interview tapes, reviewing field notes, and dividing the data into meaningful 'bins' which were used to identify the key constructs that are the topic of discussion in part seven of this thesis. For each question the interviewer developed categories for responses to the questions based on patterns and linkages in the responses. Miles and Huberman (1984) suggest that researchers may create coding patterns initially based on the conceptual framework for the research and then develop the coding categories to represent patterns or repeatable regularities in the data. The current research strategy was to use the basic framework to orient the coding scheme and to allow the data to drive most of the development of the coding scheme.

\subsubsection{The Coding Scheme}

The coding of data in grounded theory is analysis (Eisenhardt, 1989). The researcher begins with the first interviews and attempts to assign conceptual meaning to the descriptive information collected in the interviews. From the first interview the coding scheme began to evolve and patterns began to emerge resulting in the formation of categories as suggested by the data. After the interviews with the functional group leaders an initial coding scheme began to form. For the interviews with each team member the responses to the interview questions were compared to the initial coding scheme. If the responses matched the existing scheme it was coded similarly, if the response was unique then an additional category was created to reflect the observation. The first two versions of the coding scheme were quite open to be sure to retain the maximum amount of information from the data. 
The final version of the $\mathrm{T} 1$ coding scheme was used as the starting point for analyzing and coding the T2 interview data. Again, the coding scheme evolved with each additional T2 interview and the resulting coding scheme (version 3) was large with each question having several categories. A fourth version of the coding scheme was completed by examining the coding scheme after all of the interviews were completed and coded using coding scheme 3 . The data was examined for patterns and conceptual meaning and the coding categories were refined to better reflect the key concepts being suggested by the data. In total, the coding of the data went through four major revisions. The data from the STI team interviews drove the process of coding scheme development (Eisenhardt, 1989) and care was take to ensure that the resulting coding schemes had some conceptual or structural order, and were linked to the objectives of the research (Cepeda \& Martin, 2003).

\subsubsection{Qualitative Data Displays}

The second step taken in the data analysis process was to organize the data into meaningful data displays. Data displays are described as "a visual format that presents information systematically, so the user can draw valid conclusions and take the needed actions (Miles \& Huberman, 1994, p. 91). The objective of the data displays used in this case study was to provide a better view of the full data set in single display aimed at answering the research questions at hand. These data displays were designed to assist the researcher to observe the relationships between variables and begin to develop initial theory to explain change team effectiveness. The data displays also helped the researcher 
to compare results across cases and confirm the validity of the relationships that have been observed.

To organize and track the data, an excel spreadsheet was created to allow for easy access to frequency counts. A computer record for each respondent was created and the responses to the qualitative interview questions were coded and entered into their respective rows in the spreadsheet. From this spreadsheet the researcher then examined the counts for each set of coded responses and further refined the categories and coding scheme to reflect the data. The purpose of these counts was not to estimate incidence in the larger population (Sigglekow, 2007) but rather reduce the likelihood that the researcher's own personal biases would guide the development of the categories for the coding scheme.

The frequency counts described above allowed the researcher to easily compare and contrast the different categories on each question and observe the patterns being suggested by the data. The displays used for the current research are mostly descriptive frequency charts with both $\mathrm{T} 1$ and $\mathrm{T} 2$ counts displayed for analysis to allow for comparison of the responses over time. A typical frequency display used in this analysis is shown below in Table 8-9. 
Table 8-9 Sample Qualitative Data Display

Strengths of an effective change team

Time 1

Time 2

Research Question: What behaviours and values make your change team effective?

\section{$\mathrm{N}=12$}

$\mathrm{N}=12$

\begin{tabular}{l}
\hline Change Management \\
\hline Building Commitment \\
\hline $\begin{array}{l}\text { Engage others outside } \\
\text { the team }\end{array}$ \\
\hline $\begin{array}{l}\text { Developed a Change } \\
\text { Methodology }\end{array}$
\end{tabular}

Developing
Documentation

\begin{tabular}{|c|c|c|c|c|c|}
\hline & Total \# of Responses & 15 & $65 \%$ & 13 & $48 \%$ \\
\hline Team Management & & 7 & $58 \%$ & 11 & $92 \%$ \\
\hline $\begin{array}{l}\text { Disciplined and } \\
\text { professional in our } \\
\text { project management }\end{array}$ & $\begin{array}{l}\text { Very flexible and supportive, very } \\
\text { professional, followed PM principles }\end{array}$ & 5 & $42 \%$ & 5 & $42 \%$ \\
\hline $\begin{array}{l}\text { Excellent Team } \\
\text { Collaboration }\end{array}$ & $\begin{array}{l}\text { Open and sharing with information/ } \\
\text { have great ideas/ Excellent } \\
\text { collaboration around problem } \\
\text { solving }\end{array}$ & 4 & $33 \%$ & 5 & $42 \%$ \\
\hline Quality Leadership & We have very good leadership & 1 & $8 \%$ & 0 & $0 \%$ \\
\hline \multirow[t]{2}{*}{ Clarified the task } & $\begin{array}{l}\text { created clear priorities / Simplified } \\
\text { the task }\end{array}$ & 0 & $0 \%$ & 4 & $33 \%$ \\
\hline & Total \# of Responses & 10 & $35 \%$ & 14 & $52 \%$ \\
\hline
\end{tabular}

Starting from the top of the data display in Table 8-9, each qualitative display begins with the title of the table which describes the variable or research question being displayed. The next row presents the research question or description of the summary variable being 
used in the table. In all cases, the first step of the analysis involved the categorization of responses into the two main themes being explored in this thesis: change management (i.e. the response is specific to teams working on change) and team management (i.e. the response applies to all types of teams, not just change teams).

The first theme described in the table is the change management theme. In the primary change management row the total number of team members who gave a response related to change management are listed along with the percentage. These numbers are provided for both $\mathrm{T} 1$ and $\mathrm{T} 2$. The rows underneath the change management theme list the specific categories of responses which belong to the change management them. These categories are listed in descending order with the frequency with which they were mentioned. Again, the total number of team members and the percentage of the sample who gave a response in each category are provided. Finally, the last row in the under the change management theme shows the total number of responses provided by all team members and the associated percentage of responses. This was done because team members were encouraged to give multiple responses to questions. The last row was put in the data display to allow us to compare the relative frequency with which respondents talked about change versus team management.

The team management theme makes up the second half of the data display and is reported in exactly the same manner as the change management described above. 


\subsubsection{Analyzing the Quantitative Data}

The mixed-method case study format used in this thesis research offers an opportunity to examine change team effectiveness from a rich data set that combines both quantitative and qualitative observations (Eisenhardt, 1989). The primary goal of combining the quantitative and qualitative data sets was to provide a more robust analysis of the dimensions of change as potential moderating variable in the change team effectiveness model. According to Kaplan et al. (1988), combining qualitative and quantitative data sets for analysis can help to improve both testability and context in the research outcomes. Jick (1979) supports Kaplan et al.'s (1988) position and adds that mixed-method analysis can allow the researcher to effectively use triangulation to improve the accuracy of their results. Jick (1979) describes triangulation as a combination of methods that examine the same phenomenon. In the case of the current research, the variables related to the dimensions of organizational change posed a unique challenge because they had yet to be examined in the context of change team effectiveness. By cross validating the findings from the quantitative data (survey), the qualitative data (interviews) and the literature it allowed the researcher to more thoroughly evaluate the impact of these variables in the change team effectiveness framework.

While there is some overlap between the interview and the survey instruments with respect to measurement of our constructs, there are some variables that are unique to each research tool. As discussed in Section 8.3.2 the change team effectiveness survey provided data on demographic information, team satisfaction, team viability, the 
dimensions of change, and on the five team effectiveness themes based on the work of Campion et al. (1996).

The dimensions of change variables were examined in both the survey and the interview to improve the researchers understanding of the impact of the three change dimensions on team effectiveness. The interview data gave respondents an opportunity to go into greater detail about the issues that are unique to change teams and the survey data allowed a more objective assessment of the impact of change on the areas of importance identified from our literature review (ie. stress, workload, support and resistance for change). Having two sources of data also allows us to triangulate our findings and enhanced the validity of the analysis.

The quantitative data from the survey represents a significant portion of the data used to examine the change teams in the study. This subsection discusses the strategy used to organize and display the individual survey data for each change team member.

\subsubsection{Quantitative Displays}

The primary role of the quantitative data set collected for this research was to support any emergent concepts that would come out of the interview data. It was important to have an objective measure of the three team effectiveness variables. Consequently, our measure of team effectiveness came from the survey. Table 8-10 illustrates the typical style of data display used in the results section of the thesis. The frequency table shown below shows the frequency of responses for all STI team members at $\mathrm{T} 1$ and $\mathrm{T} 2$. 
Table 8-10 Sample Quantitative Data Display

\begin{tabular}{|c|c|c|c|c|}
\hline \multicolumn{5}{|l|}{ Viability } \\
\hline \multirow[t]{2}{*}{$\begin{array}{l}\text { Q. This team has the ability to work together } \\
\text { effectively in the future }\end{array}$} & \multicolumn{2}{|c|}{$\begin{array}{l}\text { Time } 1 \\
\mathrm{~N}=12\end{array}$} & \multicolumn{2}{|c|}{$\begin{array}{l}\text { Time } 2 \\
\mathrm{~N}=12\end{array}$} \\
\hline & $\mathrm{N}$ & $\%$ & $\mathrm{~N}$ & $\%$ \\
\hline Agree & 2 & $17 \%$ & $\overline{9}$ & $75 \%$ \\
\hline Neutral & 10 & $83 \%$ & 3 & $25 \%$ \\
\hline Disagree & 0 & $0 \%$ & 0 & $0 \%$ \\
\hline
\end{tabular}

The challenge of organizing and displaying this survey data in a manner that supported the qualitative data in the case study was an important research task for this study. In accordance with the suggestion of Yin (2003) the quantitative data was not aggregated across means but rather kept separate for each team member. Each individual team member had their own survey results recorded on their record along with their coded results from the interviews. This means that each change team member had all of their results on the $\mathrm{T} 1$ and $\mathrm{T} 2$ change team effectiveness surveys entered into excel and SPSS for analysis. For single item measures, the individual scores were recorded according to the respondent's selection on the item. For multi-item measures the individual score is the summed average of the items included in the measure of the constructs.

The responses of the change team members were grouped into three categories to allow for a simplified display and easier analysis of the data. Scores of 6 and 7 were grouped together in the agree category, scores of 3,4 , and 5 were grouped together as neutral responses, and scores of 1 and 2 were grouped together as disagreement. This display allows for a complete view of the team members' responses on any survey 
question. The use of each team member's responses and not group means is consistent with the case study methodology used for this research.

\subsection{DATA INTERPRETATION}

The interpretation of data in a case study represents a critical challenge for the researcher (Yin, 2009). With an abundance of qualitative and quantitative data at their finger tips the researcher must determine what constitutes a pattern and which patterns are salient to the emergent theory being considered. The longitudinal nature of the current thesis research provided an additional challenge when interpreting the changes in patterns between $\mathrm{T} 1$ and $\mathrm{T} 2$ in the study. Unlike hypothesis testing, there is no statistical test to determine the difference between a significant result and an insignificant one (Sigglekow, 2007). Instead, using the grounded theory case study methodology, we followed the steps to collect, analyze, and display the data in a manner that allowed us to make a responsible judgment on which data should be considered substantially significant and which data do not contribute to the emergent theory. The first part of this subsection discusses the interpretation of both the qualitative and quantitative data displays used for this research. The second part of this subsection discusses the interpretation of the longitudinal results of the case study.

\subsubsection{Interpretation Guidelines}

As a starting point for interpretation the researcher must consider each result in relation to the research objectives and research framework (Eisenhardt, 1989). In the 
results section of this thesis the data are divided into frequency counts and data displays as described in chapter 9.4. These data displays allowed us to see patterns and identify the emergent constructs that were salient to the research objectives of this thesis. In order to allow for more objective and systematic interpretation of the results it was necessary to establish a criterion for determining how substantive significance will be interpreted as for the purpose of this study (Yin, 2009). For example, is a $10 \%$ difference between two categories meaningful or not? The literature on the case study methodology suggests that there is no generally accepted measure for interpreting substantive significance in a case study (Miles \& Huberman, 1994; Yin, 2009). Instead, researchers are encouraged to avoid being trapped into quantitative methods of analysis when exploring the case study data. One of the main strengths of qualitative research is the rich data set that can be used to describe phenomena and researchers should employ a strategy for interpretation that allows them the flexibility to explore the entire data set. This approach is consistent with the grounded theory technique which suggests that substantive significance should be judged by whether data appear to be related to the emergent constructs and research framework.

For the purpose of this research the frequency counts for the qualitative data are listed in descending order within their two main categories: teamwork and change management. The substantive significance of the patterns interpreted from these data is predominantly determined by the relative ordering of the frequency counts rather than differences between the counts. The important factor within each time period is the direction of the difference (ie. increased or decreased over time) between response categories and not the magnitude of the difference (Patton, 2002). The perceived 
relevance of the patterns to the research framework is also a critical factor in determining which patterns are salient to the emergent theory. This approach is consistent with the grounded theory case study approach and allows the researcher to explore patterns that do not statistically stand out but may contribute to the emergent theory.

The final step in Miles and Huberman's (1984) analysis method is to draw conclusions from the systematically analyzed data displays and apply them to the theoretical model under consideration. The conclusions drawn from this research are not meant to be applied to a larger population but rather to contribute to the development of a testable theory of change teamwork. The process of qualitative analysis begins with a theoretical model and ends with a return to that model to attempt to develop a testable and valid model of change teamwork.

\subsubsection{Interpreting Longitudinal Data}

An important strength of the current research design is the longitudinal data that were collected on the STI team. Both qualitative and quantitative data were collected at $\mathrm{T} 1$ and $\mathrm{T} 2$ and the interpretation of these data yields further insight into the change teamwork phenomena. To begin we looked for changes in the rank order of the category responses from $\mathrm{T} 1$ to $\mathrm{T} 2$. In order to more effectively interpret the longitudinal data a dividing level was used to describe changes in the frequency of the response rate of categories between $\mathrm{T} 1$ and $\mathrm{T} 2$. For the purpose of this thesis an increase or decrease of $25 \%$ or greater between $\mathrm{T} 1$ and $\mathrm{T} 2$ with respect to how often a particular response was given was deemed to be a potentially substantive result by the researcher. The role of the research was to then interpret this finding by examining the relation to the overall 
research framework and emergent theory. Conversely, differences of less than $25 \%$ were interpreted as being non-substantial and responses were treated as being consistent over time for the model of team effectiveness.

The decision to use a guideline to aid the interpretation of longitudinal data was based on the need to focus the researcher on the largest changes from $\mathrm{T} 1$ to $\mathrm{T} 2$. A review of the case study literature (Miles \& Huberman, 1994; Patton, 2002) reveals that although guideline points are often used to assist in the interpretation frequency counts in case studies, there is no 'best' level (i.e. $10 \%$ or $20 \%$ changes) that is used for interpreting case study results. For the current case study the level of $25 \%$ change was used due to the sample size $(\mathrm{N}=12)$ and the nature of the phenomenon being examined (change teamwork). With a sample size of $\mathrm{N}=12$ a change of $25 \%$ would mean a difference of three team members over time which was decided upon as the guideline for flagging what a substantial change over time would be when interpreting the longitudinal data. It is important to note that the $25 \%$ difference was a guideline which meant that the researcher had the flexibility in the interpretation of the results to explore the potential of longitudinal changes that were close to the $25 \%$ if the difference aided interpretation of the data and assisted in the development of the conceptual framework. The full data displays are provided for readers. Miles and Huberman (1994) acknowledge that there will be some differences in interpretation of these data displays because the process of the subjective nature of interpreting frequency counts. The data displays highlight many of the subjective interpretation decisions of the researcher and provide the reader with an opportunity to form their own interpretations of the data (Miles \& Huberman, 1994). 


\subsection{EVALUATION OF THE RESULTS}

With theory testing studies there are standard methods for testing the validity and reliability of the results of the research. According to Eisenhardt (1989) there is no such generally accepted set of guidelines when it comes to the assessment of grounded theory research and theory development. Nevertheless, it is important that the case study researcher address the issues of validity and reliability in the research to the fullest extent possible (Yin, 2009). Eisenhardt (1989) suggests that the research should be assessed on whether it has achieved the purpose for which it was selected, to generate a novel and useful theory. Therefore, the first criterion against which the outcomes of this study should be measured is whether or not the research yields a parsimonious, testable, and logically coherent theory which emerges at the end of the study. This criterion is addressed in greater detail in the discussion part of the thesis.

The second criteria put forth by Eisenhardt (1989) deals with the chain of evidence grounding the theory and the strength of the method used to generate the theory. This criterion is related the idea of construct validity, which is the degree to which the study actually measures the phenomenon of interest (in this case change teamwork). The constant comparison method that is central to grounded theory naturally forces the close connection of the evidence to the resulting theory. Esienhardt (1989) explains that a "strength (of the grounded theory approach) is that the resultant theory is likely to be empirically valid" (p.547). This is because the emergent constructs should be so closely linked to real life data that the resulting theory should be in line with future empirical observation. Yin (2003) suggests that clarifying constructs during the interview process and allowing respondents time to ask for clarification also aids helps to improve the 
construct validity of the research. The researcher followed these guidelines and during the interview process preformed checks against the responses to make sure that the team member understood the construct being examined.

The method used in this thesis also addresses this issue of reliability. For case studies (which differ from hypothesis testing) the important characteristic of the case study is that the same study should be replicable, not that another research should necessarily get the same results. This was done in this thesis through the provision of full documentation for all the sampling, data collection, and analysis procedures (Chapters 68). All the data collection tools used in this thesis are included in appendices allowing readers to duplicate the full method if they so desire. The original results from both the survey and the interviews have also been kept in a separate data set so that future researchers may see the data and make their own interpretations of the data. A record of each of the iterations of the coding scheme and the interviews was also kept to provide a record of the constant comparison process used to obtain the final results of the study. In grounded theory the coding process involves a great deal of subjective analysis. Future researchers may look at these files and trace the steps back to see the decisions made by the researcher and the reader can judge the logic of the coding strategy.

The third and final criterion used to assess this research is that the grounded theory study should result in new insights (Eisenhardt, 1989). Replication of past theory is appropriate for theory testing but an effectiveness theory building study should result in the generation of new theory for future testing. Each of these three criteria are revisited in the discussion part of this thesis. 


\section{PART FIVE: RESULTS}

This part of the thesis presents the results of the STI Change Team case study. The results of this thesis are divided into three chapters corresponding to the three research questions put forth in Chapter 5. Chapter 9 provides the results related to Research Question \#1. More specifically it examines the data pertaining to the perceived benefits of change teams for both the organization and the individual team members. This is followed by an examination of the results relating to the challenges faced by the change teams. Chapter 10 provides the findings related to Research Question \#2 which deals with the effectiveness of the STI Change Team. Data are presented pertaining to the perceived strengths and weaknesses of change teams as well as the behaviours and values that may be common to effective change teams. Finally, Chapter 11 presents the findings that address Research Question \#3 which asks how Senior Management can better support change teams in their change agent role.

\section{Reporting format}

The organization of the results section is designed to serve two main purposes. First, the structured reporting format helps to ensure that the results are focused on the research framework and questions that serve to orient this case study. Second, the reporting format assists the reader by allowing for a more organized view of the available data from this case study. The goal of this reporting format is to allow the reader to clearly see the chain of evidence used to support the conclusions from this thesis and therefore be able to form their own interpretations of the data where possible. 
Qualitative case studies typically have a large data set to be displayed in order to fully describe the phenomena under study (Sigglekow, 2007). In order keep the number of data displays and the narrative descriptions of those data displays to a manageable level the results part of this thesis uses the following format. The data displays present the full results for the reader according to the methodology outlined in Section 8.4.1. The first part of the narrative in each chapter reviews both the research question and discusses the interview or survey questions that were used to examine this phenomenon. This research was designed with the idea that team members would give answers specific to change teams, however it was discovered that on almost every question team members gave responses that fell into one of two main themes: change management and team management. As such, the narrative discusses any patterns at this level first.

In all cases the narrative begins with the most salient patterns from the T1 results. Within each table response categories are presented in descending order, most frequent to least and it is the ranking of these categories that guides the results narrative. Each category is labelled with a descriptive name. A more complete description, using the words of team members where possible is also provided to allow the reader to more clearly understand each category and aid in the interpretation of the results.

Within each narrative the presentation of any quantitative data that are salient to the constructs being observed from the data displays is provided to the reader. The role of the survey data in this case study is to supplement the interview data and as such the data displays for the quantitative data are mixed into the discussion of the qualitative findings of this case study. 
The final component of each narrative in this results section deals with the salient longitudinal findings of this research. As discussed in Section 8.5 the criteria for determining the substantial differences between $\mathrm{T} 1$ and $\mathrm{T} 2$ was an increase or decrease of $25 \%$ in the response rate. It was not be feasible to discuss all the patterns in the longitudinal data; however, the data are displayed for the reader to interpret on their own. 


\section{BENEFITS AND CHALLENGES OF CHANGE TEAMS}

The first objective of this research is to increase our understanding of the use change teams to plan and implement organizational change. Specifically, this research objective aims to understand what the benefits and challenges of change teams are for both the individual and the organization. Research question \#1 was of primary importance in this research as it provides answers to two main questions that are relevant to the effectiveness of change teams: (1) why would an organization use a team to implement change? and, (2) why would an individual choose to join a team responsible for the implementation of change? The first two sections of this chapter address those two questions respectively. The final section of this chapter summarizes the key findings of this research with respect to research question \#1.

\subsection{BENEFITS OF CHANGE TEAMS}

The transfer to a Government wide shared services model represents one of the most wide reaching and costly transformational change efforts ever undertaken by the Canadian Federal Government (Bray, 2005). The use of the STI change team to lead the first wave of this transformational change leads us to ask why this decision was taken. Specifically, we asked: what are the benefits of using change teams? Table 9-1 displays the categorized responses to this question obtained during the interviews. The STI change team case offers several suggestions as to how organizations and individuals may benefit from the use of change teams. 
Table 9-1 Benefits of being on a Change Team

\begin{tabular}{|c|c|c|c|c|c|}
\hline \multirow{2}{*}{\multicolumn{2}{|c|}{$\begin{array}{l}\text { Research Question: What are the benefits of being on an } \\
\text { organizational change team? }\end{array}$}} & \multicolumn{2}{|c|}{$\begin{array}{c}\text { Time } 1 \\
\mathrm{~N}=12\end{array}$} & \multicolumn{2}{|c|}{$\begin{array}{c}\text { Time } 2 \\
\mathrm{~N}=12\end{array}$} \\
\hline & & $\mathrm{N}$ & $\%$ & $\mathbf{N}$ & $\%$ \\
\hline \multicolumn{2}{|c|}{ Benefits to the Organization } & 8 & $67 \%$ & 11 & $92 \%$ \\
\hline Improved creativity & 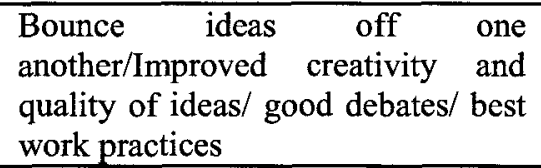 & 6 & $50 \%$ & 11 & $92 \%$ \\
\hline \multirow[t]{2}{*}{$\begin{array}{l}\text { Variety of skills and } \\
\text { experience help to deal } \\
\text { with the complexity of } \\
\text { change }\end{array}$} & $\begin{array}{l}\text { The complexity of change requires a } \\
\text { variety of skills \& experience. } \\
\text { /Subject matter experts can be used } \\
\text { to solve problems/Opportunity to } \\
\text { learn. }\end{array}$ & $\overline{3}$ & $25 \%$ & 4 & $33 \%$ \\
\hline & Total \# of Responses & 9 & $43 \%$ & 15 & $54 \%$ \\
\hline \multicolumn{2}{|c|}{ Benefits to the Individual } & 8 & $67 \%$ & 10 & $83 \%$ \\
\hline Workload sharing & $\begin{array}{l}\text { It can be tough alone/ Team mates } \\
\text { can share your workload during } \\
\text { crunch times }\end{array}$ & 5 & $42 \%$ & 6 & $50 \%$ \\
\hline Get information first & $\begin{array}{l}\text { You get information before others. } \\
\text { /You can see what is } \\
\text { coming/Reduction of stress about } \\
\text { the change }\end{array}$ & 3 & $25 \%$ & 5 & $42 \%$ \\
\hline
\end{tabular}

\begin{tabular}{llllll}
\hline & Total \# of Responses & 8 & $38 \%$ & 11 & $39 \%$ \\
\hline Benefits to both the individual and the organization & 3 & $25 \%$ & 2 & $17 \%$ \\
\hline $\begin{array}{l}\text { You have greater } \\
\text { political and social } \\
\text { strength }\end{array}$ & $\begin{array}{l}\text { The networks that your team mates } \\
\text { have gives you increased political } \\
\text { and social influence which is } \\
\text { needed to make change happen }\end{array}$ & 3 & $25 \%$ & 2 & $17 \%$ \\
\hline Total \# of Responses & 3 & $14 \%$ & 2 & $7 \%$ \\
\hline No Benefits & 1 & $8 \%$ & 0 & $0 \%$ \\
\hline
\end{tabular}

The data display shows that responses that team members gave to this question fell into three main categories: benefits to the organization, benefits to the individual, and benefits to both. All but one of the individuals in this study could identify benefits of being on a change team. STI team members were equally likely to identify benefits to the 
organization ( $67 \%$ of responses) and benefits to the individual team member $(67 \%$ responses). These results suggest that the members of the STI Change Team viewed the strategy of using a team to implement change as beneficial to both the organization and the individual team members. This even split could also be observed in the T2 data, suggesting that the benefits and challenges of change teams remains consistent over the two stages of change that the STI team went through, resistance and acceptance.

The general tone of the responses from team members on this interview question was positive with almost no team members suggesting that the formation of a change team was a poor strategy for implementing change. To many team members, the idea of forming a change team was both a practical and necessary action for the organization.

Change is so complex, working alone would be almost impossible; you need a collective. -STI Team Member

I would never attempt to do this (the change workload) alone. It would be too frustrating to be on your own for this. $\quad$ - STI Team Member

These comments from team members suggest that working closely with others may help employees to deal with the complexity and uncertainty of managing change.

\subsubsection{Benefits to the Organization}

The benefits of the STI Change Team for the organization fell into two main categories: improved creativity, and increased skills and experience. With respect to improved creativity, respondents talked about the fact that working on a team made it easier to bounce ideas off one another, to enter into productive debates, and to share best work practices with teammates. 
It is fun to bounce ideas off people, change teams just help to generate better ideas. -STI Team Member

Half of the team members at $\mathrm{T} 1$ indicated that improved creativity and better ideas were a critical benefit of the team's work together. Team members' responses suggest that the task of implementing change requires a flexible and creative approach to problem solving. Half of the team members felt that the ability to brainstorm and debate with team members led to a higher quality of decision making.

The improved creativity from teams was tied to the second benefit suggested by team members, the variety of skills and experience available to help with complex change related tasks. Team members noted that implementing a change of the magnitude of the SSI meant that team members faced complex and unique tasks on a weekly basis and that their team members helped them solve these issues. For example, several team members mentioned that they found it particularly difficult to find effective ways to communicate with the other government departments involved in the change. They also reported that their teammates were often able to help them navigate these complex issues to come up with the best strategy for getting their work done. As one team member commented,

You can't possibly know everything that comes your way in change; it is good to have a variety of subject matter experts on your team. - STI Team Member

The general tone of the team members' responses when describing the make-up of the team was one of respect and excitement at the opportunity to work with the teammates selected for the STI Team. Overall, responses from team members suggested that team performance was improved because of the variety of skills and experiences present on the team. The team members who discussed the variety of skills present on the team also felt 
that being a part of the STI team would serve as a learning opportunity and allow the organization to develop employees who were experts on organizational change.

A benefit to both the organization and the individual was the increased political and social networks that the change team allowed them to access. One in four of the respondents felt that the team made it easier to tap into political and social networks which they felt led to improved productivity and made work easier to accomplish. Team members reported that political networks were necessary to clear through the red tape of government and felt that they were more effective in their role as change agents because they had a larger political and social network to use as needed.

Getting others outside your group on board can be tough, you need support

\section{- STI Team Member}

In other words, it appears organizations that use change teams may benefit from this practice because team members were more effective in their roles as change agents.

Comparisons of the $\mathrm{T} 1$ and $\mathrm{T} 2$ responses to this question reveal two main findings. First, the number of team members who listed a benefit of change teams to the organization went up $25 \%$ over time ( 8 team members gave benefits to the organization at $\mathrm{T} 1$ compared to 11 at $\mathrm{T} 2$ ). This increase can largely be attributed to the $42 \%$ increase in the number of team members who suggested that change teams improved creativity and resulted in better work practices. 


\subsubsection{Benefits for Employees}

Two-thirds of STI team members also reported benefits to the individual team members that they felt were related to being a part of the STI Change Team. There were two main ways that team members felt that they personally benefited from team membership: workload sharing and information advantage. Workload sharing was described by $42 \%$ of team members as an important benefit from being a part of change team. Individuals who gave this response noted that the workload associated with change implementation was unpredictable at times and having team members available to help made the work more manageable.

The second benefit put forth by STI team members was the ability to get information before others in the organization. At T1, 25\% of team members listed this as a benefit of being a part of the team. This number increased to $42 \%$ at $\mathrm{T} 2$. Team members perceived that the ability to get information about the transformation first helped them to get their work done, reduced stress, and increased their status as a change leader in the organization. Team members perceived that employees outside the team were not receiving the same information about the SSI as members of the change team. They also felt that employees outside the team were anxious and uncertain of the change because they were not as informed about what was going on. Team members felt that because they were on a change team they had a full view of the change and therefore experienced reduced anxiety and stress related to the change.

Being on a team reduces your stress and uncertainty - STI Team Member 
The result was that change team members felt that they were much more comfortable with the SSI change than their colleagues who worked in the organization but outside the STI Team.

The final benefit of change team membership to the individual that was noted by team members was also put forth as a benefit for the organization. One in four STI team members reported that membership on the team benefited them personally due to the increased political and social strength. Although only a quarter of team members responded that they found this to be a benefit, those who did cite this as a benefit explained that the increased political and social strength reduced (for them anyway) the frustration of dealing with resistance from outside the team.

The hardest thing is dealing with the resistance from outside the team.

- STI Team Member

Even when the team finds the best way to get something done it can still be tough to get the political support needed to make it happen. - STI Team Member

Combating resistance and obtaining buy in from employees outside the team was described as one of the most challenging and important roles for team members. The enhanced social and political networks which team members developed made a key aspect of their day to day more manageable.

It should be noted that there were no real changes in the perceived benefits to the individual team member over time. This suggests that employees perceived these benefits of teamwork relatively early on. It also indicates that the benefits to the individuals who on the change team are more dependent on the level of support from team members than on the stage of the change that the team is in. 


\subsection{CHALLENGES OF CHANGE TEAMS}

The data described in the previous section supports the idea that change team members perceive important benefits for both the organization and employees when change teams are used to help implement change. This section considers the potential challenges faced by both management and team members when change teams are used to implement transformational change.

Table 9-2 Challenges faced by Change Teams

\section{Challenges associated with Change Teams}

Research Question: From your experience, what are some of the challenges that you have found are associated with working as a part of a change team? Challenges related to Change Management \begin{tabular}{ccccc}
\multicolumn{2}{c}{$\begin{array}{c}\text { Time 1 } \\
\mathrm{N}=12\end{array}$} & & \multicolumn{2}{c}{ Time 2 } \\
\cline { 1 - 1 } \cline { 5 - 6 } $\mathrm{N}$ & $\%$ & & \multicolumn{2}{c}{$\mathrm{N}=12$} \\
\cline { 1 - 2 } 10 & $83 \%$ & & 4 & $33 \%$
\end{tabular}

\begin{tabular}{llllll}
\hline Expectation of failure & $\begin{array}{l}\text { People are tired of change and don't } \\
\text { support your team because they expect } \\
\text { the change to fail/ it is hard to manage } \\
\text { client expectations }\end{array}$ & 6 & $50 \%$ & 2 & $17 \%$ \\
\hline $\begin{array}{l}\text { You are viewed as a } \\
\text { temporary team }\end{array}$ & $\begin{array}{l}\text { People in our organization viewed the } \\
\text { project and the team as a pilot/they } \\
\text { thought the change would go away if } \\
\text { they ignored it }\end{array}$ & 3 & $25 \%$ & 3 & $25 \%$ \\
\hline $\begin{array}{l}\text { Lack the power to force } \\
\text { people to change their } \\
\text { behaviour }\end{array}$ & $\begin{array}{l}\text { If you don't have serious senior } \\
\text { management support, then you cannot } \\
\text { create real change }\end{array}$ & 1 & $8.3 \%$ & 3 & $25 \%$ \\
\hline \multicolumn{1}{c}{ Total \# of Responses } & 10 & $63 \%$ & 8 & $33 \%$
\end{tabular}

\begin{tabular}{|c|c|c|c|c|c|}
\hline \multicolumn{2}{|c|}{ Challenges related to Team Management } & \multirow{2}{*}{7} & \multirow{2}{*}{$\begin{array}{l}58 \% \\
25 \%\end{array}$} & \multirow{2}{*}{$\begin{array}{l}11 \\
10\end{array}$} & \multirow{2}{*}{$\begin{array}{l}92 \% \\
83 \%\end{array}$} \\
\hline Work is slower & $\begin{array}{l}\text { It can be hard to rely on others for } \\
\text { information/ People work at different } \\
\text { speeds/ Bureaucracy and consensus } \\
\text { decision making slows you down }\end{array}$ & & & & \\
\hline Finding roles & $\begin{array}{l}\text { It can be difficult to balance skills and } \\
\text { personalities/dividing up the work and } \\
\text { prioritizing tasks/getting the right } \\
\text { people for the task/ interpersonal issues }\end{array}$ & 3 & $25 \%$ & 4 & $33 \%$ \\
\hline \multirow[t]{2}{*}{ Turnover } & $\begin{array}{l}\text { Losing experienced people and bringing } \\
\text { new people up to speed }\end{array}$ & 0 & $0 \%$ & 2 & $17 \%$ \\
\hline & Total \# of Responses & 6 & $37 \%$ & 16 & $67 \%$ \\
\hline
\end{tabular}


The categorized responses of the STI Team to the interview question; What are the challenges faced by change teams? are given in Table 9-2 and discussed in the section below.

The responses to this question can be divided into two main categories: challenges relating to change management and challenges relating to working in a team (see Table 10-2). At $\mathrm{T} 1,83 \%$ of STI Team Members gave a response that pertained to the challenges faced by anyone tasked with managing change. Substantially fewer (58\%) individuals talked about challenges associated with working on a team. It would appear from these data that more of the challenges faced by team members during the resistance stage of the change were related to change management issues rather than dealing with the challenges of working on a team. Several of the team members' comments reflected this focus.

A lot of people don't want to change; they'd rather keep doing their job as is. - STI Team Member at T1

We all like to see progress, but in Government it can seem like things don't move. - STI Team Member at T1

At T2, the pattern shifted and an interesting result was observed. Virtually all (92\%) of team members reported challenges that related to working as a team: an increase of $34 \%$ over the number of team members who mentioned problems with teamwork at T1 $(58 \%$ of the sample). By comparison at $\mathrm{T} 2$ only $33 \%$ of team members identified challenges that related to the fact that the team's mandate was to manage change, a decline of $50 \%$ over time in the number of team members mentioning a challenge in this category. The number of total responses also shifted from $\mathrm{T} 1$ to $\mathrm{T} 2$ in favour of team related problems 
with $67 \%$ of all responses given at $\mathrm{T} 2$ targeting challenges related to the team. In comparison, $63 \%$ of all challenges discussed at $\mathrm{T} 1$ were related to change. This change in perception was reflected in the general tone of the interviews at $\mathrm{T} 2$ where team members were more focused on the challenges of working together as a team than they were on the change.

Teams that struggle are those that are focused on themselves during change rather than the collective. - STI Team Member at T2

Near the end of the project, people became distracted because they were moving on - STI Team Member at T2

The comments of team members at $\mathrm{T} 2$ were both positive and negative but generally reflected a shift in focus from the change to the team.

\subsubsection{Challenges Related to Change Management}

At $\mathrm{T} 1$ virtually all of the respondents offered challenges that were categorized as related to the management of change. These challenges were grouped into three categories: the expectation of failure, the view that the team is temporary, and a lack of power to make change happen.

At $\mathrm{T} 1$ half of the change team said that the biggest challenge they faced was the expectation of failure by employees outside the change team. Team members explained that the organization was change weary and negative toward the change, making their task a difficult one.

People expect the project to fail, so they don't really support you. 
It is not surprising that change weariness was seen as an issue by team members given the fact that PWGSC/ITSB had undergone several changes and restructuring events in the five years prior to this study. Responses from team members also addressed the challenges of managing the expectations of the organization. The general consensus among team members was that those outside the team were uninformed about the change and were taking a passive resistant approach to working with the STI team.

Another challenge reported by STI team members at T1 was the fact that they perceived that others in their organization saw the STI team as a temporary group put together for a short period of time. STI team members reported that they felt that their colleagues who were not on the team did not want the change to happen and were at times content to 'wait out' the change and the STI team. This result has been shown to be a common occurrence during the resistance phase of the change (Elrod \& Tippett, 2002). In our case study, one in four respondents commented on this challenge. Also of interest is the finding that the team members shared this perception and acknowledged that the challenge was a legitimate one since their team was in fact temporary!

Most departments do not put the change as a high priority; they need to keep the lights on. $\quad$-STI Team Member

Everybody views you as temporary, so you don't get a reaction from people. -STI Team Member

At T2 there was a substantial shift in the perceived expectations of failure of the change with only $17 \%$ of respondents reporting that they felt that people outside of the team expected them to fail. This result is once again consistent with the work of Elrod and 
Tippett (2002) who described this type of improvement as the organization moved into the acceptance stage of the change.

Another change in the data that emerged over time was an increase in the number of team members at $\mathrm{T} 2$ who expressed concern that without strong visible support from senior leadership the team faced an uphill battle with respect to implementing the change because they lacked the power or the credibility to force people to change their behaviour.

Our change group wasn't visibly supported by senior management so it was tough to get people to react to our requests. - STI Team Member

The general tone of those giving this response at $\mathrm{T} 2$ was of frustration. Team members generally felt as though the challenges they mentioned (especially the lack of power) could be solved by strong visible support from senior management.

\subsubsection{Challenges Related to Teamwork}

Team members identified three main categories of challenges related to the fact that they had to work together as a team on the change: work was slower, they had difficulty finding roles for individuals, and the challenges of turnover on the team. As noted earlier, the response rate for teamwork themed challenges went up substantially at T2, mostly due to the large increase number of team members who reported the slow pace of teamwork as a challenge when implementing change (58\% increase over time). In fact, this frustration was systematic at $\mathrm{T} 2$ with $83.3 \%$ of team members reporting 
having difficulty relying on others for work, finding consensus, and dealing with bureaucratic attitudes within the team.

It is a bit of a consensus environment, everybody has to agree on everything or else nobody does anything. - STI Team Member

The challenges of working together as a team were likely amplified at $\mathrm{T} 2$ because the project was nearing completion and team members were forced to work closely together to produce the proof of concept document (Chapter 6.2) which was a major outcome of the team's work together.

The second challenge in the teamwork theme described by team members was the challenge of finding suitable roles for each member of the team. As described earlier, the flow of work for the STI Team was variable and required members to be versatile enough to shift their role among the functional groups as required by the workload.

We have a bit of an all-star team here; there is a lot of experience with change. -STI Team Member

While most team members were generally quite positive with the level of skill and expertise available a substantial number of team members were more concerned with how the skills and expertise of the various team members were being utilized and viewed that as a challenge for the group leaders on the STI team. These individuals were worried that skills were not being used effectively at times.

There have been times when people could have contributed to areas of the change but didn't, we can be more collaborative. - STI Team Member

Some team members were doing work at a level of detail that was not requested. - STI Team Member 
Individuals who gave this response felt that this challenge was a difficult one to address due to the complex and dynamic nature of implementing change.

The third category of responses given by team members was the challenge of managing turnover on a change team. This concern is consistent with the fact that the STI Team used several change consultants at times during the project and the transfer of knowledge and understanding when these consultants left or arrived on the team appeared to be a difficult task at times. No one gave this response at the T1 interviews and only two team members gave this response at T2. The researcher's observation of the team and informal discussions with the team leaders suggested that turnover was an important challenge which impacted the STI team.

Change programs like this tend to go on for a long period of time, which causes lots of turnover and prevents a real team environment from developing.

- STI Team Member

Turnover challenges were probably some of the biggest challenges.

- STI Team Member

\subsection{SUMMARY}

The results presented in Chapter 9 suggest that change teams offer multiple benefits to both the organization and to the individual members on the team. The results from the case study suggest that change teams may: improve creativity, improve decision making, allow team members to share their workload, and allow team members to reduce anxiety and stress related to the change. Almost the entire STI team $(92 \%$ interviewed at T2) reported improved creativity which led to better decision making as a benefit of 
working together as a team on change related tasks. STI team members also reported that the ability to share workloads was a primary benefit of membership to a change team and that the ability to obtain information about the change first was reported to reduce the stress and anxiety of team members.

A second important finding in Chapter 9 was that change teams not only face the normal challenges faced by any team but also face additional challenges related to implementing change. One of the main challenges faced by change team during the resistance phase of the change is dealing with expectations. People expect you to fail and people view the team as temporary. Additionally, STI team members reported that work may be slower at times with change teams. Finally, the results in Chapter 9 suggest that during the acceptance phase of the change, it can be difficult to get people into roles that help the team move forward and implement the change. 


\section{THE EFFECTIVENESS OF CHANGE TEAMS}

The second objective of this research is to increase the understanding of the factors which influence change team effectiveness. Specifically, this study seeks to develop a model of change team effectiveness that may guide the effective use of these teams as well as future research on change teams. In this research we asked a number of questions to help us gain an appreciation of the factors that contribute (either positively or negatively) to change team effectiveness. Specifically, we looked at:

- behaviours and values that supported the change team's ability to implement change,

- behaviours and values that limited the change team's ability to implement change,

- the critical success factors for effective change teams, and

- ways to improve the effectiveness of change teams.

The responses we obtained to questions around each of these themes form the content of this chapter which is divided into four main sections. The first section examines the interview data on the factors which team members perceive to be characteristic of change teams that are effective in their task of implementing change. The second section in this chapter shifts the focus to factors that may be detrimental to change team effectiveness. The third section in this chapter presents the quantitative data from the change team effectiveness survey. The fourth and final section of this chapter summarizes the result on change team effectiveness. 


\subsection{FACTORS HAVING A POSITIVE IMPACT ON CHANGE TEAM EFFECTIVENESS}

This section reports the data from STI team members on the factors that they felt positively influenced the effectiveness of the STI Change Team with regard to their task of implementing transformational change. The data related to the positive factors influencing the ability of change teams to support the change initiative and achieve their objective of implementing change are presented first. The second subsection reports on critical success factors for change team effectiveness. Overall, this section is designed to provide the reader with a clear description of the factors that may positively influence change team effectiveness.

\subsubsection{Supporting the Change Initiative}

A basic premise of this study is that change teams can be distinguished from other teams by looking at their primary task, implementing organizational change. Therefore a change team not only has to work well as a team but also has to effectively manage change. This issue was addressed in this thesis by asking change team members to identify, from their experience, the behaviours and values that characterize a team that is effective at meeting this mandate (i.e. supports the change agenda). We asked this question with the expectation that team members would talk about behaviours and values unique to teams with a mandate to deliver change. The results showed instead that change team members were equally likely to identify values and behaviours that characterized an effective team regardless of their mandate as they were to talk about a team focused on 
change. Table 10-1 displays the results describing the characteristics and behaviours of supportive change teams, as reported by members of the STI Change Team.

Table 10-1 Supportive Change Teams

Supportive Change Teams

Research Question: What types of behaviours or values are

characteristic of a team that is supportive of the change?

Time 1

Time 2

$\mathrm{N}=12$

$\mathrm{N}=12$

Behaviours and values related to Change Management

Be a model for the

Be a model for change - No

complainers/ high tolerance for

Change

ambiguity and conflict/flexible

innovators/open minded/collaboration

\begin{tabular}{|c|c|c|c|c|c|}
\hline Communicate the change & $\begin{array}{l}\text { Share information/clear } \\
\text { communication/Ability to communicate } \\
\text { the message of change over and over }\end{array}$ & 6 & $50 \%$ & 2 & $17 \%$ \\
\hline $\begin{array}{l}\text { Be persistent and } \\
\text { committed to the change }\end{array}$ & $\begin{array}{l}\text { High level of energy/be able to fight } \\
\text { through frustration and negativity. High } \\
\text { level of commitment to the task / Strong } \\
\text { belief in the change they are } \\
\text { implementation }\end{array}$ & 5 & $42 \%$ & 7 & $58 \%$ \\
\hline
\end{tabular}

Total \# of ResponsesResponses

$\begin{array}{llll}17 & 61 \% & 14 & 52 \%\end{array}$

\begin{tabular}{|c|c|c|c|c|c|}
\hline \multicolumn{2}{|c|}{ Behaviours and values related to Team Management } & 7 & $58 \%$ & 10 & $83 \%$ \\
\hline Interconnected & $\begin{array}{l}\text { Inter-connected - People are working } \\
\text { towards the same goal on the same } \\
\text { page/ People need to understand what } \\
\text { others are doing }\end{array}$ & 5 & $42 \%$ & 7 & $58 \%$ \\
\hline Disciplined and focused & $\begin{array}{l}\text { Disciplined and focus- Persistence, } \\
\text { adhere to project management principles } \\
\text { /stick to the mandate }\end{array}$ & 4 & $33 \%$ & 3 & $25 \%$ \\
\hline \multirow[t]{2}{*}{$\begin{array}{l}\text { Variety of skills and } \\
\text { experience }\end{array}$} & $\begin{array}{l}\text { Varied experience and skills } / \text { Wide } \\
\text { variety of skills, experience and } \\
\text { networks to tap into/ creative mix }\end{array}$ & 2 & $17 \%$ & 3 & $25 \%$ \\
\hline & Responses & 11 & $39 \%$ & 13 & $48 \%$ \\
\hline
\end{tabular}


The results from this interview question were grouped into two categories: change management, and team management. The fact that the total responses from team members were equally split between the two categories at both $\mathrm{T} 1$ and $\mathrm{T} 2$ suggests that effective change teams need to pay attention to both change management and team management issues. The one category that did show a change between $\mathrm{T} 1$ and $\mathrm{T} 2$ was the 'communicating the change' category. The number of team members who responded in this category dropped from $50 \%$ to $17 \%$ at $\mathrm{T} 2$. This result suggests that communicating the change is a critical behaviour for effective change teams during the resistance phase of the change cycle but not as important during the implementation stage of the change.

\subsubsection{Change Management Characteristics}

The change management related characteristics of an effective change team that were reported by team members were: be a model for the change, communicate the change, and be persistent and committed to the change. Within the first category half of the team members described the importance of being a model for the change at both $\mathrm{T} 1$ and T2. Team members explained that it was critical that the behaviours and actions of the STI Team be seen as a standard on which the rest of the organization could benchmark their attitudes and behaviours related to the change. Team members felt it was important that a change team was free from complaining, pessimism, or closed mindedness. Team members described the model change team as one with a high tolerance for ambiguity and conflict, flexible and open minded, and experts in collaboration. 
A sense of collaboration is critical for teams; you have to want to collaborate.

\section{- STI Team Member}

The general tone of the responses indicated that the ability to collaborate with other groups in the organization and remain open to ideas from other groups was essential to the team's success.

The second category of responses from team members described the importance of communication for effective change teams. A fundamental of solid change management (Mabin et al., 2001; Vann, 2004), the ability to communicate the message of change in a positive tone was listed by $50 \%$ of the team's members at $\mathrm{T} 1$.

It is a long program and things can shift, and that's okay, but you need to communicate. - STI Team Member

Change team members described the challenge of repeating the same message over and over to different groups in the organization.

The longitudinal data show that the perceived importance of communication declined over time (a decrease of 32\%). This result may reflect the fact that the task on which the STI team was working at $\mathrm{T} 2$, the proof of concept document, did not require as much interaction and coordination with groups outside the team. This result may also be linked to the importance of communication during the resistance stage of the change (when the T1 data were collected). This result will be discussed further in Part 7 of the thesis.

Constant communication was also linked to the third category of responses in the change management theme, persistence and commitment to the change. Almost half of the STI team members described effective change teams as being persistent and 
committed in their approach to change. A high level of energy, the ability to fight through resistance, and most of all a passion for the change were listed as the characteristics of an effective change team.

If you are passionate about the change you will convert people as you go. - STI Team Member

If you want to change peoples' minds, you better be passionate. - STI Team Member

There was no change over time in the perceived importance of passion and commitment for change team effectiveness. Change team members described the frustrations of trying to implement such a major change and explained that without a high level of persistence and commitment to the change, it would be very difficult for the team to remain supportive. This suggests that the link between change team commitment and persistence and team effectiveness does not depend on the stage of the change cycle.

\subsubsection{Teamwork Characteristics}

A number of the responses given by STI team members reflect the behaviors and values of an effective team regardless of the mandate. Within this theme responses were sorted into three main categories: interconnectedness, a disciplined and focused approach to the task, and a variety of skills and experience. According to almost half of the STI team it is critical that a supportive change team be on the 'same page' and function as a well-coordinated, interconnected team. 
A change team has to care about their work and take accountability for the whole team's work. - STI Team Member

This category was equally important at $\mathrm{T} 2$ where $58 \%$ of the team members noted the importance of working together. Some members felt that at times the STI team could have improved their ability to support the change by understanding the work of all the groups on the team.

The second category in the team management theme was the importance of maintaining a disciplined and focused approach to the team's task. According to one STI team member,

These types of change projects require a high degree of formality; informality just got us in the weeds. $\quad$-STI Team Member

This type of comment was echoed by several of the group leaders who acknowledged that the need for formality may have been influenced by the climate that they were operating in. Team members explained that change in the government requires a high degree of organization and that a sound approach to project management was essential to team effectiveness.

Projectizing your work can make your job as a leader much easier. - STI Team Member

The ability to divide the task of the STI Team into manageable projects allowed the team to improve its delivery of services to the departments involved in the change. This was viewed as an important behaviour because STI team members felt that if they were disorganized in their approach to implementing change it would result in resistance from many of the parties involved. 
The final characteristic of a supportive change team reported by team members

was a heterogeneous mix of skills and experience on the team. Approximately one in six of the of STI team members reported that they felt that teams with a varied collection of skills and experience would be in a better position to support and lead the change effort. This result remained consistent at $\mathrm{T} 2$ and is consistent with the team effectiveness literature (Campion et al., 1993; 1996) used to guide this research.

\subsubsection{Critical Success Factors for Change Team Effectiveness}

An important strength of this research design is the fact that we were able to draw on two large and well-developed bodies of literature: teamwork and organizational change. Both of these literatures offer guidance for success in each of their respective areas. To develop a model of change team effectiveness it was necessary determine which were the critical factors with respect to both teamwork and change implementation that influenced effectiveness for change teams. To address the critical factors for change team effectiveness we asked STI team members to describe the strengths of their team that they felt contributed to their effectiveness in implementing change. Table 10-2 displays the results to this research question.

Consistent with the findings in Subsection 10.1.1, a pattern in the data emerged as the responses from team members divided almost evenly into two main themes; change management and team management. At T1 $100 \%$ of the STI team members gave a response related to the implementation of change. This result was compared to the $58 \%$ of team members at $\mathrm{T} 1$ who listed strengths related to working as a team regardless of the task. 
Table 10-2 Critical factors for Change Team effectiveness

\section{Strengths of the STI Change Team}

\begin{tabular}{|c|c|c|c|c|c|}
\hline \multirow{2}{*}{\multicolumn{2}{|c|}{$\begin{array}{l}\text { Research Question: Please describe what you feel your } \\
\text { team is doing well in terms of implementing the change? }\end{array}$}} & \multicolumn{2}{|c|}{$\begin{array}{c}\text { Time } 1 \\
\mathrm{~N}=12\end{array}$} & \multicolumn{2}{|c|}{$\begin{array}{l}\text { Time } 2 \\
N=12\end{array}$} \\
\hline & & \multirow{2}{*}{$\frac{\mathrm{N}}{12}$} & \multirow{2}{*}{$\begin{array}{c}\% \\
100 \%\end{array}$} & \multirow{2}{*}{$\begin{array}{c}\mathrm{N} \\
8\end{array}$} & \multirow{2}{*}{$\begin{array}{c}\% \\
67 \%\end{array}$} \\
\hline Change Management & & & & & \\
\hline Building commitment & $\begin{array}{l}\text { Escalating commitment for } \\
\text { issues/building networks/ } \\
\text { communicating }\end{array}$ & 7 & $58 \%$ & 1 & $8 \%$ \\
\hline $\begin{array}{l}\text { Developed and } \\
\text { documented a change } \\
\text { methodology }\end{array}$ & $\begin{array}{l}\text { Our change plan can be used by } \\
\text { future change teams to help bring } \\
\text { about change }\end{array}$ & 4 & $33 \%$ & 7 & $58 \%$ \\
\hline \multirow[t]{2}{*}{$\begin{array}{l}\text { Engage others outside } \\
\text { the team }\end{array}$} & $\begin{array}{l}\text { In a tough political climate we have } \\
\text { supported the those impacted by the } \\
\text { change }\end{array}$ & 4 & $33 \%$ & 5 & $42 \%$ \\
\hline & Total \# of Responses & 15 & $60 \%$ & 13 & $48 \%$ \\
\hline Team Management & & 7 & $58 \%$ & 11 & $92 \%$ \\
\hline $\begin{array}{l}\text { Disciplined and } \\
\text { professional in our } \\
\text { project management }\end{array}$ & $\begin{array}{l}\text { Very flexible and supportive, very } \\
\text { professional, followed PM } \\
\text { principles }\end{array}$ & 5 & $42 \%$ & 5 & $42 \%$ \\
\hline $\begin{array}{l}\text { Excellent team } \\
\text { collaboration }\end{array}$ & $\begin{array}{l}\text { Open and sharing with information/ } \\
\text { have great ideas/ Excellent } \\
\text { collaboration around problem } \\
\text { solving }\end{array}$ & 4 & $33 \%$ & 5 & $42 \%$ \\
\hline Quality leadership & We have very good leadership & 1 & $8 \%$ & 0 & $0 \%$ \\
\hline \multirow[t]{2}{*}{ Clarified the task } & $\begin{array}{l}\text { created clear priorities / Simplified } \\
\text { the task }\end{array}$ & 0 & $0 \%$ & 4 & $33 \%$ \\
\hline & Total \# of Responses & 10 & $40 \%$ & 14 & $52 \%$ \\
\hline
\end{tabular}

These patterns suggest the importance of skills associated with change management, during the resistance phase of the change. At $\mathrm{T} 2$ a substantial shift in the responses occurred, with $92 \%$ of STI team members discussing teamwork strengths and only $67 \%$ of STI team members mentioning change management strengths as an important component of their effectiveness. This reversal suggests that team members may have been focusing their efforts on change management tasks during the resistance phase of 
the change and then shifted their effort and focus to working well as a team to complete the deliverables (proof of concept document) during the acceptance phase of the change.

One category of responses that was mentioned substantially more at $\mathrm{T} 2$ was the importance of clarifying the task. At T1, none of the team felt that task clarification was something that they were doing well. At $\mathrm{T} 233 \%$ of the team mentioned this category as a critical success factor for the change team. These results suggest that during the transition from the resistance to acceptance phase of the change ( $\mathrm{T} 1$ to $\mathrm{T} 2$ ) task clarification becomes more critical as a task that change teams must accomplish. Change teams that have a clear task to work on may be better positioned to build momentum and complete the implementation of the change.

The reverse trend can be seen with respect to the importance of building commitment for the change with $58 \%$ of the change team providing this response at $\mathrm{T} 1$ as compared to only $8 \%$ of the team responding in this way at T2. These results are consistent with the work of Elrod and Tippett (2002) who argue that the acceptance phase of the change ( $\mathrm{T} 2$ data collection period) is characterized by a focus on completing the task of implementation which would mean that most of the work on building commitment would be done during the resistance phase (T1). This trend is discussed further in Part Six where the life-cycle of the change and the shift in the critical factors for change team effectiveness is discussed.

\subsubsection{Change Management}

The factors related to the effective management of change that were giving by STI team members fell into three categories: building commitment, developing a 
methodology for change, and engaging outsiders. The most important factor in the effectiveness of the STI team listed at T1 was the ability to build commitment for the change (cited by $58 \%$ ). Team members discussed the importance of using networks to communicate and escalate commitment around key issues related to the change.

Employee opinion leaders can be critical; you can get whole pockets of employees who are against the change for no real reason. - STI Team Member

There was a lot of push back from other groups, it took a long time to get buy in from other groups. -STI Team Member

Many respondents felt that gaining commitment from groups outside their team during the resistance phase of the change was one of the most difficult challenges that they faced. As such, they felt that the ability to build commitment was critical to their effectiveness as a change team. Only $8 \%$ of the team mentioned building commitment as a critical success factor at $\mathrm{T} 2$, a substantial decline of $50 \%$ in the number of team members giving this response. As mentioned earlier, this decline may reflect the shift in the team's focus as the stage of the change shifted to acceptance and they were intensely working on the proof of concept document.

The second critical success factor tied to the management of change was the documentation of the change process. According to one third of team members, the STI team did an excellent job of documenting the shared services process and developing a methodology for change that could be used by future change teams working on transforming IT in the government.

It is essential that in the future we know the risk factors and the resources needed for the change. - STI Team Member 
The importance of documentation was evident in the interviews, where team members mentioned that by documenting their experiences future IT shared services transitions would have the benefit of their lessons learned. This was accompanied by some frustration from STI team members who commented that although there had been several IT related changes in the recent history of the organization they did not have the benefit of learning from those previous changes.

Surely, there was someone in our organization who could have given us a heads up on some of our major issues. - STI Team Member

The STI change team was supportive of the plan to document all of their experiences and provide a proof of concept document which would be used to guide future waves of the shared IT services change.

The final area that STI team members felt was important for the effectiveness of their change team was their role in engaging others in the change to shared IT services. One-third of STI team members $(42 \%$ at T2) felt that one of the areas that their team excelled was their ability to engage and support groups impacted by the change.

We have built a strong network of people throughout the program, and that helps to further the change effort. -STI Team Member

Our communication and engagement of our clients has been excellent. - STI Team Member

The engagement of those impacted by the change was seen as an important task for the change team who recognized the challenge of engaging an organization that had grown weary of IT changes in recent years. 


\subsubsection{Team Management}

Many of the responses provided by STI team members referred to concepts that were related to effective teamwork in general and were not specific to a team whose mandate was to implement change. Within this theme team members' responses were divided into four categories: a disciplined project management approach, team collaboration, quality leadership, and clarifying the task. The most common response in this theme $(42 \%)$ was the disciplined and professional adherence to project management principles. STI team members explained that the complexity of the task and the difficult political climate meant that the change team was forced to be organized and disciplined in their approach to implementing change.

Change team managers need to stick to project management principles and manage people formally. - STI Team Member

According to team members an effective change team should be organized and operate with clear deliverables according to project management fundamentals. Without this organized and disciplined approach, STI team members felt that the team would have been overwhelmed with the complexity and amount of work associated with implementing change. The importance of effective project management does not seem to depend on the stage of the change.

The second category of responses dealt with team collaboration. One-third of team members listed excellent team collaboration as a critical success factor for change teams.

Our full time employees have been hand-picked and mixed in well with consultants. 
Our team was very good at being inclusive and working together.

- STI Team Member

Team members acknowledged the many change teams require a variety of subject matter experts, both from within the organization and consultants. According to STI team members, a critical piece of change team effectiveness was the ability of these unique individuals to collaborate together on problems relating to the change. By collaborating well, the change team was able to improve problem solving and generate better ideas on how to handle issues as they came up.

The final two categories in the teamwork theme were the importance of quality leadership and the importance of clarifying the task. Only one team member mentioned the importance of leadership in response to the research question in Table 10-2. This result came about despite the emphasis on leadership in both the change and team literatures, which is noted here and discussed further in Part 6 of this thesis. This finding suggests that maybe leadership of teams is less critical than the leadership of the overall change effort. Also noteworthy, is the fact that there was no support for the importance of clarifying the task as a critical success factor at $\mathrm{T} 1$. The increase of this behaviour over time, with one in three team members at $\mathrm{T} 2$ noting that clarifying and simplifying their task increased the team's effectiveness suggests that the importance of this factor depends heavily on the stage of the change.

\subsection{FACTORS LIMITING CHANGE TEAM EFFECTIVENESS}

Section 10.1 put forth several critical success factors that STI team members suggested may have a positive impact on the effectiveness of the change team. Section 
10.2 presents the reverse - the factors which team members observed to have a limiting effect on the effectiveness of the STI team in their task of implementing change. As discussed earlier an important distinguishing feature of change teams is that their mandate is to support and implement organizational change. Central to this role is the ability of the change team to support and move the entire organization towards the desired state of change. This section begins by examining the factors that may prevent change teams from supporting the change effort as put forth by members of the STI team. The second half of this section presents the findings describing the areas of change teamwork that the STI team members felt required improvement in order to improve the effectiveness of the team. Together these two subsections provide insight into the factors that may negatively influence the effectiveness of change teams.

\subsubsection{Resisting the Change}

A major part of the role of the STI change team was to support and lead their organization through successful transformational change. Similar to individual change agents, change teams can vary on the level of support versus resistance to the change that they exhibit. Understanding the factors that may lead to increased resistance on change teams could help change teams avoid these pitfalls and improve their effectiveness. Table 10-3 presents the findings on the behaviours and values that may be characteristic of a team that is resistant to the change. Results from the research question on the factors that limited the change team's ability to support change again showed a pattern of responses that divided into two main categories: management of change, and management of teamwork. 
Table 10-3 Resisting the Change

\section{Resistant Change Teams}

Research Question: What types of behaviours or values are characteristic of a team that is resisting the change?

Change Management

Time 1

Time 2

$\mathrm{N}=12$

$\mathrm{N}=12$

Focus on failures

Vocal against other people's ideas/ find reasons why not/focus on failure/ don't

enjoy change/Caught up in bureaucracy

\begin{tabular}{llllll}
\hline Fails to collaborate & $\begin{array}{l}\text { My way or the highway attitude/Isolate } \\
\text { themselves against the change/ } \\
\text { Stubborn, think that their way is always } \\
\text { best }\end{array}$ & 9 & $75 \%$ & 7 & $58 \%$ \\
\hline $\begin{array}{l}\text { Not accountable for the } \\
\text { change }\end{array}$ & $\begin{array}{l}\text { Not accountable for the change: The } \\
\text { have no pride and no accountability for } \\
\text { the change }\end{array}$ & 2 & $17 \%$ & 3 & $25 \%$ \\
\hline Total \# of Responses & 20 & $67 \%$ & 19 & $68 \%$
\end{tabular}

Team Management

$\begin{array}{llll}10 & 83 \% & 8 & 67 \%\end{array}$

Poor communication

Hoard information/work in silos/ they don't communicate well/ Disconnected/

Don't return calls or requests.

Don't work hard

These teams are not willing to work hard/ those close to retirement are not interested in the long term/already looking past the change

Total \# of Responses

10

$33 \%$

$932 \%$

Team members provided close to the same number of responses in each category and the results were consistent at $\mathrm{T} 1$ and $\mathrm{T} 2$. These results suggest that these factors may limit the team's ability to support change regardless of the stage of change that they are in.

\subsubsection{Change Management Theme}

Group responses that were related to change management activities were categorized into three groups: focusing on failure, a lack of collaboration, and a lack of 
accountability. The most common response describing ineffective change teams within this theme was a focus on failures. Two-thirds of STI team members explained that change teamwork is bound to run into failure and disappointment, and that the attitude of team members during those times has a substantial impact on whether the team is supporting or resisting the change.

You have to be able to deal with some disappointments to be on a change team. -STI Team Member

When building a change team it is important to look for people who are forward thinking. - STI Team Member

The ability to deal with failure without becoming dragged down was seen as key by several team members. Similar to individuals, teams who became focused on failures were seen to be ineffective at the task of implementing change. STI team members also acknowledge that the environment of government could drag people down and frustrate the team with its slow pace.

We all want it to happen, but changing the machinery of government is slow. - STI Team Member

STI team members described the importance of always looking forward and learning from mistakes rather than becoming frustrated at the struggles associated with such a large change.

Another attitude identified by STI team members as being counterproductive to change teams was the 'my way or the highway' category, with $75 \%$ of STI team members describing a lack of collaboration as a characteristic which typified resistant change teams. Team members explained that in order to be effective, the members of the 
team must be open to new ideas and sharing the responsibility for the change within the team and with other groups affected by the change.

If you're not empathetic, if it's my way or the highway, you'll get a fight.

-STI Team Member

One of the most common points raised on this topic was that from their experience the STI team members had learned that simply telling people how the change would go didn't work. In fact, team members explained that if the groups outside the team sensed a close minded attitude from the STI team then relations with that group were bound to be full of resistance and thus would be limited in their ability to increase support for the change.

The third characteristic of resistant teams in the change management category was a lack of accountability for the change. One in five STI team members felt that resistant teams are plagued by a lack of pride in their work and a culture of avoiding responsibility for the success or failure of the change.

A good change team seeks out accountability and looks for responsibility.

- STI Team Member

Team members explained that the frustrations and failures associated with implementing change may be at the root of resistant change teams who avoid taking accountability for the change. The STI team members suggested that effective change teams take responsibility for both the success and failure of the change. 


\subsubsection{Teamwork Theme}

The second theme in the set of responses shown in Table 10-3 addresses the values and behaviors related to teamwork itself rather than change teams. The most common characteristic of resistant change teams according to STI team members was the tendency for resistant teams to become disconnected from each other. STI team members describe behaviors such as hoarding information, working in silos, and one sided communication as indicators of a disconnected change team.

People were siloed in their work at times. - STI Team Member

As shown in this comment from a team member, the effectiveness of the STI team was negatively affected at times by this type of resistant behaviour. Team members described the challenge of working with these resistant attitudes, explaining that working in isolation could become contagious as team members become increasingly frustrated with the lack of support from their colleagues.

The second category of responses in the teamwork theme was the work ethic of resistant teams. One in six STI team members, noted that while implementing change requires hard work, resistant and ineffective change teams have members who are not motivated to work hard.

If you are a lazy person, change is a barrier because it really takes considerable effort to make change happen. - STI Team Member

People who know they won't be around when the change happens are not good on change teams. $\quad$-STI Team Member

Near the end of the project, people became distracted because they were moving on. - STI Team Member 
These comments again show that STI team members were speaking from experience when they described a lack of work ethic as being counterproductive to implementing change. A small portion of the team addressed a third theme that is worth mentioning; they noted that team members who are not invested in the future of the change may not be as motivated to work hard on the change. The majority of team members were positive about the work ethic of the STI team as whole and stressed the importance of developing a culture of hard work for a change team to be effective.

\subsubsection{Improving the Effectiveness of Change Teams}

As a part of the interview STI team members were asked to describe how their team could improve their effectiveness. Responses to this question are displayed in Table 10-4. The table is again organized according to the two main themes in the data: change management and improvements to the way the team is managed. These suggestions for improvement give valuable insight into the factors that may be important to change team effectiveness. While a minority of individuals (two at T1, one at T2) could not think of ways in which their team's effectiveness could be improved, the rest of the team was able to come up with suggestions for improving change team effectiveness. An equal number of STI team members gave recommendations related to the management of change and teamwork at $\mathrm{T} 1$ and $\mathrm{T} 2$. The even split suggests that the STI team members felt that both the management of change and the management of teamwork factors were important to change team effectiveness and that there were problems in both areas that needed to be addressed to improve the team's effectiveness. 
Table 10-4 Improving Change Team Effectiveness

\section{Areas for Improvement}

Research Question: Please describe some areas that you feel

your team could improve their effectiveness?

Time 1

Time 2

Improving Change Management

$\mathrm{N}=12$

$\mathrm{N}=12$

\begin{tabular}{|c|c|c|c|c|c|}
\hline Reassess the change & $\begin{array}{l}\text { We need a clear direction/ Get formal } \\
\text { agreement from all parties impacted } \\
\text { by the change./ Asses our ability to } \\
\text { make this change last }\end{array}$ & 6 & $50 \%$ & 5 & $42 \%$ \\
\hline $\begin{array}{l}\text { Achieve a critical mass } \\
\text { of support }\end{array}$ & $\begin{array}{l}\text { We need to get more people and } \\
\text { groups involved /maintain existing } \\
\text { involvement and build commitment }\end{array}$ & 3 & $25 \%$ & 2 & $17 \%$ \\
\hline $\begin{array}{l}\text { Supporting our contract } \\
\text { workers }\end{array}$ & $\begin{array}{l}\text { Help them implement change/ don't } \\
\text { lose their value and knowledge }\end{array}$ & 1 & $8 \%$ & 2 & $17 \%$ \\
\hline \multirow[t]{2}{*}{$\begin{array}{l}\text { Get Senior level } \\
\text { support }\end{array}$} & $\begin{array}{l}\text { we need a senior sponsor for each } \\
\text { project }\end{array}$ & 0 & $0 \%$ & 4 & $33 \%$ \\
\hline & Total \# of Responses & 10 & $53 \%$ & 13 & $35 \%$ \\
\hline aproving Teamwork & & 7 & $58 \%$ & 10 & $83 \%$ \\
\hline $\begin{array}{l}\text { Improve our } \\
\text { communication }\end{array}$ & $\begin{array}{l}\text { coordination with other teams/partner } \\
\text { departments }\end{array}$ & 5 & $42 \%$ & 10 & $83 \%$ \\
\hline $\begin{array}{l}\text { Work together as a } \\
\text { team }\end{array}$ & Less isolation /more coordination & 1 & $8 \%$ & 5 & $42 \%$ \\
\hline Meet deadlines & $\begin{array}{l}\text { So that we can move more quickly to } \\
\text { on primary business processes }\end{array}$ & 1 & $8 \%$ & 2 & $17 \%$ \\
\hline \multirow[t]{2}{*}{$\begin{array}{l}\text { More efficient HR } \\
\text { processes }\end{array}$} & $\begin{array}{l}\text { We need to have a wider variety of } \\
\text { skills on our team/We needed more } \\
\text { resources to accomplish our task/ too } \\
\text { difficult to bring people on board }\end{array}$ & 0 & $0 \%$ & 4 & $33 \%$ \\
\hline & Total \# of Responses & 7 & $37 \%$ & 23 & $62 \%$ \\
\hline
\end{tabular}

An important pattern in the data was that the absolute number of responses went up substantially at $\mathrm{T} 2$. The increased response rate at $\mathrm{T} 2$ suggests that more experience on the team made STI team members more aware of the ways that the team's effectiveness could be approved. The increase in suggestions was fuelled by the large increase in the number of team members mentioning four categories of improvements: senior level support, improved communication, improved collaboration, and more efficient human 
resources processes. The frequency with which each of these response categories was mentioned went up substantially during the acceptance phase of the change. It should also be noted that all but one of the areas cited as requiring improvement had to do with team processes and not change management.

\subsubsection{Improving the Management of Change}

Team members gave four responses that related to the idea of improving change management practices within the team: reassessing the change, achieving a critical mass of support, supporting contract workers, and increasing senior level support. Half of STI team members felt that the effectiveness of the team would improve if they were able to reassess the change and determine the best strategy for getting agreement from all the departments involved in the transition.

We need to do a better assessment of the impact on the people who will have to transition. -STI Team Member

The expectations of change recipients can be very unclear, it is important to get formal agreement on change issues. - STI Team Member

Several team members felt that without a clear understanding of how the transition would take place the team was going to struggle against resistance. STI team members felt that it was necessary to reassess the strategy for change, particularly in the area of human resource transfer. This was a task that many team members felt should have been more thoroughly conducted early in the change.

We could have saved ourselves a lot of time by being better organized at the beginning. - STI Team Member 
These comments reflect the frustration that the STI Team felt towards the lack of a clear direction. Team members felt that without a full assessment of the impact of the change it would be difficult to get agreement from the parties involved which would prevent them from implementing lasting change.

The second category of responses relating to improved change management strategies was to help the STI team achieve a critical mass of support. One in four team members commented that the team still had much work to do before they could achieve that critical mass of support for the change. Team members felt that a critical mass was needed to start seeing the benefits of the change and that the way to achieve that support was to involve more groups and individuals in the process of developing the shared services model. The STI team members felt that this role was critical and that they should focus on engaging groups outside the team.

It has been difficult to get this change to go forward from the bottom up. - STI Team Member

Most of the resistance from our team was probably frustration at dealing with others outside the group who weren't cooperating with the change.

- STI Team Member

Team members felt that engaging outside groups may help to reduce resistance to the change and make their task of implementation easier in the long run.

The third category of responses dealt with the need to increase the support for change team members to help make them more effective in their role. One in six STI team members at $\mathrm{T} 2$ felt that the team and the organization as a whole needed to do a better job of supporting the contract workers on the team. 
Change consultants may or may not want to come back based on how they were treated. - STI Team Member

Change often requires consultants or outside experts, you need to manage those resources well. $\quad$-STI Team Member

Contracted resources face more resistance than FTE's when implementing change. - STI Team Member

The contract workers that respondents were referring to were consultants with experience and expertise in organizational change and STI Team Member recognized the importance to the overall success of the change effort of supporting these workers in their jobs. According to STI Team members it was important for full time employees to help contract workers navigate the bureaucratic and political sides of the organization. The idea of knowledge transfer was also linked to the responses within this grouping. STI team members felt that the team was at risk of losing valuable knowledge about the change if consultants were simply let go without transferring their knowledge of the change process to full time employees.

At T2 STI team members (33\%) also discussed the need for the team to lobby for senior management support for their change projects. This finding was a prevalent theme in the data and team members suggested that increased support form senior management would have a positive impact on change team effectiveness. Specifically, STI team members felt that the team change would be much further ahead if senior management would take ownership for the change.

People tend to look for the negative if they can't see the value to their own role. Senior Management needs to communicate the value of the change. 
Our senior leadership hasn't owned the change, and so our group has been stuck. -STI Team Member

We should have been more forceful in our communication to the top executive. - STI Team Member

As is evident from the quotes STI team members felt that each change project should have a senior level manager to sponsor it. Responses suggested that STI team members felt that senior level support would give them more credibility and alleviate many of the concerns of outside groups that were impacted by the change. This category of responses increased from zero team members to $33 \%$ of team members at T2. The STI team members reported that increased support from senior management would be particularly valuable during the acceptance stage of the change where the team was working towards the final implementation of the change.

\subsubsection{Improvements to the Team}

There were four categories of responses arising from the data that addressed the improvements to how the STI team worked together: improved communication, increased coordination, meeting deadlines, and more efficient human resource processes. At T1 almost half ( $42 \%)$ of the STI team reported that the team needed to improve their communication to outside groups and individuals. At T2 this number had doubled (83\%). This suggests that communication to those outside the team was even more important to the team during the acceptance stage of the change and that improving this area would help the team complete the final tasks related to implementing the change. 
Employees are not getting the information about the change that they need, to make informed decisions. - STI Team Member

When you communicate on a change team you have to make sure that your audience's needs are met when you are done, don't communicate blindly.

-STI Team Member

We've been say the same thing for a year, but it has taken 11 months for people to actually hear it. - STI Team Member

Team members reflected on their past year and described their communication role as one of the most important jobs of their team. The general tone of the responses was that the team felt that they were responsible for getting the message of change out to the organization but that they were not necessarily getting the support from management that would make that task easier. Nevertheless, STI team members acknowledged the importance of communicating to employees outside of their team and reported that improvements in this area would help the team to be more effective in their role.

The second area of improvement suggested by STI team members was the level of collaboration on the team. At T2 this issue was very important to team members who were working closely together to complete the proof of concept document. In fact, at T2 almost half ( $42 \%$ of STI team members) noted that their team could be more effective if they improved their level of collaboration on the change team.

When there is a disconnect between the groups and projects (within our team) the change won't be moved forward. - STI Team Member

STI team members commented that with a change as large as the one they were responsible for there were so many available tasks it was easy to lose track of what the team as a whole was trying to accomplish. Team members cautioned against becoming 
disjointed and separated in their approach. STI team members felt that change teams would perform more effectively if they were able to collaborate on projects and most importantly share information on the change.

The third category of responses for this interview question related to the ability of the STI team to meet deadlines. A small number of the team $(17 \%$ at T2) felt that the team would be more effective if they were able to move more quickly to meet deadlines. This response was tied to comments made by $33 \%$ of STI team members at T2 who stated that slow and cumbersome HR processes were holding up the work of the team.

You need to have flexible HR practices; you need to be able to get people on your team quickly. - STI Team Member

We have never had the resources necessary to do the task, we needed admin support. - STI Team Member

The general message from the STI team was that the change required an unpredictable set of skills and experiences. It was necessary at various times in their work to bring on new consultants or to transfer employees onto their team who possessed the skill sets required. However, the slow HR practices prevented the team from taking advantage of those resources and left the team short-handed for many of those tasks. STI team members recommended having a streamlined HR strategy for the change team from the start. STI team members felt that it was critical for change teams to be able to move people on and off the team as efficiently as possible to meet the demands of the task. 


\subsection{CHANGE TEAM EFFECTIVENESS}

One of the strengths of this research design is the mixed method approach to studying change team effectiveness. The first two sections of this chapter examined the positive and negative factors influencing the effectiveness of the STI change team that were reported from the interview data. This section presents the quantitative data gathered on the factors that may influence change team effectiveness. This section begins by presenting the longitudinal quantitative data on the effectiveness of the STI team. STI team members were asked to rate the performance, satisfaction, and viability of the team. The second subsection displays the results for the $\mathrm{T} 1$ and $\mathrm{T} 2$ survey data on each of the three dimensions of change examined: stress, workload, and support for the change. The third subsection presents the data on the five team effectiveness themes from Campion's model of change: task design, team interdependence, composition, process, and context. The quantitative results from the team effectiveness survey provide a clearer picture of the effectiveness of the STI team by focusing on the factors have traditionally been used to study team effectiveness.

\subsubsection{Dimensions of Change Team Effectiveness}

At the heart of the change team effectiveness model is the change team effectiveness construct. In this study the effectiveness of the STI team was measured using three change team effectiveness variables: satisfaction, performance, and viability. The questions that were used to obtain the data related to the effectiveness of the STI change team are presented in Part 2 of the survey shown in Appendix C. Table 10-5 
displays the distribution of the responses from team members on the summary variables relating to the effectiveness of the STI change team.

Table 10-5 STI Team Effectiveness

\begin{tabular}{|c|c|c|c|c|c|}
\hline \multicolumn{6}{|c|}{ STI Team Effectiveness } \\
\hline \multirow[t]{5}{*}{ Team Satisfaction } & & \multicolumn{2}{|c|}{$\begin{array}{l}\text { Time } 1 \\
\mathrm{~N}=12 \\
\end{array}$} & \multicolumn{2}{|c|}{$\begin{array}{l}\text { Time } 2 \\
\mathrm{~N}=12 \\
\end{array}$} \\
\hline & & $\overline{\mathrm{N}}$ & $\%$ & $\mathrm{~N}$ & $\%$ \\
\hline & Satisfied & 10 & $83 \%$ & 10 & $83 \%$ \\
\hline & Neutral & 2 & $17 \%$ & 2 & $17 \%$ \\
\hline & Dissatisfied & 0 & $0 \%$ & 0 & $0 \%$ \\
\hline \multirow[t]{5}{*}{ Team Performance } & & \multicolumn{2}{|c|}{$\begin{array}{c}\text { Time } 1 \\
\mathrm{~N}=12\end{array}$} & \multicolumn{2}{|c|}{$\begin{array}{l}\text { Time 2 } \\
\mathrm{N}=12\end{array}$} \\
\hline & & $\mathrm{N}$ & $\%$ & $\mathrm{~N}$ & $\%$ \\
\hline & Performing well & 11 & $92 \%$ & 10 & $83 \%$ \\
\hline & Neutral & 1 & $8 \%$ & 2 & $17 \%$ \\
\hline & Performing poorly & 0 & $0 \%$ & 0 & $0 \%$ \\
\hline \multirow[t]{5}{*}{ Team Viability } & & \multicolumn{2}{|c|}{$\begin{array}{l}\text { Time } 1 \\
\mathrm{~N}=12\end{array}$} & \multicolumn{2}{|c|}{$\begin{array}{l}\text { Time } 2 \\
\mathrm{~N}=12\end{array}$} \\
\hline & & $\mathrm{N}$ & $\%$ & $\mathrm{~N}$ & $\%$ \\
\hline & Viable & 2 & $17 \%$ & 9 & $75 \%$ \\
\hline & Neutral & 3 & $25 \%$ & 3 & $25 \%$ \\
\hline & Not Viable & 7 & $58 \%$ & 0 & $0 \%$ \\
\hline
\end{tabular}

The results show that the satisfaction levels of the STI team remained constant through both the resistance and acceptance phases of the change. Four out of every five STI team members indicated that they were satisfied with their experience on the change team and the remaining team members were neutral when asked about their level of satisfaction with the team experience. These results suggest that the STI team was generally satisfied with the team itself.

A similar result was seen in the team performance summary variable. All but one of the STI team members rated their team as performing well or higher and none of the team described the change team as performing poorly. STI team members rated their 
team's performance on quality, delivering work on time, satisfying their supervisor, and satisfying the expectations of their clients. All the results at $\mathrm{T} 2$ were similar to those given at T1 indicating that the STI team felt that they performed well during both of the resistance and acceptance phases of the change.

The STI team viability score was the one aspect of team effectiveness that was not consistent over time. During the resistance phase of the change $58 \%$ of team members reported that they did not want to work with the team on any future change projects. This result could be linked to the struggles of the resistance phase where researchers (Elrod \& Tippett, 2002) have described a feeling of despair and frustration. This frustration was shown in the responses to the question shown in Table $10-6$. Over half $(58 \%)$ of the STI team responded that they would not enjoy working together with the team in the future.

Table 10-6 Working together as a team in the future

\section{Working together in the future}

Q. I would enjoy working together with this team in the future

Time 1 $\mathrm{N}=12$
Time 2 $\mathrm{N}=12$

\begin{tabular}{llccccc} 
& & $\mathrm{N}$ & $\%$ & & $\mathrm{~N}$ & $\%$ \\
\hline & Agree & 3 & $25 \%$ & & 9 & $75 \%$ \\
\cline { 2 - 3 } \cline { 6 - 8 } & Neutral & 2 & $17 \%$ & & 3 & $25 \%$ \\
\cline { 2 - 3 } & Disagree & 7 & $58 \%$ & & 0 & $0 \%$ \\
\hline
\end{tabular}

At T2 (during the acceptance phase of the change) the viability of the team reversed and $75 \%$ of the STI team reported that they felt the team could work together effectively on similar projects in the future. Similarly, at $\mathrm{T} 275 \%$ of the team indicated that they would enjoy working together in the future. This difference between $\mathrm{T} 1$ and $\mathrm{T} 2$ may be related 
to the stage of the change. The findings related to viability are examined further in Part 7 of this thesis.

\subsubsection{Dimensions of Change}

A primary contribution of this research is the potential discovery of how the model for effective change teamwork may differ from traditional team effectiveness models. In the review of the literature three areas were identified to quantitatively measure for the case study of the STI change team: job stress, workload, and support for the change. Each of these three dimensions of change was measured in the change team effectiveness survey at both $\mathrm{T} 1$ and $\mathrm{T} 2$. For each dimension the individual team members scores were calculated by averaging the responses on each item within the summary variable then grouping the scores according to three groups: high (scores of $x \geq 3.51$ ), moderate (scores of $3.50 \geq x \geq 2.50$ ), and low (scores of $x<2.5$ ). This method for calculating scores on each of the three dimensions of change was chosen rather than simply averaging the scores for the entire team due to the qualitative nature of the study. For The results from the STI team are presented below in Table 10-7. For the STI change team levels of perceived job stress appeared to be moderate for the most part. Only one team member reported experiencing high levels of job stress at $\mathrm{T} 2$ and the majority of team members at both $\mathrm{T} 1$ and $\mathrm{T} 2$ reported that they had either moderate or low levels of job stress. 
Table 10-7 Dimensions of Change

\section{Impacts of the Change}

\begin{tabular}{|c|c|c|c|c|c|}
\hline \multirow[t]{5}{*}{ Job Stress } & & \multicolumn{2}{|c|}{$\begin{array}{c}\text { Time } 1 \\
\mathrm{~N}=12\end{array}$} & \multicolumn{2}{|c|}{$\begin{array}{c}\text { Time } 2 \\
\mathrm{~N}=12\end{array}$} \\
\hline & & $\mathrm{N}$ & $\%$ & $\mathrm{~N}$ & $\%$ \\
\hline & High & 0 & $0 \%$ & 1 & $8 \%$ \\
\hline & Moderate & 7 & $58 \%$ & 5 & $42 \%$ \\
\hline & Low & 5 & $42 \%$ & 6 & $50 \%$ \\
\hline \multirow[t]{5}{*}{ Workload } & & \multicolumn{2}{|c|}{$\begin{array}{l}\text { Time } 1 \\
\mathrm{~N}=12\end{array}$} & \multicolumn{2}{|c|}{$\begin{array}{c}\text { Time } 2 \\
\mathrm{~N}=12\end{array}$} \\
\hline & & $\mathrm{N}$ & $\%$ & $\mathrm{~N}$ & $\%$ \\
\hline & High & 0 & $0 \%$ & 0 & $0 \%$ \\
\hline & Moderate & 7 & $58 \%$ & 7 & $58 \%$ \\
\hline & Low & 5 & $42 \%$ & 5 & $42 \%$ \\
\hline \multirow[t]{5}{*}{ Resistance to the change } & & \multicolumn{2}{|c|}{$\begin{array}{c}\text { Time } 1 \\
\mathrm{~N}=12\end{array}$} & \multicolumn{2}{|c|}{$\begin{array}{c}\text { Time } 2 \\
\mathrm{~N}=12\end{array}$} \\
\hline & & $\mathrm{N}$ & $\%$ & $\mathrm{~N}$ & $\%$ \\
\hline & High & 0 & $0 \%$ & 0 & $0 \%$ \\
\hline & Moderate & 1 & $8 \%$ & 2 & $17 \%$ \\
\hline & Low & 11 & $92 \%$ & 10 & $83 \%$ \\
\hline \multicolumn{6}{|l|}{ Support for the change } \\
\hline & & \multicolumn{2}{|c|}{$\begin{array}{c}\text { Time } 1 \\
N=12\end{array}$} & \multicolumn{2}{|c|}{$\begin{array}{c}\text { Time } 2 \\
\mathrm{~N}=12\end{array}$} \\
\hline & & $\mathrm{N}$ & $\%$ & $\mathrm{~N}$ & $\%$ \\
\hline & High & 1 & $8 \%$ & 11 & $92 \%$ \\
\hline & Moderate & 10 & $83 \%$ & 1 & $8 \%$ \\
\hline & Low & 1 & $8 \%$ & 0 & $0 \%$ \\
\hline
\end{tabular}

Table 10-8 provides a better view of the fluctuations of job stress on the team. For onethird of the change team, their level of job stress was increasing during the resistance phase of the change. This trend reversed at $\mathrm{T} 2$ where $25 \%$ of the change team responded that their job stress levels were actually decreasing during the acceptance phase of the change. 
Table 10-8 Changes in job stress during the change

\section{Job Stress increase/decrease}

Q. Please think back to the amount of job related stress that you experienced in the last six months. Now think about the amount of job stress you are currently experiencing. Has your job stress:

\begin{tabular}{|c|c|c|c|c|}
\hline \multirow{2}{*}{$\begin{array}{l}\text { amount of job related } \\
\text { ed in the last six months. } \\
\text { unt of job stress you are } \\
\text { Ias your job stress: }\end{array}$} & \multicolumn{2}{|c|}{$\begin{array}{l}\text { Time } 1 \\
\mathrm{~N}=12\end{array}$} & \multicolumn{2}{|c|}{$\begin{array}{l}\text { Time } 2 \\
\mathrm{~N}=12\end{array}$} \\
\hline & $\bar{N}$ & $\%$ & $\mathrm{~N}$ & $\%$ \\
\hline Increased & 4 & $33 \%$ & 2 & $16 \%$ \\
\hline Not really changed & 8 & $67 \%$ & 7 & $58 \%$ \\
\hline Decreased & $\overline{0}$ & $0 \%$ & 3 & $25 \%$ \\
\hline
\end{tabular}

These results are consistent with Elrod and Tippett's (2002) explanation of the impact of change on employees which suggests that the resistance phase of the change is the most stressful and challenging for employees.

Similar to job stress, workload levels were found to be manageable for the STI team. One notable result shown in Table 10-9 suggests that STI team members felt that their workload levels had increased during the resistance phase of the change when compared to the initial anticipation phase. Almost half of the team felt that their workload had increased during the resistance phase of the change.

Table 10-9 Changes in workload during the change

\section{Workload increase/decrease}

Q. Please think back to the amount of time you spent in work-related activities six month ago. Now think about your current workload. Has your workload:

Time 1

$\mathrm{N}=12$
Time 2

$\mathrm{N}=12$

$\begin{array}{lll}\mathrm{N} & \mathrm{N} & \mathrm{N}\end{array}$

\begin{tabular}{lcccc} 
Increased & 5 & $42 \%$ & 2 & $16 \%$ \\
\hline Not really changed & 6 & $50 \%$ & 8 & $67 \%$ \\
\hline Decreased & 1 & $8 \%$ & 1 & $8 \%$ \\
\hline
\end{tabular}


These results suggest that during the resistance phase change teams should be prepared for an increase in the amount of work and adjust their staffing strategies accordingly. During the acceptance phase the workload levels appeared to remain at levels comparable to the resistance phase with two-thirds of the team indicated that the level of workload remained consistent during the acceptance phase.

The final two variables examining the impact of the change environment on change team effectiveness were the levels of support and resistance for the change that was present on the team. The data for this summary variable show that support for the change increased substantially at T2 with $92 \%$ of STI team members indicating that the team was fully supportive of the change (an increase of $83 \%$ over T1). However, at T1 three out of every four STI team members responded that they did not actively encourage others to support the change. At T2 $83 \%$ of the team reported that they actively encouraged others in their organization to support the change effort. This increase in the level of support for the change initiative may be tied to the stage of the change. As discussed earlier, the resistance phase of the change (T1) is a naturally occurring phenomenon which has been shown to effect individual's performance and their attitudes as they work on the change. The findings in Table 10-7 support the existing literature (Elrod \& Tippett, 2002) and suggest that teams working on change may struggle to stay supportive during the resistance phase and supports the idea that individuals on change teams go through a decline in support for the change similar to those not working on a change team. 


\subsubsection{Dimensions of Teamwork}

Having examined the impact of the organizational change factors on the STI team this section completes the picture of change team effectiveness by presenting the data on the dimensions of traditional teamwork that were measured for the STI change team. As discussed in Section 8.3.2.1 five teamwork themes were measured in the survey: task design, interdependence, composition, context, and process. This subsection presents the responses from STI team members on each of the variables contained within the five teamwork themes. For each of the variables the results from $\mathrm{T} 1$ are presented first followed by a description of how the results changed over time.

\subsubsection{Change Team Task Design}

The task design theme is made up of six variables related to the task of the change team: task direction, task identity, self-management, participation, task variety, and task significance. Table 10-10 presents the data for each of the six variables in the task design theme.

The data on task direction for the STI change team indicates that at $\mathrm{T} 1$, team members did not feel that their team's task was clear and specific (i.e. almost half (42\%) of the team felt that the team lacked a clear and specific set of tasks to guide their work). At T2 the opinions of STI team members were more evenly split with only $33 \%$ of team members reporting that the team still lacked a clear direction, compared to $25 \%$ of the team responding that they felt that the team did in fact have a clear and specific task. 
Table 10-10 Task design

\section{Task Design Variables}

Task Direction: The team's task is clear and

Time 1

$\mathrm{N}=12$

Time 2 specific

\begin{tabular}{lcccc} 
& $\mathrm{N}$ & $\%$ & $\mathrm{~N}$ & $\%$ \\
\cline { 2 - 5 } High & 1 & $8 \%$ & 3 & $25 \%$ \\
\hline Medium & 6 & $50 \%$ & 5 & $42 \%$ \\
\hline Low & 5 & $42 \%$ & 4 & $33 \%$ \\
\hline
\end{tabular}

Task Identity: This team works on a clearly identifiable task.

Time 1

$\mathrm{N}=12$

Time 2

$\mathrm{N}=12$

\begin{tabular}{lcccc} 
& $\mathrm{N}$ & $\%$ & $\mathrm{~N}$ & $\%$ \\
\cline { 2 - 5 } High & 1 & $8 \%$ & 3 & $33 \%$ \\
\hline Medium & 8 & $67 \%$ & 7 & $58 \%$ \\
\hline Low & 3 & $25 \%$ & 0 & $0 \%$ \\
\hline
\end{tabular}

Self-Management: The team has a high level of autonomy in their work

Time 1

Time 2

$\mathrm{N}=12$

$\mathrm{N}=12$

\begin{tabular}{lcccc} 
& $\mathrm{N}$ & $\%$ & $\mathrm{~N}$ & $\%$ \\
\cline { 2 - 5 } High & 3 & $25 \%$ & 8 & $67 \%$ \\
\hline Medium & 8 & $67 \%$ & 4 & $33 \%$ \\
\hline Low & 1 & $8 \%$ & 0 & $25 \%$ \\
\hline
\end{tabular}

Participation: This team has balanced participation from team members on decisions that impact the team.

Time 1

$\mathrm{N}=12$
Time 2

$\mathrm{N}=12$

\begin{tabular}{lcccc} 
& $\mathrm{N}$ & $\%$ & $\mathrm{~N}$ & $\%$ \\
\cline { 2 - 5 } High & 5 & $42 \%$ & 10 & $83 \%$ \\
\hline Medium & 2 & $17 \%$ & 2 & $17 \%$ \\
\hline Low & 5 & $42 \%$ & 0 & $0 \%$ \\
\hline
\end{tabular}

Task Variety: The team provides a variety of tasks for team members to perform

Time 1

Time 2

$\mathrm{N}=12$

$\mathrm{N}=12$

\begin{tabular}{lcccc} 
& $\mathrm{N}$ & $\%$ & $\mathrm{~N}$ & $\%$ \\
\cline { 2 - 5 } High & 2 & $17 \%$ & 2 & $17 \%$ \\
\hline Medium & 6 & $50 \%$ & 9 & $75 \%$ \\
\hline Low & 3 & $25 \%$ & 1 & $8 \%$ \\
\hline
\end{tabular}

Task Significance: The team views their task as meaningful and significant

Time 1

Time 2

High

$\mathrm{N}=12$

$\mathrm{N}=12$

\begin{tabular}{lcccc}
\cline { 2 - 5 } High & 3 & $25 \%$ & 8 & $67 \%$ \\
\hline Medium & 8 & $67 \%$ & 4 & $33 \%$ \\
\hline Low & 1 & $8 \%$ & 0 & $25 \%$ \\
\hline
\end{tabular}


Overall, these data indicate that the overall perception of the STI team was that their work task was not clear. At $\mathrm{T} 1$ the lack of clarity was particularly pronounced suggesting that during the resistance phase of the change it is difficult for change team members to understand what it is they need to do. This result is suggests that the change team felt a need for task clarity as they entered the acceptance phase.

The task identity of a team refers the degree to which a team works on a clearly distinguishable task. STI team members reported that at T1 they did not feel that their task was clearly identifiable throughout the organization. This finding is consistent with comments during the interviews conducted in the resistance phase. At T2 the team felt that their task was more identifiable, with one in three team members perceiving a clear task identity.

The third variable in the task design theme is the level of self-management that the team experienced. The results in Table 10-10 show that team member's perceptions underwent a major shift between the $\mathrm{T} 1$ and $\mathrm{T} 2$ data collection periods. In the resistance phase of the change only $25 \%$ of the team members felt that the team had a high level of autonomy in their task as compared to the $67 \%$ of the team who felt that they had a high level of autonomy at $\mathrm{T} 2$.

The level of participation experienced by STI team members was another variable which showed a substantial increase change over time. At T2 twice as many team members felt that team decisions were made based on balanced participation from team members.

The final two variables in the task design theme were task variety and task significance. The task variety data indicated that the majority of ST team members did 
not feel that their task offered a varied amount of work for the team. This result remained consistent at $\mathrm{T} 2$ suggesting that the variety of tasks offered to team members was not dependent on the stage of the change. In contrast, the responses of STI team members concerning the level of task significance changed substantially from T1 to T2. At T1 only $17 \%$ of the team indicated that the felt that their work on the change was important to the organization and the change effort as a whole. At T2, three out of every four STI team members responded that that they found their task both meaningful and significant at $\mathrm{T} 2$. This shift in perceived significance may be related to the phase of the change and the attitude of the organization towards the Wave 1 change initiative. During the resistance phase many in the organization viewed the change negatively. When the organization moved into the acceptance phase the attitude shifted to a more positive view, which seems to have put the work of the STI team in a better light and had an impact on the perceived significance of the task for STI team members. This is seen by comparing the number of STI team members at T2 who felt that their work with their team helped them to feel important to the organization to the number of team members at $\mathrm{T} 1$ who gave this response at $\mathrm{T} 1$ (an increase of $42 \%$ over time).

\subsubsection{Change Team Interdependence}

The importance of interdependence for team effectiveness is a fundamental of teamwork that is strongly supported in the teamwork literature (Saavedra et al., 1993). The team interdependence theme is made up of three variables related to the level of interdependence: task, goal, and feedback interdependence. Table 10-11 presents the data for each of the three variables in the team interdependence theme. 
Table 10-11 Change team interdependence

\begin{tabular}{|c|c|c|c|c|}
\hline \multicolumn{5}{|l|}{ Team Interdependence Variables } \\
\hline $\begin{array}{l}\text { Task Interdependence: The team has a high level } \\
\text { of interaction required to complete their task }\end{array}$ & \multicolumn{2}{|c|}{$\begin{array}{l}\text { Time } 1 \\
\mathrm{~N}=12 \\
\end{array}$} & \multicolumn{2}{|c|}{$\begin{array}{l}\text { Time } 2 \\
\mathrm{~N}=12\end{array}$} \\
\hline & $\bar{N}$ & $\%$ & $\mathrm{~N}$ & $\%$ \\
\hline High & 1 & $8 \%$ & 5 & $42 \%$ \\
\hline Medium & 7 & $58 \%$ & 6 & $50 \%$ \\
\hline Low & 4 & $33 \%$ & 1 & $8 \%$ \\
\hline $\begin{array}{l}\text { Goal Interdependence: The team and individual } \\
\text { goals are interdependent }\end{array}$ & \multicolumn{2}{|c|}{$\begin{array}{l}\text { Time } 1 \\
\mathrm{~N}=12\end{array}$} & \multicolumn{2}{|c|}{$\begin{array}{l}\text { Time } 2 \\
\mathrm{~N}=12\end{array}$} \\
\hline & $\mathrm{N}$ & $\%$ & $\mathrm{~N}$ & $\%$ \\
\hline High & 3 & $25 \%$ & 5 & $42 \%$ \\
\hline Medium & 7 & $58 \%$ & 7 & $58 \%$ \\
\hline Low & 2 & $17 \%$ & 0 & $0 \%$ \\
\hline $\begin{array}{l}\text { Feedback Interdependence: The team receives } \\
\text { feedback based on the team's performance }\end{array}$ & \multicolumn{2}{|c|}{$\begin{array}{l}\text { Time } 1 \\
\mathrm{~N}=12\end{array}$} & \multicolumn{2}{|c|}{$\begin{array}{l}\text { Time } 2 \\
\mathrm{~N}=12\end{array}$} \\
\hline & $\mathrm{N}$ & $\%$ & $\mathrm{~N}$ & $\%$ \\
\hline High & 1 & $8 \%$ & 4 & $33 \%$ \\
\hline Medium & 7 & $58 \%$ & 5 & $42 \%$ \\
\hline Low & 4 & $33 \%$ & 3 & $25 \%$ \\
\hline
\end{tabular}

At $\mathrm{T} 1$ the majority of team members reported moderate to low levels of task, goal, and feedback interdependence. As the team moved from the resistance to acceptance phase of the change the results at $\mathrm{T} 2$ show that, in general the level of interdependence on the STI team increased over time, suggesting that as change teams near the end of the change during the acceptance phase their level of interdependence may increase. In addition, the results also indicate that feedback interdependence was the lowest form of interdependence experienced by the STI team. This result may be symptomatic of the lack of clarity in the team's task, as indicated by team members, which would have made providing feedback on the team's task difficult. 


\subsubsection{Change Team Composition}

The composition of the change team was a prevalent theme in the interview data examining team effectiveness that was presented in Sections 10.1 and 10.2. STI team members discussed the need for a variety of skills and experience and the importance of flexibility in the team member's roles.

Table 10-12 Change team composition

\section{Composition Variables}

Bounded Membership: The team is recognizable as a distinct unit in the organization

Time 1 $\mathrm{N}=12$
Time 2 $\mathrm{N}=12$

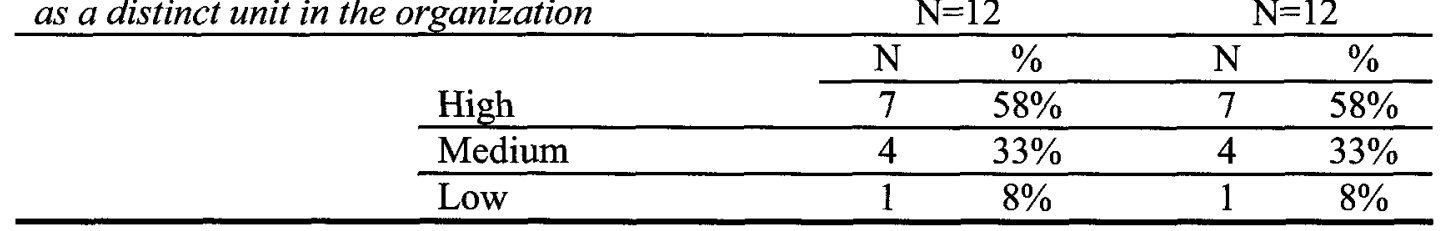

Heterogeneity: The team has an adequate mix of skills/talents and experience to complete the task

Time 1

\begin{tabular}{l} 
skills/talents and experience to complete the task \\
\hline
\end{tabular}

Time 2 $\mathrm{N}=12$

Flexibility: The team is able to adjust roles to fit the demands of the task

Time 1 $\mathrm{N}=12$
Time 2 $\mathrm{N}=12$

\begin{tabular}{lcccc} 
& $\mathrm{N}$ & $\%$ & $\mathrm{~N}$ & $\%$ \\
\cline { 2 - 5 } High & 3 & $25 \%$ & 3 & $25 \%$ \\
\hline Medium & 5 & $42 \%$ & 8 & $67 \%$ \\
\hline Low & 4 & $33 \%$ & 1 & $8 \%$ \\
\hline
\end{tabular}

Relative Size: The team has an adequate number of members to perform their task

Time 1

\begin{tabular}{lcccc} 
& \multicolumn{2}{c}{$\mathrm{N}=12$} & \multicolumn{2}{c}{$\mathrm{N}=12$} \\
\cline { 2 - 5 } High & $\mathrm{N}$ & $\%$ & $\mathrm{~N}$ & $\%$ \\
\hline Medium & 7 & $58 \%$ & 7 & $58 \%$ \\
\hline Low & 5 & $42 \%$ & 5 & $42 \%$ \\
\hline
\end{tabular}


The quantitative measure of team composition was a part of the change team survey and consists of four variables: bounded membership, heterogeneity, flexibility, and relative size. Table 10-12 presents the data for each of the four variables in the team composition theme. The data on team composition identifies three areas where the STI team members perceived that the team's membership was well set up to accomplish their task: bounded membership, heterogeneity, and size. The responses to the bounded membership and size questions showed that at both $\mathrm{T} 1$ and $\mathrm{T} 2$ the majority of the team (58\%) agreed that the team was recognizable as a distinct unit in the organization and had an adequate number of members to perform their tasks.

The response data from the heterogeneity variable showed that at $\mathrm{T} 1$ a number of STI team members $(33 \%)$ did not perceive that their team had the right mix of skills and experience to handle the resistance phase of the change. These numbers improved during the acceptance phase where $75 \%$ of the team perceived that the team had the necessary mix of skills and experience to implement the change (an increase of $25 \%$ over time).

The final variable in the team composition theme was team flexibility. Consistent with the qualitative data in this study, the data shows that at both $\mathrm{T} 1$ and $\mathrm{T} 2$ the majority of STI team members did not feel that their team had the flexibility to adjust the roles on the team to better accomplish their task. The negative perception was most pronounced during the resistance phase of the change where one-third of team stated that they didn't believe that the team had enough flexibility to address their task of implementing change. 


\subsubsection{Change Team Processes}

The team processes that influence change team effectiveness were the topic of the fourth set of variables included in the change team effectiveness survey. Included in this theme were four variables: potency, social support, workload sharing, and within-team communication. Table $10-13$ presents the data for each of the four variables in the team processes theme.

\section{Table 10-13 STI Change Team Processes}

\section{Process}

\begin{tabular}{|c|c|c|c|c|}
\hline $\begin{array}{l}\text { Potency: The team believes that it can be } \\
\text { effective }\end{array}$ & & & & \\
\hline & $\overline{\mathrm{N}}$ & $\%$ & $\overline{\mathrm{N}}$ & $\%$ \\
\hline High & 3 & $25 \%$ & 7 & $58 \%$ \\
\hline Medium & 4 & $33 \%$ & 5 & $42 \%$ \\
\hline Low & 4 & $33 \%$ & 0 & $0 \%$ \\
\hline
\end{tabular}

Social Support: Team members support one another

\begin{tabular}{lcccc} 
& \multicolumn{2}{c}{$\mathrm{N}=12$} & \multicolumn{2}{c}{$\mathrm{N}=12$} \\
\cline { 2 - 5 } High & $\mathrm{N}$ & $\%$ & $\mathrm{~N}$ & $\%$ \\
\hline Medium & 4 & $33 \%$ & 9 & $75 \%$ \\
\hline Low & 2 & $17 \%$ & 3 & $25 \%$ \\
\hline
\end{tabular}

\begin{tabular}{|c|c|c|c|c|}
\hline $\begin{array}{l}\text { Workload Sharing: The team does a good job } \\
\text { of sharing work as required }\end{array}$ & \multicolumn{2}{|c|}{$\begin{array}{c}\text { Time } 1 \\
\mathrm{~N}=12\end{array}$} & \multicolumn{2}{|c|}{$\begin{array}{l}\text { Time } 2 \\
N=12\end{array}$} \\
\hline & $\mathrm{N}$ & $\%$ & $\mathrm{~N}$ & $\%$ \\
\hline High & 1 & $8 \%$ & 1 & $8 \%$ \\
\hline Medium & 10 & $83 \%$ & 11 & $92 \%$ \\
\hline Low & 1 & $8 \%$ & 0 & $0 \%$ \\
\hline
\end{tabular}

Communicating within the team: The team communicates and coordinates work well with each other

\begin{tabular}{lcccc} 
& \multicolumn{2}{c}{ Time 1 } & \multicolumn{2}{c}{ Time 2 } \\
& \multicolumn{2}{c}{$\mathrm{N}=12$} & \multicolumn{2}{c}{$\mathrm{N}=12$} \\
\cline { 2 - 5 } High & $\mathrm{N}$ & $\%$ & $\mathrm{~N}$ & $\%$ \\
\hline Medium & 6 & $50 \%$ & 9 & $83 \%$ \\
\hline Low & 0 & $0 \%$ & 2 & $8 \%$ \\
\hline
\end{tabular}


The response data from the change team processes theme yielded some interesting and varied results. The first process variable was team potency. At T1 very few team members believed that the team could accomplish their goals (in fact, at $\mathrm{T} 1$ one in three STI team members felt that their team could not accomplish their goals). This is consistent with the research on the resistance phase of the change where individuals may begin to doubt the ability of the organization to change. At T2 the perception of the team was much more positive ( $58 \%$ with high potency) with none of the team's members indicating that they had a low level of potency in regards to the ability of the team accomplish their goals.

The level of social support on the STI team was another area that was perceived as being very low during the resistance phase of the change. The fact that $50 \%$ of the STI team felt that the team was not there to support each other during the most difficult stage of the change was an unexpected result. Whether team members felt more social support than they would have if they were working in isolation is a topic that merits future research as this would be an area where teams could in theory help to lessen the frustration and negativity that characterizes the resistance phase of the change. At T2 the level of perceived social support rose dramatically with over $75 \%$ of the team indicated that they felt well supported by each other. The perceived support from teammates may also be related to phase of the change in which the team is operating. Elrod and Tippet (2002) would suggest that the need for support would be highest during the resistance phase. In contrast, during the acceptance phase team members need less support from others as their task is clearer and their work less stressful. It may be that the level of 
support was constant over time and that these findings may therefore reflect the need for support rather than a lack of support for the team.

The final two variables in the team processes theme yielded two distinctly different results. Almost the entire team gave a neutral rating to the amount of workload sharing that the STI team engaged in at both T1 and T2. On the other hand, communication within the team was shown to be lacking in the eyes of half of the team's members at T1 but at T2 over $80 \%$ of the team felt that the STI team had a good level of intra-team communication. These results suggest that workload sharing was a weakness of the STI team and are consistent with interview and survey data which showed an uneven distribution of workloads across the team. It also appears that the team may have struggled to communicate with each other during the resistance phase but improved substantially during the acceptance phase.

\subsubsection{Change Team Context}

The importance of the context in which change teams operate is a fundamental part of the rationale for conducting this research. In this case study the STI team operates within PWGSC/ITSB to lead each of the Wave 1 departments through the change to shared services. To measure the context of the STI change team the survey asked questions of team members resulting in summary scores for three context variables: training, managerial support, and communication between teams. Table 10-14 presents the data for each of the three variables in the change team context theme. 
Table 10-14 Change Team Context

\section{Context}

\begin{tabular}{llcccc}
\multicolumn{2}{l}{$\begin{array}{l}\text { Training: The team receives adequate training to } \\
\text { complete their task }\end{array}$} & \multicolumn{2}{c}{$\begin{array}{c}\text { Time 1 } \\
\text { N=12 }\end{array}$} & \multicolumn{2}{c}{$\begin{array}{c}\text { Time } 2 \\
\mathrm{~N}=12\end{array}$} \\
\hline & & $\mathrm{N}$ & $\%$ & $\mathrm{~N}$ & $\%$ \\
\hline & High & 0 & $0 \%$ & 3 & $25 \%$ \\
\cline { 2 - 6 } & Medium & 3 & $25 \%$ & 4 & $33 \%$ \\
\cline { 2 - 6 } & Low & 9 & $75 \%$ & 4 & $33 \%$ \\
\hline
\end{tabular}

\begin{tabular}{|c|c|c|c|c|}
\hline $\begin{array}{l}\text { Managerial Support: The team receives adequate } \\
\text { managerial support for their work }\end{array}$ & \multicolumn{2}{|c|}{$\begin{array}{l}\text { Time } 1 \\
N=12\end{array}$} & \multicolumn{2}{|c|}{$\begin{array}{l}\text { Time } 2 \\
\mathrm{~N}=12\end{array}$} \\
\hline & $\mathrm{N}$ & $\%$ & $\mathrm{~N}$ & $\%$ \\
\hline High & 3 & $25 \%$ & 8 & $67 \%$ \\
\hline Medium & 3 & $25 \%$ & 4 & $33 \%$ \\
\hline Low & 6 & $50 \%$ & 0 & $0 \%$ \\
\hline $\begin{array}{l}\text { Communication/cooperation between teams: The } \\
\text { team communicates and works well with other } \\
\text { teams in the organization }\end{array}$ & \multicolumn{2}{|c|}{$\begin{array}{l}\text { Time } 1 \\
\mathrm{~N}=12\end{array}$} & \multicolumn{2}{|c|}{$\begin{array}{l}\text { Time } 2 \\
\mathrm{~N}=12\end{array}$} \\
\hline & $\mathrm{N}$ & $\%$ & $\mathrm{~N}$ & $\%$ \\
\hline High & 1 & $8 \%$ & 1 & $8 \%$ \\
\hline Medium & 10 & $83 \%$ & 11 & $92 \%$ \\
\hline Low & 1 & $8 \%$ & 0 & $0 \%$ \\
\hline
\end{tabular}

The first two variables in the change context theme were training and managerial support. The data show that the STI team members' perception of both of these factors of team effectiveness improved substantially over time. The level of training offered for the STI at T1 was found to be lacking by $75 \%$ of the team. STI team members clearly did not feel that they received the adequate level of training needed to handle the work that occurred during the resistance phase of Wave 1 . At T2 the results were slightly more positive, with one third of the team indicating that they were not adequately trained for their work and one quarter of the team suggesting that they were in fact well-trained. At first glance it may appear that the level of training improved during the acceptance phase however, when comparing these results to the interview data another interpretation arises. 
The STI change team received very little on the job training so it may be that the team member's previous training was better suited to the tasks that were completed during the acceptance phase and not the resistance phase. This interpretation would explain the negative view of their training at $\mathrm{T} 1$ and their neutral response at $\mathrm{T} 2$. These results would also suggest that specific training for the work in the resistance phase of the change may be a valuable way to improve change team effectiveness.

The managerial support variable followed a similar pattern to the data on the level of training provided to the STI team. At T1 (during the resistance phase of the change) half of STI team members reported that they did not feel that their team received adequate managerial support for their work. This finding along with data from the interviews suggests that managerial support may be an important factor in helping change teams to complete their work during the resistance phase of the change. At T2 the level of perceived managerial support increased as two out of every three STI members indicated that their team received an adequate level of support from management. Since the managers stayed the same during both time periods, this data suggests that of the change has a substantial impact on team ratings of both training and managerial support. It may be that team members were displacing their frustrations during the resistance phase onto the mangers. However, these results may also mean that training and managerial support need to be targeted at supporting the team during the resistance phase of the change.

The final variable in the context theme measured the level of perceived communication and coordination between the STI team and other groups in their organization. There were virtually no differences in the response given to this question over time with almost the entire team ( $83 \%$ at $\mathrm{T} 1,92 \%$ at $\mathrm{T} 2)$ indicating that they were 
neutral on the topic. This is a bit of a concern considering that the role of the change team is to lead the organization through transformational change.

\subsection{SUMMARY}

Chapter 10 laid the foundation for understanding the factors that may contribute to the effectiveness of change teams. Table 10-15 presents the major findings from the qualitative data for both T1 and T2 according to the two major themes in the data (change management and team management).

Table 10-15 Summary of the Qualitative STI change team data

\section{Qualitative Results (phase)}

\begin{tabular}{|c|c|c|c|c|c|c|}
\hline & \multicolumn{3}{|c|}{ Change Management } & \multicolumn{3}{|c|}{ Team Management } \\
\hline & $\begin{array}{l}\text { Resistance } \\
\text { Phase } \\
\text { (T1) }\end{array}$ & $\begin{array}{c}\text { Acceptance } \\
\text { Phase } \\
\text { (T2) }\end{array}$ & Both & $\begin{array}{l}\text { Resistance } \\
\text { Phase } \\
\text { (T1) }\end{array}$ & $\begin{array}{l}\text { Acceptance } \\
\text { Phase } \\
\text { (T2) }\end{array}$ & Both \\
\hline $\begin{array}{l}\text { Supportive } \\
\text { Change Teams } \\
\text { (Table 11-1) }\end{array}$ & $\begin{array}{l}\text { Communicate } \\
\text { the change }\end{array}$ & & $\begin{array}{l}\text { - Be a model for } \\
\text { change } \\
\text { - Be persistent and } \\
\text { committed }\end{array}$ & & & $\begin{array}{l}\text { - Interconnected } \\
\text { - Disciplined and } \\
\text { focused } \\
\text { - Variety of skills } \\
\text { and experience }\end{array}$ \\
\hline $\begin{array}{l}\text { Strengths of an } \\
\text { Effective Change } \\
\text { Team } \\
\text { (Table 11-2) }\end{array}$ & $\begin{array}{l}\text { - Build } \\
\text { Commitment }\end{array}$ & $\begin{array}{l}\text { - Develop a } \\
\text { change } \\
\text { methodology }\end{array}$ & $\begin{array}{l}\text { Engage others } \\
\text { outside the team }\end{array}$ & & $\begin{array}{l}\text { - Clarified the } \\
\text { task }\end{array}$ & $\begin{array}{l}\text { - Disciplined } \\
\text { project } \\
\text { management } \\
\text { - Team } \\
\text { collaboration }\end{array}$ \\
\hline $\begin{array}{l}\text { Resisting the } \\
\text { change } \\
\text { (Table 11-3) }\end{array}$ & & & $\begin{array}{l}\text { - Focus on failures } \\
\text { - Failure to } \\
\text { collaborate } \\
\text { - No } \\
\text { accountability }\end{array}$ & & & $\begin{array}{l}\text { - Poor } \\
\text { communication } \\
\text { - Doesn't work } \\
\text { hard }\end{array}$ \\
\hline $\begin{array}{l}\text { Improving } \\
\text { Change Team } \\
\text { Effectiveness } \\
\text { (Table 11-4) }\end{array}$ & & $\begin{array}{l}\text { - Senior level } \\
\text { support }\end{array}$ & $\begin{array}{l}-+ \text { Reassess the } \\
\text { change } \\
-+ \text { Critical mass }\end{array}$ & & $\begin{array}{l}\text { - Improve our } \\
\text { communication } \\
\text { - Work together } \\
\text { - More efficient } \\
\text { HR }\end{array}$ & \\
\hline
\end{tabular}

Throughout the chapter an important pattern that emerged was that STI team members talked about two main themes when it came to change team effectiveness: change management and team management. These suggest that in order to model change team 
effectiveness it is necessary to consider factors related to both the management of change and the management of teamwork literatures.

In the first section of this chapter STI team members put forth several factors that they felt had a positive impact on their ability as a team to implement change. The results suggest that change teams who are able to communicate the change, build commitment, engage outsiders, and be a role model for behavior may be at an advantage in their role as agents of change. On the teamwork side, the data suggest that a variety of skills and experience, a high level of interconnectedness, a disciplined approach to project management, and a clear, specific task are all potentially influential factors of change team effectiveness. In addition to identifying some of the factors that may positively influence change team effectiveness, the data included in this section also highlighted which factors were necessary for team effectiveness regardless of the phase of the change and which factors varied in importance depending on the phase of the change the team was in.

To further examine the phenomenon of change team effectiveness, Section 10.2 presented the factors which may inhibited change team effectiveness. The data presented in this section suggest that a lack of support from management, an unclear direction for the change, a lack of accountability, and a non-collaborative approach may all serve to limit the change team's ability to support and implement change. This section also presented the factors that may limit the change team's ability to work together effectively as a team. Some of the limiting factors include: poor intra-team communication, a lack of motivation, inefficient human resources processes, and a lack of coordination and collaboration on the team. Another finding in this section was that many of the factors 
that were reported to be limiting at $\mathrm{T} 1$ were not reported at $\mathrm{T} 2$, and visa versa. Due to the fact that the data collection periods came during two different phases of the Wave 1 change, this finding highlights the potential impact that the phase of the change may have on the effectiveness of change teams. It should also be noted that the factors which the team members felt had a negative impact on change team effectiveness also informed the development of a model of change team effectiveness (i.e this is not what to do).

Finally, in Section 10.3 the quantitative data from the change team effectiveness survey were presented to give us a more complete picture of the relationship between change and the $\mathrm{T} 1$ and $\mathrm{T} 2$ survey data used to quantify the five themes of effective teamwork and measure the three dimensions of change in the research framework. These results are summarized in Table 10-16.

Finally, it is important to note that in many cases both the quantitative and qualitative responses varied widely depending on the phase of the change that the team was operating in. This finding has an impact on how change teams may operate and suggests that the phase of the change merits consideration for the model of change team effectiveness. 
Table 10-16 Summary of the Quantitative STI change team data

\section{Quantitative Data (Phases)}

\begin{tabular}{|c|c|c|}
\hline & Resistance Phase & Acceptance Phase \\
\hline & Description of Responses & $\begin{array}{c}\text { Description of Responses } \\
\text { (increase/decrease from T1) }\end{array}$ \\
\hline \multicolumn{3}{|l|}{ Task Design } \\
\hline Direction & Majority low & $\begin{array}{l}\text { Majority low } \\
\text { (slight increase) }\end{array}$ \\
\hline Identity & Majority low & $\begin{array}{l}\text { Neutral/high } \\
\text { (Increased) }\end{array}$ \\
\hline Self-Management & Majority neutral & $\begin{array}{l}\text { Majority high } \\
\text { (increase) }\end{array}$ \\
\hline Participation & Bimodal - half yes, half no & $\begin{array}{l}\text { Majority high } \\
\text { (increase) }\end{array}$ \\
\hline Task Variety & Bell curve - majority neutral & $\begin{array}{l}\text { Positive skew } \\
\text { (increase) }\end{array}$ \\
\hline Task Significance & Neutral to high & $\begin{array}{l}\text { Majority high } \\
\text { (increase) }\end{array}$ \\
\hline \multicolumn{3}{|l|}{ Interdependence } \\
\hline Task & Majority low & $\begin{array}{l}\text { Majority high } \\
\text { (increased) }\end{array}$ \\
\hline Goal & Bell curve - majority neutral & $\begin{array}{l}\text { Majority medium/high } \\
\text { (increased) }\end{array}$ \\
\hline Feedback & Majority neutral/low & $\begin{array}{l}\text { Even distribution of responses } \\
\text { (increased) }\end{array}$ \\
\hline \multicolumn{3}{|l|}{ Composition } \\
\hline Bounded Membership & Majority high & $\begin{array}{l}\text { Majority high } \\
\text { (no change) }\end{array}$ \\
\hline Heterogeneity & Mostly high & $\begin{array}{l}\begin{array}{l}\text { Majority high } \\
\text { (increased) }\end{array} \\
\end{array}$ \\
\hline Flexibility & Even distribution of responses & $\begin{array}{l}\text { Mostly medium } \\
\text { (no change) }\end{array}$ \\
\hline Relative Size & Majority high & $\begin{array}{l}\text { Majority high } \\
\text { (no change) }\end{array}$ \\
\hline \multicolumn{3}{|l|}{ Process } \\
\hline Potency & Even spread & $\begin{array}{l}\text { Mostly high } \\
\text { (increased) }\end{array}$ \\
\hline Social support & Bimodal & $\begin{array}{l}\text { Majority high } \\
\text { (increase) }\end{array}$ \\
\hline Workload sharing & Majority moderate & $\begin{array}{l}\text { Majority moderate } \\
\text { (no change) }\end{array}$ \\
\hline $\begin{array}{l}\text { Communications within } \\
\text { team }\end{array}$ & Bimodal & $\begin{array}{l}\text { Majority high } \\
\text { (increase) }\end{array}$ \\
\hline \multicolumn{3}{|l|}{ Context } \\
\hline Training & Majority low & $\begin{array}{l}\text { Even distribution of responses } \\
\text { (increased) }\end{array}$ \\
\hline Managerial Support & Majority low & $\begin{array}{l}\text { Majority high } \\
\text { (increase) }\end{array}$ \\
\hline $\begin{array}{l}\begin{array}{l}\text { Communication } \\
\text { between teams }\end{array} \\
\end{array}$ & Almost all moderate & $\begin{array}{l}\text { Almost all moderate } \\
\text { (no change) }\end{array}$ \\
\hline \multicolumn{3}{|l|}{ Dimensions of Change } \\
\hline Workload & Moderate and low & $\begin{array}{l}\text { Moderate and low } \\
\text { (no change) }\end{array}$ \\
\hline Job Stress & Moderate and low & $\begin{array}{l}\text { Moderate and low } \\
\text { (no change) }\end{array}$ \\
\hline Support for the change & Majority moderate & $\begin{array}{l}\begin{array}{l}\text { Majority high } \\
\text { (increased) }\end{array} \\
\end{array}$ \\
\hline Resistance to the change & Low & $\begin{array}{l}\text { Low } \\
\text { (no change) }\end{array}$ \\
\hline
\end{tabular}




\section{SUPPORTING THE CHANGE TEAM}

The third objective of this research is prescriptive in nature and aims to provide recommendations for how improve the level of support provided to teams that are implementing change. This objective fits with the central theme of this research as it is assumed that a well supported change team will be better suited for effectiveness in their role implementing change. To address this objective, STI team members were asked several questions aimed at understanding what was necessary to support change teams in their role of implementing change. This chapter presents the key findings regarding this issue.

\subsection{IMPROVING SUPPORT FROM SENIOR MANAGEMENT}

The previous chapters in the results section have examined the performance of the STI change team and presented team members responses on the factors that may improve the effectiveness of change teams. This section focuses on the role of senior leadership and management support for change teams. Table 11-1 displays the results for the interview question asking team members to describe how they felt the organization could better support change teams.

The table of results shown above illustrates the recommendations can be broken down into three categories: supporting the implementation of change, supporting better teamwork, and support to help both the change and teamwork. Within the three main themes, the only area of consensus that emerged from the data was that team members felt that their change team needed greater support for the change. 
Table 11-1 Supporting Change Teams

\section{How can your organization better support change teams?}

Research Question: What could your organization do to help maximize the benefits and minimize the challenges associated with being a part of a change team?

Time 1

$\mathrm{N}=12$
Time 2

\begin{tabular}{lllllc}
\hline Supporting Change Management & 12 & $100 \%$ & 12 & $100 \%$ \\
\hline $\begin{array}{l}\text { Politically support the } \\
\text { change at the senior level }\end{array}$ & $\begin{array}{l}\text { Provide stronger leadership/get a } \\
\text { stronger mandate for change }\end{array}$ & 9 & $75 \%$ & 9 & $75 \%$ \\
\hline $\begin{array}{l}\text { Communicate to those } \\
\text { impacted by the change }\end{array}$ & $\begin{array}{l}\text { Make it easier for people to understand } \\
\text { the change/ Give updates on } \\
\text { progress/provide clear metrics to our } \\
\text { team }\end{array}$ & 6 & $50 \%$ & 7 & $58 \%$ \\
\hline $\begin{array}{l}\text { Provide a clear formal } \\
\text { plan for the change }\end{array}$ & $\begin{array}{l}\text { We need to clarify expectations/we } \\
\text { need a plan to institutionalize our work }\end{array}$ & 4 & $33 \%$ & 7 & $58 \%$ \\
\hline
\end{tabular}

Do a full assessment of our organization and impacted departments

We need to know what we are getting into when we try to bring a department

$2 \quad 17 \% \quad 5 \quad 42 \%$
on board with the change

Leverage our team's knowledge and experience

Support out team members and help them to transfer knowledge to full time employees who will carry on our work

$\begin{array}{llll}0 & 0 \% & 4 & 33 \%\end{array}$

Total \# of Responses

$\begin{array}{llll}21 & 70 \% & 32 & 71 \%\end{array}$

\section{Supporting Teamwork \\ Give the team more power

Give the team more
power

3

3

$25 \% \quad 4 \quad 33 \%$

Provide a better work environment for the team More power to help us get the job done/
give us a bigger say in the direction of
the project We need a more collaborative work space with fewer distractions from our work on a team

\begin{tabular}{|c|c|c|c|c|c|}
\hline & Total \# of Responses & 3 & $10 \%$ & 5 & $11 \%$ \\
\hline Supporting both & & 6 & $50 \%$ & 8 & $67 \%$ \\
\hline \multirow[t]{2}{*}{$\begin{array}{l}\text { Give the team the } \\
\text { resources it needs to get } \\
\text { the job done }\end{array}$} & $\begin{array}{l}\text { Make the HR side of things } \\
\text { easier/make the resources more } \\
\text { flexible }\end{array}$ & 6 & $50 \%$ & 8 & $67 \%$ \\
\hline & Total \# of Responses & 6 & $20 \%$ & 8 & $18 \%$ \\
\hline
\end{tabular}

At both $\mathrm{T} 1$ and $\mathrm{T} 2100 \%$ of the team gave a recommendation to senior management that dealt with change management practices within the organization. By comparison, 
relatively few STI team members made requests that pertained to improvements in team management ( $25 \%$ at $\mathrm{T} 1,33 \%$ at $\mathrm{T} 2)$. Finally, it was felt that one category of responses, providing resources for the team, was related to improving both the management of change and teamwork effectiveness. A majority of respondents in both time periods made this request.

Three categories of responses were given more frequently at $\mathrm{T} 2$ then at $\mathrm{T} 1$ : providing a clear formal change plan (increased by $25 \%$ ), doing a full assessment of the change (increased by $33 \%$ ), and leveraging the knowledge of change team (increased by $28 \%$ ). According to team members, a lack of assessment and planning can seriously frustrate a change effort. Team members saw the leveraging of the STI team's knowledge and experience as another area in which senior management could improve their organization's capability to implement change in the future. Overall, the team's view of the link between managerial support and overall change team effectiveness became more apparent over time in this study. A number of STI team members stated that, in fact, many of the frustrations that they encountered during the resistance phase could have been alleviated if management had better addressed the three areas of support mentioned above. All three of these factors dealt with the importance of diagnosing the change, having a plan, and meshing the skills of the change team with that plan prior to embarking on a transformational change.

\subsubsection{Supporting Change Management}

There were five categories of responses relating to supporting the change management role that emerged in this study: providing political support, communicating 
to the organization, developing a clear plan, providing a full assessment of the change, and leveraging the team's experience. Providing strong political support for the change and the change team was the most common response at both phases of the change and represented a common theme throughout the interviews.

At the senior level, it has been hot one day, cold the next; they have been very risk averse. - STI Team Member

At both $\mathrm{T} 1$ and $\mathrm{T} 2$ three quarters of STI team members expressed concern that the senior leadership in the organization had failed to fully support the change. Team members perceived that much of the concern and resistance to the change that they perceived to have occurred was a result of the fact that employees in their own organization (PWGSC/ITSB) were unsure of the direction of the change. The STI team felt that groups and individuals in both their organization (PWGSC/ITSB) and in the Federal Government, in general, would continue to passively resist the change until senior management displayed full public support for the change.

The second category of responses from STI team members related to the level of communication from senior management to employees who were influenced by the change. At both T1 and T2 half of STI team members listed effective communication about the change as a major area in which senior management could support the work of the change team.

Senior management needs a clear communication strategy. They need to passionately communicate around the change. This will align the resources needed to change; unfortunately that has not happened here. - STI Team Member 
The general tone of the responses was that the lack of clear communication about the change from senior management created confusion and fostered resistance both on their own team and with groups outside of the STI team.

We needed some clear metrics to motivate our team and others about the progress of the change. - STI Team Member

STI team members explained that a major problem was that people were unsure how the change was progressing and what was the next step for the change. A suggestion was to provide clear metrics around the change so that those working on the change could clearly see the progress and get informed on the projects that were underway.

A clear and formal plan was cited as the third most important way in which senior management could improve support for the change team. One in three STI team members at $\mathrm{T} 1$ and $58 \%$ at $\mathrm{T} 2$ stated that senior management could better support change teams if they could clarify expectations and provide a plan that showed how the change would be institutionalized.

Senior Management has been reluctant to make key decisions around the change. -STI Team Member

The team needs to understand how their work fits into the larger change; they have to feel that their work is important. -STI Team Member

Many STI team members felt that Senior Management had been reluctant to commit to a formal plan of action for the implementation of Shared IT Services. According to team members, this meant that the team and the organization were left to wonder where their current work fit into the changed workplace. STI team members explained that the lack of a formal plan caused resistance to their work and made it more difficult to stay 
motivated about the future of the change effort. This result speaks to the importance of front end diagnosis around the change, which is a fundamental principle in the change management literature (Kotter, 1995).

The final two responses in the change management theme addressed the ability of PWGSC/ITSB to move forward with the change and reflect a 'voice of experience' theme in the responses (ie. mentioned at $\mathrm{T} 2$ but not T1). According to $42 \%$ of STI team members at T2, senior management in PWGSC/ITSB needed to go back and do a full assessment of their own organization and any other departments that would be a part of the Shared Services. Team members explained that in particular, a full assessment on the impact of the change on human resources was necessary.

We need to do a better assessment of the impact on the people who will have to transition. -STI Team Member

The human resource issue was by far the most complex issue in this change we still don't know how we are going to do it. - STI Team Member

If you get lost on a change initiative it can take a while to get back on track. - STI Team Member

From their recent experience STI team members explained that failure of senior management to fully assess the change meant that the change team had run into challenges and resistance that could be avoided in the future. One in three STI team members also felt that part of the assessment of future change projects should include the knowledge and experience that existed on the STI change team.

We've built up a significant expertise on this type of change; it would be a waste to lose that expertise. -STI Team Member 
STI team members expressed concern that several of the key resources on the team were leaving and that senior management wasn't properly supporting them to allow them to transfer their experience and knowledge to full time employees.

\subsubsection{Supporting Teamwork}

The first category of responses related to improved teamwork was the need for senior management to give the team more power. Those who responded in this category $(17 \%$ at $\mathrm{T} 1,25 \%$ at $\mathrm{T} 2)$ explained that they would like to see senior management give the team more power to make their current work easier and more influence on the direction of the project. This category of responses is consistent with the 'voice of experience' pattern of responses discussed under the change management theme. Team members felt that they did not always have the power needed to get their work done and combat resistance in the organization. Team members suggested that more visible support from Senior Management as well as a stronger mandate to make the change happen would help give the team the power it needed to make the change happen.

Providing a better work environment for team members was the final response category given by team members. Only a small number of team members $(8 \%$ at $\mathrm{T} 1,17 \%$ at T2) commented on the team's work environment but the pattern fits in with other comments team members' made relating to the lack of coordination and cooperation within the team at times.

If there is anything slowing the team down it is the environment, it is not conducive to getting teamwork done. -STI Team Member 
Teams need team environments, you can't be distracted. -STI Team Member

STI team members explained that the team's workspace may have contributed to a lack of coordination and decreased the efficiency of the team at times. Team members suggested that the team needed a more collaborative workspace with fewer distractions to the team, a finding that is consistent with the our results on support for the change and workload.

\subsubsection{Supporting both the Change and the Team}

There was one category of responses that addressed the role of senior management in improving both the implementation of change and the process of teamwork: providing the change team with the resources required for the task. Half of STI team members at $\mathrm{T} 1$ explained that change teams needed more flexible and available resources to get their job done. This perceived need increased over time as $67 \%$ of team members also reported at $\mathrm{T} 2$ that the team required better support from management when it came to obtaining the human resources needed to meet the demands of implementing change.

If you really want to get the change done, you have to dedicate people to it.

$$
\text { - STI Team Member }
$$

This pattern of responses was consistent with the challenges reported by STI team members in Section 9.2. Team members explained that both the type of work and the amount of work related to implementing change was unpredictable at times and therefore required a flexible set of skills. They felt that senior management could support the work of change teams by helping to make the acquisition of new resources throughout the 
change more efficient. Several team members also took the perspective that if management could improve the flexibility and availability of resources for the team then they may also improve the ability of the team to work together as an effective unit. Specifically, team members felt that senior management could have significantly assisted the team by making it easier to bring new team members on board as was required by the work.

\subsection{SUMMARY}

The results presented in Chapter 11 suggest that support from management may have a substantial impact on the effectiveness of change teams. The results from this chapter are summarized in Table 11-2 according to the change management and team management themes as well as the $\mathrm{T} 1$ and $\mathrm{T} 2$ data. The results suggest that poor management of the change from senior management has a substantial negative impact on the work of the change team. In other words, change teams cannot make up for poor leadership at the top.

Table 11-2 Summary of the Qualitative Data on Supporting Change Teams

\section{Qualitative Results (phase/theme)}

\begin{tabular}{|c|c|c|c|c|c|c|}
\hline & \multicolumn{3}{|c|}{ Change Management } & \multicolumn{3}{|c|}{ Team Management } \\
\hline & $\begin{array}{l}\text { Resistance } \\
\text { Phase Only }\end{array}$ & $\begin{array}{l}\text { Acceptance } \\
\text { Phase Only }\end{array}$ & $\begin{array}{l}\text { Both Phases of } \\
\text { the Change }\end{array}$ & $\begin{array}{c}\text { Resistance } \\
\text { Phase } \\
\text { Only }\end{array}$ & $\begin{array}{l}\text { Acceptance } \\
\text { Phase Only }\end{array}$ & $\begin{array}{c}\text { Both Phases of } \\
\text { the Change }\end{array}$ \\
\hline $\begin{array}{l}\text { Supporting } \\
\text { Change } \\
\text { Teams from } \\
\text { the Top } \\
\text { (Table 12- } \\
\text { 1) }\end{array}$ & - None & $\begin{array}{l}\text { - Provide a clear } \\
\text { plan } \\
\text { - Do a full } \\
\text { assessment of } \\
\text { the impact } \\
\text { - Have a plan for } \\
\text { leveraging } \\
\text { experience }\end{array}$ & $\begin{array}{l}\text { Politically } \\
\text { support the } \\
\text { change } \\
\text { - Communicate } \\
\text { to those } \\
\text { impacted } \\
\text { - Make the HR } \\
\text { process more } \\
\text { flexible }\end{array}$ & - None & - None & $\begin{array}{l}\text { - Give the team } \\
\text { more power to } \\
\text { get the job done } \\
\text { - Staff the team } \\
\text { with adequate } \\
\text { resources }\end{array}$ \\
\hline
\end{tabular}


Table 11-2 shows that the majority of recommendations for improving senior level support for change teams came during the T2 interviews. The results also show that Team members felt the need for senior level support more acutely within the change management than the teamwork context. To support the work of change teams, the data suggest that senior management needs to offer full political support for the change team, have a communication plan and execute it, provide a clear vision for the change, and give the team the resources that they need to be successful in their role as agents of change. 


\section{PART SIX: DISCUSSION AND CONCEPTUAL REFINEMENT}

The purpose of this case study research is to explore the use of change teams to implement change and more specifically, the factors that may contribute to the effectiveness of change teams. The results put forth in Part Five of this thesis enable the refinement and expansion of the initial research framework section developed in Chapter 5. This part of the thesis is divided into two chapters, dedicated to the three research objectives of this thesis. The discussion begins with Chapter 12 which discusses the pros and cons of using teams as a strategy for implementing organizational change. In the second chapter of the discussion, Chapter 13 addresses the primary conceptual task of this thesis with a discussion of the framework for understanding change team effectiveness. The impact of the change life-cycle on change team effectiveness is a central component of the discussion in this chapter on change team effectiveness. Also included in Chapter 13 is a discussion of the role of senior management support in the model of change team effectiveness. 


\section{USING TEAMS TO IMPLEMENT CHANGE}

This chapter discusses the factors that organizations should take into account when considering the use of a change team to lead the implementation of transformational change. Several researchers in the area of team effectiveness have suggested that teams can have a positive impact on productivity, financial outcomes, individual behavioural outcomes, and the attitudinal outcomes for individuals (Delerue et al., 2008). This case study extends our understanding of teams in the context of organizational change and suggests that change teams offer both team members and organizations several benefits which may improve the ability of the organization to successfully implement transformational change. The findings of this case study also suggest that there are challenges and drawbacks resulting from the use of change teams as an implementation strategy that organizations need to consider. Figure 12.1 uses the findings from this case study to develop a model that outlines the potential benefits and drawbacks that organizations may be able to expect from the decision to use a change team to lead their transformational change. 
Figure 12.1 - Using Teams to Implement Change

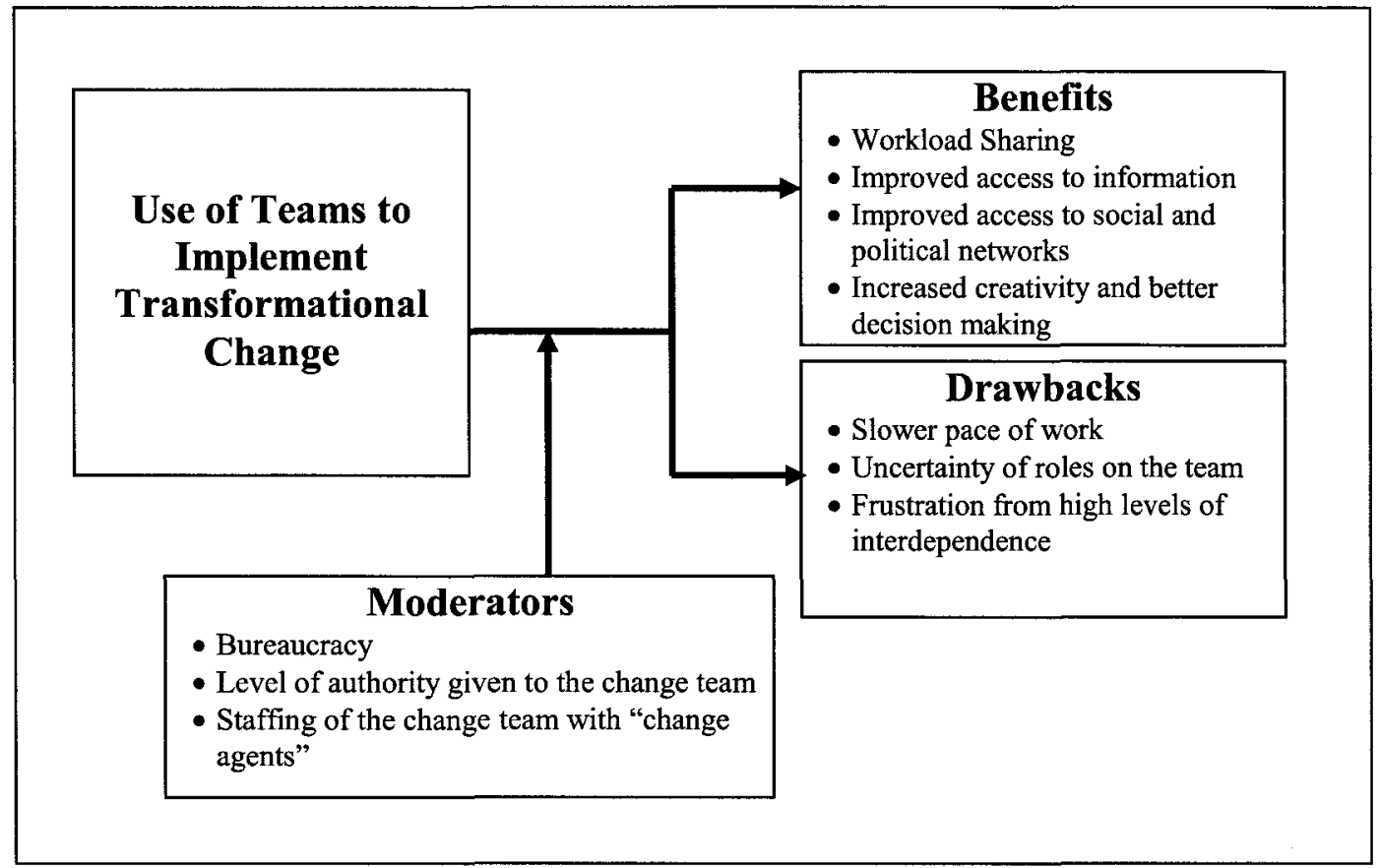

This model also includes factors, all under the control of the organization that this study suggests moderate the relationship between the use of change teams and the benefits and drawbacks that the organization can expect to experience.

This chapter begins with a discussion of the positive outcomes that change teams may offer to the organization and the individual team members. The second section of this chapter examines the potential drawbacks of being on a change team and the risks that organizations should consider when using teams to implement change. Throughout the chapter the discussion highlights the suggested impact of the three moderators (bureaucracy, empowerment, and staffing) on the positive and negative outcomes of using teams to implement change. 


\subsection{ADVANTAGES OF CHANGE TEAMS}

Although several researchers have put forth the idea that teams may be a useful tool for implementing organizational change (Guzzo \& Dickson, 1996; Verville \& Halington, 2003), there has been little research to date examining specific benefits of using teams to implement change. The case study of the STI team addresses this gap in the change research by identifying four areas in which teams may offer an advantage for both the organization and the individual workers: workload sharing, access to information, improved access to political and social networks, and improved creativity and better decision making.

A primary theme that emerged from the longitudinal data set was the idea that the STI change team offered positive outcomes at the level of the individual worker. A substantial benefit for individuals that came out of the data on the STI team was the improved ability of individual team members to manage their workload. This benefit of change teams arose from two primary forms of support: the emotional and social support in the face of resistance, and workload sharing when the number of tasks becomes overwhelming for the individual.

There is a consensus in the literature that implementing public sector organizational change can be a frustrating and emotionally draining experience, especially during the resistance phase of the change (Elrod \& Tippett, 2002; Nutt \& Backoff, 1993). Over half the STI team members discussed the challenges that they faced and how important it was for the team's effectiveness that they were able to remain persistent and committed to the change in the face of this resistance. Team members commented that facing these challenges alone would be difficult to manage if they were 
working is isolation on the change. Respondents indicated that they appreciated the support offered by team membership, a result that is consistent with the existing literature (Cannon-Bowers et al., 1995). One of the key moderators for this outcome appeared to be the staffing of the change team. Several STI team members discussed the extensive skills and experience related to change that were present on the team. The result was that the STI team members were a group who were well aware of the 'death valley' of the change and understood that supporting each other through the resistance would help the team to be more effective in their work.

In addition to providing social support, STI team members found it advantageous to utilize their teammates when workloads became unmanageable or overwhelming. This benefit of teamwork has been linked to improved team effectiveness by teamwork researchers (Campion et al., 1993; Gladstein, 1984) and the data from this case study suggest that workload sharing may have increased benefit in a change context because change teams may encounter varied and at times intense levels of workload. At T2 50\% of the STI team reported that sharing work between team members was an important advantage for them. The ability to share work as needed with team members was also reported by some team members to help performance and increase satisfaction with their experience. These findings suggest a link between workload sharing with increased change team effectiveness.

Another benefit of change teams found in this study is the increased access to information about the change that membership on the team offers individuals. Almost half $(42 \%)$ of the STI team at T2 mentioned being able to access information about the change as a benefit of team membership. Team members suggested that the increased 
awareness of the change helped to reduce their stress about the change because they could see what was coming with regard to the transformation. This benefit may be linked to literature in the area of change management (Mabin et al., 2001) which suggests that engaging employees in the change process can help to reduce their anxiety and resistance to change.

According to the case study data, team member's ability to get information and get their work done was also improved because team members could tap into the political and social networks of other members to get their work done more effectively.

From experience I know how important it is to be in tune to the political side of things during change. -STI Team Member

Researchers have noted the importance of the political and social landscape in an organization undergoing change, especially a public sector organization such as PWGSC/ITSB (Nutt \& Backoff, 1993; O’Reilly \& Tushman, 2004; Wise, 2002). The individual STI team members reported that there was a need to engage and communicate more effectively to outside groups during the change which was enhanced by the increased access to political and social networks offered by the change team. Team members also reported being able to get information more quickly because they were on a change team, suggesting that being linked into the political and social networks of the team help to inform team members about the organization and the change. These results suggest that the staffing of the change team may be a moderating factor that influences the political and social networks that the team encompasses. One-third of STI team members indicated that their team was well put together with a wide variety of backgrounds and experience. This finding implies that when staffing a change team 
management should ensure to staff the team from a wide spectrum of social and political networks within the organization.

The data related to the benefits of change teams for organizational performance suggest that the organization can benefit from change teams in two primary ways: first, the improved ability of team members to get their work done as described above in the discussion of individual level benefits of change teams and second, the organization may obtain more creative solutions to change related tasks. Almost the entire STI team ( $92 \%$ at T2) felt that the improved creativity may lead to better debates and a high quality of decision making form the group. This perception of improved creativity and decision making is consistent with existing research on teams (Catmull, 2003; Hackman, 1990; Nurmi, 1996). STI team members explained that many of the tasks performed as part of their role in implementing change required group debates and discussions to arrive at the best solution.

When you are working on a change all ideas are good, don't be scared to voice your opinions. - STI Team Member

The idea that teams may generate more creative solutions and help in the decision making process has received some support from researchers (Sutton \& Hagadon, 1996). Other researchers (Allen \& Hecht, 2004; Paulus, 2000) suggest that further research is needed to examine the factors which may support or inhibit creativity in teams.

The case study results from this thesis suggest that the creativity of the STI team may have been moderated by three factors suggested by team members. First, team creativity may have benefited from a heterogeneous mix of team members with different experiences and expertise who could contribute to their unique expertise to the creative 
process. Second, the high level of experience with organizational change appeared to help with group decision making and the creative process.

It was good to work with such an experienced group, they really knew their stuff. -STI Team Member

Third, the effectiveness of the change team may be limited by the lack of authority given to the team in regard to decision making around key issues for the change. One quarter of the team expressed their frustration at $\mathrm{T} 2$ that their teams decisions were often restricted by a lack of authority granted to the team. Creative solutions will not benefit the organization if the team's opinion is not considered in the decision making process. These findings highlight the importance of creativity as a benefit of change teamwork and offer a starting point for further examination into the creativity and decision making of change teams.

In summary, the data from this research suggest that change teams may experience similar benefits to other teams that have been studied in organizations (Cohen \& Bailey, 1997; Griffin et al., 2001); however, in this case the benefits can be linked to the mandate of change, which suggests that the benefits of using teams may improve an organizations ability to implement change. The increased creativity on change teams may lead to better decision making for the team and thus improve the effectiveness of the team as agents of change. As well, the ability to share the workload, get information, and tap into social and political networks of the team may also benefit the individual and improve the team's ability to implement change. The data also show that in this case the benefits offered from change teams may be moderated by the ability of management to adequately staff the team with skilled and experienced change agents. These findings are 
promising given the abysmal rate of success (Balogun \& Hailey, 2004; Beer \& Nohria, 2000) of planned transformational change and show the need for further research to empirically test these theoretical propositions related to the benefits of organizational change teams.

\subsection{DRAWBACKS OF CHANGE TEAMS}

Along with an examination of the benefits of change teams for individuals and teams this case study also examined the potential drawbacks that could occur as a result of using teams to implement change. The data presented in Chapter 9 outlined several of the challenges that were associated with the use of teams to implement change and are shown in Figure 12.1.

The most prominent drawback of change teams that emerged from the data was the fact that working together on the change often slowed down the pace of work for the STI team members. This finding is consistent with the fact that other researchers (Nurmi, 1996) have noted that a slower pace when working together as a team is a common challenge for teams. This challenge was also seen as particularly detrimental during the implementation of change, where momentum was critical. Members on the team worked at different paces and often had to rely on the work of others to complete a task (i.e. high task interdependence). This was found to be a frustrating experience for some change team members.

The study also determined that uncertainty regarding team roles and responsibilities was another potential drawback of working on a change team. The 
following comments reflect the challenges associated with finding the proper roles for team members which may have slowed the pace of work at times.

Getting consensus makes teamwork a very complex experience. -STI Team Member

It can take a long time to get certain roles on the team right. $\quad$-STI Team Member

The frustration with the slow pace of work and the difficulty in finding the correct roles for team members was accentuated at T2 when the STI team was working towards completing both of their primary tasks. At this time the level of interdependence was higher for the team, which may have exacerbated the drawbacks of a slower pace of work. The frustration at the slow pace of decision making and the bureaucratic factors affecting the group was also expressed by some team members. The moderating impact of bureaucracy may have been more pronounced in the public sector context.

STI team members suggested that the extent of the drawbacks of working on a team during change were moderated by the staffing of the team. A consistent theme in the data was that change teams need to be staffed with employees who have a high tolerance for the ambiguity, frustration, and negativity that is often associated with change. STI team members explained that those employees who did not have the qualities of an effective agent of change simply prevented the team from being as effective as they could. The data revealed that team members experienced a high level of resistance, both passive and active, from individuals and groups outside the team. STI team members explained that at times they were battling negative perceptions of the change and the team in an effort to engage the organization.

It takes a certain personality to be on a change team. - STI Team Member 
We had to shed the resistors on the team. We couldn't move forward with them.

-STI Team Member

Those team members who could not remain positive and committed to the change were found to be detrimental to the team's work. This represents a challenge for organizations putting together a change team and appears to be a challenge unique to change teams. Finding enough employees with the experience and skills required to be an agent of change may not be easy. The data suggest that having technical expertise is not enough to contribute effectively on a change team. Change team members need to have the qualities of effective individual change agents. Several comments from STI team members suggest that supplementing the full time employees on the team with external consultants who are effective change agents may be a useful strategy for organizations.

An important take away from this thesis research is that organizations must be aware of the drawbacks of using change teams as a strategic tool for implementing change. Further research into the possible benefits of creativity and workload sharing for teams implementing change must consider the factors that could limit the team's ability to implement change. The pace of work of teams may be an important consideration for organizations implementing change. When staffing the change team it appears the attitudes of team members toward that change effort should be taken into consideration. Finally, this research shows that as a tool for implementing change, teams should be used in conjunction with solid leadership from senior management. This finding is discussed further in Chapter 13. 


\section{A MODEL OF CHANGE TEAM EFFECTIVENESS}

The data discussed in Chapter 12 suggest that change teams may be a useful tool to help improve the way that organizations implement transformational change. However, a common theme in the teamwork literature is that organizations should carefully examine the factors that influence team effectiveness on a given task before committing to teamwork as a strategy to improve their chances of success (Allen \& Hecht, 2004; Hackman, 1990). In other words, before we can expect to realize the benefits that change teams may offer it is necessary to understand which factors must be present for teams working on change to be successful.

The second objective of this research is to increase our understanding of change team effectiveness by developing a model of change team effectiveness that can be used in future research on change teams. Figure 13.1 illustrates the model of change team effectiveness which was developed based on the results presented in Part 5 of this thesis.

The first section in this chapter will discuss the conceptualization of change team effectiveness that was used in this thesis research: viability, satisfaction, and performance. The data from the STI change team case study suggest that while this conceptualization of effectiveness appeared to be useful, the stage of the change should be considered when evaluating the performance of the change team.

The second part of the chapter justifies and discusses the four predictors of change team effectiveness model in Figure 13.1. These predictors are grouped into four sets of variables as follows: defining the team's task, staffing the team, team processes, and managing the change. Each of the predictor groups in the model contains multiple 
variables identified from the STI Team case study which may contribute to a change team's ability to effectively lead a transformational change. The second section in this chapter discusses each of these four sets of predictors and the variables that fall within each of these themes.

Figure 13.1- General Model of Change Team Effectiveness

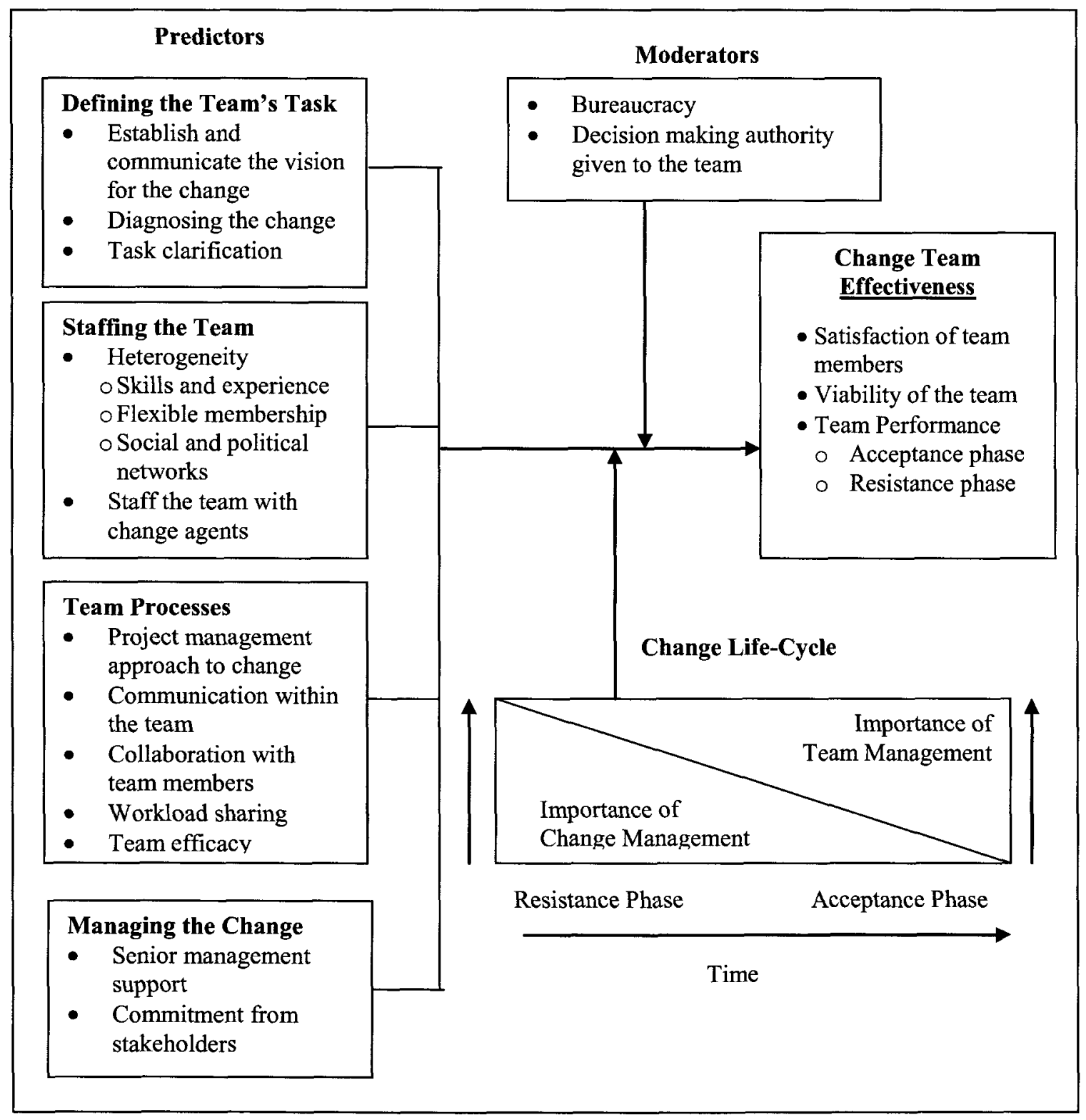


In addition to the four primary themes in the change team effectiveness model, multiple moderating variables were identified as having an impact on the effectiveness of change teams. These are discussed in the third section this chapter. The most important moderating variable that came out of the data was stage of the change life-cycle. As such it is discussed first. This is followed by an examination of two additional variables felt to moderate the relationship between predictors and change team effectiveness: the level of bureaucracy in the organization and the decision making authority given to the change team.

\subsection{CHANGE TEAM EFFECTIVENESS}

What does it mean to be an effective change team? As a general standard, team effectiveness refers to the multi-dimensional construct that has become most commonly used to describe team outcomes in teamwork models (Ilgen, 1999). The case study of the STI change team suggests that change teams are similar to traditional project teams in many aspects however the complexity and difficulty of their task (implementing change) requires a modified approach to conceptualizing team effectiveness. This is an expected result as teamwork researchers have long struggled to agree upon one standard framework for measuring team outcomes. It is also consistent with Guzzo and Dickson's (1996) suggestion that there is no singular, uniform definition of outcome effectiveness for teams and that effectiveness may be unique to the context in which the team operates. This section discusses the validity of the team effectiveness construct within the context of the change team effectiveness model. When undertaking this evaluation it is important to recognize that by a number of objective standards (i.e. team awards and successful 
completion of tasks) the STI change team can be considered an effective change team. This realization helped us in the development of the model.

\subsubsection{Change Team Satisfaction}

The first component of change team effectiveness used in this case study was the level of satisfaction reported by team members with respect to their task and their interpersonal relationships experienced as a part of their work on the STI change team (Campion et al., 1993; 1996). Almost the entire team (83\%) indicated that they were satisfied with their experience working on the STI team at both $\mathrm{T} 1$ and $\mathrm{T} 2$ survey points. The results from the interview data support these findings as team members commented that they were satisfied with their teamwork experience.

The experience of being on a change team helps you to build your skill set.

-STI team member

I am amazed at the incredible amount of work that a couple of my team members can put through. - STI Team Member

These comments reflect the high level of satisfaction common to the STI team. The limitations of the case study design suggest that further research is need to determine whether the measure of satisfaction for change teams used in this study is valid for change teams. The findings of this case study do suggest that team satisfaction is an important outcome for change teams and merits inclusion in the model of change team effectiveness. 


\subsubsection{Change Team Viability}

The second component of change team effectiveness included in the model was the viability of the team. Team viability refers to the ability of the change team to work together in the future (Sundstrom et al., 1990; Wagemen et al., 2005) and was measured using self-report survey questions filled out ST team members. In the literature review it was noted that this measure of effectiveness may have increased relevance to the study of change teams as large transformational change efforts can continue on for several years (as is the case in the current research) and teams must consider the importance of working together on future tasks. A team that 'burns' itself out may not be in the best interest of the organization or the long term transformational change effort. The survey results show an interesting finding when examining the viability of the STI team. At T1 only $17 \%$ of team members indicated that they could see the team performing well together in the future. In contrast, at $\mathrm{T} 275 \%$ of the team members who were surveyed felt that the team could perform at a high level on future tasks. These results suggest that a change team's viability may be affected by the life-cycle of change. It is logical that during the resistance phase, which is characterized by resistance, negativity, and a slow pace of work, that team members may be pessimistic about the future of the team. However, during the acceptance phase the STI team are likely to see their hard work pay off as departments began to transition and they began to complete specific deliverables related to the change. The implication for future research is that caution should be observed when interpreting the viability of change teams during the resistance phase of the change. One option may be to have an experienced manager who understands the impact of the change life-cycle on team, assess the team's ability to work together in the 
future. The other implication is that change teams that are disbanded during the resistance phase are unlikely to be able to work on a change team together in the future.

\subsubsection{Change Team Performance}

The third and final component of change team effectiveness was the team performance variable. Team performance has proven to be one of the most challenging parts of team effectiveness for researchers to measure (Guzzo and Dickson, 1996). In the STI case study team performance refers to the team member's judgment of the team's performance levels on their primary task. All but one of the STI team members who were interviewed rated their team as performing at a high level at $\mathrm{T} 1$ and none of the team described the change team as performing poorly. STI team members rated their team's performance on quality, delivering work on time, satisfying their supervisor, and satisfying the expectations of their clients. All the results at $\mathrm{T} 2$ were similar to those given at T1 indicating that the STI team felt that they performed well during both of the resistance and acceptance phases of the change. Support for these high scores can be seen in the external team awards such as the team's silver medal at the Canadian Government Technology Exhibition and Conference Distinction Awards Gala in 2008. The STI change team was recognized for their hard work and dedication to moving IT shared services in the GoC forward.

When examining the implications of these findings on change team performance for future research it is important to look at whether or not the measure of team performance appeared to be a valid measurement for our study. The results suggest that future research should in fact consider a different approach to measuring change team 
performance. The problem with the conceptualization of team performance used in this case study stems from the fact that team performance was defined as the team's performance on their primary task, which was explained to STI team members as the overall implementation of change. However, longitudinal data from this study show that the primary task of the change team during the resistance phase of the change would be better measured by an assessment of the team's ability to engage stakeholders and reduce resistance to the change. At $\mathrm{T} 2$, during the acceptance phase of the change the performance of the team shifts to a more traditional view of team performance with change teams working together on specific project deliverables. Using the results of this case study as a guide future research should have two separate measures of performance: one to measure the performance of the team during the resistance phase and one to measure performance of the team during the acceptance phase of the change.

\subsection{CHARACTERISTICS OF EFFECTIVE CHANGE TEAMS}

What makes an effective change team? The case study of the STI Change Team suggests that effective change teams simultaneously balance the challenges of effective team management with the challenges of managing change. Despite the obvious challenges involved in combining these two areas of research, the results of this thesis do offer several suggestions for improved change team effectiveness related to how the team's task is defined, how the team is staffed, how the team works together (i.e. team processes), and how the team is affected by the organization's ability to manage change.

The discussion of the characteristics of effective change teams is organized according to the four groups of change team effectiveness predictors outlined in Figure 
13.1. The chapter begins with a discussion of the importance of defining the team's task for change team effectiveness. This is followed by a discussion of how organizations can staff their change teams to potentially improve effectiveness. The third subsection offers insight into the possible team processes that may lead to increased effectiveness. The final subsection of this chapter discusses how support from senior management and commitment from stakeholders may influence the ability of the change team to be effective in their role as agents of change.

\subsubsection{Defining the Change Team's Task}

Consistent with existing team effectiveness research (Campion et al., 1996; Wageman et al., 2005) the data from this thesis suggest that a clearly defined task is important for team effectiveness in a change setting. STI team members suggested that three main elements of task definition were related to change team effectiveness: establishing a vision for the change, diagnosing the change landscape, and a clearly articulating the specific deliverables that the change team will work towards. Within this section each variable is defined and discussed in terms of its link to the literature, the data in this case study, and the variable's place in the model of change team effectiveness.

\subsubsection{Establishing a Vision for the Change}

The importance of developing and communicating a vision for the change is a generally accepted principle of effective change management in the change literature (Kanter et al., 1992; Kotter, 1995). In the change team effectiveness model this concept is 
representative of the respondent's desire for the development and communication of the general direction and plan for the change. In this case study, over half of STI team members who were interviewed at $\mathrm{T} 2$ suggested that the ability of the team to implement change would be dramatically improved if they were able to work with senior management to develop and communicate a vision for how the change would be institutionalized.

The results from this study also show that it is important for the direction and vision for the change to be communicated to stakeholders in the change, a finding supported by recent research on change communication (Allen et al., 2007). Half of the STI team interviewed at $\mathrm{T} 1$ responded that communicating the direction of the change and providing clear updates to stakeholders on the progress of the change was an important component of managing the vision for the change. STI change team members also felt that teams who were effective in supporting the change would be able to work with senior management to enhance the communication around the vision for change.

Creating and communicating the vision for change is widely regarded as a fundamental part of change management and several researchers (Dawson, 2003; Kotter 1999) have stressed the importance of a clear vision and a well communicated strategy to help engage employees in the change. The survey data suggest that the STI team felt that at $\mathrm{T} 1$ the team lacked a clear and specific direction for the change (only one team members felt that the direction was clear). As well, the comments from STI team members show that at $\mathrm{T} 1$ they felt that the team was ready to help with the vision but ultimately the direction for the change needed to be communicated from the top and that 
senior management had been reluctant to commit to a formal plan of action for the implementation of shared IT services.

(Change leaders) must communicate about the strategic direction of the change to their teams; people need to understand the impact of their work.

- STI Team Member

Senior management has been reluctant to make key decisions around the change. - STI Team Member

The ability of the change team to work with senior management to develop and communicate the vision for the change is included in the model of change team effectiveness because the data suggests that change teams where this takes place are more likely to be effective at implementing transformational change.

\subsubsection{Diagnosing the Change Landscape}

Diagnosing the change team's task and context refers to a set of activities that serve to inform the change team of the forces for and against change, the resources that are required, the risk factors that are present, and any other relevant history or information that might give the change team an advantage when it comes to implementing change. At both $\mathrm{T} 1$ and T2 approximately half of STI team members reflected back on their experience and voiced their concerns about the lack of information that they had going into their task. Most team members felt that the effectiveness of the team would improve if they were able to stop their current task and reassess the change to determine the best strategy for getting agreement from all the departments involved in the transition. 
We need to do a better assessment of the impact on the people who will have to transition. -STI Team Member

STI team members felt that without thorough assessment of the people, processes, and structures that they were trying to change, the team would be at a serious disadvantage when it came time to implement the change. When this concern became a reality at $\mathrm{T} 2$ $42 \%$ of STI team members who were interviewed stated that it was necessary to go back and reassess the strategy for change, particularly in the area of human resource transfer.

We found a number of systemic weaknesses in the organization that we didn't know existed until we started the transition. - STI team member

This was a task that many team members felt should have been more thoroughly conducted early in the change.

We could have saved ourselves a lot of time by being better organized at the beginning. - STI Team Member

The importance of diagnosing the team's task is not a common theme in the team effectiveness literature as most teams go into their task with a brief assessment of the situation and are able to work through most of the unforeseen challenges that arise during their work together. However, the fact the primary task of change teams is to implement change means that their task is often considerably more complex and risk filled than the work of many other project teams. The data from this case study suggest that a diagnosis of the forces for and against change may be a critical component of change team effectiveness. 


\subsubsection{Clarifying the Task}

The final variable linked to task definition is the level of task clarity perceived by the change team. Task clarification refers to the extent to which the change the team is able to clearly understand the requirements of their task. This concept is similar to the task identity variable in Campion et al.'s (1993) model of team effectiveness. Task identity refers to the degree to which the team completes a whole, identifiable, and separate piece of work in the organization. The data from the STI case study and the literature both suggest that clarifying the change team's deliverables may help to focus the team's effort and motivate the team to improve their effectiveness. At $\mathrm{T} 1$ there was no support for the importance of clarifying the task as a critical success factor for change team effectiveness. However, at T2 one in three team members who were interviewed noted that clarifying and simplifying their task had increased the team's effectiveness. These findings combined with support from existing research (Randall \& Procteur, 2008) suggests that the importance of this factor may depend on the stage of the change.

The data also indicate how this clarification had occurred. First a substantially greater number of STI members indicated that they felt had better support from senior management at $\mathrm{T} 2$ than $\mathrm{T} 1$. They also indicated that they had worked to reframe their task to improve clarity with respect to the direction that they were to take as well as the key deliverables for the work related to the change. Furthermore, respondents' comments indicated that team members felt that it was necessary to break the change down into clear manageable tasks to increase clarity around their work. For example,

We needed some clear metrics to motivate our team and others about the progress of the change. -STI Team Member 
Team members also indicated that one of the team's biggest strengths had been their ability to clarify their own work and create clear priorities for the team.

\subsubsection{Staffing Change Teams}

The second theme that came out of the case study data identified the staffing of change teams as an important component of change team effectiveness. Staffing the change team refers to how members are selected to be a part of the change team. Team composition is commonly included in many traditional team effectiveness models (Campion et al., 1993; Gladstein, 1984; Hackman, 1987) as a factor that is linked to team effectiveness. The data from the STI change team highlighted two areas related to how change teams are staffed that warranted inclusion in the model of change team effectiveness: the heterogeneity of the team (common to the effectiveness of many teams) and the degree to which change team members exhibit the characteristics of effective change agents (specific to the effectiveness of change teams).

\subsubsection{Heterogeneous Change Teams}

What does the experience of the STI change team tell us about staffing a change team? One of the most important themes coming out of the interview data was that selecting a heterogeneous group offers several potential advantages for implementing change. Research in this area indicates that this finding is an expected one as is evident from the inclusion of heterogeneity in Hackman's (1987) influential model of team effectiveness. This case study suggests that change teams may benefit from 
heterogeneous membership even more than traditional project teams. The demands of implementing change for the STI change team were found to be quite complex and unpredictable, suggesting that a wide variety of skills and experience may best meet the challenges of implementing change. This subsection discusses the how a heterogeneous mix of skills, experience, and political and social networks is required to implement transformational change.

The first dimension of change team composition included in this theme is a wide variety of skills and experience selected for the team. Bowers et al. (2000) suggest that for complex tasks, where individuals with special skills and abilities can be brought together, a heterogeneous mix of skills and experience may result in improved performance. Such a mix appears to be a necessity for change teams.

Change is so complex, working alone would be almost impossible, you need a collective. - STI Team Member

This comment reflects the theme in the data that change team members rely heavily on each other to complete their task. Other indicators of the importance of skills and experience include the fact that two thirds of STI team members surveyed at T2 felt that the team had an adequate mix of skills and experience to meet the demands of their task and one third of the STI team in the interview sample indicated that a primary benefit of the change team was that their combined skills and experience helped the team to deal with the complexity and scope of the change. These data suggest that a change team with a variety of skills and experience with change may be more effective at meeting the challenges required to implement transformational change. 
Although the STI team was generally satisfied with the mix of skill and experience on the team, one recommendation from the interviews stuck out in regards to staffing; the need to alter the team's membership throughout the life of the change. According to Elrod and Tippett (2004) change is a constantly evolving task which may require a different set of skills depending on the phase of the change or the task at hand. A major theme in the data was the need for a flexible team membership. Two-thirds of the team explained in the interviews that the tasks that arose from change implementation required a wide variety of skills and experience at different times in the project. To be effective change teams needed to be able to bring on new members, with specific skills and experience as the task required.

You need to have flexible HR practices; you need to be able to get people on your team quickly. - STI Team Member

Unnecessarily restrictive HR policies prevent this and slowed the work of the team. This comment illustrates the need for change teams to be able to adapt to their task by bringing on new personnel as required.

When staffing change teams, the data from this thesis suggest that along with the skills and experience of team members, organizations should consider the political and social networks that are represented on the change team. Having a variety of team members who are able to tap into various political and social networks to help accomplish the teams task is a quality of effective change management that is supported by Bramson and Buss (2002) who argue that this aspect of change management may be even more critical in public sector environments. In the interviews one quarter of the STI team members at $\mathrm{T} 1$ reported that they were able to tap into the various political and 
social networks of their team members which enabled them to extend their influence in the organization. Team members explained that the wide variety of political and social networks present on the team was a primary benefit of membership on the change team and felt that such networks improved effectiveness.

\subsubsection{Staffing the Team with Change Agents}

The second staffing issue arising from the data was the idea that change teams should be made up of individuals who have the qualities of change agents. Change agents are those individuals who facilitate the process of change, enable and empower other employees to take responsibility for the change, and act as consultants in the coordination and project management of change (Nickolauou, Gouras, Vakolaa, \& Bourantas, 2006). Nickolauou et al. (2007) argue that these individuals are best identified by their dispositional traits as opposed to any specific skills related to change. This idea that there are individuals in an organization whose attitude and approach to change gives them an advantage over other employees is consistent with the findings of this thesis. In the interviews STI team members, although not formally using the term 'change agents', continually described the characteristics and attitudes that were common to traditional descriptions of change agents and in their minds necessary to be a productive member of a change team. This subsection describes the attitudes and personal characteristics of effective change agents and explains why staffing a change team with these individuals may lead to improved change team effectiveness. These attitudes will, when appropriate, be contrasted with the qualities of individuals who identified by respondents as change resistors. 
According to respondents, the most important behaviour or value that typified a supportive change team member was that they should be a model for change. An overwhelming majority of the team members who were interviewed described stubborn and isolated individuals as counterproductive to the goal of supporting and implementing change.

If you're not empathetic, if it's my way or the highway, you'll get a fight. - STI Team Member

Change team members need a high Emotional Quotient (EQ), if you don't have it, don't bother; you need a high EQ for change. - STI Team Member

On the other hand, desirable traits of change team members included the ability remain positive, collaborate with others, work extremely hard, take accountability, and enjoy the uncertainty of change. A common theme in the data was the idea the STI team members felt that the qualities of an effective change agent were very important and that finding employees with those qualities may be a challenge for organizations.

If you are a lazy person, change is a barrier because it really takes considerable effort to make change happen. - STI Team Member

You have to be able to deal with some disappointments to be on a change team.

- STI Team Member

These comments reflect the need for change team members to be able to deal with the frustrations of implementing change and continue to work towards the vision for the change. These findings are consistent with research on team effectiveness linking emotional stability to team effectiveness (Driskell et al., 2006). Emotional stability, which is made up of adaptability and self-esteem, is a part of the Big Five personality 
dimensions that have been used by researchers to study the impact of member personality on team effectiveness. In their review of the literature, Driskell et al. (2006) suggest that individuals who are more adaptable and possess higher self-esteem may be better suited to circumstances in which the organization is in a transition or realignment state. This idea fits well with the data from the STI change team and suggests that the qualities mentioned above may be used as a criterion when selecting for the change team.

\subsubsection{Team Processes}

The third theme in the model change team effectiveness is the change team process theme. Team processes are a fundamental building block of understanding team effectiveness and researchers have proposed a wide variety of team processes which may influence teamwork outcomes (Campion et al., 1993; Gladstein, 1984; Klein et al., 2009). The STI change team case study suggests that there are five team process variables that affect change team effectiveness: project management approach, communication within the team, collaboration within the team, workload sharing, and team efficacy. This section defines each variable, discusses the link between the literature and the related data from the case study, and discusses the role of each variable in the model of change team effectiveness. 


\subsubsection{Project Management Approach}

A common theme in the interviews with the STI change team was the value of taking a project management approach to change management. According to team members, a project management approach referred to the process of planning, organizing, and managing the implementation of change by breaking the team's overall task down into manageable subtasks. At T1 one-third of the STI change team explained that supportive teams should strive to take disciplined and organized approach to change, specifically by sticking to a well-organized project schedule. Several team members mentioned that their task of implementing change could become overwhelming if the team failed to take an organized and manageable approach.

At times it was difficult to tell what projects made up this change.

\section{- STI Team Member}

At $\mathrm{T} 2$ a project management approach was again a consistent topic in the interviews, with $42 \%$ of the STI team indicating that their disciplined and professional approach to managing the change was one of the best features of the team's processes. Although this theme was prominent in the case study data, team effectiveness researchers have not traditionally included project management activities in their models of team effectiveness. Most models tend to stress the importance of task definition and structure at the outset of the team's task. However, it is important to note the STI team members were clear that a project management approach refers to a style of management throughout the implementation of the change. As an example, one STI team member explained that the team tried to ensure that each subtask for the team was sponsored by a 
full time employee on the team, to ensure that responsibility for the success of that subtask could eventually be handed over to a full time member of the organization.

It is essential that you have a full time employee to sponsor each change project, if it is a consultant they will not have the power to make the project stick.

\section{- STI Team Member}

Overall, the data from this thesis suggest that change teams who are able to divide the task of implementing change into distinct projects, with specific resources, timelines, and deliverables may be better suited to implement change.

\subsubsection{Communicating within the Team}

Communication within groups has been linked to team effectiveness by several researchers and is one of the most dominant themes in the team effectiveness literature (Campion et al., 1996; Katz, 1982; McGrath, 1984). This variable refers to the level of communication that occurs between team members related to either the maintenance of the team or the team's task. Internal group communication has also shown up in the limited research on change teams (James \& Ward, 2001) who argued that communication between team members was an important team process. James and Ward (2001) suggest that formal ground rules for communicating may be a solution to some of the communication challenges faced by change teams. The survey and the interview findings both support the idea that poor communication, including information hoarding and poor listening, may have had a negative impact on change team effectiveness $(50 \%$ surveyed at $\mathrm{T} 1$ felt that the team had poor internal communication). 
When you communicate on a change team you have to make sure that your audience's needs are met when you are done; don't communicate blindly.

- STI Team Member

People were siloed in their work at times.

- STI Team Member

These comments illustrate some of the within team communication challenges faced by STI team members. In fact, at both $\mathrm{T} 1$ and $\mathrm{T} 2$ over half of the team indicated that teams who had poor internal communication were most likely to be resisting the change.

Why is inter-team communication important to change team effectiveness? In the interview, respondents noted that the work of the change team was divided into several tasks. Quality communication between team members was the only way to keep people informed and take advantage of the full resources of the team. In summary, the results of this case study suggest that internal communication is an important team process which may increase change team effectiveness.

\subsubsection{Collaboration}

According to the STI team members a supportive change team should be on the 'same page' and function as well-coordinated, interconnected team. A high level of collaboration is closely linked to the task interdependence variable in several team effectiveness models (Hackman, 1987; Saavedra et al., 1993; Shea \& Guzzo, 1987). Team collaboration refers to the extent to which the work of change team members is interconnected and team members are required to work with other team members to get 
their work done. STI team members frequently discussed collaboration as an important process for change team effectiveness.

A change team has to care about their work and take accountability for the whole team's work. $\quad$-STI Team Member

A sense of collaboration is critical for teams; you have to want to collaborate.

- STI Team Member

Where there is a disconnect between the groups and projects (within the team) the change won't be moved forward. - STI Team Member

Each of these comments illustrates the importance task interdependence for change team effectiveness. The STI change team had the bulk of the team's work split into functional work groups so team members felt it was easy to become isolated at times during the change project. This was seen at $\mathrm{T} 1$, where only one team member in the survey sample felt that they their team had a high level of task interdependence. At T2 that number increased substantial ( $42 \%$ of the team) but still remained at less than half of the team. The interview data suggests that STI team members recognized the importance of collaboration with three quarters of the team at $\mathrm{Tl}$ indicating that low levels of collaboration were linked to resistant change teams. Team members who did comment on the importance of task interdependence stressed the link between staying connected as a team and improved creativity and decision making. This data suggests that teams who have a higher level of collaboration may be more likely to achieve increased levels of team effectiveness. 


\subsubsection{Workload Sharing}

The fourth team process variable in the change team effectiveness model is the extent to which teams share their workloads in order manage fluctuations in the demands of the task. Almost half of STI team members reported that the ability to share work between team members was a primary benefit of being on the change team, suggesting that this variable is a critical area in which teams may be more effective than individuals in implementing change. Team members also reported that the workload related to the implementation of change was best suited to a flexible team structure where team members could easily share duties as required.

As discussed in the literature review, several researchers (Cox-Fuenzalida et al., 2006; Smith \& Burke, 1992) have highlighted the impact of increased workload associated with implementing change. Based on this literature a measure of workload was included in change team effectiveness survey. At both T1 and T2 none of the STI team members reported high levels of workload. This finding has two possible interpretations: either the workload of the STI team was moderate or the workload sharing processes of the team served to lower the workload strain on team members. Support for the later explanation comes from the fact that a number of team members specifically mentioned in the interviews that workload sharing was a primary benefit of change teamwork because it allowed the team to handle these fluctuations in workload and reduced their stress.

As discussed in the previous subsection on task design, STI change team members found that their task of implementing change was both complex and dynamic, thus making it difficult at times to define the task and the roles of each team member. 
Team effectiveness researchers (Campion et al., 2003; Sundstrom et al., 1990) have put forth flexibility as a feature of effective teamwork that may help to enhance a team's ability to share workload and adjust roles to meet the demands of the task. Comments from STI members suggest that flexibility may be critical for change teams.

If you like to have rigid roles and responsibilities change isn't for you. - STI Team Member

The survey data illustrate the struggles that the team had with regard to flexibility. At T1 $33 \%$ of the team felt that the team was struggling to adjust the roles of team members to fit the task. At $\mathrm{T} 2$, the perceptions of team members improved slightly but it was clear that team flexibility remained an area that team members felt could improve team effectiveness. Despite the challenges of achieving flexible work roles, STI team members recognized the importance of achieving a flexible change team that was capable of adjusting to share workloads as demanded by their task. As such, we consider it an important variable to include in our model.

\subsubsection{Team Efficacy}

Efficacy or potency as it is often labelled in later team research (Pescosolido, 2003) refers to the team's individual and collective beliefs that it can accomplish the task at hand (Shea \& Guzzo, 1987). Consistent with Driskell et al. (2006) maintaining team potency was reported as an important part of change team effectiveness. In fact, the most common challenge during the resistance phase (T1) related to the change effort according to STI team members was dealing with the expectation of failure from the organization. 
Some people in our organization view the team and the project as a pilot. They feel that if they ignore us the change will go away. - STI Team Member

Sometimes it can be like the Stockholm Syndrome, where you become resistant by spending time around those you are trying to get to change. -STI Team Member

These comments suggest that while maintaining a belief that the team can successfully implement change may be very difficult for change team members, it is also likely to be key to the effectiveness of the team. Survey results showed that team potency increased substantially from $\mathrm{T} 1$ to $\mathrm{T} 2$, a possible indication that the team was becoming more comfortable in their role and with their ability to implement change. Responses from STI team members suggest that change teams who can maintain their positive belief in the task and the team will be more effective in their role as change agents. The patterns in the data suggest that the ability to maintain a belief in the team's ability to accomplish the task may be of increased importance in a change setting due to the resistance often associated with the task of implementing change.

\subsubsection{Managing the Change}

The final pair of change team effectiveness variables falls under the category of change management. Organizational change is the context in which change teams operate and two variables in particular stood out as important components of change team effectiveness that were specifically linked to the external change environment: support from senior management and commitment from stakeholders. This subsection defines both variables, discusses the link between the data and the literature, and explains the role of these variables within the change team effectiveness model. 


\subsubsection{Support from Senior Management}

One of the most dominant themes to come out of the entire case study data set was the critical role of senior managerial support for change team effectiveness. Senior management support in this context refers the extent to which the work of the change team is perceived by stakeholders to be supported by upper level management. Compared to traditional team effectiveness models, managerial support (in particular, senior management support) appears to have substantially increased importance in the change team effectiveness model. It should be noted that traditionally, immediate supervisors are considered to be the most important component of managerial support for the team (Campion et al. 1993). That was not the case however, for the STI change team. This unique finding related to change teams may be a reflection of the critical importance of senior leadership during transformational change (Kanter et al., 1992; Kotter, 1995). These findings require further investigation to determine whether the importance of immediate supervisor role is diminished in a change team setting or whether it is simply overshadowed by the critical importance of senior leadership for change teams. This subsection discusses the role of senior management in supporting change team effectiveness.

Leadership from senior management was shown to be very important to the change team's ability to implement change. The most common recommendation for how the organization could better support the change team put forth in the interviews $(75 \%$ of STI team members at both $\mathrm{T} 1$ and $\mathrm{T} 2$ ) was that senior management needed to be more politically supportive of the change effort and the change team. 
If a change team isn't visibly supported by senior management it will always be tough to get people to react to your requests. $\quad$ - STI Team Member

Our senior leadership hasn't owned the change and so our group has been stuck. - STI Team Member

These comments reflect the tone of the change team who felt that it was critical to the team's success that senior leadership in the organization publicly take ownership for the change and support the work of the change team. STI team members explained that regular communication about the progress of change programs is one of the ways in which senior leadership can show support for the change team and their work. Senior leadership should also work to develop a plan for communicating about the change in partnership with the change team.

The significant impact of senior management on change agents is consistent with change management researchers who promote the importance of leadership from the top of the organization during change management (W. Burke, 2002; Kotter, 1999). Acting as change agents for the entire organization, visible support from senior management legitimizes the work of the team and gives them to political power needed to influence stakeholders to change. In the change team effectiveness model increased levels of senior management support may be linked to improved team effectiveness.

\subsubsection{Building Commitment with Stakeholders}

The second variable in the context of managing change is the ability of the team to build commitment with stakeholders. This variable refers to the extent to which change teams are able to communicate, engage, and support stakeholders outside their team 
throughout the transformation. Building stakeholder commitment is another variable that emerged from the case study data which is not normally found in team effectiveness models. At $\mathrm{T} 1$, during the resistance phase of the change, $58 \%$ of STI team members interviewed indicated that building commitment for the change was one of the most important strengths of their team. Interestingly, at $\mathrm{T} 2$ only one team member interviewed felt that building commitment was important for the team's success, suggesting that building commitment is moderated by the change life cycle.

Within the context of change management, engaging stakeholders is a fundamental part of the change management literature (Russ, 2008; Weick, 2000). In this study this idea is linked to change team effectiveness. For example, almost half of the STI team who were interviewed indicated that engaging stakeholders was an important way to maintain commitment and may help the team to successfully implement the change.

For change teams it appears that some of the biggest obstacles impeding the implementation of change may be the attitudes and opinions of those not on the team.

People expect the project to fail, so they don't really support you.

- STI Team Member

The hardest thing is dealing with the resistance from outside the team.

- STI Team Member

Sometimes you feel like you are working in a vacuum with this change. It has been difficult to get this change to go forward from the bottom up. - STI Team Member 
Each of these responses reflects the difficulty and importance of positively engaging outside stakeholders in the change effort. According to the STI team members, this is done by boosting the efficacy of the organization, addressing resistance, and fully engaging outside individuals and groups.

The results from the interview data also showed that the ability to communicate and share information with groups outside the team may play an important role in how effectively change teams are able to gather commitment from stakeholders. Half the STI team members who were interviewed at $\mathrm{T} 1$ stressed the importance of being able to communicate the same message repeatedly to build commitment.

It is a long program and things can shift, and that's okay, but you need to communicate. - STI Team Member

Our communication and engagement of those involved in the transition has been excellent. - STI Team Member

These comments from STI team members describe some of the main behaviours that they felt made them more effective in their implementation role. The decrease in the number of responses related to communication at T2 may be due to the nature of the STI team's task at $\mathrm{T} 2$, where the team was mostly working on the proof of concept document. Overall, the findings from this case study support the idea that interacting with the stakeholders and communicating to those affected by the change appears to be a critical activity of change teams. 


\subsection{MODERATING VARIABLES}

The discussion of the change team effectiveness in the previous section described twelve constructs that may influence change team effectiveness. The data from the STI change team case study also suggest that the extent to which each of these constructs will affect change team effectiveness will be moderated by the change life-cycle, the level of bureaucracy, and the decision making authority given to the team. Furthermore, the data suggest that the change life-cycle, which describes the stage of the change in which the team is operating, will be the most influential moderating variable in change team effectiveness model. Drawing on the work of Elrod and Tippett (2002) this subsection begins with a discussion of the impact of the final two stages of the change life-cycle (resistance and acceptance) on the model of change team effectiveness. This is followed by a discussion of the additional moderating variables in the change team effectiveness model.

\subsubsection{The Change Life-Cycle and Change Team Effectiveness}

Chapter 6.2.3 explained the work of the STI change team from the perspective of Elrod and Tippett's (2002) life-cycle of model of organizational change. According to Elrod and Tippett (2002) organizational change follows a consistent pattern from the start of the change to the end of the change that can be divided into three phases: anticipation, resistance, and acceptance. Chapter7.2.3 established the case for the interpreting the $\mathrm{T} 1$ data of this case study as being collected during the resistance phase of the change, while the T2 data were collected during the acceptance phase of the change. When examined through this lens the STI change team case study data reveal an important finding related 
to the effectiveness of change teams. Specifically, this study suggests that the relationship between a number of constructs in our model and change team effectiveness will be moderated by the stage of the change life-cycle. Table 13.1 provides a summary of how the change life-cycle on the model of change team effectiveness.

Table 13-1 The Impact of the Change Life-Cycle on Change Team Effectiveness

$\begin{array}{lcc}\text { Change Team Effectiveness } & \text { Resistance Phase } & \text { Acceptance Phase } \\ \text { Predictors } & \text { (T1) } & \text { (T2) }\end{array}$

Defining the Team's Task

\begin{tabular}{|c|c|c|}
\hline $\begin{array}{l}\text { Establish and communicate } \\
\text { the vision }\end{array}$ & $\begin{array}{l}\text { Very important to establish and } \\
\text { communicate the vision for change }\end{array}$ & $\begin{array}{l}\text { Important to continue to } \\
\text { communicate the vision }\end{array}$ \\
\hline Diagnose the change & $\begin{array}{l}\text { Change teams must have a full } \\
\text { assessment of the forces for/against } \\
\text { change }\end{array}$ & $\begin{array}{l}\text { May need to reassess the change if } \\
\text { resistance is too high }\end{array}$ \\
\hline Task clarification & & $\begin{array}{l}\text { Very important that the team has a } \\
\text { set of clear and motivating tasks }\end{array}$ \\
\hline \multicolumn{3}{|l|}{ Staffing the team } \\
\hline Heterogeneity & \multicolumn{2}{|c|}{$\begin{array}{l}\text { Heterogeneous mix of skills, experience, and social and political networks } \\
\text { is an advantage during both phases of the change life-cycle }\end{array}$} \\
\hline Change Agents & \multicolumn{2}{|c|}{$\begin{array}{l}\text { Change teams should be staffed with change agents during both phases of } \\
\text { the change life-cycle }\end{array}$} \\
\hline
\end{tabular}

\section{Team Processes}

\begin{tabular}{|c|c|c|}
\hline $\begin{array}{l}\text { Project management to } \\
\text { change }\end{array}$ & \multicolumn{2}{|c|}{$\begin{array}{l}\text { Disciplined project management may offer benefits for change teams in } \\
\text { both phases of the change life-cycle }\end{array}$} \\
\hline $\begin{array}{l}\text { Communication within the } \\
\text { team }\end{array}$ & $\begin{array}{c}\text { A lack of communication can } \\
\text { cause resistance and decrease } \\
\text { effectiveness. }\end{array}$ & $\begin{array}{l}\text { Increased importance as change } \\
\text { teams become more focused on } \\
\text { specific deliverables }\end{array}$ \\
\hline $\begin{array}{l}\text { Collaboration with team } \\
\text { members }\end{array}$ & $\begin{array}{l}\text { Collaboration can help team } \\
\text { members to solve problems and } \\
\text { creatively address resistance }\end{array}$ & $\begin{array}{l}\text { Collaboration is essential during the } \\
\text { acceptance phase where team } \\
\text { members work closely to complete } \\
\text { final implementation. }\end{array}$ \\
\hline Workload Sharing & \multicolumn{2}{|c|}{$\begin{array}{l}\text { Change teams need to be flexible enough to share workloads throughout } \\
\text { the change life-cycle }\end{array}$} \\
\hline Team Efficacy & $\begin{array}{l}\text { Change teams need high efficacy } \\
\text { in the overall direction of the } \\
\text { change to get through the difficult } \\
\text { resistance phase }\end{array}$ & $\begin{array}{l}\text { Change team needs to believe in its } \\
\text { ability to complete tasks during the } \\
\text { acceptance phase }\end{array}$ \\
\hline \multicolumn{3}{|l|}{ Managing the Change } \\
\hline $\begin{array}{l}\text { Senior Management } \\
\text { Support }\end{array}$ & $\begin{array}{c}\text { Senior level support can help } \\
\text { decrease resistance during this } \\
\text { phase }\end{array}$ & $\begin{array}{l}\text { Without senior level support the } \\
\text { team will struggle to implement } \\
\text { lasting change during this phase }\end{array}$ \\
\hline Building Commitment & $\begin{array}{l}\text { Critically important for the change } \\
\text { team to build commitment and } \\
\text { engage other groups during the } \\
\text { resistance phase }\end{array}$ & $\begin{array}{l}\text { Team needs to maintain } \\
\text { commitment }\end{array}$ \\
\hline
\end{tabular}


In Table 13.1 each construct in the model is listed along with a description of how the relationship between this construct and change team effectiveness varies with the life cycle stage. In those cases where the data suggest that such a moderating relationship does not exist (i.e. there is an impact on each construct throughout the change life cycle) the description of the variable is merged into both columns.

The following subsection discusses the moderating impact of the change lifecycle on the model of change team effectiveness. The focus of this discussion is on the constructs in the change team effectiveness model which are influenced by the change life-cycle and relationships that are not affected by the change life cycle stage will not be discussed.

\subsubsection{Change Team Effectiveness during the Resistance Phase}

The first period of data collection for this case study took place during the resistance phase of the Wave 1 change to Shared IT Service. In their 'death valley of change' article Elrod and Tippett (2002) describe the resistance phase of change as being characterized by a realization of losses, frustration, decreased motivation, denial, grief, anger, and a decrease in performance. Given that the existing literature on organizational change suggests that organization was experiencing this decline in performance and support for the change during the $\mathrm{T} 1$ data collection period the data were examined closely to see how this may have affected change team effectiveness during this period.

The first pattern that emerged from the data was that the majority of responses relating to change team effectiveness at $\mathrm{T} 1$ dealt with the change management. When 
asked at T1 to describe the strengths of an effective change team, every STI team member described a characteristic that fell under the theme of effective change management (compared to only $67 \%$ at T2). Similarly, when asked to describe the behaviours and values common to a team that was effective in their role as change agents, $60 \%$ of all responses from STI team members were related to change management behaviours. These findings suggest that during the resistance phase change team members perceived change management (rather than team management) activities to be critical to change team effectiveness. This pattern fits with Elrod and Tippett's (2002) model, which predicts that change teams would struggle to help push the organization forward during the resistance phase of the change. To do this change agents would need to be focused on change management activities such as: communicating the vision of the change to others in the organization, building commitment with stakeholders, and dealing with resistors to the change.

The prominence of the change management theme during the resistance phase of the change is best appreciated by looking at two constructs in the change team effectiveness model: communicating the vision for change outside the team and engaging stakeholders to build commitment for the change. At T1 half of the STI team viewed communicating the vision for the change to their organization as a positive factor influencing the effectiveness of the team in their role supporting the change (versus $17 \%$ at T2). Communicating the message of change has been shown to be one of the most important parts of change implementation (Armenakis \& Harris, 2002). This research suggests it may also be an important predictor of the success of a change team. While the survey data showed that the STI team had only moderate levels of communication with 
groups outside their own, $67 \%$ of the STI team felt that the failure to communicate the message of change outside the change would be a limiting factor for the team's effectiveness in supporting the change effort. These results highlight the importance of communicating the vision for change to the entire organization as a key component of change team effectiveness during the resistance phase of the change.

Another common theme in the interview data was the importance of building commitment and engaging the stakeholders during the resistance phase of the change. STI team members felt that to build commitment, the team needed to go beyond simply communicating to groups affected by the change and had to also involve stakeholders in decisions impacting the change.

We need to build trust within the organization and the outside community. -STI Team Member

Many team members noted that building commitment and trust was a critical part of engaging stakeholders and changing the attitude of the organization (which was seen to be negative towards the change) and a key factor in the team's ability to push the change forward

People think of another change team as a make work project. -STI Team Member

This conclusion is supported by the fact that over half of the STI team (58\%) indicated that they felt commitment building during the resistance phase was an important characteristic of an effective change team. It is also supported by researchers in the area of change implementation (Kanter et al., 1995; Kotter \& Schlesinger, 1979; Morgan \& 
Zeffane, 2003) who recommend engaging stakeholders as a way to reduce the challenges of the resistance phase of change.

\subsubsection{Change Team Effectiveness during the Acceptance Phase}

The second period of data collection for this case study took place during the acceptance phase of the Wave 1 change to Shared IT Service. In the 'death valley of change' article Elrod and Tippett describe the acceptance phase of change as being characterized by an acceptance of the reality that change will happen, exploration, creativity, openness, and readiness. Following the guidance of these researchers the influence that this organizational climate may have had on the predictors of change team effectiveness was examined. The following subsection discusses the differences in change team effectiveness that were observed during the acceptance phase of the change.

The first trend that was observed when comparing the $\mathrm{T} 1$ and $\mathrm{T} 2$ data was the importance of team management to change team effectiveness in the acceptance phase of the change as compared to the resistance phase which had a focus on change management. Two-thirds of all $\mathrm{T} 2$ interview responses dealt with aspects of general team effectiveness as a way to improve the ability of change teams to implement change (versus $47 \%$ at $\mathrm{T} 1$ ) and respondents were significantly more likely to link team effectiveness strategies to change team effectiveness during the $\mathrm{T} 2$ interviews compared to the $\mathrm{T} 1$ interviews. The results can potentially be explained by the nature of the work that is common during the acceptance phase of the change. In the resistance phase an important part of the STI team's task was to engage stakeholders, deal with resistance, and build commitment for the change. In the acceptance phase, on the other hand, the STI 
change team was engaged in the final implementation of the change, which meant completing specific tasks and projects that would make up the deliverables of the change project. It makes sense, therefore that the need for traditional teamwork processes and strategies to 'get the job done' was likely greater during this stage of the change.

Along with the general trend toward team management discussed above the longitudinal data in this study allowed us to examine each of the change team effectiveness constructs to see which variables played a more prominent role in change team effectiveness during the acceptance phase of the change. This analysis showed that the following team management constructs were more important to change team effectiveness in the acceptance phase of the change than the resistance phase: task clarification, team collaboration, and the level of support from senior management. Details on each are given below.

The data suggest that clarification of a change team's task is more important to team effectiveness during the acceptance phase of the change than during the resistance phase. For example, at T2 $35 \%$ of STI team members explained that one of the major contributing factors to the success of their team was their ability to clarify their task (no team member gave this response at $\mathrm{T} 1$ ). The survey data also showed that task direction, which refers to the purpose and goals of the team, improved during the acceptance phase of the change. It would appear from these data that change teams may be able to improve their effectiveness during the acceptance phase of the change by clarifying their to focus their efforts on implementation projects.

Team collaboration was another variable in the model which may be of increased importance during the acceptance phase of the change. In the acceptance phase, just 
under two-thirds of STI team members suggested that teams who were effective in their supporting role as change agents needed to find a way to stay interconnected while performing their tasks. These team members viewed team collaboration as an important factor in the team's ability to handle the multiple and often overlapping tasks that were associated with the implementation of the change and felt that the ability to work closely together on tasks was seen as an important way in which the team could improve effectiveness. The survey data indicated that the STI team reported higher levels of task interdependence during the acceptance stage of the change than in the resistance phase of the change. These results together support our hypothesis that increased collaboration may be necessary during the acceptance stage and may help the team to coordinate their efforts and ensure that they are 'on the same page' with the direction of the change.

The final change team effectiveness construct that appeared to be of elevated importance during the acceptance phase was the level of support that was present from senior management. At T1, STI members commented that they felt that the implementation of the change would run into serious road blocks without improved support from the top of the organization.

Our senior leadership hasn't owned the change, and so our group has been stuck. - STI Team Member

At T2, however the number of team members who saw the need for support from the top as key to the effectiveness of the change team increased by $33 \%$. While planning and communicating the change was important to reduce resistance when it came to actually implementing the change and asking people to change, the change team felt that the lack of senior level support was essential. This result is consistent with the recommendations 
of several researchers on change management (W. Burke, 2002; Miller, 2002) who argue that without strong leadership at the top of the organization, the change effort is likely to struggle to accomplish real lasting change.

\subsubsection{Other Moderating Variables}

In addition to the change life-cycle, two other moderating variables are included in the model of change team effectiveness: the level of bureaucracy in the organization and the level of decision making authority given to the change team. The emergence of both of these moderators may be linked to the fact that the STI team operated in a public sector organization. Traditionally, public sector organizations have been characterized as bureaucratic and hierarchical with decision making authority being centred near the top (Bramson \& Buss, 2002; Robertson \& Seneviatne, 1995; Wise, 2002). Further research is required; however, before they are included in a general model of change team effectiveness. This section discusses the potential moderating effect of the level of bureaucracy and decision making authority on change team effectiveness.

\subsubsection{Bureaucracy}

Public sector organizations have often been assumed to be characterized by high levels of bureaucracy which can limit the ability of the organization to successfully execute transformational change (Robertson \& Seneviatne, 1995). In this study bureaucracy is defined as the extent to which the organization can be described as having a high level of division of labour and specific tasks, a formal authority structure, and 
standardized rules that regulate decision making responsibilities of individual organization members. In the model of change team effectiveness the level of bureaucracy is hypothesized to be a moderating variable in the relationship between the team's ability to work together and the effectiveness of the team. The following data support this hypothesis. First, at both T1 and T2 the majority of STI team members who were interviewed suggested that obtaining resources for the team's work was a challenge due to rules and regulations that where inflexible and slow. STI team members felt that the dynamic nature of organizational change was not compatible with a highly bureaucratic organizational structure. At T2 $83 \%$ of the STI change team who were interviewed indicated that bureaucracy had slowed the work of the team down and made it more difficult to achieve their deliverables. A third major challenge related to the level of bureaucracy was the ability of the team to quickly bring new members onto the team who had specific areas of change expertise. One-third of the team who was interviewed at T2 indicated that more efficient HR processes, less red tape to bring someone on board would help the team to improve effectiveness.

\subsubsection{Decision Making Authority}

The second moderating variable that came out of the data was the level of decision making authority that the team was given in regard to getting their task done. This variable refers to the extent to which the change team has input into and control over the decisions relating to the planning and execution of their task. The level of decision making is tied to the team autonomy variable put forth in several traditional models of team effectiveness (Hackman, 1987; Pearce \& Ravlin, 1987; Sundstrom et al., 1990). 
The primary concern put forth by STI change team members was that as the requirements of the task changed, the team did not have the authority to make adjustments to their strategy for executing the change. One quarter of the team $25 \%$ interviewed at $\mathrm{T} 2$ indicated that a lack of power to force people to change limited the team's ability to implement change. One quarter of the STI team at T2 also suggested that the team's effectiveness would be improved if senior management had given the team more power to get the job done and a bigger say in the direction of the change. Change team members suggested that the implications of the lack of decision making authority were seen in the change teams struggles to acquire the resources they needed for their task and to addresses the resistance to change throughout the organization.

\subsection{SUMMARY}

The model of change team effectiveness developed in this section represents the primary contribution of this thesis research. Specifically, Chapter 13 contributes to our understanding of change team effectiveness with two important propositions related to the effectiveness of change teams. First, the case study findings suggest that change team effectiveness is predicted by four groups of constructs: defining the task, staffing the change team, change team processes, and managing the change. Within each group there are multiple constructs which predict change team effectiveness in the model. These constructs form a foundation for future empirical research on change team effectiveness.

The second proposition presented in our model of change team effectiveness is that the relationship between the predictor variables and change team effectiveness is moderated by three variables: the stage of the change life-cycle, the level of bureaucracy, 
and the level of decision making authority given to the team. In particular, this case study revealed that the stage of the change life-cycle in which the team is operating plays a critical moderating role for the relationships shown in the model. 


\section{PART SEVEN: CONCLUSIONS}

The goal of this research is to improve the way in which organizations implement organizational change. Part seven of this thesis presents the conclusions of this research and discusses the potential contributions, limitations, and directions for future research that have emerged from this study. 


\section{CONCLUSIONS AND CONTRIBUTIONS OF THIS RESEARCH}

This thesis represents one of the first attempts to examine team effectiveness in the context of a planned public sector transformational change effort. The overarching goal of this research was to enhance our understanding of change teams and their ability to successfully implement organizational change. As a tool for understanding the unique features of change team effectiveness, this thesis offers guidance to practitioners and future researchers in three main areas: understanding the benefits and drawbacks of using teams to implement transformational change, understanding the factors that impact the effectiveness of change teams, and advice for improving senior management support for change teams.

One of the most important conclusions from the case study of the STI change team is that although change teams have several similarities to traditional project teams, they are a unique form of organizational team. In our review of the literature several taxonomies of teams in organization were examined with the goal of understanding where change teams fit into our existing classifications of teams in organizations. The case study revealed that the primary distinguishing characteristic of change teams is that they are heavily influenced by their task and their context; as can be seen by noting that organizational change permeates almost every aspect of the change team effectiveness model developed in this thesis.

While change teams resemble the description of project teams used by Cohen and Bailey (1997), they also share similarities with parallel teams (i.e. teams which are brought together from different parts of the organization to work on a task not typically 
performed by the organization). In addition change teams also appear to overlap two types of teams defined in Sundstrom et al.'s (1990) taxonomy of teams: project and development teams and advice and involvement teams. Similarly, Devine's (2002) taxonomy of teams contains multiple forms of teams that share characteristics with the change team in our case study. These similarities suggest that change teams may be a combination of several forms of teams typically found in organizations. Given the strategic importance of organizational change to organizations (Balogun \& Hailey, 2004; Lloyd \& Maguire, 2002; Weick, 2000) future classifications of organizational teams should consider the inclusion of change teams as a unique type of team and determine how they should be best described.

The first objective of this research is to increase the understanding of why change teams are used to plan and implement organizational change and what benefits and challenges are associated with the use of change teams to implement change. Specifically, research question \#1 asks: What are the benefits and challenges of using change teams to implement change? The results of this study suggest that change teams offer multiple benefits for both individuals and organizations. Benefits identified in this thesis include: workload sharing, improved access to information, improved access to social and political networks, and finally increased creativity and better decision making. Each of these benefits suggests that change teams offer the possibility of raising employees' performance and thus improve the organizations ability to successfully implement change.

The findings of this case study also shed insight into the potential drawbacks of using change teams as a strategy for implementing change. More specifically, this case 
study suggests that change teams may lead to a slower pace of work, a decline in role clarity, and increased frustration due to high levels of interdependence within the team. Furthermore, this thesis suggests that these drawbacks, which are common to teamwork in general, may be intensified by the context of change which has been shown to be characterized by increased ambiguity and frustration throughout the change process (Elrod \& Tippett, 2002). This case study adds to our understanding of the issue by indentifying three moderating factors which seem to be important when considering the benefits and drawbacks of change teams. First, the level of bureaucracy may serve to increase the drawbacks found to be associated with change teams (ie. the higher the bureaucracy, the more prevalent and bothersome the challenges). Second, in this case study the level of authority given to the change team positively related to the team's ability to generate creative solutions and better decisions. Finally, staffing the change team with individuals who have the characteristics and values of effective "change agents' may be a requirement for realizing the benefits of workload sharing and limiting the drawbacks from increased interdependence.

In summary, each of the findings of this thesis related to the benefits and challenges of change teams contributes to our understanding of how change teams should be used as a strategy to implement organizational change. Taken as a whole this thesis supports the following conclusion: change teams can be an effective strategy for planning and implementing transformational change within the public sector.

The second objective of this research is to increase our understanding of the factors associated with change team effectiveness. We met this objective by developing a model of change team effectiveness that can be used in future research on change teams. 
This thesis represents one of the first attempts to model team effectiveness in the context of a transformational change effort. The model of change team effectiveness was discussed in full detail in Chapter 13 and offers several important contributions to researchers and practitioners.

This case study concludes that the effectiveness of change teams appears be heavily influenced by a combination of sound change management and effective team management strategies that may vary depending on the change life-cycle. The results of this study show that during the resistance phase of the change, where the organization is affected by a decline in performance and an increase in negative attitudes toward the change, change management strategies such as engaging stakeholders and overcoming resistance may drive the effectiveness of the change team. When the change moves into the acceptance phase of the life-cycle, and the emphasis is on completing the change, traditional teamwork strategies take on an increased importance with respect to the effectiveness of change teams. These findings have implications for how change teams are formed, how they work together to bring about change, and how their work should be evaluated in each stage of the change. The inclusion of the change life-cycle in the model of change team effectiveness represents the most unique feature of change team effectiveness and one of the most important contributions of this thesis.

The model put forth in this thesis demonstrates the similarities between traditional team effectiveness models (Campion et al., 1993; Hackman, 1987) and change team effectiveness. For example, the model of change team effectiveness developed in this research postulates that four sets of constructs will impact change team effectiveness: defining the team's task, staffing the team, team processes, and managing the change. 
The first three themes are similar in nature to Campion et al.'s (1993) model of team effectiveness while the fourth theme reflects the context of organizational change in which the change team operates. The similarities between the two models suggest that existing team effectiveness research can contribute substantially to the further development of the change team effectiveness model.

Along with the similarities to existing team effectiveness models this research makes a significant contribution by identifying several factors of team effectiveness that may be unique to change teams. The first set of variables unique to change teams deal with defining the change team's task. When defining the task of the change team this case study suggests that it is critical for management to formally establish a vision for the change and undertake a complete diagnosis of the change landscape. This case study suggests that both of these variables can help to improve a change team's chances of effectively implementing change.

This thesis research also suggests at that there are several unique factors for managers to consider when they are staffing change teams. Within the staffing the team theme, the results of this case study suggest that a heterogeneous mix of team members from different social and political networks is an important consideration when staffing a change team. As well, when selecting individuals for the change team, the findings from this case study suggest that team members should have a positive outlook on change, collaborate well with others, work extremely hard, take accountability, and enjoy the uncertainty of change. In other words, it is important to staff a change team with change agents. 
Another important insight from this case study is the importance of managing the context of organization change for overall change team effectiveness. Two unique contributions within this theme are the engagement of stakeholder and the level of senior management support. The findings from this case study suggest that change teams must engage individuals and groups who will be impacted by the change if they want to be effective. This is an important way in which change teams manage their surroundings. By communicating and including stakeholders in the planning and decision making process change teams may be able to increase engagement and improve their ability to implement change.

In addition to gathering commitment from stakeholders, this case study showed that change team effectiveness may be influenced directly by the level of senior management support. While change teams can be at the forefront of the change, this study found that many of the tasks needed to make the change a reality require having political support and a clear direction that can only be provided by senior management.

The third objective of this research is prescriptive in nature and aims to explore one of the most prevalent themes in the STI case study data, the support from senior management for change teams. To address this objective, Research Question \#3 asked, how can organizations better support change teams? As our study of the STI change team evolved, one of the critical factors for change team effectiveness that emerged was the role of senior leadership in supporting the work of the change team. An important outcome of this research objective is a list of four recommendations that senior management can use to support change teams in their role as agents of change for the organization: (1) assess the impact of the change, (2) provide a clear direction for the 
team, (3) supply the team with flexible resources, and (4) communicate the progress of the change.

The first recommendation coming out of this research, regarding how senior management could improve their political support for change teams, is to provide the change team with a thorough assessment of the impact of the change on their organization. Half of the STI team members reported that the team would improve their effectiveness if they could go back and reassess the change. More specifically, team members suggested conducting a thorough assessment of the impact of the change and the risk factors that the change team will need to be aware of. This finding is consistent with recommendations from the change management literature that senior leadership is responsible for ensuring that a thorough examination of the organization and the environment is conducted before the change effort begins (Burke, 2002).

The need for better assessment of the change was tied to the need for a clear direction when operating on a change team. STI team members also suggested that a review of the risk factors would help to ensure that the team was engaging the right people in the organization who could help move the change forward. It is also important that the assessment of change risk factors contains an honest assessment of the team's ability to institutionalize the change. Dawson (2003) points out that change plans should be flexible enough to allow for reassessment and reformulation of the strategy for the change. By providing the team with a complete assessment of the change senior management can better assesses the resources and time frame needed for the change team. The clear assessment represents a useful starting point for developing a positive strategy for implementing future change. 
The second recommendation that emerged from the case study data was the importance of providing a clear vision and road map for the work of the change team. When asked how to improve change team effectiveness, just over half of the STI team members suggested that senior management could improve change team effectiveness by clarifying expectations and developing a plan to show how the work could be institutionalized. This is again consistent with what is reported in the change management literature. For example, Kotter (1999) explains that failing to communicate a clear vision for the change is one of the most common mistakes that senior leadership can make. Todnem By (2005) also suggests that a primary reason for failed change efforts is the lack of a valid strategy for seeing the change through to completion. By providing a formal plan for the change and setting out clear deliverables for the change team senior management may improve both the team and the organization's belief in the change.

The third recommendation for senior level support put forth by the STI team members was the importance of providing the team with the resources necessary to accomplish their task. Two-thirds of change team members interviewed at T1 and T2 thought that the best way for senior management to support the change team would be to provide the team with the resources needed to complete their task. STI team members specified that those resources need to be flexible to respond to changes that occur as a result of shifting work demands. Senior management should work with the human resources department to ensure that the change team hire team members as required by the demands of the task. 
The fourth recommendation for senior level support relates to the communication from management during the change effort. According to this study it is critical that senior management consistently communicates to the organization during a change effort. Similarly, Kotter (2005) argues that one of the most common mistakes of senior leadership in organizations undergoing a change is to under communicate to their organization about the change and keep those affected by the change informed about the status and direction of the change. This theme can also be observed in the change management literature. Vann (2004) for example, argues that consistent communication from senior leadership can help public sector change efforts to create a shared meaning around principles, processes, and language throughout the change process.

This case study also suggests that the communication from senior management should carry with it clear political support for the change team. As noted in the literature, by politically supporting the change team and their work through regular communication, senior management can improve the ability of the change team to implement the change (Burke, 2002; Kotter, 1999). More specifically, this case study supports the idea that a more effective communication strategy would increase team effectiveness by helping to prepare the organization for the change. To do this the STI team suggested that the organization provide clear metrics for the change so employees could see the progress and understand the path that the change would take, and include the change team as a part of the communication strategy.

Each of the four recommendations for improved support of change teams identify potential areas in which senior management could contribute to improved change team effectiveness. Further study into the impact of senior level support on the effectiveness of 
change teams is needed to enhance the ability of change teams to successfully implement change.

In conclusion, the outcomes of this grounded theory case study represent a first step towards a better understanding of the factors related to the effectiveness of teams responsible for implementing organizational change. In particular, the development of a model of change team effectiveness moves research in this area forward and provides a foundation for future empirical research in this area. To date, the study of change team effectiveness has been lacking in both the organizational change and team work literatures. It is hoped that this conceptualization of change team effectiveness will promote further examination of the change team effectiveness model and improve the capability of organizations to successfully implement transformational change.

\subsection{LIMITATIONS}

There are several limitations of this research that should be discussed in order to put the contributions of this study into context. First, the primary limitation of this study stems from the fact that the results of this case study are limited to change teams implementing planned transformational change in the Canadian Public Sector. Caution should be used when attempting to generalize the model of team effectiveness and the recommendations that emerged from this study to larger populations. The context of organizational change differs greatly between organizations and further research is required to examine the effectiveness of change teams in other contexts. The decision to use a theoretical sampling technique and the case study method to examine the role of teams in a large scale organizational change limits the generalizability of these research 
findings to change teams operating outside the public sector. That being said, the strong link between the model of change team effectiveness and the team effectiveness and change management literatures combined with the fact that model has strong face validity suggests that the model may be largely generalizable. It also means that the model of change team effectiveness developed in this thesis has the potential to provide a rich foundation from which future research can build the understanding of change teams. Future research using larger sample sizes, and conducted in various sectors, should be done to build upon the relationships identified in this thesis research.

The second limitation relates to the potentially idiosyncratic nature of the model of change team effectiveness put forth in this thesis. While the study was exploratory in nature, there may have been issues closely related to change team effectiveness which simply did not emerge from this study. For example, there were several variables within the initial orienting framework that did not emerge from the case study data. We cannot conclude, therefore, from this one study, that task variety, task identity, self-management, feedback and reward interdependence, and training do not play a role in change team effectiveness. Future research is needed explore why these variables are not included in the model.

The use of the Campion et al. $(1993 ; 1996)$ model of team effectiveness for the initial framework in this thesis may have also influenced the emergent model of change team effectiveness and represents a third potential limitation of this thesis. The Campion model of team effectiveness is one of the most influential models of teamwork available. However, there are several other input/process/output based team effectiveness models (Cummings, 1981; Gladstein, 1874; Hackman, 1987; Shea \& Guzzo, 1987; Sundstrom et 
al., 1990) that also contribute to our understanding of team effectiveness. Testing the usefulness of all of these models in a change team context was judged to be beyond the scope of this thesis research. Future research in this area should examine change teams using these models as the starting framework to see how they contribute to our understanding of change teams.

The fourth limitation of this thesis stems from the small sample size that characterizes this case study research. While a theoretical longitudinal sample $(\mathrm{N}=12)$ is acceptable from a grounded theory approach, it does limit this case study's ability to generalize the findings of this thesis to other change teams.

The fifth limitation of this thesis is linked to the decision to allow for multiple responses from each respondent in the semi-structured interviews with the STI change team. With only twelve team members in the sample, the decision to allow multiple responses from respondents was made to ensure that each topic was explored to the fullest extent with each respondent (e.g. on interview questions such as "What types of behaviours or values are characteristic of a team that is supportive of the change?"). Encouraging multiple responses from STI team members is consistent with the exploratory nature of the case study however; it did allow the opportunity for more vocal respondents to influence the results of the interviews disproportionately. Accepting the limitations inherent in allowing multiple responses to interview questions was viewed as an acceptable trade off for the benefit of receiving additional information on the effectiveness of the change team.

The sixth limitation of this thesis related to both the change effectiveness model and the recommendations for senior leadership that emerged out of this study. A 
cautionary note to those interpreting the recommendations of this case study is needed to remind readers that the objectives of this research were exploratory in nature and not intended to test any hypothesis relating to change team effectiveness. As such, the model of change team effectiveness and the recommendations for improved managerial support are meant to promote further exploration into this research area. The desired outcome of this case study research is to improve the successful implementation of transformational change. This goal will only be made possible through an increased research focus on the area of change team effectiveness. It is our belief that the model developed in this thesis will provide an excellent starting point for those working at the intersection of teams and organizational change.

\subsection{FUTURE RESEARCH}

The conclusions and contributions of this thesis should act as a catalyst for future research in a number of areas related to change team effectiveness. The first direction for future research is to continue to develop the comprehensiveness of the change team effectiveness model. As discussed in the limitations section, the emergent constructs in this thesis did not address several of the traditional variables associated with team effectiveness in general. As a result future research should continue to explore the predictors of change team effectiveness using studies similar to this in order to develop a comprehensive list of the potential variables that warrant inclusion in the model of change team effectiveness. To accomplish this task, future researchers could use a case study methodology similar to that described earlier to refine the model of change team effectiveness. 
The influence of the change life-cycle on change team effectiveness represents one of the most important contributions of this thesis research. To extend the findings of this research, future researchers should examine change team effectiveness throughout the change life-cycle. The current study examined change team effectiveness in the final two stages of the change. It remains to be seen however, if the first stage of the change, the anticipation stage, also has an influence on the change team effectiveness model. By studying change team effectiveness using a longitudinal design throughout the change cycle researchers may be able to provide a more comprehensive model and a more useful set of guidelines for practitioners using change teams. In addition, researchers should be wary of cross-sectional models of change team effectiveness that do not explicitly situate themselves within the change life-cycle.

Following the refinement of the model of change team effectiveness throughout the change life-cycle the next step for extending this thesis research is to test the external validity of the model of change team effectiveness and recommendations put forth in this thesis. Future research can carry out this task by examining the usefulness of the model and recommendations for support in other change contexts. To do this, researchers could replicate this case study design and collect interview and survey data for change teams in different populations and settings. Specifically, an important step to extend the contributions of this research would be the examination of the validity of the model in a private sector organization.

Another possible avenue for future research on change teams is to apply the lessons of this thesis to research areas that are closely linked to organizational change. One such research area is the project management literature. It has been suggested in the 
project management literature that organizational change can be viewed as a large project and that successful project management may be linked to the ability of the organization to implement strategy (Kenny, 2003). These arguments are consistent with comments from STI team members who suggested that taking a project management approach to change may help the team to be more effective in supporting and implementing organizational change. The link between IT change and project management is an area that has already received some attention from project management researchers (Legris \& Collerette, 2006). Pointing to the high failure rate of IT projects, Legris and Collerete (2006) suggest that closer involvement of stakeholders, attention to social factors, and a closer integration of project management with change management fundamentals would benefit the success of IT projects. For example, recent research by Crawford and Nahmias (2010) applied change management fundamentals to the role of project manager on projects within an organizational change in an attempt to show how project managers could provide stronger leadership of change. This research illustrates the potential synergies between the two research areas and suggests that the project management literature may help to develop the conceptual model change team effectiveness in this thesis. The research by Crawford and Nahmias (2010) also suggests that the findings of this thesis may contribute to the project management research area, particularly in projects where teams are the primary structure used for completing the work.

The second area of research that could be used to further develop the outcomes of this thesis is the area of public policy. The transformational change studied in this thesis was a large scale public sector initiative that evolved considerably throughout the life of the change (LeGoff, 2005; Whitfield, 2007). The structure, processes, and culture of the 
GoC impacted the work of the team in a number of ways. STI team members discussed the impact that bureaucracy and a lack of decision making authority had on the team. Team members suggested that the team was operating in less than ideal political conditions at times which may have impacted their ability to support and implement transformational change. Willdavsky (1973) suggests that public policy decisions are extremely complex and that planned organizational change may not be possible due to the shifting political, social, and economic factors that make public policy more emergent than planned. Similarly, Lindblom (1959) describes the reality of decision making for policy makers, who are forced 'muddle through' the decisions that impact public policy and in turn would impact the work of change teams. When applied to the current research, it is possible that the work of the STI team was impacted by challenging nature of the policy decisions made throughout the Shared IT Services transformational change life-cycle. The team level may not be the ideal level of analysis to gain insight into the policy decisions that are made by politicians and senior administrators. Future research could examine the policy decisions that impact the work of the team and change team effectiveness from the perspective of the senior politicians and executives who are involved in the decisions. This level of analysis would serve to help refine the role of public policy decisions in the change team effectiveness model.

Future researchers would also be well advised be to examine more closely the best way to conceptualize and measure the outcomes of change teamwork. The current research relied on team member ratings of performance, satisfaction, and viability to measure the effectiveness of the change team. There is evidence from the data that 
suggests the importance of engaging external stakeholders may merit the inclusion of outside evaluations of team performance in the measure of change team effectiveness.

An eventual direction for change team effectiveness research would be to move toward hypothesis testing where measures are developed and researchers are confident in the constructs place in the model of change team effectiveness. The survey of team effectiveness used in this thesis offers a useful starting point for designing a change team effectiveness questionnaire that could be used to test the relationships presented in the model of change team effectiveness.

\subsection{IMPLICATIONS FOR PRACTICE}

In spite of the large amount of conceptual development and testing still required to validate the model of change team effectiveness put forth in this thesis there are several implications for management practice that are suggested by this research. First and foremost, this research illustrates the unique contextual factors that are relevant to organizational change teams. This study illustrates that change teams are a unique form of teamwork in organizations and that the effectiveness of change teams, as well as the supports that they require, may be influenced by the phase of the change life-cycle in which the change team is operating. This information can be used to guide practitioners who should understand that change teams who are effective in one phase of the change may not necessarily be effective in the next phase.

From the model of change team effectiveness it can be inferred that a clear direction for the team, the importance of communicating and engaging stakeholders, and the flexibility of team members may be more important when the mandate is to 
implement change than in other teamwork settings. Management should be aware that the work of the team appears to be substantially affected by the leadership and direction provided from senior management in the organization.

This research also offers guidance in the task of staffing organizational change teams. More specifically, this research suggests that change teams should be composed of a heterogeneous mix of members from unique social and political networks throughout the organization. This case study also suggests that when staffing a change team the qualities of a successful agent of change should be given increased weight, in terms of membership selection, rather than looking just at the technical skills and experience of employees. Furthermore, this research suggests that the composition of a change team needs to be flexible to accommodate changes in the tasks faced by change teams. This implies that organizations must develop flexible human resources policies and have a bank of available change experts to choose from to allow for the team to have the human resources needed to implement change.

Finally, the discussion of the role of management in supporting the effectiveness of change teams provides direction for practitioners. The four primary recommendations for management that were put forth by the STI change team offer a useful starting point for understanding management's role in change team effectiveness. Assessing the change, providing direction, giving the team resources, and supporting the team through communication are all practical steps that senior management can take to facilitate the implementation of change by their change teams. 


\section{REFERENCES}

Allen, N.J. \& Hecht, T.D. (2004). The 'romance of teams': Toward an understanding of its psychological underpinnings and implications, Journal of Occupational and Organizational Psychology, 77(4), 439-461.

Allen, J., Jimmieson, N.L., Bordia, P. \& Irmer, B.E. (2007). Uncertainty during Organizational Change: Managing Perceptions through Communications, Journal of Change Management, 7(2), 187-210

Armenakis, A., \& Harris, S. (2002). Crafting a change message to create transformational readiness, Journal of Organizational Change, 15(2), 169-183.

Ashford, S.J. (1988). Individual Strategies for Coping with stress during organizational transitions, Journal of Applied Behavioral Science, 24(1), 19-36.

Atkinson, P. (2005). Managing Resistance to Change, Management Services, 49(1), 1419.

Balogun, J. \& Hailey, V.H. (2004). Exploring Strategic Change, $2^{\text {nd }}$ Ed., London: Prentice Hall.

Bamford, D.R. \& Forrester, P.L. (2003). Managing Planned and Emergent Change Within an Operations Management Environment. International Journal of Operations \& Production Management, 23(5), 546-564.

Bartunek, J.M., Rynes, S.L., \& Ireland, R.D. (2006). What makes Management Research Interesting, and why does it matter?, Academy of Management Journal, 49(1), 9-15.

Beer, M. \& Nohria, N. (2000). Breaking the Code of Change, Harvard Business School Press, Boston, MA..

Bohen, H. \& Viveros-Long, A. (1981). Balancing jobs and family life, Temple University Press.

Bordia, P., Jones, E., Gallos, C., Callin, V.J., \& Difonzo, N. (2006). Management are aliens: Rumors and Stress during organizational change. Group and Organizational Management, 31(5), 601-621.

Bowers, C.A., Pharmer, J.A., \& Salas, E. (2000). When member homogeneity is needed in work teams, Small Group Research, 31(3), 305-327.

Bramson, R.A. \& Buss, T. (2002). Methods for whole system change in public organizations and communities: An overview of the issues, Public Organization Review, 2, 211-221. 
Bray, R. (2005). For Better or Worse: Government of Canada creeps towards a shared services model for IT, Summit Magazine, Sept., 13-16.

Brockner, J., O'Malley, M., Reed, T., \& Glynn, M. (1993). Threat of future layoffs, selfesteem, and survivors' reactions: evidence from the laboratory and the field. Strategic Management Journal, 14, 153-166.

Burke, R.J. (2002). Organizational Transitions. In The New World of Work, C. Cooper and R. Burke (Eds.), 3-28, Oxford, U.K.: Blackwell.

Burke, W. (2002). Organizational Change: Theory and practice, London: Sage Publications.

Burke, W. (2008). Organization Change: Theory and Practice, Sage Publications: Los Angelas, CA.

Burke, W., Lake, D.\& Paine, J. (2009). Organization Change: A Comprehensive Reader, Jossey-Bass: San Francisco, CA.

Burnes, B. (2004a). Kurt Lewin and Complexity Theories: Back to the Future? Journal of Change Management, 4(4), 309-328.

Burnes, B. (2004b). Emergent Change and Planned Change - Competitors or Allies? The case of XYZ construction. International Journal of Operations \& Production Management, 24(2), 886-902.

Callan, V. J. (1993). Individual and organizational strategies for coping with organizational change. Work and Stress, 7, 63-75.

Campion, M.A, Medsker, G.J, \& Higgs, A.C. (1993). Relations between work group characteristics and effectiveness: Implications for designing effective work groups, Personnel Psychology, 46, 823-850.

Campion, M.A, Papper, E.M, \& Medsker, G.J. (1996), "Relations between work group characteristics and effectiveness: A replication and extension", Personnel Psychology, $49,429-452$.

Cannon-Bowers, J.A., Tannenbaum, S.I, Salas, E., \& Volpe, C.E. (1995). Defining competencies and establishing team training requirements. In R. Guzzo and E. Salas (Eds.). Team Effectiveness and Decision Making in Organizations, 333-380, Josey Bass: San Francisco.

Catmull, E. (2003), How Pixar Fosters Collective Creativity, Harvard Business Review, Sept, 128-135. 
Cepeda, G. \& Martin, D. (2005). A review of case studies publishing in Management Decision 2003-2004, Management Decision, 43(6), 851-876.

Coch, L. \& French, J. (1948). Overcoming Resistance to Change. Human Relations, August, 512-532.

Cohen, S.G. \& Bailey, D.E. (1997). What makes teams work: Group Effectiveness Research from the Shop Floor to the Executive Suite, Journal of Management, 23(3), 239-290.

Colquitt, J. \& Zapata-Phelan, C. (2007). Trends in Theory Building and Theory Testing: A Five-Decade Study of the Academy of Management Journal, Academy of Management Journal, 50 (6), 1281-1303.

Cordery, J. (2004). Another case of the Emperors New Clothes, Journal of Occupational and Organizational Psychology, 77, 481-484.

Cox, K. (2003). The Effects of Interpersonal, Intragroup, and Intergroup Conflict on Team Performance Effectiveness and Work Satisfaction, Nursing Administration Quarterly, 27(2), 153-163.

Cox-Fuenzalida, L., Beeler, C. \& Sohl, L. (2006). Workload History Effects : A Comparison of Sudden Increases and Decreases on Performance, Current Psychology, 25(1),8-14.

Crawford, L. \& Nahmias, A. (2010). Competencies for managing change, International Journal of Project Management, 28, p.405-412.

Cummings T.G. (1981). "Designing effective work groups”, In Nystrom PC, Starbuck WH (Eds.), Handbook of organization design (2, 250-271). New York: Oxford University Press.

Cummings, T. (1999). The Role and Limits of Change Leadership. In Leaders Change Handbook, Conger, J., Spreitzer, G., \& Lawler E. (eds.), 301-320, Jossey Bass: San Fransico.

Cutcher, L. (2009). Resisting change from within and without the organization, Journal of Change Management, 22 (3), pp. 275-289.

Dawson, P. (2003). Understanding Organizational Change: the contemporary experience of People at work, London: Sage Publications.

De Dreu, C. (2002). Team innovation and team effectiveness: The importance of minority dissent and reflexivity, European Journal of Work and Organizational Psychology, 11(3), 285-298. 
Decker, D., Wheeler, G.E., Johnson, J, \& Parsons, R.J. (2001). Effect of Organizational Change on the Individual Employee. Health Care Manager, 19(4), 1-12.

Delarue, A., Hootegem, G.V., Procter, S., \& Burridge, M. (2008), Teamworking and Organizational Performance: A review of survey based research, International Journal of Management reviews, 10(2), 127-148.

Devine, D.J. (2002). A review and Integration of Classification Systems Relevant to Teams in Organizations, Group Dynamics, 6(4), 291-310.

DiMaggio, P. J. 1995. Comments on "what theory is not", Administrative Science Quarterly, 40: 391-397.

Driskell, J. E., Salas, E., \& Johnston, J. (1999). Does stress lead to a loss of team perspective? Group Dynamics: Theory, Research, and Practice, 3, 291-302.

Driskell, J.E., Goodwin, G.F., Salas, E., \& O'Shea, P.G. (2006). What Makes a Good Team Player? Personality and Team Effectiveness, Group Dynamics: Theory, Research, and Practice, 10(4), 249-271.

Druskat, V.U. \& Wolff, S.B. (2001). Building the Emotional Intelligence of Groups, Harvard Business Review, 79, 81-90.

Eisenhardt, K.M. (1989). Building Theories from Case Study Research, Academy of Management Review, 14(4), 532-550.

Esienhardt, K.M. \& Graebner, M.E. (2007). Theory Building from Cases: Opportunities and Challenges, Academy of Management Journal, 50(1), 25-32.

Elrod, D., \& Tippett, D. (2002). The Death Valley of Change, Journal of Organizational Change Management, 15, 1-16.

Erikkson, M. \& Sundgren, M. (2005). Managing Change: Strategy or Serendipity Reflections from the Merger of Astra and Zeneca, Journal of Change Management, 5(1), $15-28$.

Ferguson, E. \& Cheyne, A. (1995). Organizational Change: Main and Interactive Effects, Journal of Occupational and Organizational Psychology, 68, 101-107.

Ferlie, E, Hartley, J. \& Martin, S. (2003). Changing Public Service Organizations: Current Perspectives and Future Prospects, British Journal of Management, 14, S1-S14.

Fernandez-Alles, M \& Llamas-Sanchez, R. (2008). The Neoinstitutional Analysis of Change in the Public Sector, Journal of Change Management, 8(1), pp. 1-2. 
Fisher, Hunter, \& Macrosson, 1997). Team or Group? Managers' perceptions of the differences, Journal of Managerial Psychology, 12(4), 232-242.

French, W. (1969). Organizational Development, Originally appeared in California Management Review, 12, Take from Natemeer and McMahon, Classics of Organizational Behaviour $3^{\text {rd }}$ Ed., 446-463, Long Grove, ILL: Waveland Press.

Ford, J., Ford, L., D'Amelio, A. (2008). Resistance to Change: The Rest of the Story, Academy of Management Review, 33 (2), 362-377.

Gersick, C. (1991). Revolutionary Change Theories: A Multilevel Exploration of the Punctuated Equilibrium Paradigm, Academy of Management Review, 16(1), 10-36.

Gladstein, D. L. (1984). Groups in Context: A Model of Task Effectiveness, Administrative Science Quarterly, 29, 499-517.

Gladstein, D. L., \& Reilly, N. P. (1985). Group decision making under threat: The tycoon game. Academy of Management Journal, 28, 613-627.

Glaser, B., \& Strauss, A. (1967). The discovery of grounded theory: Stragtegies of qualitative research. London: Wiedenfeld and Nicholson.

Goffee, R. \& Scase, R. (1992). Organizational Change and the Corporate Career: The Restructuring of Managers' Job Aspirations, Human Relations, 45, 363-387.

Graetz, F. \& Smith, A. (2005). Organizing Forms in Change Management: The Role of Structures, Processes and Boundaries in a Longitudinal Case Analysis, Journal of Change Management, 5(4), 311-328.

Greiner, L.E. (1972). Evolution and Revolution as organizations grow, Harvard Business Review, 50(4), 37-46.

Greiner, L.E. \& Cummings, T.G. (2004). Wanted: OD More Alive than Dead! Journal of Applied Behavioral Science. 40(4), 374-391.

Griffin, M.A., Patterson, M.G., \& West, M.A. (2001), Job satisfaction and teamwork: the role of supervisor support, Journal of Organizational Behaviour, 22(5), 537-550.

Gross, T., Pascale, R. \& Athos, A. (1998). The Re-Invention Roller Coaster: Risking the present for a powerful future. Harvard Business Review on Change, 83-112, Review Press: MA.

Gummenson, E. (2000). Qualitative Methods in Management Research, $2^{\text {nd }}$ Ed., Thousand Oaks, CA: Sage. 
Guzzo, R.A. \& Dickson, M.W., (1996). Teams in organizations: recent research on performance and effectiveness, Annual Review Psychology, 47, 307-338.

Guzzo, R.A. \& Shea, G.P. (1992). Group performance and intergroup relations in organizations, in Dullette, M.D., Hough, Hackman, R.J. (1987). The design of work teams, In Handbook of Organizational behavior; ed. J.W. Lorsch, 315-42. Englewood Cliffs, NJ: Prentice Hall.

Hackman, R.J. (1987). The design of Work Teams, In Lorsch, J.W., Handbook of Organizational Behaviour, 315-342, Englewood Cliffs, NJ: Prentice Hall.

Hackman, R.J. (1990). Groups that work (and those that don't), San Francisco, California: Jossey-Bass Inc.

Hackman, R.J. \& Morris, C.G. (1975). Group tasks, group interaction process, and group performance effectiveness: a review and proposed integration, In Leonard Berkowitz (ed.), Advances in Experimental Social Psychology, 8, 45-99, New York: Academic Press.

Hammer, M. (1990). Reengineering Work: Don't Automate, Obliterate, Harvard Business Review, July-Aug., 104-112.

Hartley, J. (1994). Case Studies in Organizational Research. In C. Cassell \& Symon, G. (1994). Qualitative Methods in Organizational Research, 208-229, London: Sage.

Hayes, J. (2002). The Theory and Practice of Change Management, Palgrave, Basingstoke.

Herscovitch, L., \& Meyer, J.P. (2002). Commitment to organizational change: Extension of a component model, Journal of Applied Psychology, 87, 474-487.

Heywood, J.S., Jirjahn, U., \& Wei, X. (2008), Teamwork, monitoring, and absence, Journal of Economic Behavior and Organization, 68(3/4), 676-690.

Hoag, B.G, Ritschard, H.V. \& Cooper, C.L. (2002). Obstacles to effective organizational change the underlying reasons, Leadership and Organization Development Journal, 23(1), 6-15.

Huguet, P., Galvaing, M. P., Monteil, J. M., \& Dumas, F. (1999). Social presence effects in the Stroop task: Further evidence for an attentional view of social facilitation. Journal of Personality and Social Psychology, 77, 1011-1025.

Hunter, L.W. \& Thatcher, S. (2007). Feeling the Heat: Effects of Stress, Commitment, and Job Experience on Job Performance, Academy of Management Journal, 50(4), 953969. 
Ilgen, D.R. (1999). Teams embedded in Organizations, American Psychologist, February, 129-140.

Ilgen, D.R., Hollenbeck, J.R., Johnson, M. \& Jundt, D. (2005). Teams in Organizations: From Input-Process-Output Models to IMOI Models, Annual Reviews in Psychology, 43, 517-543.

ITS Fact Sheets (2008), Delivering Government of Canada IT Shared Services, Public Works and Government Services Canada, August 1, 2008. Retrieved on Apr. 04, 2009, from: http://www.tpsgc-pwgsc.gc.ca/apropos-about/fi-fs/its-sct-eng.html

James, M. \& Ward, K. (2001). Leading a Multinational team of change agents at Glaxco Wellcome, Journal of Change Management, 2(2), 148-159.

Jick, T.D. (1979). Mixing Qualitative and Quantitative Methods: Triangulation in action, Administrative Sciences Quarterly, 24, 602-612.

Jimmieson, N. L., Terry, D. J., \& Callan, V. J. (2004). A longitudinal study of employee adaptation to organizational change: The role of change-related information and changerelated self-efficacy. Journal of Occupational Health Psychology, 9, 11-27.

Kanter, R. (1985). Managing the human side of change. Management Review, 74, 52-56.

Kanter, R., Stein, B., and Jick, T. (1992). The Challenge of Organizational Change, Toronto, ON: MacMillan Publishing.

Kaplan, B., \& Duchon, D. (1988). Combining Qualitative and Quantitative Methods in Information Systems Research: A Case Study, MIS Quarterly, 12(4), 571-588

Karau, S.J. \& Williams, K.D. (1993). Social Loafing: A Meta-Analytic Review and Theoretical Integration, Journal of Personality and Social Psychology, 65(4), p. 681-706.

Karp, T. \& Helgo, T (2009). From Change Management to Change Leadership: Embracing Chaotic Change in Public Sector Organizations, Journal of Change Management, 8(1), 85-96

Katz, R. (1982), "The effects of Group longevity on project communication and performance", Administrative Science Quarterly, 27, .87-104.

Katzell, R.A., \& Guzzo, R.A. (1983), Psychological approaches to productivity improvement, American Psychologist, 38, 468-472.

Katzenbach, J. (1996). Real Change Leaders, Research Quarterly, 1, 148-164.

Katzenbach, J. \& Smith, K. (1993). The wisdom of teams, Boston, MA: Harvard Business School Press. 
Kenny, J. (2003). Effective project management for strategic innovation and change in an organizational context, Project Management Journal, 34(1), p.43-53.

Kerr, N.L., MacCoun, R.J., \& Kramer, G.P. (1996). Bias in judgment: Comparing individuals and groups, Psychological Review, 103, 687-1719.

Kiffen-Petersen, S.A. \& Cordery, J.L. (2003). Trust, individualism and job characteristics as predictors of employee preference for teamwork, International Journal of Human Resource Management, 14(1), 93-116.

Kirkman, B.L., Telsuk, P.E. \& Rosen, B. (2001). Assessing the incremental validity of team consensus ratings over aggregation of individual-level data in predicting team effectiveness, Personnel Psychology, 54, 645-669.

Klein, C., DiazGranados, Salas, E., Huy, L., Burke, S., \& Goodwin, G. (2009). Does Team Building Work?, Small Group Research, 40(2), pp. 181-222.

Kotter, J. (1995). Leading Change: Why Transformations Efforts Fail. Harvard Business Review, 73(2), 106-113.

Kotter, J. (1999). Leading Change: Eight Steps to Transformation, in Leaders Change Handbook, Conger, J., Spreitzer, G., \& Lawler E. (eds.), 87-99, Jossey Bass: San Fransico.

Kotter, J. \& Schlesinger, L. (1979). Choosing Strategies for Change. Harvard Business Review, Mar-Apr., 106-113.

Langton, N. and Robbins, S.P. (2007). Organizational Behaviour $4^{\text {th }}$ Canadian Ed., Toronto: Prentice Hall.

Lawerence, P.R. (1964). How to deal with Resistance to Change, Harvard Business Review, Jan-Feb.

Lazarus, R.S. (1999). Towards better research on stress and coping, American Psychologist, 55, 665-673.

Le Goff, P. (2005), Shared Services: Lower Costs, Improved Services and a Change in Culture, Parliamentary Information and Research Service, Economic Division, Library of Parliament, Ottawa.

Legris, P. \& Collerette, P. (2006). A Roadmap for IT Project Implementation: Integrating Stakeholders and Change Management Issues, Project Management Journal, 37(5), 6475. 
LePine, J. A., Podsakoff, N. P., \& LePine, M. A. (2005). A meta-analytic test of the challenge stressor-hindrance stressor framework: An explanation for inconsistent relationships among stressors and performance. Academy of Management Journal, 48, $764-775$.

Lester, S.W., Meglino, B.M., \& Korsgaard, M.A. (2002). Antecedents and consequences of group potency: a longitudinal investigation of newly formed groups, Academy of Management Journal, 45, 352-368.

Lewin, K. (1951). Field Theory in Social Sciences. New York: Harper \& Row.

Lewin, K. (1958). Group decision and social change. in Readings in Social Psychology, eds. E. E. Maccoby, T. M. Newcomb, and E. L. Hartley, Holt, Rinehart and Winston, New York, 197-211.

Lindblom, C. (1959). The Science of "Muddling Through", Public Administration Review, 19(2), p. 79-88.

Lloyd M. \& Maguire, S. (2002). The Possibility Horizon, Journal of Change Management, 3(2), 149-157.

Mabin, V.J., Forgeson, S. and Green, L. (2001). Harnessing Resistance: Using the theory of constraints to assist change management, Journal of European Industrial Training, 25(2), 168-191.

Madsen, S.R., Miller, D. and John, C.R. (2005). Readiness for Organizational Change: Do Organizational Commitment and Social Relationships in the Workplace make the difference?, Human Resource Development Quarterly, 16(2), 213-233.

Marks, M. and Shaw, R. (1995).Sustaining Change: Creating the Resilient Organization, in D. Nadler, R. Shaw, A. Walton \& Associates, Discontinuous Change, 97-113, San Fransico: Jossey Bass.

McGrath, J.E. (1984), Groups: Interaction and performance, Englewood Cliffs, NJ: Prentice-Hall.

McHugh, M. (1997). The Stress Factor: another item for the change management agenda? Journal of Organizational Change Management, 10(4), 345-362.

Miller, D. (2002). Successful Change Leaders: What makes them? What to they do that is different?, Journal of Change Management, 2(4), 359-368.

Miles, M.B. \& Huberman, A.M. (1984). Qualitative Data Analysis: A Sourcebook of New Methods, Sage Publications: Newbury Park. 
Miles, M.B. \& Huberman, A.M. (1994). Qualitative Data Analysis: An Expanded Sourcebook, $2^{\text {nd }}$ Ed., Sage Publications: Newbury Park.

Morgan, D.E. \& Zeffane, R. (2003). Employee involvement, organizational change and trust in management, International Journal of Resource Management, 14(1), 55-75.

Murhpy, S. (2000). Mental Health in the workplace: a multidisciplinary examination of the individual and organizational antecedents and outcomes of stress, anxiety, and depressed mood, PhD Thesis - Carleton University, Ottawa, Ontario, Canada.

Nadler, D.A. \& Tushman, M.L. (1995). Types of Organizational Change: From Incremental Improvements to Discontinuous Transformation. In D. Nadler, R. Shaw, A. Walton \& Associates, Discontinuous Change,14-33, San Francisco: Jersey Bass.

Neal, D. \& Taylor, T. (2006). Spinning on dimes: the challenges of introducing transformational change into the UK Ministry of Defence, Strategic Change, 15, 15-22.

Newell, H. \& Dopson, S. (1996). Muddle in the Middle: Organizational Restructuring and middle Management careers, Personnel Review, 25(4), 4 -20.

Nickolauou, I., Gouras, A., Vakolaa, M. \& Bourantas, D. (2006). Selecting Change Agents: Exploring traits and skills in a simulated environment, Journal of Change Management, 7(3), 291-313.

Nurmi, R. (1996). Teamwork and team leadership, Team Performance Management, 2(1), 9-13.

Nutt, P. \& Backoff, R. (1993). Transforming Public Organizations with Strategic Management and Strategic Leadership, Journal of Management, 19(2), 299-347.

Nutt, P. \& Backoff, R. (1997). Facilitating Transformational Change. Journal of Behaviour Science, 33, 490-508.

O'Reilly, C. \& Tushman, M. (2004). The Ambidextrous Organization. Harvard Business Review, April, 74-81.

Orth, M.S. (2002). Factors Related to Resistance and Support of Organizational Change, PhD Thesis: Colorado State University, Fort Collins, Colorado.

Pascale, R.T. \& Sternin, J. (2005). Your Company's Secret Change Agents. Harvard Business Review, May, 78-81.

Paulus, P. (2000). Groups, Teams, and Creativity: The creative potential of idea generating groups, Applied Psychology: An international review, 49(2), 237-262. 
Patton, M. (2002). Qualitative Research and Evaluation Methods. Thousand Oaks, CA: Sage.

Pearce, J.A. \& Ravlin, E.C. (1987). The design and activation of self-regulating work groups, Human Relations, 40, 751-782.

Pescosolido, A.T. (2003). Group efficacy and group effectiveness: the effects of group efficacy over time on group development and performance, Small Group Research, 34, $20-42$.

Pettigrew, A.M. (2000). Linking Change Processes to Outcomes. In Beer, M. \& Nohria, N. (2000). Breaking the Code of Change, Boston, Massachusetts: Harvard Business School Press.

Piderit, S.K. (2000). Rethinking Resistance and Recognizing Ambivalence, Academy of Management Review, 25(5), 783-794.

Price, A. \& Chahal, K. (2006). A Strategic Framework for Change Management, Construction Management and Economics, 24, 237-251.

PWGSC/ITS Fact Sheets (2008). Information Technology Services: Delivering Governemtn of Canada IT Shared Services, ITS Fact Sheets, Aug $1^{\text {st }}$, 2008. Retrieved April 27,2008 from http://www.tpsgc-pwgsc.gc.ca/apropos-about/fi-fs/its-sct-eng.html

Randall, J. \& Procteur, S. (2008). Ambiguity and ambivalence: Senior managers' accounts of organizational change in a restructured government department, Journal of Organizational Change, 21(6), 686-700.

Rizzo, J., House, R. \& Lirtzman, S. (1970). Role Conflict and ambiguity in complex organizations, Administrative Sciences Quarterly, 15, 150-163.

Robertson, P.J. \& Seneviratne, S.J. (1995). Outcomes of Planned Organizational Change in the Public Sector: A Meta-Analytic Comparison to the Private Sector, Public Administration Review, Nov/Dec, 55(6), 547-558.

Robinson, O. \& Griffiths, A. (2005). Coping with stress of Transformational Change in a Government Department. The Journal of Applied Behavioural Science, 41(2), 204-221.

Romanelli, E. \& Tushman, M.L. (1994). Organizational Transformation as Punctuated Equilibrium: An empirical test. Academy of Management Journal, 37(5), 1141 - 1166.

Russ, T.L. (2008). Communicating Change: A Review and critical analysis of programmatic and participatory implementation approaches, Journal of Change Management, 8(3-4), 199-211. 
Salas, E., Stagl, K.C. \& Burke, C.S. (2004). 25 years of team effectiveness in organizations: research themes and emerging needs, in Cooper, C.L. and Robertson, I.T. (Eds), International Review of Industrial and Organizational Psychology, 19, 47-91.

Saavedra, R., Earley, C.P., \& Van-Dyne, L. (1993), Complex interdependence in task performing groups, Journal of Applied Psychology, 78(1), 61-72.

Schein, E. (1999). Transforming Culture: Unlearning and Relearning Culture. In, The Corporate Survival Guide, 161-180, San Fransico, CA: Jossy Bass.

Shea, G.P. \& Guzzo, R.A. (1987). Group Effectiveness: What Really Matters?, Sloan Management Review, Spring, 25-31.

Siggelkow, N. (2007). Persuasion with case studies. Academy of Management Journal, Vol. 50, No. 1, 20-24.

Simpson, R. (1998). Presenteeism, Power, and Organizational change: Long Hours as a Career Barrier and the Impact on the Working Lives of Women Managers, British Academy of Management, 9, 37-50.

Sinangli, H. \& Avallone, F. (2002). Organizational Development and Change, in Handbook of Industrial, Work and Organizational Psychology, Vol. 2: Organizational Psychology (eds. Andersone, Ones, Sinangil, and Viswesvaran), 332-345, London: Sage.

Sminia, H. \& Van Nistelrooij, A. (2006). Strategic Management and Organization Development: Planned Change in a Public Sector Organization, Journal of Change Management, 6(1), 66-113.

Smith, M. \& Burke, S. (1992). Teacher Stress: Examining a model based on context, workload, and satisfaction, Teaching and Teacher Education, 8, 31-46.

Stanley, D. J., Meyer, J.P., \& Topolnytsky, L. (2005). Employee Cynicism and Resistance to Organizational Change, Journal of Business and Psychology, 19(4), 429 468.

Strauss, A., \& Corbin, J. (1998). Basics of qualitative research: Techniques and procedures for developing grounded theory (2nd ed.). Thousand Oaks, CA: Sage Publications.

Strebel, P. (1996). Why do Employees Resist Change? Harvard Business Review, 74(3), 86-92.

Streiner, D. \& Norman, G. (1989). Health Measurement Scales: A practical guide to their development and use, New York: Oxford University Press. 
Strubler, D.C. \& York, K.M. (2007). An Exploratory Sutdy of the Team Characteristics Model Using Organizational Teams, Small Group Research, 38(6), 670-695.

Sundstrom, E., De Meuse, K.P \& Futrell, D. (1990). Work teams: applications and effectiveness, American Psychologist, February, 45, 120-133.

Sutton \& Hargadon A. (1996). Brainstorming groups in context: Effectiveness in a product firm. Administrative Science Quarterly, 41, 685-718.

Terry, D. \& Callan, V.J. (1998). In-Group Bias in Response to an Organizational Merger, Group Dynamics, 2(2), 67-81.

Thomas, P., Pinto, J.K., Parente, D.H., \& Druskat, V.U. (2002). Adaption to selfmanaging work teams, Small Group Research, 33, 3-31.

Tichy, N. and DeRose, C. (2002). The Death and Re-Birth of Organizational Development, in Organization 21 C (ed. Subir Chowdhury), 155-173, Toronto: Prentice Hall.

Todnam By, R. (2005). Organisational Change Management: A Critical Review, Journal of Change Management, 5(4), 369-380.

Todnem By, R., Thomas, D. \& Klarner, P. (2008). Getting Organizational Change Right in the Public Services: The Case of European Higher Euducation, Journal of Change Management, 8(1), 21-35.

Treasury Board of Canada (1996), Shared Systems Initiative, April, Ottawa. retrieved on 03/18/09 from http://www.tbs-sct.gc.ca/ssi-isp/documents/criticaldocs/initiatives/1996/initiative00-eng.asp

Tushman, M. \& O'Reilly, C. (1996). Ambidextrous Organizations: Managing Evolutionary and Revolutionary Change, California Management Review, 36(4), 8-30.

Vakola, M. \& Nikolaou, I. (2005), Attitudes towards organizational change, Employee Relations, 27(2), 160-174.

Van De Ven, A.H. \& Poole, M.S. (1995). Explaining development and change in organizations. Academy of Management Review. 20(3), 510- 540.

Vann, J.L. (2004). Resistance to Change and the Language of Public Organizations: A Look at "Clashing Grammars" in Large-Scale Information Technology Projects, Public Organization Overview, 4, 47-73.

Verville, J. \& Halingten, A. (2003). The effect of team composition and group role definition on ERP acquisition decisions, Team Performance Management: an International Journal, 9(5/6), 115-130. 
Wageman, R., Hackman, J.R., \& Lehman, E. (2005). Team Diagnostic Survey: Development of an instrument, The Journal of Applied Behavioural Science, 41(4), 373398.

Wang, E.T.G., Ying, T., Jiang, J.J. \& Klein, G. (2006). Group Cohesion in organizational innovation: an empirical examination of ERP Implementation, Information and Software Technology, 48, 235-244.

Weick, K.E. (2000). Emergent Change as a Universal in Organizations. In Beer, M. \& Nohria, N. (2000). Breaking the Code of Change, Boston, Massachusetts: Harvard Business School Press.

Weick, K.E.\& Quinn, R.E. (1999). Organizational Change and Development. Annual Review of Psychology. 50, 361-386.

Willdavsky, A. (1973). If Planning is Everything, Maybe it's Nothing, Policy Sciences, 4 (1), p. 127-153.

Wischnesvsky, J.D. (2004). The Impact of Organizational Transformation on Firm Survival in a Shifting Environment, Organizational Analysis, 12(4), 361-377.

Wise, L.R. (2002). Public Management Reform: Competing Drivers of Change, Public Management Reform, 62(5), 555-558.

Whitfield, D. (2007). Shared Services in Canada: A report for the Public Service Association of South Australia, Retrieved 03/15/09 from http://www.cpsu.asn.au/webnews/Shared_Services_Can.pdf

Yin, R.K. (1984). Case Study Research. Beverley Hills, CA: Sage.

Yin, R.K. (2003). Case study research: Design and Methods. Thousand Oaks, CA: Sage.

Yin, R.K. (2009). Case Study Research: Design and Methods (4th Edition). Thousand Oaks, CA: Sage.

Young, M. (2009). A meta model of change, Journal of Organizational Change Management, 22(5), pp. 524-548.

Zaltman, G., \& Duncan, R. (1977). Strategies for Planned Change. New York: Wiley. 


\section{APPENDIX A: RECRUITMENT LETTER}

Hello,

My name is Rob Smart and I am a PhD candidate from Eric Sprott School of business working under the supervision of Dr. Linda Duxbury. For my thesis research, I am examining the use of teams at ITSB and the GoC during the transition to a Shared Services Environment.

This research is designed to help ITSB to better understand the role of teams as effective organizational change agents. To accomplish this objective we need to collect both quantitative (survey) and qualitative (interview) data from team members and their managers. The outcomes of this research will help your organization to understand the factors that contribute to change team effectiveness. Some of the critical areas to be examined are the impact of stress, workload, and communication on the success of organizational change teams.

My interest in the topic stems from my work with Dr. Linda Duxbury on several Organizational Change related courses and projects related closely to the IT-SSO transition. The transition to a shared services environment offers a merger of these two interests and I am grateful for the opportunity to work with your team for my thesis research.

You have been identified as one of the members of your organization who can help with this research based on your current experience with teams and organizational change. The survey will require about 20 minutes of your time. The results will be used to assess the impact and effectiveness of teamwork during organizational change at the GoC. Please be assured that your responses will be held in confidence by the researchers. Although complete anonymity is not possible in this type of team-level analysis, we will take care to minimize the risks to you as a participant. No one in your organization will see your questionnaire and only summary results from the entire survey will be presented in the final report document.

Thank you again for helping with my research and I am looking forward to working with you on this project. If you have any comments, questions, or especially if you have any suggestions please don't hesitate to email (rsmart@connect.carleton.ca) or call (613-292-1838) to discuss them. You may also contact my supervisor Linda Duxbury (Linda_Duxbury@carleton.ca) or Leslie MacDonald Hicks, Research Ethics Committee Coordinator, (leslie_macdonald-hicks@carleton.ca) if you have any questions or concerns about this research. Your participation is greatly appreciated. Have a great day and I will be in contact soon.

Sincerely,

Rob Smart

Carleton University 


\title{
APPENDIX B: INTERVIEW SCRIPT
}

\section{Organizational Change and Teamwork}

\author{
Interview
}

\section{Introduction Script:}

$H i$,

My name is Rob Smart and I am a PhD candidate from Eric Sprott School of business working under the supervision of Dr. Linda Duxbury. For my thesis research, I am examining the use of teams at ITSB and the GoC during the transition to an information technology shared services organization (ITSSO). This research will examine the role of teams as agents for change at the GoC. As part of this study we are conducting a series of surveys with team members and interviews with key senior employees related to the teams. The goal of these interviews is to determine how best to manage and support teams during organizational You have been chosen as one of the people we would like to interview as we feel that the fact that you supervise a team that is working on change will give you unique and valuable insights into this issue. The outcomes of this research will help you to make corrections to your teams actions and activities that should help you to cope with the stress of implementing change and improve your team's chances of success.

The interview contains 14 short questions and will last approximately 25 minutes. The interview is divided into five sections; the first section contains general questions about yourself and your team. The second section deals with the change initiative and the role of the team in implementing the change; the third section focuses on the impacts of change on team members. The fourth section asks questions relating to the performance of the team in implementing the change. Finally, the fifth section will provide you with an opportunity to give specific recommendations that will help to make change teams more effective.

Please feel free to ask for clarification if you do not understand any of the questions that we are asking or if you have any questions about the interview process. Please know that you can stop me at any point of time and you may decide to pass on a question that you do not wish to answer. Lastly, please be assured that data will be aggregated across groups and individuals will not be named in the resulting report. The results will be used to assess the impact and effectiveness of teamwork during organizational change at the GoC. Please be assured that your responses will be held in confidence by the researchers. Although complete anonymity is not possible in this type of team-level analysis, we will take care to minimize the risks to you as a participant. No one in your organization will see your questionnaire and only summary results from the entire study will be presented in the final report document.

Comments and questions can be e-mailed to rsmart@connect.carleton.ca. You may also contact my supervisor Linda Duxbury (Linda_Duxbury@carleton.ca) or Leslie MacDonald Hicks, Research Ethics Committee Coordinator, (leslie_macdonald-hicks@carleton.ca) if you have any questions or concerns about this research. Thank you for taking the time to fill out this questionnaire. Your response is appreciated.

Do you have any questions before I begin?

Thank you for agreeing to participate in this study. Before we begin, I would like to have your permission to tape our conversation. I am not taping right now and will only start recording if you give me your permission. The reason that we like to tape the interview is that it allows us to proceed more quickly as I don't have to write things down as I go. Once again, I would like to ensure you of the confidentially of these results. Nowhere on the tape will you be identified by your full name. The tape will contain only your first name and a serial number we assigned to you when you did the online survey. The tape will be destroyed after the results have been coded. You are not obligated to answer all the questions, and if you want to terminate the interview at any point, just let me know.

(Turn on the tape.) Please confirm that I have your permission to tape our conversation. 


\section{Part 1 - General Information}

The first set of questions deals with general information about yourself and the team. These questions (*) can be almost completely be filled in by the interviewer so that the interviewee doesn't have to spend more time.

\section{Team/Department Information}

a) Your Department*:

b) Your Team*:

c) Your position with the team*? (please circle)

Team Leader Group Leader Team Member

d) Please describe your role with the team (define role if necessary):

e) How long have you been working with this team? (months)

\section{Personal Information}

a) Age (please circle): $<29 \quad 30-35 \quad 35-40 \quad 40-45 \quad 45-50 \quad 50-55 \quad 55-60 \quad 60+$

b) Gender (please circle)*: $\quad$ M F

\section{Work Experience:}

a) \# of years with the organization: 
Part 2 - Change Team Description

*part 1 and 2 only needs to be asked at Time 0 . Time 1 and 2 interviews can simply discuss if there are changes and only with the team manager.

\section{Primary Team Task}

a) Please describe your teams' primary role or tasks related to the implementation of the change to the IT-SSO):

b) When your team's task is complete will each of the members return to their respective functional role, continue on a different project with this team, or go their separate ways?

c) Are the majority of your team members dedicated specifically to your team's task?

d) How often do you meet face to face as a team: (per week)

\section{Team Composition}

a) How many team members are on your team:

b) Which functional areas in your organization are represented on your team?

c) Which levels of employment within your organization are represented on your team?

d) Has your team worked together in the past? If yes, on what? 


\section{Part 3 - Impacts of Transformational Change}

This set of questions deals with the impacts of implementing organizational change on the members of your team.

6. Change agents can be in the form of both individuals and teams in an organization. You are currently working as a member of a team tasked with implementing a part of the transition to the IT-SSO.

a) What are the main benefits of being a part of a change team?

b) What are some of the challenges associated with being a part of a change team?

c) What could your organization do to help maximize the benefits and minimize the challenges associated with being a part of a change team?

7. Change teams can play a critical role in supporting the change effort in an organization.

a) What types of behaviours are characteristic of a team that is supportive of the change?

b) What types of behaviours or values are characteristic of a team that resists the change?

c) What percentage of the time do you feel your team is supportive/resistant to the change?

d) How does this compare to six months ago (ie. Has support or resistance Increased/decreased/stayed same over time).

Why do you say this? 


\section{Part 4 - Change Team Effectiveness}

The last set of questions asks about the impact of the transformation to a shared IT services organization.

8. Please describe the primary tasks or responsibilities of your team*: (this is in part 2)

(Prompt: Go over your answer question in part 2)

9. What group or set of individuals would you describe as the primary recipients of your teams' work?

10. Please indicate the extent to which you agree/disagree with each of the following statements related to your team's performance on their primary tasks.

(Prompt: Review their answers from the survey if available)

a. The work produced by this team is of high quality

\begin{tabular}{ccccccc}
$\begin{array}{c}\text { Strongly } \\
\text { Disagree }\end{array}$ & \multicolumn{2}{c}{ Neutral } & & \multicolumn{2}{c}{$\begin{array}{c}\text { Strongly } \\
\text { Agree }\end{array}$} \\
1 & 2 & 3 & 4 & 5 & 6 & 7 \\
1 & 2 & 3 & 4 & 5 & 6 & 7
\end{tabular}

b. This team delivers work within the set deadlines

$\begin{array}{lllllll}1 & 2 & 3 & 4 & 5 & 6 & 7\end{array}$

d. The team's supervisor is pleased with the
performance of the team
$\begin{array}{lllllll}1 & 2 & 3 & 4 & 5 & 6 & 7\end{array}$

e. Please describe what you feel your team is doing well in terms of implementing the change.

f. Please describe some areas that you feel your team can improve their performance.

g. How can your organization help your team to improve performance? 


\section{Part 5 - Final Questions}

In terms of this change initiative, I'm now going to ask you if you have any specific recommendations for improving the effectiveness of change implementation teams at your organization.

12. What one thing (if possible) could your organization (ITSB) do to improve the effectiveness of your team in implementing the transition to the IT-SSO?

13. What one thing could your partner organizations (e.g. Health Canada) do to improve your team's effectiveness in implementing the transition to the IT-SSO?

14. What one piece of advice would you give someone placed on a change team?

15. What one piece of advice would you give someone who is managing a change team?

\section{THE END}

Thank you for your time and patience. Do you have any other questions?

Would you be interested in receiving a copy of this report?

If so can we have your email address? 


\section{APPENDIX C: SURVEY}

\section{Transformational Change and Teamwork \\ Survey - Team Member}

The survey will require about 20 minutes of your time. The results will be used to assess the impact and effectiveness of teamwork during organizational change at the GoC. Please be assured that your responses will be held in confidence by the researchers. Although complete anonymity is not possible in this type of team-level analysis, we will take care to minimize the risks to you as a participant. No one in your organization will see your questionnaire and only summary results from the entire survey will be presented in the final report document.

Comments and questions can be e-mailed to rsmart@connect.carleton.ca. You may also contact my supervisor Linda Duxbury (Linda_Duxbury@carleton.ca) or Leslie MacDonald Hicks, Research Ethics Committee Coordinator, (leslie_macdonaldhicks@carleton.ca) if you have any questions or concerns about this research.

Thank you for taking the time to fill out this questionnaire. Your response is appreciated.

Sincerely,

Rob Smart - Carleton University

\section{Instructions:}

This team member survey consists of four main parts:

1. Team Member Information: general information about the team member.

2. Outcomes of Teamwork: questions in this section examine the satisfaction of team members with their teamwork experience

3. Impacts of Organizational Change: questions in this section examine the impact that being involved in an organizational change has on team members.

4. Characteristics of Effective Change Teams: questions in this section examine the characteristics of organizational change teams.

The questions in this survey consist of two primary types of questions:

1. Agree/Disagree Statements: These questions are statements about you, your team, and how your team functions.

*For these questions please circle answer that represents the extent to which you feel reach statement describes your team according to the following common response scale (*leave blank if you don't know or the statement is not applicable):

(1) Strongly Disagree (2) Disagree (3) Somewhat disagree

(4) Nether agree or disagree

(5) Somewhat Agree (6) Agree (7) Strongly agree

2. Short Answer/Open Response Questions: These questions are short answer questions about topics related to the impact of organizational change and the effectiveness of your team. Please feel free to answer in your own words. 


\section{Part One: General Information}

\section{Team/Department Information}

a) Your Department:

b) Are you currently responsible for work directly related to implementing the change to SSO? (Please circle) Y N

c) Are you currently working on a team responsible for work directly related to the change to SSO? (Please circle) $\mathrm{Y} N$

If yes;

i) Your Team:

ii) Please describe your role on the team?

iii) How long have you been with this team? (Months)

\section{Personal Information}
a) Age: (please circle)
$<29 \quad 30-35 \quad 35-40$
$40-45$
$45-50 \quad 50-55 \quad 55-60 \quad 60+$
b) Gender (please circle) $\mathrm{M} \quad \mathrm{F}$

\section{Work Experience}

a) \# of years with the organization:

b) How much experience have you had:

i) With organizational change

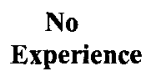

Moderate

Considerable

Experience

Experience

Experience

ii) Working on teams

$\begin{array}{lllllll}1 & 2 & 3 & 4 & 5 & 6 & 7\end{array}$

iii) Working on change teams

$\begin{array}{lllllll}1 & 2 & 3 & 4 & 5 & 6 & 7\end{array}$

$\begin{array}{lllllll}1 & 2 & 3 & 4 & 5 & 6 & 7\end{array}$ 


\section{Part 2: Outcomes of Teamwork}

\section{Overall Satisfaction}
a. Overall, I am satisfied with my team experience.

\begin{tabular}{ccccccc}
$\begin{array}{c}\text { Strongly } \\
\text { Disagree }\end{array}$ & & Neutral & & \multicolumn{2}{c}{$\begin{array}{c}\text { Strongly } \\
\text { Agree }\end{array}$} \\
1 & 2 & 3 & 4 & 5 & 6 & 7
\end{tabular}

\section{Satisfaction with the task}

a. I enjoy the kind of work we do in this team
Strongly

Disagree

12
Neutral

(1)

Strongly

Agree

$6 \quad 7$

b. I find the work we do on this team to interesting and challenging.

c. I find the work we do on this team to be beneficial to my knowledge and skills.

\section{Satisfaction with the team}

a. I enjoy the experience of working with this team

$\begin{array}{ccccccc}\begin{array}{c}\text { Strongly } \\ \text { Disagree }\end{array} & & \text { Neutral } & & & \begin{array}{c}\text { Strongly } \\ \text { Agree }\end{array} \\ 1 & 2 & 3 & 4 & 5 & 6 & 7\end{array}$

b. Working on this team is an exercise in frustration $(R)$

12

c. Generally speaking, I am very satisfied the 1 23

$\begin{array}{llll}4 & 5 & 6 & 7\end{array}$
interpersonal relationships that have been formed on this team

\section{Satisfaction with the customer}

a. I enjoy working with our team's customers

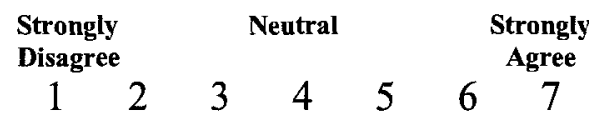

b. I find working with our team's customers to be an exercise in frustration (R)

c. Working with our customer (s) is an excellent learning opportunity 


\section{Ability to work together on future projects}

a. I would enjoy working with this team on future projects.

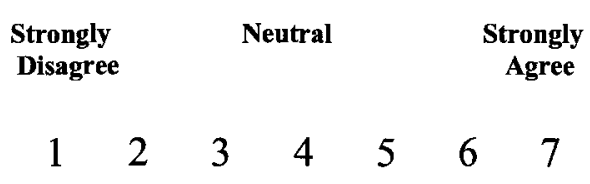

b. This team could work effectively on a similar project in the future.

$\begin{array}{lllllll}1 & 2 & 3 & 4 & 5 & 6 & 7\end{array}$

c. I feel that there must be a change in personnel or team processes in order for this team to work effectively in the future. (R)

$\begin{array}{lllllll}1 & 2 & 3 & 4 & 5 & 6 & 7\end{array}$

\section{Team Performance}

a. The work produced by this team is of high quality

\begin{tabular}{ccccccc}
$\begin{array}{c}\text { Strongly } \\
\text { Disagree }\end{array}$ & \multicolumn{3}{c}{ Neutral } & & \multicolumn{2}{c}{$\begin{array}{c}\text { Strongly } \\
\text { Agree }\end{array}$} \\
1 & 2 & 3 & 4 & 5 & 6 & 7 \\
1 & 2 & 3 & 4 & 5 & 6 & 7
\end{tabular}

b. This team delivers work within the set deadlines

c. The primary recipients of the team's work is satisfied with the deliverables from this team.

$\begin{array}{lllllll}1 & 2 & 3 & 4 & 5 & 6 & 7\end{array}$

d. The team's supervisor is pleased with the performance of the team

$\begin{array}{lllllll}1 & 2 & 3 & 4 & 5 & 6 & 7\end{array}$




\section{Part Three: Impacts of Organizational Change}

\section{Workload}

a. I feel that I can comfortably handle the amount

Strongly

Disagree

12

Neutral

ral

Strongly
Agree

of work I have to do during the day. (R)

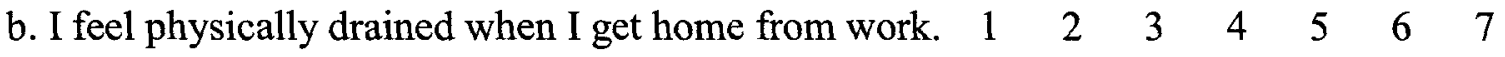

c. I feel emotionally drained when I get home from

$\begin{array}{lllllll}1 & 2 & 3 & 4 & 5 & 6 & 7\end{array}$ work.

d. I feel I have to rush to get everything done each day. $\begin{array}{llllllll}1 & 2 & 3 & 4 & 5 & 6 & 7\end{array}$

e. I feel I don't have enough time for myself.

$\begin{array}{lllllll}1 & 2 & 3 & 4 & 5 & 6 & 7\end{array}$

f. The amount of work I have negatively impacts

$\begin{array}{lllll}1 & 2 & 3 & 4 & 5\end{array}$

the effort I can expend on work related to the change

g. How much time per week (hours) do you spend on work related to the change? Please include time at the office and outside the office (i.e. home, other sites)

h. How much time per week (hours) do you spend it total on work related activities? Please include time at the office and outside the office (i.e. home, other sites)

g. Please think back to the amount of time you spent in work-related activities six month ago. Now think about your current workload. Has your workload: (please circle)

(1) Increased significantly (i.e. by 5 or more hours per week)

(2) Increased somewhat (i.e. 1 to 4 hours per week)

(3) Not really changed

(4) Decreased somewhat (i.e. 1 to 4 hours per week)

(5) Decreased significantly (i.e. by 5 or more hours per week) 


\section{Job Stress}

a. I work under a great deal of tension

\begin{tabular}{ccccccc}
$\begin{array}{c}\text { Strongly } \\
\text { Disagree } \\
1\end{array}$ & & & Neutral & & \multicolumn{2}{c}{$\begin{array}{c}\text { Strongly } \\
\text { Agree }\end{array}$} \\
& 2 & 3 & 4 & 5 & 6 & 7
\end{tabular}

b. I have felt fidgety or nervous as a result of my work $\begin{array}{llllllll}1 & 2 & 3 & 4 & 5 & 6 & 7\end{array}$ during my time with this team
c. If I had a different job my health would probably improve.

d. Problems associated with my job have kept my awake $\begin{array}{llllllll}1 & 2 & 3 & 4 & 5 & 6 & 7\end{array}$ at night.

e. I often "take my job home with me" in the sense that $\begin{array}{llllllll}1 & 2 & 3 & 4 & 5 & 6 & 7\end{array}$ I think about it when doing other things.

g. Please think back to the amount of job related stress you experienced six month ago. Now think about the amount of job related stress you are currently experiencing. Has your job stress: (please circle)
(1) Increased significantly
(2) Increased somewhat
(3) Not really changed
(4) Decreased somewhat
(5) Decreased significantly 


\section{Resistance and Support for Change}

a. I openly speak out against components of this

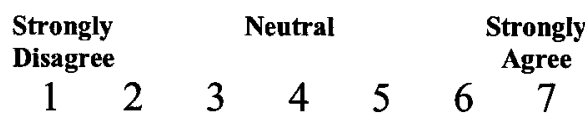
change to my colleagues.

b. I argue with my supervisor about components of this change.

$\begin{array}{llllllll}\text { c. I openly speak out against components of this change } & 1 & 2 & 3 & 4 & 5 & 6 & 7\end{array}$ with customers/colleagues outside of our organization.

$\begin{array}{llllllll}\text { d. I verbally agreed to support this change but have not } & 1 & 2 & 3 & 4 & 5 & 6 & 7\end{array}$ actually done so.

$\begin{array}{llllllll}\text { e. I have withheld information or resources that would } & 1 & 2 & 3 & 4 & 5 & 6 & 7\end{array}$ have supported this change effort.

$\begin{array}{lllllllll}\text { f. I perform change related tasks only when specifically } & 1 & 2 & 3 & 4 & 5 & 6 & 7\end{array}$ asked to do so.

$\begin{array}{lllllllll}\text { g. I encourage others to support the change effort. } & & 1 & 2 & 3 & 4 & 5 & 6 & 7\end{array}$

$\begin{array}{llllllll}\text { h. I would help co-workers who were having } & 1 & 2 & 3 & 4 & 5 & 6 & 7\end{array}$ difficulties performing tasks related to the change.

i. I consistently work extra hours to help implement $\quad \begin{array}{llllllll}1 & 2 & 3 & 4 & 5 & 6 & 7\end{array}$ this change.

j. I try to explain the benefits of this change to other $\quad \begin{array}{llllllll}1 & 2 & 3 & 4 & 5 & 6 & 7\end{array}$ employees or customers.

$\begin{array}{llllllll}\text { k. I try to keep myself informed about initiatives related } & 1 & 2 & 3 & 4 & 5 & 6 & 7\end{array}$ to the change effort.

1. I am tolerant of disruptions to my work that are caused by this change effort. 


\section{Part Four: Characteristics of Effective Change Teams}

\section{Task Design}

1. Task Direction: the purpose and goals of the team.

a. There is a great deal of uncertainty and ambiguity

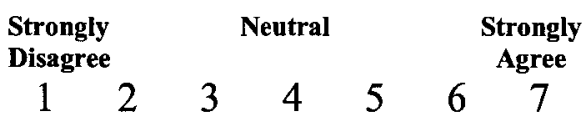
about the task that this team is supposed to accomplish. (R)

b. This teams purposes are specified so clearly that $\begin{array}{lllllll}1 & 2 & 3 & 4 & 5 & 6 & 7\end{array}$ all members should know exactly what the team exits to accomplish.

c. In your own words briefly describe the main purpose of this team:

2. Task Identity: the degree to which the team completes a whole, identifiable, and separate piece of work in the organization.

a. The team concept allows all the work on a given

\begin{tabular}{cccccc}
$\begin{array}{c}\text { Strongly } \\
\text { Disagree }\end{array}$ & & Neutral & & \multicolumn{2}{c}{$\begin{array}{c}\text { Strongly } \\
\text { Agree }\end{array}$} \\
1 & 2 & 3 & 4 & 5 & 6
\end{tabular}
service to be completed by the same set of people.

b. My team is responsible for all aspects of a service or product for its area.

$\begin{array}{lllllll}1 & 2 & 3 & 4 & 5 & 6 & 7\end{array}$

c. My team is responsible for its own unique area or $\begin{array}{llllll}1 & 2 & 3 & 4 & 5 & 6\end{array}$ segment of the change. 
3. Self-Management: the level of autonomy that the team operates with.

a. The work of this team leaves little room for the

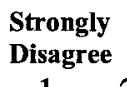

Strongly
Disagree

Neutral

$\begin{array}{lllllll}1 & 2 & 3 & 4 & 5 & 6 & 7\end{array}$

exercise of judgment or initiative (R)

b. The work we do requires the team to make many

123

$\begin{array}{llll}4 & 5 & 6 & 7\end{array}$ judgment calls as we carry it out.

c. The members of my team are responsible for determining the methods, procedures, and schedules with which the work gets done.

d. Most work related decisions are made by the members of my team rather than by my manager.

\section{$\begin{array}{lllllll}1 & 2 & 3 & 4 & 5 & 6 & 7\end{array}$}

$\begin{array}{lllllll}1 & 2 & 3 & 4 & 5 & 6 & 7\end{array}$

4. Participation: the degree to which all members are allowed to participate in team decisions.

a. As a member of a team, I have a real say in how

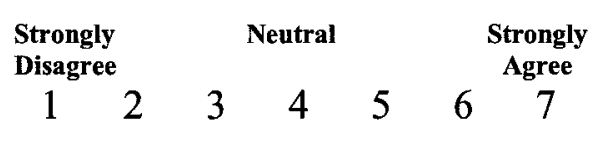
the team carries out its work.

b. Most members of my team get a chance to

$\begin{array}{lllllll}1 & 2 & 3 & 4 & 5 & 6 & 7\end{array}$ participate in decision making.

c. My team is designed to let everyone participate

$\begin{array}{lllllll}1 & 2 & 3 & 4 & 5 & 6 & 7\end{array}$
in decision making. 
5. Task Variety: giving each member a chance to perform a number of the team's tasks.

a. Most members of my team get a chance to learn

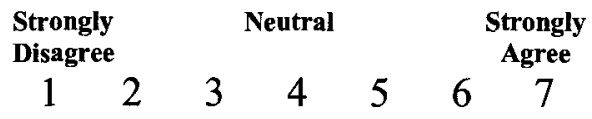
the different tasks the team performs.

b. Most everyone on my team gets a change to do the more interesting tasks.

c. Task assignments often change from day to day to meet the work load.

$\begin{array}{lllllll}1 & 2 & 3 & 4 & 5 & 6 & 7\end{array}$

$\begin{array}{lllllll}1 & 2 & 3 & 4 & 5 & 6 & 7\end{array}$

6. Task Significance: the belief that the team's task has significant consequences for the organization and/or customers.

a. The purposes of this team don't make much of a Strongly difference to anybody else. (R)

$\begin{array}{ccccccc}1 & 2 & 3 & 4 & 5 & 6 & 7\end{array}$

b. The work performed by my team is very important $\quad \begin{array}{lllllll}1 & 2 & 3 & 4 & 5 & 6 & 7\end{array}$ to the people that we work with.

$\begin{array}{llllllllll}\text { c. My team helps me feel that my work is important } & 1 & 2 & 3 & 4 & 5 & 6 & 7\end{array}$ to the company.

d. The work performed by my team is very important $\quad \begin{array}{llllllll}1 & 2 & 3 & 4 & 5 & 6 & 7\end{array}$ to the success of the change effort 


\section{Interdependence}

7. Task Interdependence: the degree to which team members must interact and depend on one another to accomplish the work.

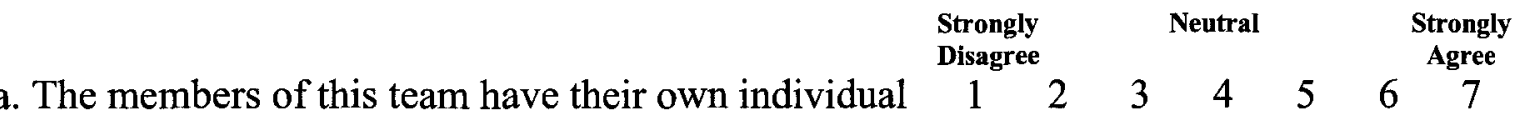
jobs to do, with little need for them to work together. (R)

b. I cannot accomplish my tasks without information $\begin{array}{llllllll}1 & 2 & 3 & 4 & 5 & 6 & 7\end{array}$ or materials from other members of my team.

c. Other members of my team depend on me for

$\begin{array}{lllllll}1 & 2 & 3 & 4 & 5 & 6 & 7\end{array}$

information or materials needed to perform their tasks.

d. Within my team, jobs performed by team members $\quad \begin{array}{llllllll}1 & 2 & 3 & 4 & 5 & 6 & 7\end{array}$ are related to one another.

8. Goal Interdependence: the degree to which individual and team goals are linked.

a. My work goals come directly from the goals of my

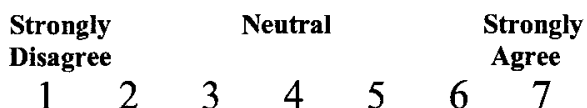
team.

$\begin{array}{llllllll}\text { b. My work activities on any given day are determined } & 1 & 2 & 3 & 4 & 5 & 6 & 7\end{array}$ by my team's goals for that day.

$\begin{array}{llllllll}\text { c. I do very few activities on my job that are not } & 1 & 2 & 3 & 4 & 5 & 6 & 7\end{array}$ related to the goals of my team.

9. Feedback and Reward Interdependence: the degree to which feedback and rewards are linked to the team's performance.

a. Feedback about how well I am doing my job comes

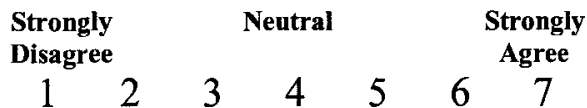
primarily from information about how well the entire team is doing.

b. My performance evaluation is strongly influenced $\begin{array}{lllllll}1 & 2 & 3 & 4 & 5 & 6 & 7\end{array}$ by how well my team performs.

c. Many rewards from my job (eg. pay, promotion, etc.) $1 \begin{array}{lllllll}1 & 2 & 3 & 4 & 5 & 6 & 7\end{array}$ are determined in large part by my contribution as a team member. 


\section{Composition}

10. Bounded membership: the degree to which team membership is identifiable in the organization.

a. Team membership is quite clear- anyone who

$\begin{array}{ccccccc}\begin{array}{c}\text { Strongly } \\ \text { Disagree }\end{array} & & \text { Neutral } & & & \begin{array}{c}\text { Strongly } \\ \text { Agree }\end{array} \\ 1 & 2 & 3 & 4 & 5 & 6 & 7\end{array}$
knows this team could say exactly who is and isn't on this team.

b. There is so much ambiguity about who is on this team that would be nearly impossible to generate an accurate membership list. (R)

$\begin{array}{lllllll}1 & 2 & 3 & 4 & 5 & 6 & 7\end{array}$

11. Heterogeneity: the mix of talents/skills/experience on the team.

a. The members of my team vary widely in their

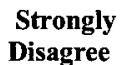

Neutral

Disagree expertise

$\begin{array}{lllllll}1 & 2 & 3 & 4 & 5 & 6 & 7\end{array}$

b. The members of my team have a variety of different

12

23

$\begin{array}{llll}4 & 5 & 6 & 7\end{array}$ backgrounds and experience.

c. The members of my team have skills and abilities that compliment each other.

$\begin{array}{lllllll}1 & 2 & 3 & 4 & 5 & 6 & 7\end{array}$

12. Flexibility: the extent to which team members are flexible enough to perform each others tasks as needed.
a. Most members of my team know each other's jobs.
Strongly
Disagree
Neutral
12
$\begin{array}{lllll} & 4 & 5 & 6 & { }^{\text {Agree }}\end{array}$
b. It s easy for the members of my team to fill in for one $\quad \begin{array}{llllllll}1 & 2 & 3 & 4 & 5 & 6 & 7\end{array}$ another.
c. My team is very flexible in terms of changes in
$\begin{array}{llllll}1 & 2 & 3 & 4 & 5 & 6\end{array}$
7 membershiץ

13. Relative Size: the number of team members relative to the amount of work required. 
a. The number of people in my team is too small for the work to be accomplished. (R)

b. Team members occasionally engage in social

$\begin{array}{lllllll}1 & 2 & 3 & 4 & 5 & 6 & 7\end{array}$
loafing activities because we have more than enough people to perform our task. (R)

c. How many team members make up the team? 


\section{Context}

15. Training: the level of training received by the team members related to the task

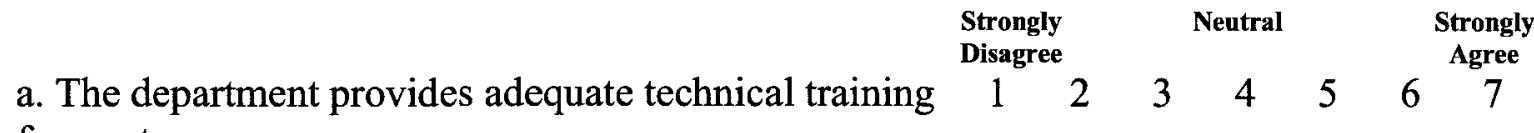 for my team.
b. The department provides adequate quality and customer service training for my team.
c. The department provides adequate team skills training $\begin{array}{llllllll}1 & 2 & 3 & 4 & 5 & 6 & 7\end{array}$ for my team (e.g. communication, organization, interpersonal, etc.)

16. Managerial Support: the level of management controlled resources (materials, information) made available for the team.

a. Higher management in the department supports the Strongly work of our team.

b. My manager supports the work of our team.

$\begin{array}{lllllll}1 & 2 & 3 & 4 & 5 & 6 & 7\end{array}$

17. Communication/Cooperation between Groups: the degree to which teams communicate and cooperate with other groups within the organization to help achieve their goals.

a. I frequently talk to other people in the department

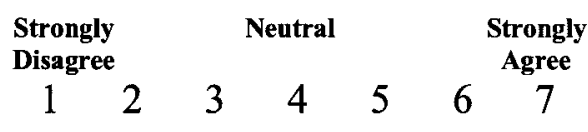
besides the people on my team.

b. There is little competition between my team and other teams in the department.

c. Teams in the department cooperate to get the work c. Teane.

$\begin{array}{lllllll}1 & 2 & 3 & 4 & 5 & 6 & 7\end{array}$




\section{Process}

18. Potency: the team's belief that it is capable of being effective in their task.

a. Members on my team have great confidence that

\begin{tabular}{ccccccc}
$\begin{array}{c}\text { Strongly } \\
\text { Disagree } \\
1\end{array}$ & \multicolumn{2}{c}{ Neutral } & & \multicolumn{2}{c}{$\begin{array}{c}\text { Strongly } \\
\text { Agree }\end{array}$} \\
1 & 3 & 4 & 5 & 6 & 7
\end{tabular}
the team can perform effectively.

b. My team can take on nearly any task and complete

$\begin{array}{lllllll}1 & 2 & 3 & 4 & 5 & 6 & 7\end{array}$ it.

c. My team has a lot of team spirit.

$\begin{array}{lllllll}1 & 2 & 3 & 4 & 5 & 6 & 7\end{array}$

19. Social Support: the extent to which team members help each other and have positive social interactions.

a. Being in my team gives me the opportunity to work

$\begin{array}{ccccccc}\begin{array}{c}\text { Strongly } \\ \text { Disagree }\end{array} & & \text { Neutral } & & & \begin{array}{c}\text { Strongly } \\ \text { Agree }\end{array} \\ 1 & 2 & 3 & 4 & 5 & 6 & 7\end{array}$
in a team and provide support to other team members.

b. My team increases my opportunities for positive $\quad \begin{array}{llllllll}1 & 2 & 3 & 4 & 5 & 6 & 7\end{array}$ social interaction.

$\begin{array}{lllllllll}\text { c. Members of my team help each other out at work } & & 1 & 2 & 3 & 4 & 5 & 6 & 7\end{array}$ when needed.

20. Workload Sharing: the extent to which team members are willing to accept and share each others work in order to achieve the team's goals.

a. Everyone on my team does their fair share of the

\begin{tabular}{ccccccc}
$\begin{array}{c}\text { Strongly } \\
\text { Disagree }\end{array}$ & \multicolumn{2}{c}{ Neutral } & & \multicolumn{2}{c}{$\begin{array}{c}\text { Strongly } \\
\text { Agree }\end{array}$} \\
1 & 2 & 3 & 4 & 5 & 6 & 7
\end{tabular}
work.

b. No one in my team depends on other team members $\quad \begin{array}{lllllll}1 & 2 & 3 & 4 & 5 & 6 & 7\end{array}$ to do the work for them. (R)

c. Nearly all the members on my team contribute equally to the work.

$\begin{array}{lllllll}1 & 2 & 3 & 4 & 5 & 6 & 7\end{array}$


21. Communication/Cooperation within Groups: the degree to which team members communicate and cooperate with other team members to help achieve their goals.

a. Members of my team are very willing to share

Strongly
Disagree

Neutral

1

2

3

45

Strongly Agree information with other members about our work.

b. Teams enhance the communication among people working on the same product.

c. Nearly all the members on my team contribute equally to the work.

$\begin{array}{lllllll}1 & 2 & 3 & 4 & 5 & 6 & 7\end{array}$

$\begin{array}{lllllll}1 & 2 & 3 & 4 & 5 & 6 & 7\end{array}$

